AUTARQUIA ASSOCIADA À UNIVERSIDADE DE SÃO PAULO

DESCARTE DE RESÍDUOS QUÍMICOS NA REGIÃO METROPOLITANA DE SÃO PAULO, SEUS IMPACTOS SOCIOAMBIENTAIS - UMA PROPOSTA DE POLÍTICA PÚBLICA PARA ENFRENTAMENTO DE SITUAÇÕES EMERGENCIAIS

JORGE LUIZ NOBRE GOUVEIA

Tese apresentada como parte dos
requisitos para obtenção do Grau de
$\begin{aligned} & \text { Doutor em Ciências na Área } \\ & \text { de Tecnologia Nuclear - Materiais }\end{aligned}$

Orientadora:

Profa. Dra. MARIA APARECIDA FAUSTINO PIRES 
INSTITUTO DE PESQUISAS ENERGÉTICAS E NUCLEARES

Autarquia associada à Universidade de São Paulo

DESCARTE DE RESÍDUOS QUÍMICOS NA REGIÃO METROPOLITANA DE SÃO PAULO, SEUS IMPACTOS SOCIOAMBIENTAIS - UMA PROPOSTA DE POLÍTICA PÚBLICA PARA ENFRENTAMENTO DE SITUAÇÕES EMERGENCIAIS

JORGE LUIZ NOBRE GOUVEIA

Tese apresentada como parte dos
requisitos para obtenção do Grau de
$\begin{aligned} & \text { Doutor em Ciências na Área } \\ & \text { de Tecnologia Nuclear - Materiais }\end{aligned}$
Orientadora:
Profa. Dra. MARIA APARECIDA FAUSTINO
PIRES

Versão Corrigida

$\#$

São Paulo

2015 


\section{AGRADECIMENTOS}

À minha esposa Ligia Pizani Ywagatuma, companheira de jornada, pela compreensão, paciência e por estar ao meu lado em todos os momentos.

Às minhas filhas Lilian Ywagatuma Nobre e Laura Ywagatuma Nobre pela compreensão em razão de minhas constantes ausências.

À minha mãe, Maria das Neves Nobre (in memoriam) e meu pai Guilherme da Cruz Gouveia (in memoriam), pela oportunidade que tive na vida e por me mostrar que, por maiores que sejam os obstáculos, sempre é possível superá-los.

À minha orientadora Maria Aparecida F. Pires, por acreditar na pesquisa e me aceitar como orientando. Agradeço também por apontar rumos e perspectivas nos pontos mais cruciais dessa jornada.

À colaboração da Geógrafa Cláudia Matos Fagundes, pela elaboração de mapas temáticos utilizados nesse trabalho.

Aos técnicos especialistas em áreas contaminadas da CETESB, nas pessoas de Elton Gloeden e Rodrigo Cesar de Araújo Cunha.

Aos colegas de trabalho do Setor de Atendimento a Emergências da CETESB, Ednaldo do Prado e Laércio F. Parmagnani pela companhia durante os trabalhos de campo.

Ao Eng ${ }^{\circ}$ Anderson Pioli do Setor de Atendimento a Emergências da CETESB, pelo constante apoio na elaboração de planilhas, mapas e gráficos.

À Dra. Ana Luiza Silva Spínola, pela ajuda na revisão inicial do Plano de Trabalho.

À Rita de Cássia Guimarães, pela ajuda com o trabalho de formatação da Tese.

Ao Centro de Química e Meio Ambiente do Instituto de Pesquisas Energéticas e Nucleares (CQMA/IPEN) pela vasta contribuição e pela oportunidade de aprendizado.

Por fim, agradeço à CETESB pela oportunidade de continuar meus estudos. 


\title{
DESCARTE DE RESÍDUOS QUÍMICOS NA REGIÃO METROPOLITANA DE SÃO PAULO, SEUS IMPACTOS SOCIOAMBIENTAIS - UMA PROPOSTA DE POLÍTICA PÚBLICA PARA ENFRENTAMENTO DE SITUAÇÕES EMERGENCIAIS
}

\author{
Jorge Luiz Nobre Gouveia
}

\begin{abstract}
RESUMO
O descarte de resíduos químicos é uma prática lesiva ao meio ambiente e à saúde da população. Nesse trabalho foi realizado levantamento dos impactos socioambientais com base nos registros de descartes de resíduos químicos da Companhia Ambiental do Estado de São Paulo - CETESB, no período de 2005 a 2013, tomando como referência a Região Metropolitana de São Paulo - RMSP, em especial as cidades de São Paulo e Guarulhos. Dentre os resultados que nortearam o trabalho se destacam a caracterização da prática de descarte de resíduos químicos, sobrepondo a mapas temáticos georreferenciados de rodovias e recursos hídricos. Também por meio de pesquisa dirigida aos principais atores intervenientes dos cenários acidentais,foi possível conhecer os processos atuais de intervenção e de tratamento, aplicados nos descartes de resíduos químicos nas esferas municipais e estaduais. Nesse contexto, o Decreto Estadual $\mathrm{n}^{\circ}$ 59.263/2013, que regulamenta a Lei $\mathrm{n}^{\circ}$ 13.577/2009 sobre a proteção da qualidade do solo e gerenciamento de áreas contaminadas criou o Fundo Estadual para Prevenção e Remediação de Áreas Contaminadas (FEPRAC), destinado à identificação e remediação das "áreas órfãs". O FEPRAC apresentase como um instrumento econômico capaz de elidir o perigo nos casos de emergências químicas envolvendo o descarte de resíduos sem a identificação do responsável.
\end{abstract}

Palavras-chaves: descartes de resíduos, emergências químicas, resíduos químicos 


\title{
ILLEGAL DUMPING OF CHEMICAL WASTES IN THE METROPOLITAN REGION OF SÃO PAULO, ITS SOCIAL AND ENVIRONMENTAL IMPACTS - A PROPOSAL FOR PUBLIC POLICY FOR COPING EMERGENCY SITUATIONS
}

\author{
Jorge Luiz Nobre Gouveia
}

\begin{abstract}
The disposal of chemical waste is a harmful practice to public health and the environment.This work was carried out survey of social and environmental impacts based on the records of illegal dumping of chemical waste of the Environmental Agency of São Paulo State - CETESB, in the period 2005-2013, with reference to the Metropolitan Region of São Paulo - especially cities of São Paulo and Guarulhos. Among the results that guided the work stand out the characterization of the practice of disposal of chemical waste, overlaying the GIS thematic maps of roads and water resources. Also through research aimed at key stakeholders of accident scenarios it was possible to know the current processes of intervention and treatment applied in illegal dumping of chemical waste in the municipal and state levels. In this context, the State Decree $N^{0} 59.263 / 2013$, which regulates Law $N^{0} 13.577 / 2009$ on the protection of soil quality and management of contaminated areas created the State Fund for Prevention and Remediation of Contaminated Sites (FEPRAC) for the identification and remediation of these so-called "orphan areas". The FEPRAC presents itself as an economic instrument that can eliminate the danger in such cases of chemical emergencies involving illegal dumping of chemical wastes without identifying the responsible.
\end{abstract}

Key words: illegal dumping, chemical emergencies, chemical wastes 


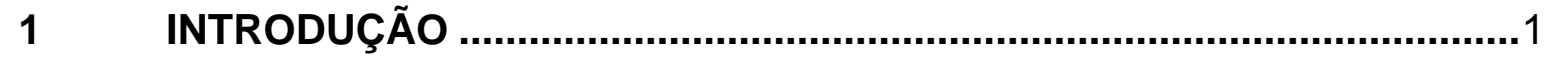

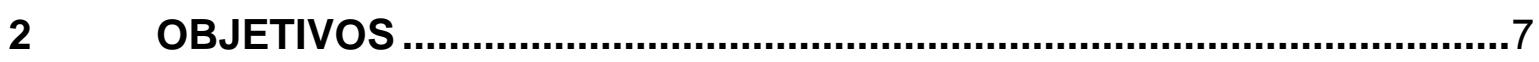

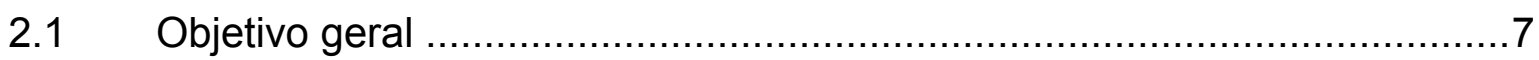

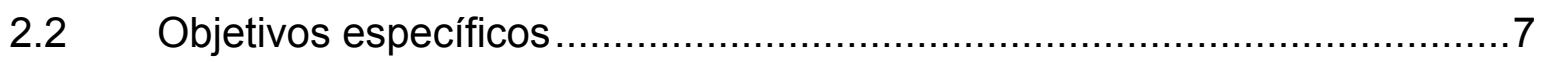

3 RELEVÂNCIA CIENTÍFICA DA PESQUISA ..............................................

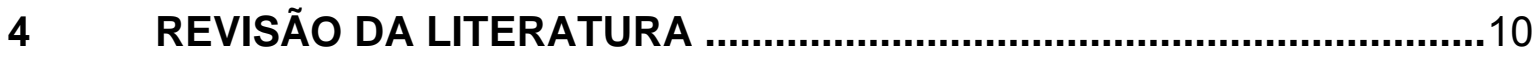

4.1 Descarte de resíduos químicos no contexto internacional.......................10

4.2 Descartes de resíduos químicos no contexto nacional ...........................17

4.3 Avaliação ambiental nas emergências envolvendo descarte de

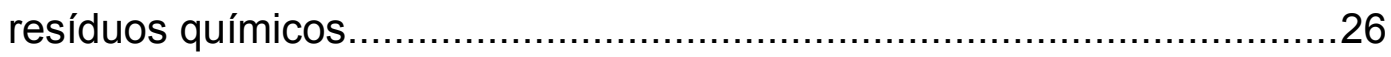

4.4 Relação da ocorrência de descartes de resíduos e as áreas contaminadas nos Estados de São Paulo, Rio de Janeiro e Minas Gerais

4.4.1 Descartes de resíduos químicos e as áreas contaminadas no

Estado de São Paulo

4.4.2 Descartes de resíduos químicos e as áreas contaminadas no

Estado doRio de Janeiro

4.4.3 Descartes de resíduos químicos e as áreas contaminadas no

Estadode Minas Gerais

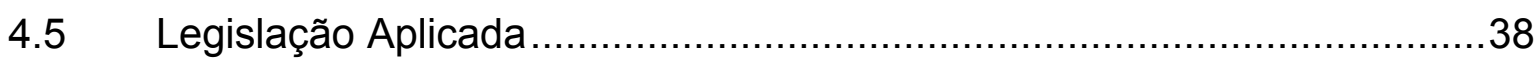

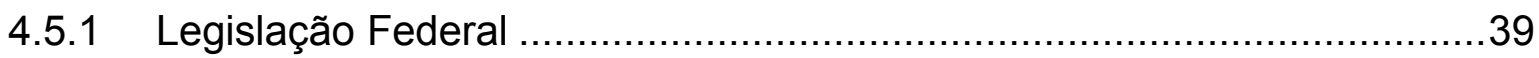

4.5.2 Legislação no Estado de São Paulo ...................................................47

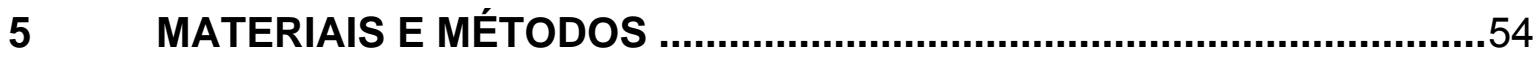

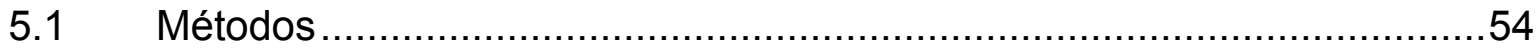

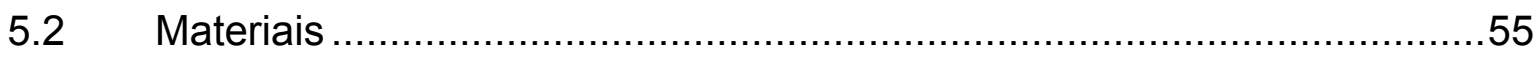

5.2.1 Coleta de Dados (fontes secundárias) ……….................................56

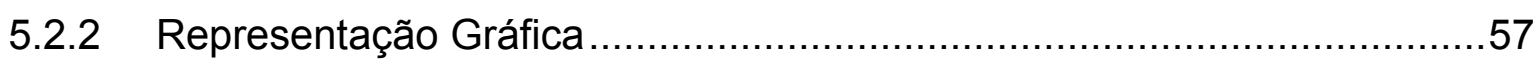

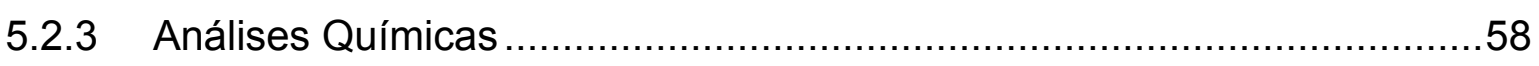

5.2.4 Equipamentos Portáteis de Detecção...................................................60 


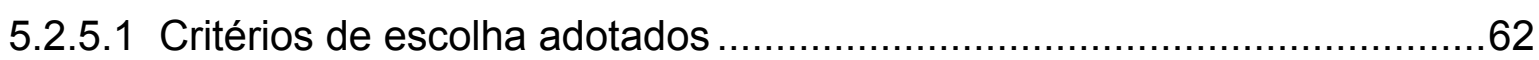

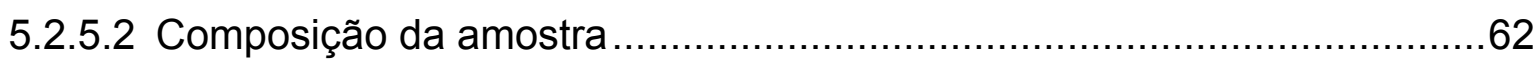

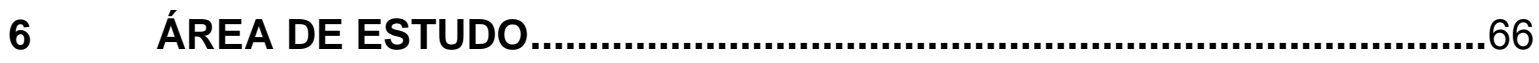

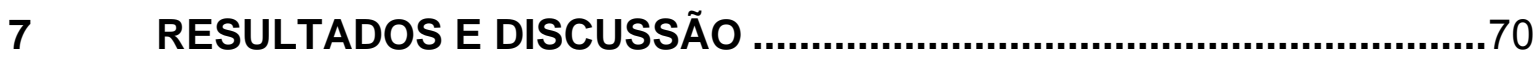

7.1 Diagnóstico ambiental quanto à distribuição espacial dos descartes de resíduos químicos no Estado de São Paulo com detalhamento de recursos hídricos

7.2 Diagnóstico ambiental quanto à distribuição espacial dos descartes de resíduos químicos no Estado de São Paulo com detalhamento do sistema viário ........................................................................ 75

7.3 Distribuição espacial dos descartes de resíduos químicos na Região Metropolitana de São Paulo .

7.4 Diagnóstico socioambiental quanto à distribuição espacial dos descartes de resíduos químicos nos distritos da cidade de São Paulo

7.5 Diagnóstico socioambiental quanto à distribuição espacial dos descartes de resíduos químicos nos bairros da cidade de Guarulhos.

7.6 Pesquisa de campo aplicada por meio de questionário a representantes de instituições públicas que participam de atendimentos emergenciais envolvendo descarte de resíduos químicos....................................108

7.6.1 Análise dos resultados da pesquisa .......................................... 108

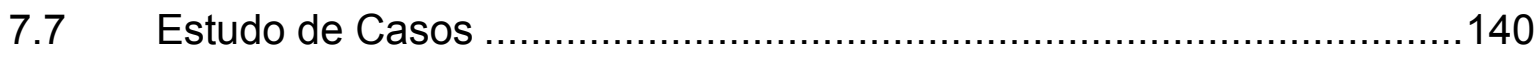

7.7.1 Descarte de resíduo inorgânico: escória de fundição ..........................141

7.7.2 Descrição de atendimento emergencial envolvendo descarte de resíduos químicos orgânicos e estimativa de custos da operação para remoção e destinação dos resíduos químicos.

8 CONCLUSÕES E RECOMENDAÇÕES ..........................................165

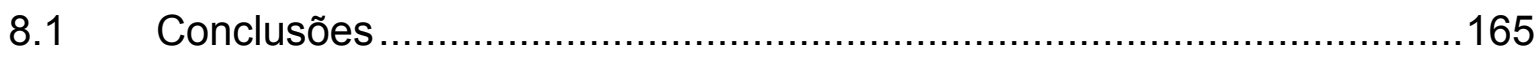

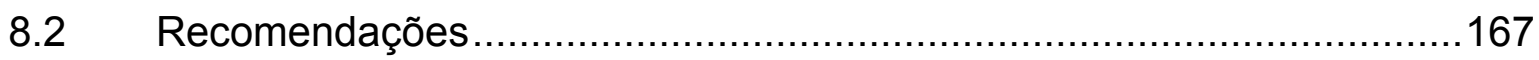

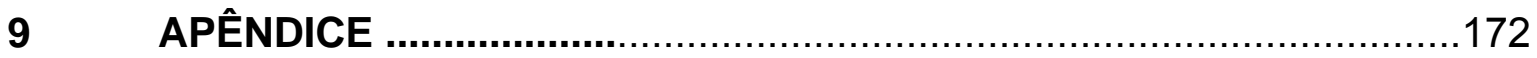

10 REFERÊNCIAS BIBLIOGRÁFICAS .............................................177 


\section{LISTA DE FIGURAS}

FIGURA 1- Mobilização de técnicos de subprefeituras para remoção de tambores comresíduos químicos

FIGURA 2- Emergências químicas atendidas pela CETESB por atividade,

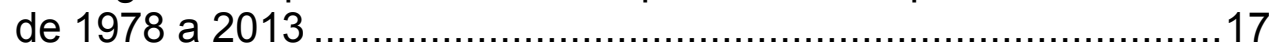

FIGURA 3- Distribuição anual das emergências químicas atendidas pela CETESB envolvendodescartes de resíduos químicos ..................19

FIGURA 4- Emergências químicas atendidas pela CETESB por atividade

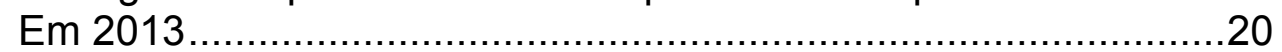

FIGURA 5- Distribuição das emergências químicas atendidas pelo INEA RJ por atividade no período de 1983 a 2013 ..............................22

FIGURA 6 - Registro fotográfico da combustão espontânea resultante de resíduo químico disposto diretamente sobre o solo .....................24

FIGURA 7- Registro fotográfico da utilização de pá-carregadeira para retirada dos resíduos ...............................................................25

FIGURA 8- Registro fotográficoda saída de caminhão caçamba do local do acidente devidamente lonado com os resíduos químicos para a destinação final adequada .....

FIGURA 9- Registro fotográficoda chegada do caminhão transportando os resíduos químicos na empresa pro-ambiental .............................26

FIGURA 10 - Evolução das áreas contaminadas no Estado de São Paulo

FIGURA 11- Distribuição por Região das áreas contaminadas no Estado de São Paulo, segundo a CETESB.

Registro de descarte de resíduos químicos por Região atendidos pela CETESB no período de 1984 a 2013

FIGURA 13- Distribuição das atividades que resultam em áreas contaminadas no Estado de São Paulo

FIGURA 14 - Distribuição por atividade das áreas contaminadas no Estado do Rio de Janeiro.

FIGURA 15 - Página "web"da CETESB para pesquisa sobre emergências químicas.

FIGURA 16 - Registro fotográfico do fotoionizador portátil utilizado para determinação de amônia anidra ...

FIGURA 17 - Mapa da Região Metropolitana de São Paulo.

FIGURA 18 - Distribuição territorial da população na Região Metropolitana de São Paulo

FIGURA 19 - Classificação das 22 Unidades de Gerenciamento de Recursos Hídricos- UGRHI - por Vocação.

FIGURA 20 - Distribuição das emergências químicas atendidas pelaCETESB por municípios da RMSP envolvendo descartes de resíduos químicos

FIGURA 21 - Descartes de resíduos químicos no Estado de São Paulo com detalhamento de recursos hídricos. Período - 2005 a 2013. 
FIGURA 22 - Distribuição das ocorrências de descarte de resíduos químicos no Distrito de Grajaú com destaque para áreas de proteção e recuperação de mananciais. Período - 2005 a 2013.

FIGURA 23 - Descartes de resíduos químicos no Estado de São Paulo com detalhamento do Sistema Viário. Período - 2005 a 2013 ................76

FIGURA 24 - Descartes de resíduos químicos na Região Metropolitana de São Paulo. Período - 2005 a 2013 ...........................................79

FIGURA 25 - Descartes de resíduos químicos nos distritos da cidade de São Paulo.Período - 2005 a 2013

FIGURA 26 - Distribuição dos registros de descarte de resíduos químicos por distritos na cidade de São Paulo

FIGURA 27 - Distribuiçãodas ocorrências de descarte de resíduos químicos nos distritos da cidade de São Paulo - estimativa de vazamento de resíduos - período - 2005 a 2013

FIGURA 28 - Informações sobre registros de descarte de resíduos químicos $\mathrm{Na}$ cidade de São Paulo

FIGURA 29 - Distribuição das ocorrências de descarte de resíduos químicos nos Distritos de Tremembé e Mandaqui com destaque para o Parque Estadual da Cantareira e o Sistema Cantareira

FIGURA 30 - Registro fotográfico do "bota-fora" da Avenida Sezefredo

Fagundes

FIGURA 31- Distribuição das ocorrências de descartes de resíduos químicos nos bairros da cidade de Guarulhos.Período - 2005 a 2013 ..........99

FIGURA 32 - Distribuição dos registros de descarte de resíduos químicos por bairros da cidade de Guarulhos

FIGURA 33 - Distribuição das ocorrências de descarte de resíduos químicos nos bairros da cidade de Guarulhos - estimativa de vazamento de resíduos - período - 2005 a 2013

FIGURA 34 - Informações sobre registros de descarte de resíduos químicos na cidade de Guarulhos ...................................................106

FIGURA 35 - Informações do perfil do pesquisado quanto à faixa etária ...........109

FIGURA 36 - Informações do perfil do pesquisado quanto ao grau de instrução (escolaridade)...

FIGURA 37 - Informações sobre o tempo de atuação do pesquisado na Empresa

FIGURA 38 - Número de atendimentos emergenciais envolvendo descarte De resíduos químicos

FIGURA 39 - Resultado da pesquisa quanto ao meio físico/estrutura afetada..112

FIGURA 40 - Meios atingidos pelos descartes de resíduos químicos nas emergências atendidas pela CETESB

FIGURA 41 - Registro fotográfico de descarte de resíduos químicos com contaminação direta do solo

FIGURA 42 - Registro fotográfico de descarte de resíduos químicos com ocorrência de contaminação direta de corpo d'água

FIGURA 43 - Registro fotográfico de ação emergencial decorrente de descarte de tambor contendo resíduo químico em frente à residência ......116

FIGURA 44 - Registro fotográfico de descarte de diversas embalagens contendo resíduos químicos em via pública (Av. Presidente Wilson) 
FIGURA 45 - Registro fotográfico de ocorrência de descarte de resíduo Químicona margem da Rod. Anhanguera.

FIGURA 46 - Avaliação da percepção dos entrevistados quanto aomissão ou do retardo das autoridades públicas ematender prontamente emergências envolvendo descarte deresíduos químicos

FIGURA 47 - Registro fotográfico de diversas bombonas plásticas e tambores metálicos de 200 litros contendo resíduos químicos deixados em

via pública

FIGURA 48 - Realização de treinamento/capacitação sobre aspectos de segurança com ênfase para atendimento a emergências com produtos químicos.

FIGURA 49 - Disponibilidade para atendimento emergencial 24hs em casos de descarte deresíduos químicos

FIGURA 50 - Disponibilidade de Equipamentos de Proteção Individual (EPIs) para atendimento emergencial............................................126

FIGURA 51 - Resposta da pesquisa quanto ao registro dos atendimentos emergenciais em Banco de Dados

FIGURA 52 - Resultado da pesquisa quanto à identificação dos responsáveis pelo descarte de resíduos químicos

FIGURA 53 - Registro fotográficoda ocorrência de descarte de diversas embalagens contendo resíduos químicos

FIGURA 54 - Registro fotográficode uniformes descartados juntos com resíduos químicos

FIGURA 55 - Tempo médio utilizado para encerrar a fase emergencial

FIGURA 56 - Registro fotográfico da retirada dos tambores utilizando-se técnicas de "Rapel"

FIGURA 57 Registro fotográfico de veículos mobilizados para remoção dos tambores contendo resíduos químicos

FIGURA 58 - Registro fotográfico da avaliação de riscos químicos por técnicos da CETESB

FIGURA 59 - Registro fotográficoda operação de transporte de tambor com Resíduo químico

FIGURA 60 - Participação em grupos de trabalho para tratar das questões relacionadas ao descarte de resíduos químicos

FIGURA 61 - Notificação à Polícia em decorrência do descarte de resíduos Químicos

FIGURA 62 - Mapa de localização do Registro de Emergência Química REQ $273 / 2013$

FIGURA 63 - Registro fotográfico dos resíduos químicos descartados na Estrada do Caracol

FIGURA 64 - Registro fotográfico da coleta do resíduo descartado na Estrada do Caracol.

FIGURA 65 - Registro fotográfico da amostra de resíduo utilizado no teste 
FIGURA 66 - Avaliação da concentração de gases e vapores no interior da capela do Laboratório de Química Inorgânica da CETESB, antes do início do teste

FIGURA 67 - Avaliação da concentração de gases e vapores sobre a amostra seca

FIGURA 68 - Aplicação de água deionizada sobre a amostra de resíduo 149

FIGURA 69 - Avaliação da concentração de gases e vapores sobre a amostra úmida

FIGURA 70 - Mapa de localização do registro REQ 017/2009 153

FIGURA 71 - Registro fotográfico de resíduos dispostos em área do Parque Estadual da Cantareira

FIGURA 72 - Registro fotográficodo atendimento emergencial para reduzir ação de água de chuva sobre os resíduos ................................155

FIGURA 73 - Registro fotográficoda colocação dos resíduos em "big bags" .....160

FIGURA 74 - Registro fotográficodo armazenamento temporário dos "big bags" na Sub-Prefeitura Jaçanã Tremembé

FIGURA 75 - Registro fotográficoda operação de remoção de carcaça de Caixas eletrônicos e automóveis.

FIGURA 76 - Notícia na página "web"dos Arautos do Evangelho sobre a remoção dos resíduos

FIGURA 77 - Situações envolvendo o descarte de resíduos químicos 


\section{LISTA DE TABELAS}

TABELA 1 - Ocorrências atendidas pela Diretoria de Prevenção e Emergência Ambiental (DEAMB) no período de 2008 a 2013

TABELA 2 - Número de áreas contaminadas por atividades causadoras áreas acompanhadas pela FEAM - Ano 2014

TABELA 3 - Parâmetros analisados na amostra de resíduo (Boletim de Análises n EAAl/39393/2014)

TABELA 4 - Registros de descartes de resíduos químicos por distritos na Zona Norte de São Paulo.

TABELA 5 - Registros de descartes de resíduos químicos por distritos na Zona Leste de São Paulo.

TABELA 6 - Registros de descartes de resíduos químicos por distritos na Zona Sul de São Paulo

TABELA 7 - Registros de descartes de resíduos químicos por distritos na Zona Oeste de São Paulo

TABELA 8 - Registros de descartes de resíduos químicos por distritos na Zona Central de São Paulo

TABELA 9 - Registros de descartes de resíduos químicos por bairros em Guarulhos

TABELA 10 - Resumo das ocorrências onde foi possível a identificação dos responsáveis ou de seus corresponsáveis pela ação do descarte.

TABELA 11 - Resultados analíticos dos ensaios na massa bruta (Boletim de Análises $N^{\circ}$ (EAAI/39393/2014)

TABELA 12 - Resultados analíticos do solubilizado (Boletim de Análises $N^{\circ}$ EAAI/39343/2014)

TABELA 13 - Resultados analíticos do lixiviado (Boletim de Análises No EAAI/39413/2014).

TABELA 14 - Resultados das análises químicas da amostra de resíduo. 156

TABELA 15 - Estimativa de custo de uma operação para atendimento de emergência. Estudo de caso 


\section{LISTA DE SIGLAS}

ABAL

ABNT

ABRELPE

APP

CAPES

CDR

$\mathrm{CDHU}$

CET

CPTM

COVs

CERCLA

CETESB

CNUMAD

CONAMA

CONSEMA

DEAMB

DER

EMPLASA

EPA

EPIs

ESRI

ETA

ETE

FATMA

FEAM

FEPRAC
Associação Brasileira do Alumínio

Associação Brasileira de Normas Técnicas

Associação Brasileira de Empresas de Limpeza Pública

e Resíduos Especiais

Área de Proteção Ambiental

Coordenadoria de Aperfeiçoamento de Pessoal de Nível Superior

Centro de Disposição de Resíduos

Companhia de Desenvolvimento Habitacional e Urbano

Companhia de Engenharia de Tráfego

Companhia Paulista de Trens Metropolitanos

Compostos Orgânicos Voláteis

Comprehensive Environmental Response,

Compensation and Liability Act

Companhia Ambiental do Estado de São Paulo

Conferência das Nações Unidas sobre o Meio Ambiente

e o Desenvolvimento

Conselho Nacional do Meio Ambiente

Conselho Estadual do Meio Ambiente

Diretoria de Prevenção e Emergência Ambiental

Departamento de Estradas de Rodagem

Empresa Paulista de Planejamento Metropolitano

Environmental Protection Agency

Equipamentos de Proteção Individual

Environmental Systems Research Institute

Estação de Tratamento de Água

Estação de Tratamento de Esgoto

Fundação do Meio Ambiente

Fundação Estadual do Meio Ambiente

Fundo Estadual para Prevenção e Remediação de

Áreas Contaminadas 
FID

GLP

GIS

IBAMA

IBC

IBGE

INEA

IPC

IPVS

LII

LINACH

LPO

MERCOSUL

MMA

MTE

ONU

OPAS

OSHA

PCBs

PI

PIB

PVA

PID

PVC

REQ

RMSP

RPC

SABESP

SEADE

SEMAD

SciELO

SIEQ
Detector de lonização de Chama

Gás Liquefeito de Petróleo

Sistema de Informações Geográficas

Instituto Brasileiro do Meio Ambiente e Recursos

Naturais Renováveis

Intermediate Bulk Conteinner

Instituto Brasileiro de Geografia e Estatística

Instituto Estadual do Ambiente

Índice de Preços ao Consumidor

Índice Paulista de Vulnerabilidade Social

Limite Inferior de Inflamabilidade

Lista Nacional de Agentes Cancerígenos para Humanos

Limite de percepção olfativa

Mercado Comum do Sul

Ministério do Meio Ambiente

Ministério do Trabalho e Emprego

Organização das Nações Unidas

Organização Panamericana de Saúde

Occupational Safety and Health Administration

Bifenilas Policloradas

Potencial de lonização

Produto Interno Bruto

Acetato de Polivinila

Detector de Fotoionização

Cloreto de Polivinila

Registro de Emergências Químicas

Região Metropolitana de São Paulo

Responsabilidade Pós Consumo

Companhia de Saneamento Básico do Estado de SãoPaulo

Fundação Sistema Estadual de Análise de Dados

Secretaria de Estado de Meio Ambiente e

Desenvolvimento Sustentável

Scientific Eletronic Library Online

Sistema de Informações sobre Emergências Químicas 
SOPEA

STEL

TGCA

UGRHI

UPRs

UNEP

USP

UTM

WISER
Serviço de Operações de Emergência

Short Term Exposure Limit

Taxas de Crescimento Anual da População

Unidades de Gerenciamento de Recursos Hídricos

Unidades de Planejamento Regional

United Nations Environment Programme

Universidade de São Paulo

Universal Transversa de Mercator

Wireless Information System for Emergency Responders 



\section{INTRODUÇÃO}

No último século, com o surgimento de novos produtos decorrentes dos avanços tecnológicos, com o crescimento demográfico associado à densificação urbana e, ainda, com o fenômeno da globalização das trocas comerciais, a utilização e o consumo de recursos naturais e de energia aumentaram exponencialmente. As sociedades, em termos gerais, passaram a consumir ainda mais do que aquilo que se produzia em seu redor (VIEIRA, 2012).

Um dos desafios e reflexões apontado por JACOBI (2012) sobre resíduos sólidos nas cidades brasileiras, se expressa quando se refere à produção de cerca de 11 mil toneladas de resíduos por dia no Município de São Paulo e mais de 17 mil toneladas por dia na Região Metropolitana de São Paulo (RMSP).

O que se verifica na prática é a íntima relação entre a expansão da capacidade de consumo das sociedades modernas e os impactos ambientais decorrentes da geração de resíduos sólidos.

Passou-se de uma sociedade da escassez para a sociedade da abundância e do consumo hedonístico (SANTOS, 2008).

RIBEIRO (2009) complementa que há hoje um forte apelo na sociedade urbana pelo consumismo e que a qualidade de vida está associada ao consumo de bens materiais com a consequente devastação da natureza e pressão sobre os recursos naturais. Da transformação desses recursos são produzidos diariamente milhares de toneladas de lixo e resíduos sólidos. O consumo compulsivo e exacerbado, voltado para atender a demandas supérfluas da minoria, cede lugar à satisfação das necessidades básicas, materiais e imateriais, a partir de um projeto da sociedade.

VEIGA e ISSBERNER (2012) observam que os economistas convencionais tentam ignorar a dependência do sistema econômico em relação à biosfera. No 
entanto, a atividade econômica dela extrai recursos e a ela os devolve, ao longo e no fim do processo produtivo, na forma de resíduos, poluição, lixo, etc.

Torna-se inevitável a pergunta: o que fazer com as enormes quantidades de resíduos sólidos em escala crescente da sociedade de consumo que se estabeleceu após a segunda guerra mundial?

Como se pode observar na análise de MILLER (2007), a maioria dos resíduos sólidos é um sintoma do desperdício de recursos, cuja produção causa poluição e degradação ambiental. Segundo o autor, a sociedade produzirá sempre algum tipo de resíduo sólido, direta ou indiretamente a partir da criação dos produtos e serviços que utiliza.

No prefácio da publicação "Planos de Gestão de Resíduos Sólidos: Manual de Orientação", do Ministério do Meio Ambiente (BRASIL, 2012) ficam evidentes os enormes desafios que a grande maioria dos municípios brasileiros enfrenta para assegurar a promoção de um ambiente mais saudável, com menos riscos à população.

O crescimento das cidades brasileiras não foi acompanhado pela provisão de infraestrutura e de serviços urbanos, entre eles os serviços públicos de saneamento básico, que incluem 0 abastecimento de água potável; a coleta e tratamento de esgoto sanitário; a estrutura para a drenagem urbana e o sistema de gestão e manejo dos resíduos sólidos (BRASIL, 2012).

A mudança de perfil dos resíduos sólidos nas últimas décadas torna 0 problema ainda mais grave, na medida em que sua natureza era na metade do século passado basicamente composta de restos de comida, detritos de varrição como folhas, entre outros, e passam a assumir, com o avanço da tecnologia, uma natureza constituída por substâncias tóxicas e/ou persistentes, como plásticos, pilhas e baterias, lâmpadas, embalagens de produtos químicos e os resíduos químicos.

Segundo CÂMARA et al. (2010), os processos produtivos são constituídos por elementos de produção e de consumo nos quais o ser humano, por meio de sua capacidade de trabalho, transforma as matérias primas em produtos. 
Nesse sentido, são quatro as etapas principais desse complexo processo. A primeira se caracteriza pela obtenção da matéria prima e seu transporte ao local de produção; a segunda pelo processo de transformação da matéria prima em produtos, particularmente nas indústrias; a terceira pelo consumo dos produtos e, por último, a quarta, pela formação de resíduos finais.

A Organização Pan-americana de Saúde adverte no documento "Avaliação Regional dos Serviços de Manejo de Resíduos Sólidos Municipais na América Latina e Caribe":

[...] O crescimento acelerado e desordenado do setor industrial causa diretamente a contaminação biológica, química e física; provoca aumentos no transporte e no consumo de energia; gera mais refugos e torna inadequada sua disposição. A industrialização, somada aos efeitos negativos da mudança climática, está contribuindo para a deterioração do ambiente e da qualidade de vida e da saúde da população. Os processos de produção - as explorações mineiras,petrolíferas e agrícolas (as que empregam agroquímicos nos cultivos), os hospitais, centros de saúde e laboratórios, as usinas de energia e a indústria manufatureira - são os maiores geradores de refugos químicos e resíduos sólidos perigosos. O consumo de bens e serviços é um grande desafio à gestão ambiental em termos do controle de riscos e promoção da saúde (ORGANIZAÇÃO PANAMERICANA DA SAÚDE, 2005 p.219).

Em 1992 a Organização das Nações Unidas (ONU) realizou, no Rio de Janeiro, a Conferência das Nações Unidas sobre o Meio Ambiente e o Desenvolvimento (CNUMAD), mais conhecida como Rio 92 (BRASIL, 2014a).

Desse evento resultou a Agenda 21, documento de 40 Capítulos com diretrizes de planejamento para a construção de sociedades sustentáveis, em diferentes bases geográficas, justiça social e eficiência econômica (BRASIL, 2014a).

A preocupação com os resíduos químicos é tratada no Capítulo 20 da Agenda 21 onde é abordado o Manejo Ambientalmente Saudável dos Resíduos Perigosos, incluindo a Prevenção do Tráfico Internacional llícito de Resíduos Perigosos (BRASIL, 2014a).

Três questões importantes merecem destaque no Capítulo 20, em seu item 20.20: 
- há falta de conhecimento sobre a contaminação e poluição do meio ambiente e dos riscos que resultam da exposição a resíduos perigosos para a saúde da população, especialmente de mulheres e crianças, e dos ecossistemas;

- é preciso tomar medidas para identificar as populações expostas a altos riscos e, se necessário, aplicar medidas corretivas;

- é necessário fortalecer as capacidades das instituições responsáveis pelo manejo dos resíduos perigosos.

SPINOLA (2011) destaca que, no contexto brasileiro, a preocupação com a poluição do solo e com as áreas contaminadas é bastante recente e vem, especialmente a partir do ano 2000 , despertando a atenção das autoridades federais, estaduais e municipais.

No relatório anual do UNITED NATIONS ENVIRONMENT PROGRAMME (UNEP) de 2013, reconheceu-se que apesar dos produtos químicos exercerem forte influência no crescimento econômico dos países, é essencial a boa gestão em todo o seu ciclo de vida, evitando-se assim significativos impactos na saúde humana e nos ecossistemas, bem como custos adicionais para as economias dos países (UNITED NATIONS ENVIRONMENT PROGRAMME, 2014).

O descarte de resíduos químicos em vias públicas é uma ameaça à saúde da população e ao meio ambiente. Essa prática representa mais uma atividade geradora de acidentes potencialmente poluidora do solo, do ar, de águas superficiais e subterrâneas, assim como o transporte rodoviário de produtos químicos, a indústria, os postos e sistemas retalhistas de combustíveis, entre outras. Segundo GÜNTHER (2006),

Nas últimas décadas do século $\mathrm{XX}$, a questão dos resíduos sólidos evidencia-se não só pelo aumento dramático da quantidade, mas pela presença cada vez maior de substâncias perigosas nos processos industriais e em algumas atividades comerciais e domésticas.

Nesse sentido a questão do descarte de resíduos especiais é citada por 
(VIANNA, 2012) na sua Tese de Doutorado defendida em 2012 no Programa de Pós-Graduacão da Universidade de São Paulo,

\begin{abstract}
Um fator preocupante, e que oferece riscos à população, está relacionado ao manejo de resíduos especiais - principalmente quando são perigosos - que envolvem riscos de contaminação do solo, como resíduos dos serviços de saúde, industriais, de construção e demolição, pneumáticos, pilhas e baterias, lâmpadas fluorescentes; embalagens de agrotóxicos e resíduos de equipamentos elétricos e eletrônicos.
\end{abstract}

São inúmeros os casos atendidos por instituições públicas, como Corpo de Bombeiros, Defesa Civil e Órgãos Ambientais envolvendo o abandono de resíduos químicos em tambores, bombonas, sacos plásticos e outras embalagens, ou nos casos mais graves, a granel, em margens de rodovias e seus acessos marginais ou como em algumas situações decorrentes de roubo de carga.

A FIG. 1 ilustra a cobertura jornalística sobre o descarte de resíduos químicos ocorrido em 18 de junho de 2007 na zona leste da cidade de São Paulo,próximo à nascente do córrego Aricanduva, quando ali foram deixados 21 tambores, contendo borra de tinta que contaminaram o córrego. Desse fato resultou a mobilização de 70 trabalhadores, incluindo técnicos da CETESB Companhia Ambiental do Estado de São Paulo, Corpo de Bombeiros e Defesa Civil e 6 (seis) subprefeituras para a remoção dos resíduos.

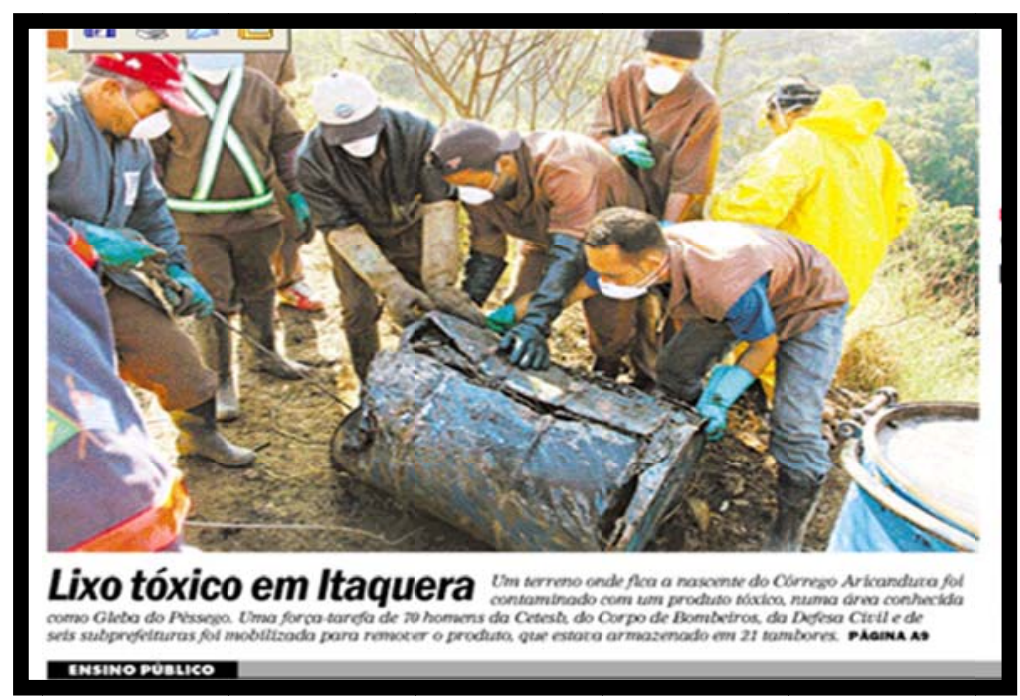

FIGURA 1- Mobilização de técnicos de subprefeituras para remoção de tambores com resíduos químicos.

Fonte: Jornal Destak (acesso em http://www.destakjornal.com.br/virtual/) 
Diz BRAGA (2009):

Teme-se que muitos dos problemas que têm sido detectados com relação ao descarte de resíduos químicos representem apenas uma pequena parte de todos os problemas gerados no passado, devido ao mau uso e disposição de resíduos químicos tóxicos no meio ambiente.

Nesse contexto destacam-se também algumas propriedades pertencentes a massas falidas, via de regra, áreas industriais fechadas ou abandonadas nas quais no passado se utilizaram substâncias nocivas e que ao encerrarem suas atividades, seja por razões econômicas, comerciais ou ambientais, deixaram para trás resíduos químicos perigosos armazenados de forma inadequada, muitas vezes lançados diretamente sobre o solo ou em condições precárias de armazenamento e, não raro, com ocupação humana nesses locais. A ocorrência dessa situação é mais comum na Região Metropolitana de São Paulo (RMSP), segundo o Sistema de Informações sobre Emergências Químicas (SIEQ) da CETESB - Companhia Ambiental do Estado de São Paulo. De acordo com SÁNCHEZ (2001):

A maioria das indústrias hoje instaladas não seguiu os principais preceitos da boa gestão ambiental, devendo provavelmente tomar medidas corretivas quando de sua desativação. Práticas que eram usuais no passado originaram passivos ambientais de monta. 


\section{OBJETIVOS}

\subsection{Objetivo geral}

O presente trabalho objetiva avaliar o impacto socioambiental decorrente das emergências químicas ocorridas na Região Metropolitana de São Paulo (RMSP) com descarte de resíduos químicos, com vistas à proteção ambiental e da saúde pública, servindo como base para a complementação de políticas públicas para enfrentamento de situações emergenciais.

\subsection{Objetivos específicos}

Realizar análise dos registros de descartes de resíduos químicos no Sistema de Informações de Emergências Químicas (SIEQ) da CETESB - Companhia Ambiental do Estado de São Paulo, no período de 2005 a 2013, tomando como referência a RMSP,demonstrando os impactos desses acidentes nos compartimentos solo, ar e água;

Caracterizar a incidência de prática de descarte de resíduos químicos, sobrepondo a mapas temáticos de rodovias e recursos hídricos, utilizando como ferramenta o sistema de georreferenciamento;

Realizar um diagnóstico socioambiental quanto à distribuição espacial de ocorrência e abundância quanto aos descartes de resíduos químicos na RMSP com ênfase para os municípios de São Paulo e Guarulhos;

Avaliar por meio de pesquisa dirigida aos principais atores intervenientes dos cenários acidentais a eficiência dos processos atuais de intervenção e de tratamento aplicados nos descartes de resíduos químicos nas esferas municipais e estaduais;

Apresentação de dois estudos de casos atendidos pela CETESB - Companhia Ambiental do Estado de São Paulo com descarte de resíduos químicos. Em um dos casos estimar o custo da fase emergencial;

Propor soluções que atendam desde a necessidade de intervenção imediata 
dos órgãos públicos, considerando os casos de descarte de resíduos químicos em que não seja possível a identificação do infrator responsável, bem como de procedimentos técnicos adequados de avaliação dos principais riscos químicos, de remoção, de transporte, de armazenamento temporário e responsabilidades até que se defina pelo seu destino final adequado com acompanhamento do órgão ambiental competente. 


\section{RELEVÂNCIA CIENTÍFICA DA PESQUISA}

O expressivo aumento nos últimos anos de descartes de resíduos químicos na RMSP registrados pela CETESB - Companhia Ambiental do Estado de São Paulo, demonstra a relevância socioambiental da pesquisa. Tal fato se deve à necessidade de propor solução que vise atender aos interesses da sociedade para remoção, transporte e armazenamento temporário dos resíduos químicos descartados de forma irregular no Estado de São Paulo e, nos casos em que se fizer necessário, adotar medidas para investigação da contaminação do solo e água subterrânea.

Observa-se na pesquisa a relevância tanto social quanto científica, com destaque para seu ineditismo no campo acadêmico em âmbito nacional.

A pesquisa produz novos conhecimentos, contribuindo para o encaminhamento de soluções para problemas como esse de poluição ambiental e de saúde pública. Tal situação é tratada em São Paulo e demais Estados da Federação de forma desarticulada e sem procedimentos técnicos previamente estabelecidos pelos órgãos ambientais brasileiros e demais instituições dos setores de segurança e saúde.

Entende-se, portanto, ser imprescindível que as Políticas Públicas Estaduais que tratam da matéria contemplem essas situações e prevejam ações rápidas, conjuntas e ajustadas com a infraestrutura necessária para os atores públicos normalmente presentes nessas ocorrências como defesa civil municipal, prefeituras, órgãos ambientais, secretarias de saúde e corpo de bombeiros enfrentarem problemas advindos do descarte de resíduos químicos. 


\section{REVISÃO DA LITERATURA}

\subsection{Descarte de resíduos químicos no contexto internacional}

O problema dos resíduos perigosos é de fato uma questão de abrangência internacional.

Em decorrência do lançamento desses tipos de resíduos praticado em países em desenvolvimento, a Convenção da Basiléia sobre o Controle do Movimento entre Fronteiras de Resíduos Perigosos e seu Descarte foi sediada na cidade Suíça que lhe deu o nome, em 1999 e assinada por mais de 100 países, incluindo o Brasil (MANAHAN, 2013a).

JENKINS et al. (2009) destacam que logo após a segunda guerra mundial, a disposição de resíduos sólidos a céu aberto, associado a sua queima como forma de destruição, era comum no gerenciamento de resíduos sólidos municipais nos Estados Unidos. Essa prática contribuía para a presença de catadores de lixo. Entre os catadores estavam crianças que reviravam o lixo diariamente. Periodicamente os lixões eram queimados como forma de reduzir o volume de resíduos, o que produzia uma série de efeitos adversos à saúde dos moradores locais. Em outras cidades, incluindo Nova York, a fumaça dos lixões algumas vezes eram a causa de acidentes de trânsito além de provocar acúmulo de fuligem em casas e suas estruturas.

Ainda nesse contexto, WILLIAMS e MATHENEY (1995) complementam que muitas áreas utilizadas como meio de dispor resíduos sólidos nos Estados Unidos foram à causa de contaminação do ar, água subterrânea e superficial. Foram inúmeros casos espalhados pelo território americano de lixões que continham resíduos químicos perigosos misturados aos resíduos domésticos.

LANDRIGAN e GROSS, em um artigo publicado em 1981, relatam explosões e incêndios em área de descarte de resíduos químicos em Elizabeth e Logan Township, Nova Jersey e em Chester, Pensilvânia; resíduos químicos entraram em combustão no Rio Cuyahoga em Cleveland; solventes escoaram para sistemas de esgoto e explodiram sobre as ruas de Louisville, Kentucky (LANDRIGAN \& GROSS, 1981). 
Ainda segundo os autores, um risco específico resultante da queima de resíduos químicos é a formação de substâncias tóxicas a partir de sua combustão: o superaquecimento de cloreto de polivinila (PVC) libera ácido clorídrico; acrilonitrila produz ácido cianídrico; bifenilaspolicloradas (PCBs) formam tetraclorodibenzofuranos; benzenos clorados produzem tetraclorodibenzodioxinas.

Nas palavras de JENKINS ET al. (2009) haviam vários argumentos para maior envolvimento do governo americano na questão do gerenciamento de resíduos sólidos. Áreas destinadas a depósito a céu aberto de resíduos sólidos possuíam potencial para contaminar a água subterrânea - uma externalidade, cujos efeitos poderiam ficar mascarados por longos períodos de latência. A queima de resíduos a céu aberto geraria poluição do ar e levantaria a questão do uso indevido pelos catadores que não teriam a plena consciência dos riscos a que estariam expostos.

Nos Estados Unidos a Environmental Protection Agency (EPA) considera o descarte de resíduos como "illegal dumping" e como bem descrito no seu "Guia de prevenção de Descarte de Resíduos" (ENVIRONMENTAL PROTECTION AGENCY, 1998) é um dos principais problemas de muitas comunidades ao longo do território americano. Esse problema suscita grande preocupação com a saúde pública, segurança, o patrimônio privado e a qualidade de vida.

Ainda segundo o Guia da EPA, "illegal dumping" é também conhecido pelos americanos como "open dumping" e "midnight dumping" uma vez que os resíduos são normalmente descartados a partir de veículos em áreas abertas ao longo de rodovias e tarde da noite. Esse tipo de descarte nos Estados Unidos é principalmente constituído por materiais não perigosos, como entulhos de construção, pneus inservíveis, mobília, resíduos de jardim e os infratores assim o fazem para livrar-se das taxas do governo concedidas para disposição adequada, assim como, para reduzir o tempo de obtenção da licença do órgão ambiental. "Illegal dumping" nos Estados Unidos também registra inúmeros casos de resíduos químicos. 
Nos Estados Unidos o programa ambiental conhecido como "Superfund" foi criado para lidar com áreas contendo resíduos perigosos abandonados. É também o nome do fundo estabelecido pela Comprehensive Environmental Response, Compensation and Liability Act (CERCLA) de 1980 (ENVIRONMENTAL PROTECTION AGENCY, 2013a).

Essa lei foi promulgada com a descoberta de despejos de resíduos tóxicos como o Love Canal e Times Beach em 1970. Com a criação do Fundo, a EPA pôde efetuar a limpeza das áreas contaminadas e exigir dos responsáveis que executassem a limpeza ou reembolsassem o governo pelos trabalhos de recuperação ambiental (ENVIRONMENTAL PROTECTION AGENCY, 2013a).

A legislação contida na CERCLA (Superfund) trata dos lançamentos reais ou prováveis de materiais perigosos com possibilidade de colocar em risco a saúde da população ou o ambiente circundante em locais de descartes de resíduos não controlados nos Estados Unidos. A lei exige que as partes responsáveis ou o governo limpe essas áreas (MANAHAN, 2013b).

Ainda segundo MANAHAN (2013b),

Entre as principais finalidades da CERCLA estão:

- a identificação de locais contaminados;

- a avaliação do perigo em áreas de descarte;

- a avaliação de danos a recursos naturais;

- o monitoramento do lançamento de substâncias perigosas;

- a remoção ou limpeza de resíduos pelas partes responsáveis ou pelo governo.

O processo de limpeza pelo Superfund é complexo. Envolve as etapas necessárias para avaliar os locais contaminados e colocá-los na lista de prioridades nacionais, estabelecendo e implementando planos de recuperação apropriada. Esse é um processo de limpeza da área contaminada a longo prazo. Além disso, a Agência Ambiental tem a autoridade para realizar ações 
de remoção imediata onde a situação assim requeira para o caso (ENVIRONMENTAL PROTECTION AGENCY, 2013a).

Antes da regulamentação da EPA sobre resíduos perigosos, grande parte dos resíduos dos Estados Unidos eram armazenados ou descartados incorretamente em aterros sem as devidas proteções ambientais ou simplesmente abandonados em campos abertos ou descartados ao longo de estradas (ENVIRONMENTAL PROTECTION AGENCY, 2011).

Além disso, instalações industriais abandonadas que utilizaram produtos químicos e outras substâncias perigosas podem não ter armazenado corretamente seus resíduos antes de fechar as operações. Hoje, esses locais estão passando por ações de remediação em longo prazo, que podem levar vários anos para que se conheça a real extensão da contaminação e desenvolver a tecnologia mais apropriada para a descontaminação pelos resíduos perigosos (ENVIRONMENTAL PROTECTION AGENCY, 2011).

A EPA não ignora a possibilidade de graves ameaças imediatas para o ambiente ou para as pessoas que vivem ou trabalham em torno dessas áreas contaminadas que necessitam de intervenção imediata antes mesmo que a ação em longo prazo se complete. Se houver quaisquer ameaças imediatas presentes nesses locais, a EPA pode responder rapidamente para executar uma ação de remoção (ENVIRONMENTAL PROTECTION AGENCY, 2011).

As ações de remoção da EPA contemplam uma ampla gama de ameaças, incluindo situações de emergência, aonde a EPA chega ao local onde há presença de resíduos perigosos dentro de horas, bem como situações onde há uma importante contaminação e demanda resposta em até seis meses. Em algumas situações Intervenções imediatas por parte do programa Superfund podem eliminar ações de longo prazo para remediar uma área contaminada (ENVIRONMENTAL PROTECTION AGENCY, 2011).

O Ministério do Meio Ambiente do Japão realizou em 2004 o levantamento de seus resíduos industriais para compreender os casos de descartes ilegais. 
Nesse sentido, o governo japonês tem implementado políticas públicas para eliminar os casos de descartes ilegais de resíduos no país. No entanto, a completa erradicação de disposição inadequada de resíduos ainda não foi alcançada (MINISTRY OF THE ENVIRONMENT GOVERNMENT OF JAPAN, 2005).

Segundo o Ministério do Meio Ambiente do Japão, em 2005 foi compilado o número de descartes ilegais de uma mistura de sulfatos e resíduos de hidrocarbonetos ("sulfate pitch") com características corrosivas e de geração de gases tóxicos. Esse trabalho foi obtido com a cooperação de órgãos governamentais municipais e de centros de saúde. Foram treze casos confirmados de descarte ilegal de uma mistura de sulfato e resíduos de hidrocarbonetos, o que totalizou 1.127 tambores metálicos de 200 Litros. Ainda em 2005 foram contabilizados 17 tambores metálicos de uma borra de argila ativada utilizada no refino de óleo leve. Nesse caso foram 4.055 tambores metálicos (MINISTRY OF THE ENVIRONMENT GOVERNMENT OF JAPAN, 2006).

Segundo TANAKA (2007), grande quantidade de resíduos químicos descartados ilegalmente no norte do Japão reascendeu novamente a discussão nacional sobre essa polêmica questão. Quem deve ser responsabilizado pela limpeza dos resíduos ali descartados? A contaminação teve como origem uma grande quantidade de tambores contendo resíduos químicos. No Japão há aproximadamente 70.000 companhias de gerenciamento de resíduos. Noventa por cento dessas empresas estão diretamente envolvidas na coleta e transporte desses resíduos para as instalações de tratamento. Entretanto, por economia de custos algumas optam pelo caminho mais fácil conhecido como descarte de resíduos químicos.

ICHINOSE e YAMAMOTO (2010) relatam que "o descarte de resíduos ocorre por várias razões, um dos motivos que induz a essa prática está associado com a falta de instalações adequadas para tratamento de resíduos". Na falta dessas instalações o custo para tratamento adequado torna-se elevado e como resultado algumas pessoas são de certa forma, motivadas a realizarem o 
descarte de resíduos de forma aleatória violando totalmente as regras de segurança e desrespeitando o meio ambiente.

SIGMAN (1998) citado por ICHINOSE e YAMAMOTO (2010) estudou os descartes de resíduos oleosos nos Estados Unidos e demonstrou seu aumento a partir de imposições restritivas à destinação adequada de óleo usado.

KIM et al. (2008) também analisaram a prática de descarte ilegal de resíduos a partir de outro ponto de vista. Eles argumentaram que o descarte de resíduos teria sido induzido pelo preço único estabelecido por autoridades municipais na Coréia do Sul.

A Agência Ambiental do Reino Unido estima que o custo anual para investigar e promover a limpeza da área afetada por descarte de resíduos é de cerca de $£ 100$-150 milhões. Como resposta a esta realidade, muitos países têm reexaminado suas legislações com vistas a torná-la mais severa por meio de punições administrativas e criminais (ENVIRONMENT AGENCY, 2010a).

Uma importante e exitosa atuação de investigação promovida pela Agência Ambiental do Reino Unido (ENVIRONMENT AGENCY, 2010b) concluída em abril de 2012, encontra-se resumidamente descrita a seguir.

"Gangue resíduos químicos é processada com sucesso pela Agência Ambiental".

Uma gangue de quatro empresários que atuava com resíduos foi processada com sucesso pela Agência Ambiental do Reino Unido por armazenar ilegalmente toneladas de resíduos químicos perigosos, alguns dos quais acabou sendo descartado no norte da Inglaterra.

Durante a sentença, a Juíza Badley disse que todos os quatro réus foram "persistentes na busca de lucro, cada vez mais ousados e agiram fora dos regulamentos, claramente por motivos financeiros". 
A descoberta de resíduos químicos ilegalmente descartados em uma estrada em Yorkshire, Lancashire e Shropshire demandou uma investigação nacional pela Agência de Meio Ambiente, que recebeu o nome de "Operação Pandora".

A investigação conduzida pelo tribunal de Preston Crown identificou seis áreas clandestinas contendo resíduos químicos ao longo do território de Lancashire todas operadas pelos réus.

- em uma dessas áreas foram identificados 100 tambores contendo resíduos químicos, incluindo ácidos, frascos farmacêuticos e comprimidos esmagados danificados.

- um dos recipientes encontrados possuía a inscrição no rótulo "Produto reativo com água".

- funcionários da Agência Ambiental localizaram 11 contêineres do tipo IBC (Intermediate Bulk Conteinner) com capacidade para 1000 Litros com o rótulo "Conteúdo Cancerígeno" distante cerca de 125 metros do estuário do Rio Ribble, um importante ambiente de interesse científico, todos haviam sido armazenados por Christian Briely.

- o sério risco ambiental tornou-se evidente quando tambores contendo resíduos químicos vazaram e atingiram o Rio Tawd.

Os trabalhos conduzidos pela equipe técnica da Agência de Meio Ambiente do Reino Unido demandou o uso de roupas de proteção química e equipamentos de proteção respiratória, em razão das características físicas e químicas dos resíduos.

Todos os sentenciados foram punidos por trabalho não remunerado.

O Chefe da Agência Ambiental do Reino Unido, MatCrocker disse: "Esta sentença envia a mensagem de que o crime de resíduos é uma ofensa grave. Delinquentes podem e serão enviados para a prisão". 


\subsection{Descartes de resíduos químicos no contexto nacional}

Segundo dados do SIEQ, o mais amplo e detalhado registro de emergências químicas do país, criado em 1978, o descarte de resíduos químicos respondeu por $4,7 \%$ do total de 9.673 emergências químicas registradas no Sistema desde o seu início até 2013.

Para efeito desse trabalho emergência química é um evento repentino, indesejável e inesperado envolvendo produtos químicos, que pode causar danos às pessoas, ao meio ambiente e ao patrimônio (Vasconcellos, et al., 2014).

A quarta principal causa de emergências químicas no Estado de São Paulo segundo a CETESB é o descarte de resíduos químicos,como demonstrado na FIG. 2.

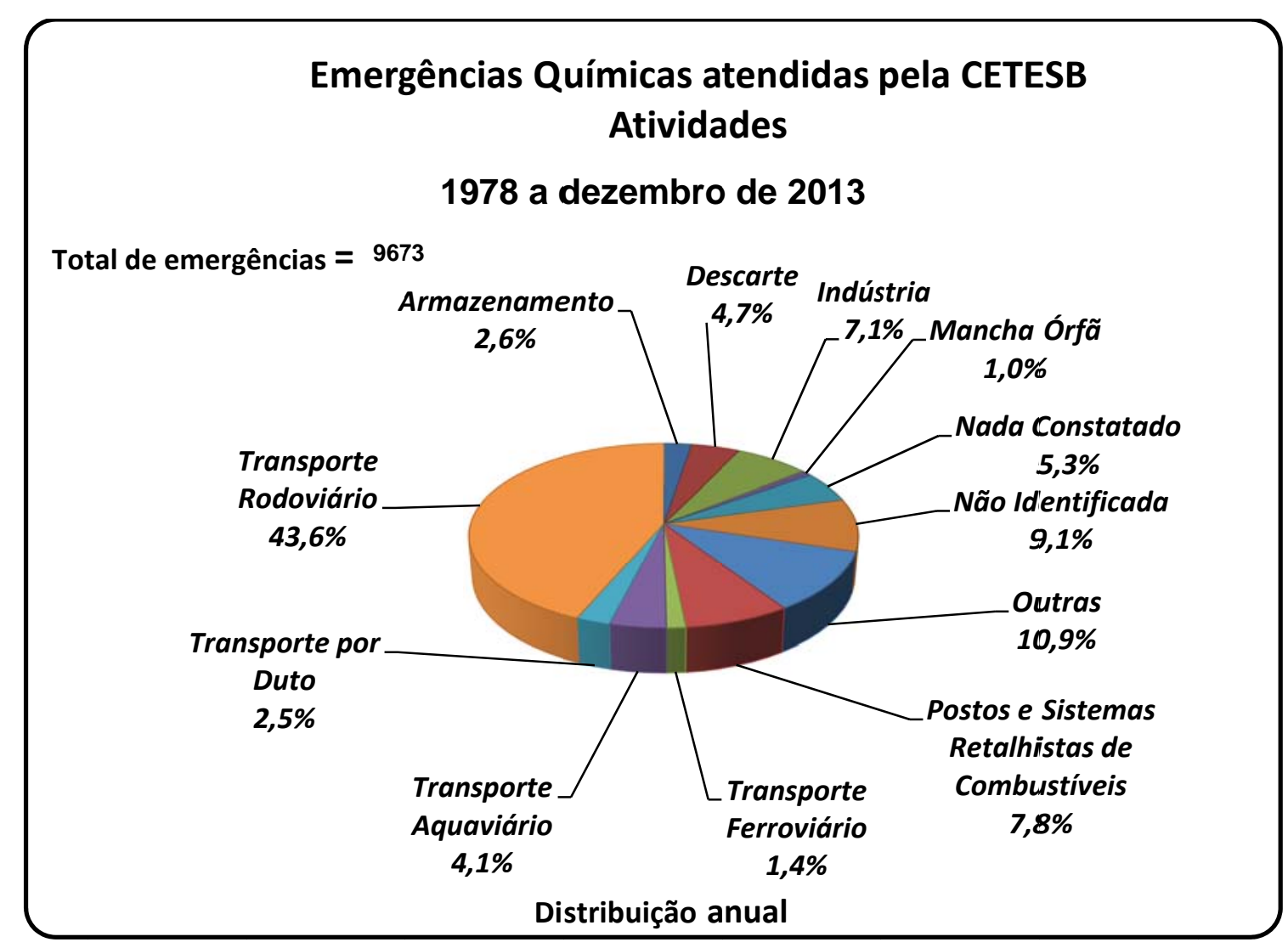

FIGURA 2 - Emergências químicas atendidas pela CETESB por atividade, de 1978 a 2013. Fonte:(CETESB - COMPANHIA AMBIENTAL DO ESTADO DE SÃO PAULO, 2013a, adaptado do SIEQ) 
As emergências químicas aqui apresentadas dizem respeito tão somente àqueles eventos em que o órgão ambiental foi comunicado, por isso, certamente há um sub-registro nesses dados. Mesmo internamente na CETESB - Companhia Ambiental do Estado de São Paulo há aquelas situações onde o atendimento foi realizado e não foi contabilizado no SIEQ o que afeta negativamente a qualidade dos registros na medida em que não traduz toda a realidade dos fatos.

Na FIG.2 a atividade classificada como "Nada constatado", refere-se às situações onde o acionamento feito à CETESB - Companhia Ambiental do Estado de São Paulo indicava uma possível emergência, no entanto, após a avaliação de campo não ficou caracterizada tal situação. Este conceito difere substancialmente do contido no item "Não identificada", que se refere às emergências em que de fato existia algum produto envolvido, mas a identificação da fonte geradora não foi possível, como, por exemplo, quando ocorre o descarte de produto químico em galerias de esgoto ou de águas pluviais.

O item "Mancha órfã" refere-se às manchas de óleo que aparecem na superfície do mar ou de outros corpos de água e cuja origem não foi identificada.

O item "Outras" refere-se aos atendimentos realizados em estabelecimentos comerciais, empresas, aterros sanitários, laboratórios de instituições de ensino e outras que não se enquadram nas demais atividades.

Emergências químicas envolvendo descarte de resíduos químicos diferenciamse das demais por tratar-se, geralmente, de ocorrências que demandam um grau de dificuldade maior para o seu enfrentamento e controle da situação.

Essas ocorrências são, em geral, comunicadas pela população local, porém sem a identificação de seus responsáveis ou da placa do veículo que realizou o transporte clandestino dos resíduos descartados. Esse fato dificulta a ação administrativa a ser imputada pelas autoridades competentes, como órgãos ambientais, em autuar aqueles que praticam esse ato lesivo ao meio ambiente. 
A distribuição anual dos atendimentos realizados pela CETESB - Companhia Ambiental do Estado de São Paulo referentes aos descartes de resíduos químicos no estado de São Paulo tem crescido, desde quando se começou a registrar os eventos (FIG. 3).

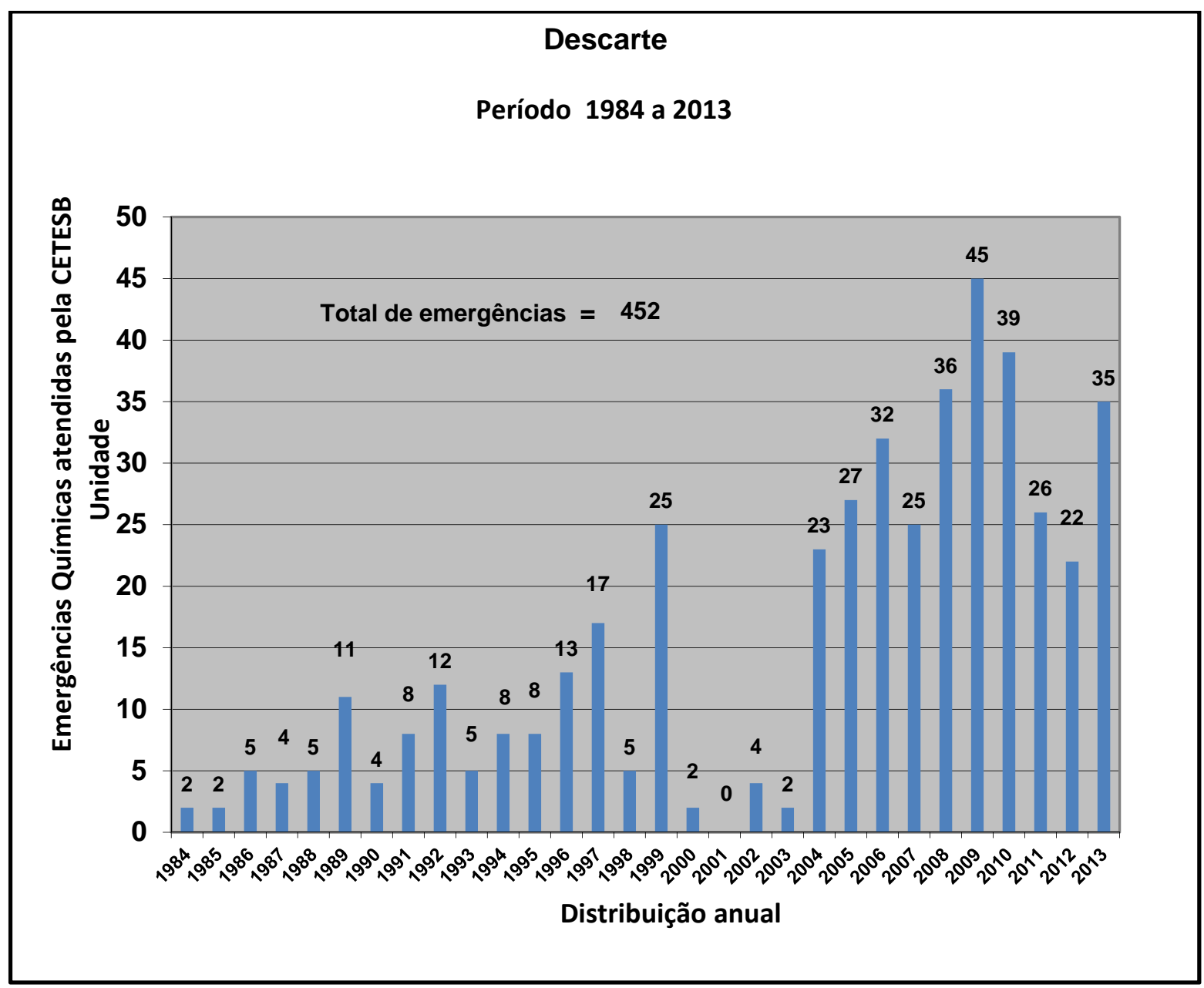

FIGURA 3 - Distribuição anual das emergências químicas atendidas pela CETESB envolvendo descartes de resíduos químicos.

Fonte:(CETESB - COMPANHIA AMBIENTAL DO ESTADO DE SÃO PAULO, 2013a, adaptado do SIEQ)

A partir dos registros de emergências químicas apresentados na FIG. 3 podese concluir que a média dos últimos dez anos (2004 a 2013) são de 31 casos de descartes de resíduos químicos por ano notificados a CETESB - Companhia Ambiental do Estado de São Paulo.

Analisando as emergências químicas atendidas pela CETESB - Companhia Ambiental do Estado de São Paulo em 2013 como demonstrados na FIG. 4, observa-se que os descartes de resíduos químicos alcançaram a significativa 
proporção de $9,1 \%$, ocupando a $2^{a}$ posição, sendo superado apenas pelo transporte rodoviário.

O aumento do número de ocorrências verificado em 2013 merece ser acompanhado com cautela pelo setor público nos próximos anos, a fim de se identificar se haverá tendência no incremento nessa prática lesiva ao meio ambiente e à saúde pública.

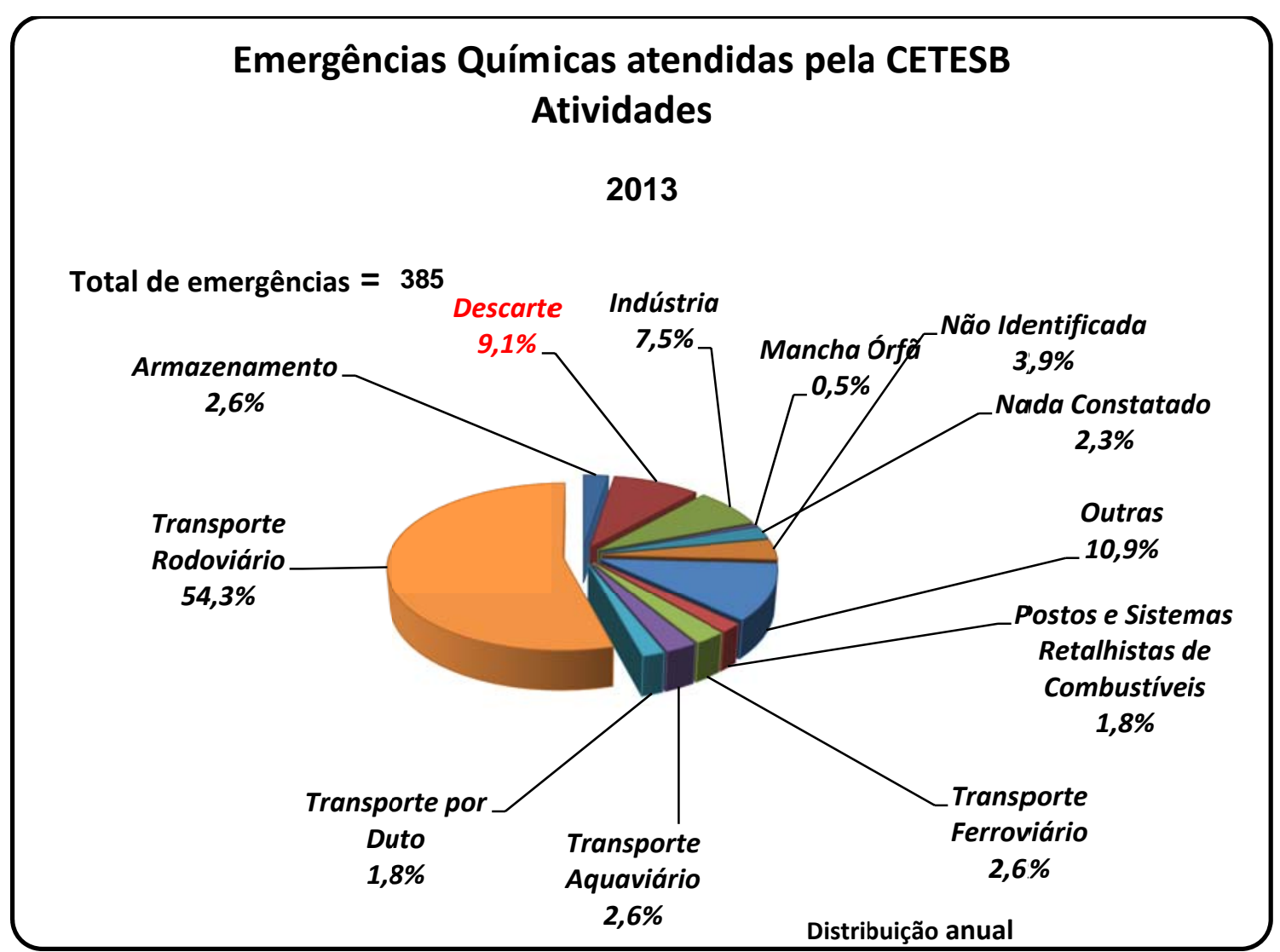

FIGURA 4 - Emergências químicas atendidas pela CETESB por atividade em 2013.

Fonte: (CETESB - COMPANHIA AMBIENTAL DO ESTADO DE SÃO PAULO, 2013a, adaptado do SIEQ)

Vale destacar que os atendimentos emergenciais a essas ocorrências duram em média três dias, em razão da necessidade de mobilização de recursos humanos e materiais para a etapa final dos trabalhos, o que muitas vezes envolve a identificação imediata de local temporário para armazenamento dos resíduos e em determinadas situações a coleta de amostras para sua caracterização. Essa é uma das grandes dificuldades para o atendimento a esse tipo de acidente, pois a maioria dos municípios não dispõe de local 
adequado previamente identificado nem tampouco de recursos humanos e materiais para realização desse trabalho.

Este trabalho possibilitou realizar, por intermédio da CETESB - Companhia Ambiental do Estado de São Paulo, uma consulta preliminar aos órgãos ambientais nacionais quanto aos registros de emergências químicas. Dos 08 (oito) órgãos ambientais estaduais consultados Rio de Janeiro, Minas Gerais, Bahia, Rio Grande do Sul, Paraná, Espírito Santo, Pernambuco e Santa Catarina, apenas Rio de Janeiro e Minas Gerais responderam que possuíam registros de emergências envolvendo o descarte clandestino de resíduos químicos. O Estado de Santa Catarina respondeu que não havia registro de ocorrências de descarte de resíduos atendidos pela Fundação do Meio Ambiente (FATMA) os demais não responderam a consulta.

No Estado do Rio de Janeiro, o Instituto Estadual do Ambiente (INEA) possui registro dos atendimentos emergenciais a partir de 1983. Entre os diversos tipos de atendimentos emergenciais, aqueles referentes ao descarte clandestino de resíduos químicos representa $1,6 \%$ do total de casos atendidos. Os atendimentos são realizados pelo Serviço de Operações de Emergência do INEA (SOPEA) (INSTITUTO ESTADUAL DO AMBIENTE, adaptado do SERVIÇO DE OPERAÇÕES DE EMERGÊNCIA, Rio de Janeiro, 2013a)

Em termos percentuais o descarte clandestino de resíduos representa a sétima atividade que mais demanda atendimentos emergenciais, como demonstrado na FIG.5. 


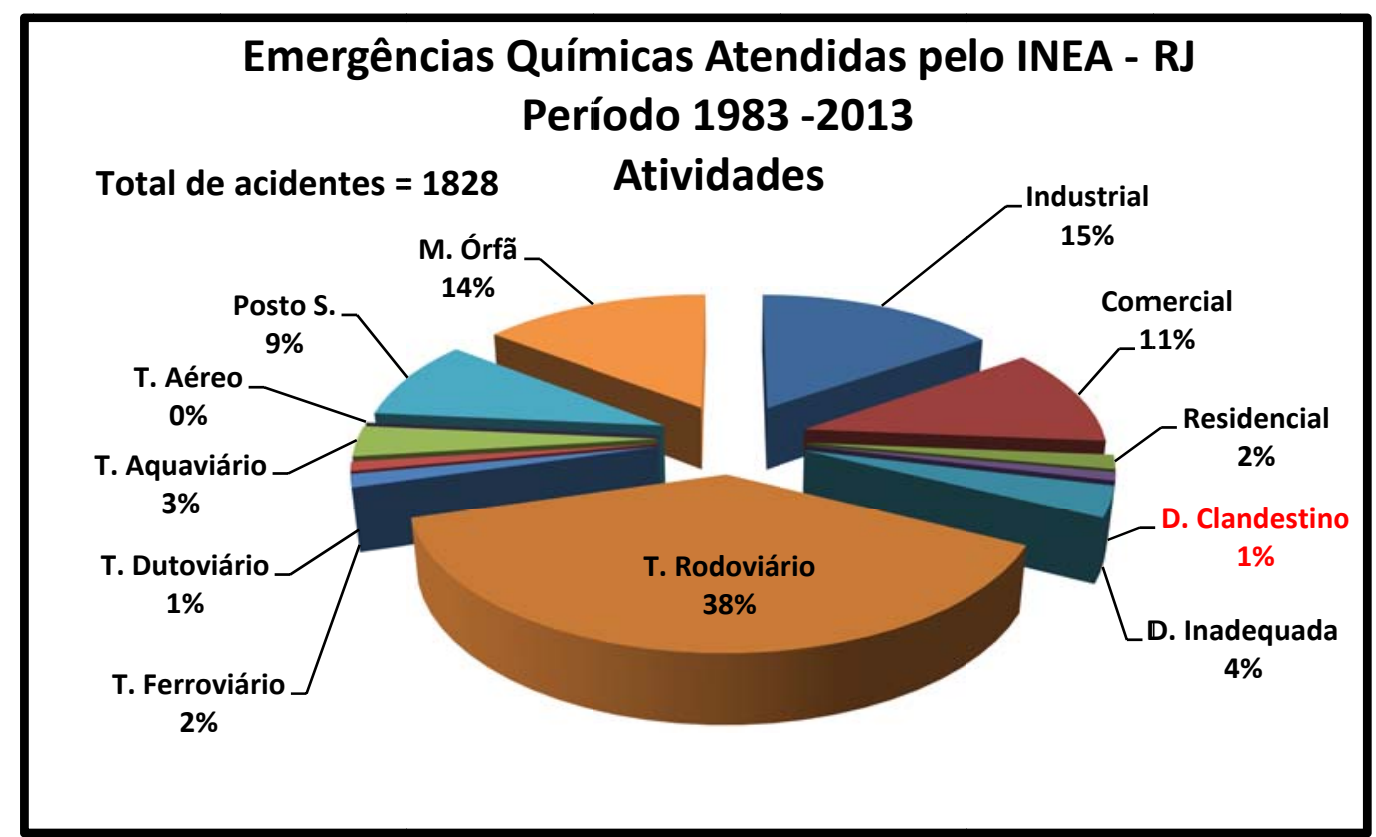

FIGURA 5-Distribuição das emergências químicas atendidas pelo INEA - RJ por atividades no período de 1983 a 2013.

Fonte: (INSTITUTO ESTADUAL DO AMBIENTE, adaptado do SERVIÇO DE OPERAÇÕES DE EMERGÊNCIA, Rio de Janeiro, 2013a)

Na FIG. 5 poder ser observado uma distinção nas atividades referentes aos resíduos químicos como a "Disposição Inadequada (4\%)" e o "Descarte Clandestino (1\%)". Em consulta ao INEA foi esclarecido que os descartes clandestinos de resíduos químicos são aqueles lançados intencionalmente em áreas externas, enquanto que a "Disposição Inadequada" é devido à falta de critérios técnicos e de proteção ambiental na disposição final dos resíduos.

No Estado de Minas Gerais, a Secretaria de Estado de Meio Ambiente e Desenvolvimento Sustentável (SEMAD), por meio da Diretoria de Prevenção e Emergência Ambiental (DEAMB) é responsável pelos atendimentos a emergências ambientais. Por solicitação dessa pesquisa, a DEAMB enviou informações e dados sobre os atendimentos naquele estado envolvendo descarte de resíduos químicos no período de 2008 a dezembro de 2013, conforme apresentado na TAB.1. 
TABELA1 - Ocorrências atendidas pela Diretoria de Prevenção e Emergência Ambiental (DEAMB) no período de 2008 a 2013.

\begin{tabular}{l|l}
\hline Ano & \multicolumn{1}{|c}{ Ocorrências } \\
\hline 2008 & Não consta este tipo de acidente. \\
\hline 2009 & $\begin{array}{l}7-9-2010-\text { Santa Rita do Sapucaí - Abandono de galões de produto químico } \\
\text { identificado como OXI-DR-127 - produto decapante, classe de risco 8. }\end{array}$ \\
\hline 2010 & Não consta este tipo de acidente. \\
\hline
\end{tabular}

9-1-2011 - Carbeto de silício, encontrado em caminhão carregado com este produto próximo à danceteria em Contagem.

23-9-2011Abandono de resíduos em margem da Rodovia. MG 252, km 27. Município de Perdigão. Material de cor marrom que após reação apresenta coloração vermelha.

17-3-2012 - Disposição inadequada de 4bombonas de produto químico não identificado no loteamento - Residencial Laville no município de Carmo do Cajuru/MG. O produto foi encaminhado para destinação final na empresa Pro-

2012 Ambiental em Lavras/MG.

15-6-2012 - Transeuntes encontraram um galão de 50 litros de capacidade abandonado em terreno baldio no loteamento Belvedere no município de Areado/MG. abandonados em lote no condomínio Lagoa do Miguelão em Nova Lima/MG.

01-10-2013 - Abandono de 17 tambores contendo produto ainda não identificado em terreno que foi comercializado para instalação de unidade da AMBEV em Uberlândia/MG.

Fonte: (SECRETARIA DE ESTADO DE MEIO AMBIENTE E DESENVOLVIMENTO SUSTENTÁVEL, 2013) (adaptado de DIRETORIA DE PREVENÇÃO E EMERGÊNCIA AMBIENTAL, 2013)

De acordo os dados do DEAMB, constantes da TAB.1, foram 07 (sete) ocorrências envolvendo o descarte de resíduos químicos para o período de 2008 a 2013. Observa-se também que não foram atendidas emergências pelo DEAMB nos anos de 2008 e 2010.

Em 23 de setembro de 2011 técnicos do DEAMB realizaram atendimento emergencial envolvendo resíduo de coloração vermelha não identificado na 
Rodovia MG 252, município de Perdigão. De acordo com informações obtidas no local uma pessoa que entrou em contato com o material ali depositado apresentou queimaduras. Por falta de equipamentos adequados não foi possível coletar o material naquele dia.

O material descartado reagiu rapidamente ao entrar em contato com uma pá utilizada para sua coleta. Verificado que o mesmo reagiu com um bambu gerando grande quantidade de calor e posteriormente fogo. As equipes de atendimento emergencial estimaram entre 1 e 2 toneladas de resíduos descartados.

Na FIG. 6 tem-se uma representação fotográfica que demonstra o momento que o resíduo apresentava sua característica principal, a combustão espontânea.

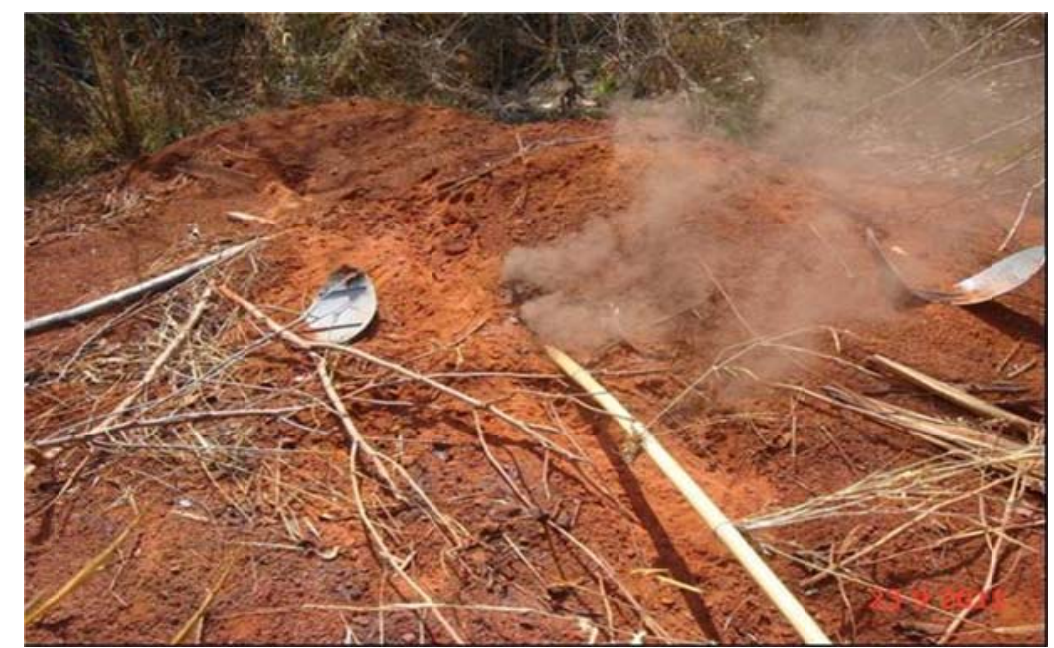

FIGURA 6 - Registro fotográfico da combustão espontânea resultante de resíduo químico disposto diretamente sobre o solo. Fonte:(SECRETARIA DE ESTADO DE MEIO AMBIENTE E DESENVOLVIMENTO SUSTENTÁVEL, 2013)

Em 28 de setembro de 2011, foi realizada nova vistoria para coleta do material e verificado tratar-se de material de cor marrom, que após reação, apresenta coloração vermelha. Foi coletada uma pequena amostra do material e acondicionada em vidro. O resíduo continuou reagindo com o ar dentro do vidro processando uma violenta reação exotérmica que esquentou o frasco violentamente e quase atravessou o isopor na qual foi acondicionado. Em 27 de outubro de 2011, cerca de um mês após a notificação do acidente foi 
realizada as atividades de coleta do resíduo e acondicionamento do mesmo em veículo do tipo caçamba cedido pelo Departamento de Estradas de Rodagem (DER) com auxílio de pá-carregadeira cedida pela Prefeitura de Perdigão como ilustrado nas FIG.7 e 8.

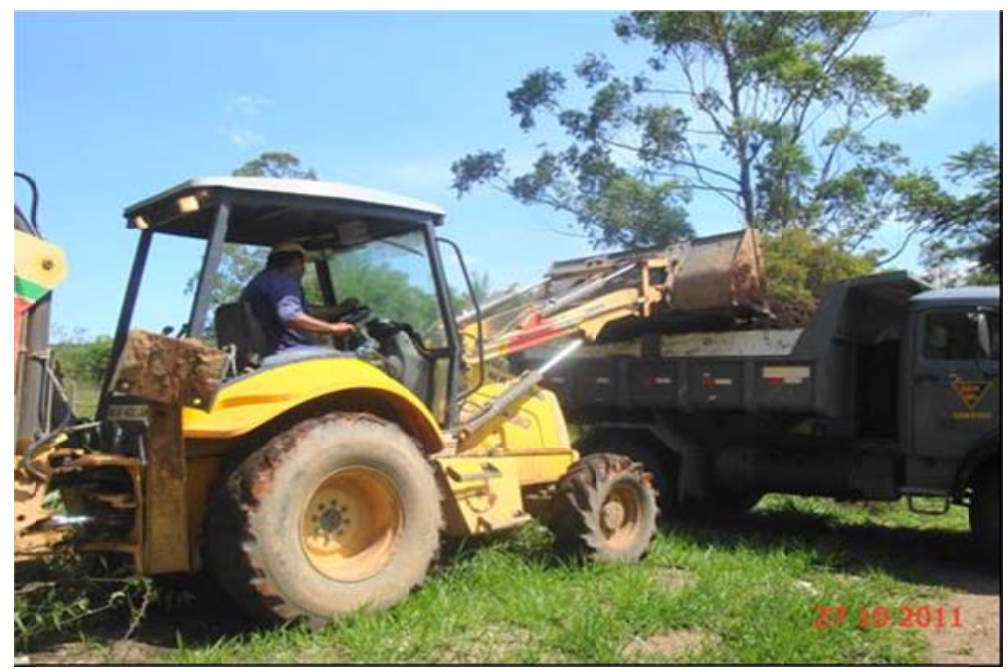

FIGURA 7 - Registro fotográfico da utilização de pá-carregadeira para retirada dos resíduos.

Fonte: (SECRETARIA DE ESTADO DE MEIO AMBIENTE E DESENVOLVIMENTO SUSTENTÁVEL, 2013)

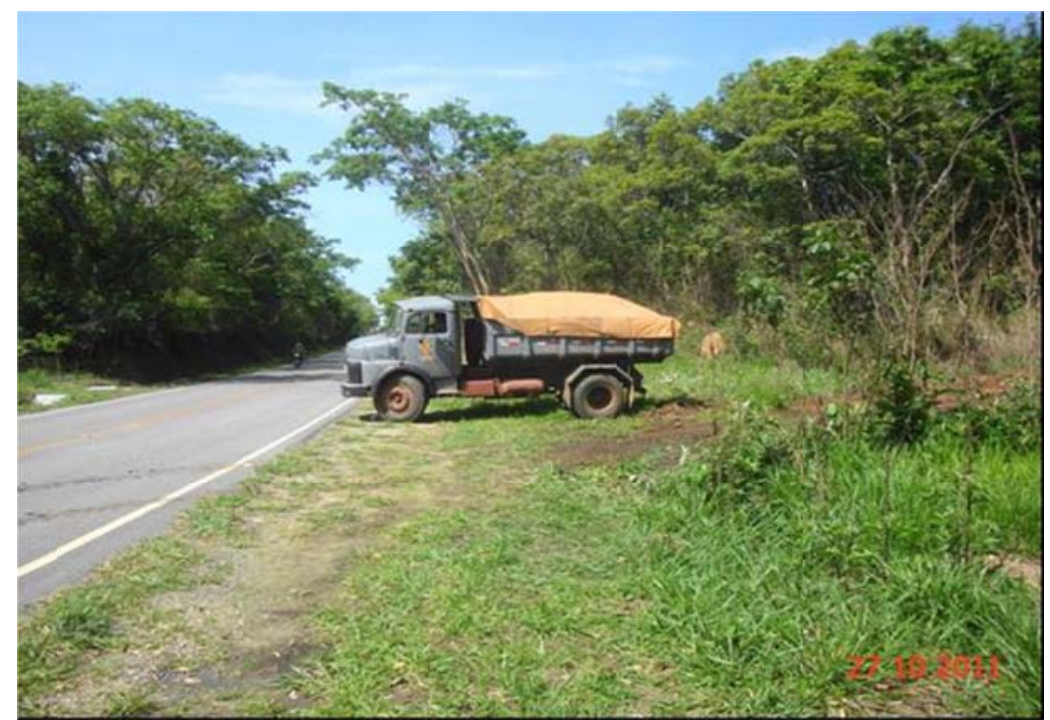

FIGURA 8 - Registro fotográfico da saída de caminhão caçamba do local do acidente, devidamente lonado com os resíduos químicos para a destinação final adequada.

Fonte:(SECRETARIA DE ESTADO DE MEIO AMBIENTE E DESENVOLVIMENTO SUSTENTÁVEL, 2013) 
Após acondicionamento do resíduo no veículo o mesmo foi coberto por lona e todo o transporte até as instalações da empresa pro-ambiental localizada no Município de Lavras, foi acompanhado pelo analista do DEAMB/SEMAD.

A FIG. 9 ilustra a chegada do caminhão transportando os resíduos químicos na empresa pro-ambiental.

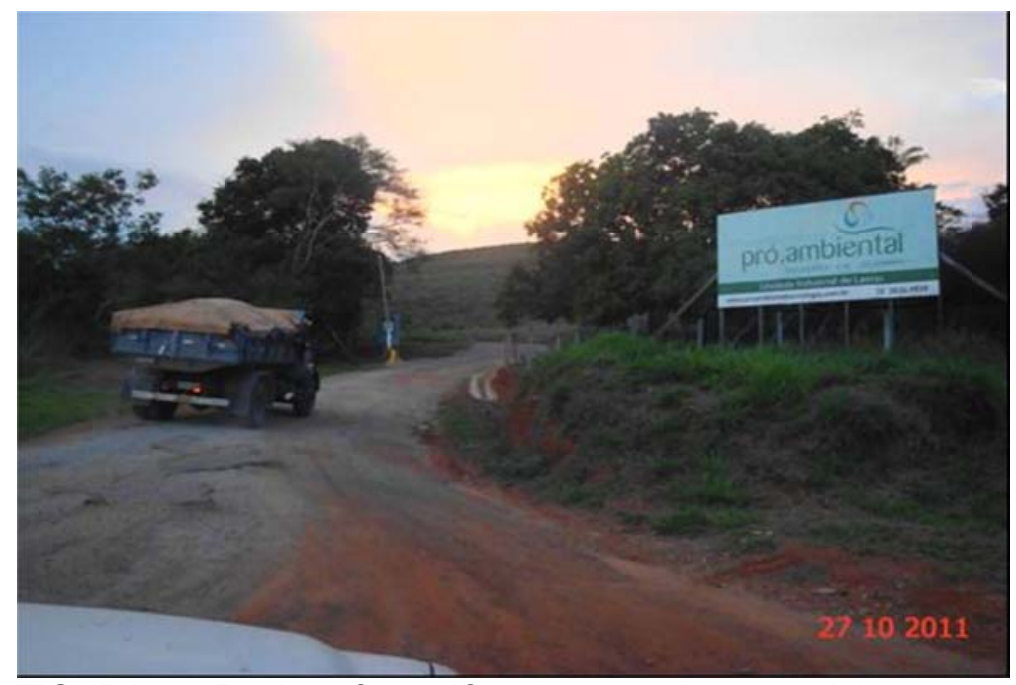

FIGURA 9 - Registro fotográfico da chegada do caminhão transportando os resíduos químicos na empresa pro-ambiental. Fonte:(SECRETARIA DE ESTADO DE MEIO AMBIENTE E DESENVOLVIMENTO SUSTENTÁVEL, 2013)

Esse atendimento aqui relatado demonstra as dificuldades enfrentadas pelos órgãos ambientais diante de situações de descarte de resíduos. Normalmente o tempo para mobilização de recursos humanos e materiais nem sempre é compatível com a gravidade da situação. Nesse caso foi necessário apoio do DER e da Prefeitura de Perdigão muitas vezes com recursos não apropriados como tipo de veículo, falta de capacitação específica do condutor para este tipo de material e ausência do uso de Equipamentos de Proteção Individual (EPIs) durante as atividades de aproximação com o resíduo químico.

\subsection{Avaliação ambiental nas emergências envolvendo descarte de resíduos químicos}

Os resíduos químicos perigosos descartados tanto no estado líquido como sólido, apresentam como principais perigos, a corrosividade, a inflamabilidade, a emanação de Compostos Orgânicos Voláteis (COVs) e a reatividade com 
água, podendo provocar incêndios ou explosões, formação de compostos, misturas, vapores ou gases tóxicos.

As equipes sejam elas de órgãos públicos ou privados designados para avaliar os riscos químicos e físicos de resíduos dispostos inadequadamente em vias públicas, margens de rodovias, terrenos baldios ou em margens de corpos d'água, devem estar devidamente preparadas, tanto no que se refere aos EPIs exigidos para o enfrentamento da situação, quanto ao uso de equipamentos portáteis de detecção necessários para efetuar medições com o intuito de caracterizar os principais riscos à saúde humana e ao meio ambiente.

Apesar da aparência segura das embalagens dos produtos químicos, é preciso ter sempre em conta alta periculosidade de muitos dos materiais ali contidos e as condições adversas de transporte a que foram submetidos, como altas temperaturas, choques e vibrações que podem potencializar acidentes, já que as substâncias químicas sempre possuem características como corrosividade, reatividade, inflamabilidade e toxicidade (HIRATA et al.2012).

No entendimento da agência de proteção ambiental americana, resíduos perigosos exibem pelo menos uma das características descritas abaixo (ENVIRONMENTAL PROTECTION AGENCY, 2013b):

- $\quad$ inflamabilidade: Resíduos inflamáveis podem gerar incêndios sob certas condições, são espontaneamente inflamáveis ou tem um ponto de inflamação inferior a $60^{\circ} \mathrm{C}$. Exemplos incluem óleos usados e solventes.

- $\quad$ corrosividade: Resíduos corrosivos são ácidos ou alcalinos (pH menor ou igual a 2, ou maior ou igual a 12,5) que são capazes de corroer o aço, recipientes de metal, tais como tanques de armazenamento, tambores e barris.

- $\quad$ reatividade: Resíduos reativos são instáveis sob condições normais. Podem causar explosões, gases tóxicos, gases ou vapores, quando aquecido, comprimido ou misturado com água. 
- toxicidade: resíduos tóxicos são prejudiciais ou fatais quando ingerido, inalado ou absorvido pela pele.

A avaliação ambiental realizada durante a fase emergencial visa identificar os principais perigos que os resíduos químicos possam oferecer, uma vez que na maioria dos casos trata-se de uma mistura de substâncias e não um produto puro. Os parâmetros e procedimentos apresentados a seguir são indispensáveis nessa etapa para se alcançar a estabilização da situação ainda na fase emergencial.

- Inflamabilidade

A medição da concentração de gases e vapores inflamáveis é realizada com equipamento denominado oxi-explosímetro. Tal equipamento deve ser intrinsecamente seguro e devidamente calibrado. Normalmente as substâncias utilizadas na calibração são metano ou hexano. Entretanto, não há como efetuar a correlação do Limite Inferior de Inflamabilidade - L.I.I ${ }^{1}$ com os valores específicos para cada substância, pois os resíduos descartados quase sempre são misturas de substâncias. Nesses casos o valor de referência como sendo limitante para a tomada de ações é o de $20 \%$ do L.I.I. (VASCONCELLOS et al. 2014).

- $\quad$ compostos orgânicos voláteis - COVs

A concentração de compostos orgânicos voláteis pode ser detectada com a utilização de equipamentos portáteis que utilizam principalmente técnicas como detector de fotoionização (PID) e de detector de ionização de chama (FID).

LII ${ }^{1}$ Limite Inferior de inflamabilidade - mínima concentração de gás que, misturada ao ar atmosférico, é capaz de provocar a combustão do produto a partir do contato com uma fonte de ignição. 
Essas técnicas oferecem uma avaliação total da concentração de gases e vapores na atmosfera sem especificar a substância, porém resultados elevados de COVs implicam em medidas de proteção dos técnicos envolvidos, uma vez que ali podem estar presentes produtos de elevada toxicidade (VASCONCELLOS et al. 2014).

- corrosividade

$\mathrm{O}$ pH (Potencial Hidrogeniônico) é uma informação fundamental para se avaliar se os resíduos são alcalinos ou ácidos. Normalmente pHs $\leq 2,0$ ou $\geq 12,0$ implicam em condições extremamente corrosivas e que podem oferecer riscos à saúde da população e ao meio ambiente, como por exemplo alterar a qualidade de corpos hídricos (VASCONCELLOS et al. 2014).

- $\quad$ reatividade com água

Portando os EPIs apropriados como roupa de proteção, luvas e máscara facial contra gases ácidos e vapores orgânicos, pode-se aplicar algumas gotas do produto sob investigação em um recipiente com água, para observar se ocorre reação.

Se constatado que o material possui tal reatividade, devem-se priorizar medidas visando eliminar o contato do resíduo com água. Como em situações emergenciais decorrente de descarte de resíduos as ações de respostas demandam tempo deve-se como medida preventiva promover a cobertura das embalagens contendo os resíduos.

Essa situação se agrava quando alguns resíduos são queimados, o que torna mais difícil a extinção do fogo por parte do Corpo de Bombeiros. Nesses casos há que se investigar o destino das águas utilizadas no combate ao incêndio (VASCONCELLOS et al. 2014).

As determinações aqui mencionadas não serão suficientes para identificar o material descartado, dadas às limitações dos equipamentos portáteis de detecção, porém apontarão quais os principais riscos químicos associados ao(s) resíduo(s) (VASCONCELLOS et al. 2014). 


\subsection{Relação da ocorrência de descartes de resíduos e as áreas contaminadas nos estados de São Paulo, Rio de Janeiro e Minas Gerais}

A Resolução do CONAMA n 420 de 28 de dezembro de 2009, estabelece critérios e valores orientadores de qualidade do solo quanto à presença de substâncias químicas e estabelece diretrizes para o gerenciamento ambiental de áreas contaminadas (CONSELHO NACIONAL DO MEIO AMBIENTE, 2009).

A citada Resolução estabelece que os órgãos ambientais competentes, observando o sigilo necessário, dêem publicidade, principalmente em seus portais institucionais sobre áreas contaminadas identificadas e suas principais características na forma de relatório (CONSELHO NACIONAL DO MEIO AMBIENTE, 2009).

De acordo com essa Resolução CONAMA n 420, cabe ao Instituto Brasileiro do Meio Ambiente e Recursos Naturais Renováveis (IBAMA) implementar em seu sistema de informação institucional ações de divulgação, tornando pública as informações enviadas pelos órgãos estaduais de meio ambiente, na forma organizada e sistematizada (CONSELHO NACIONAL DO MEIO AMBIENTE, 2009).

É muito provável que o número de áreas contaminadas nos três estados com maior índice de desenvolvimento da federação (São Paulo, Rio de Janeiro e Minas Gerais), seja superior àqueles que são anualmente divulgados pelos respectivos órgãos ambientais. A contabilização dessas áreas aumentou com o aperfeiçoamento do processo de gestão e licenciamento ambiental. Esse fato foi observado na CETESB - Companhia Ambiental do Estado de São Paulo, no estado de São Paulo, que a partir de 2002, passou a divulgar a lista das áreas contaminadas. O mesmo ocorreu nos estados do Rio de Janeiro que iniciou esse processo a partir do ano de 2013 e Minas Gerais, em 2007.

\subsubsection{Descartes de resíduos químicos e as áreas contaminadas no estado de São Paulo}

O Estado de São Paulo possui 645 municípios e uma população de aproximadamente 42 milhões de habitantes. Cerca de 20 milhões concentramse na RMSP, formada por 39 municípios, tendo apenas a capital 11 milhões de 
habitantes. Outras quatro Regiões Metropolitanas estão formalmente organizadas: a de Campinas, a da Baixada Santista, a do Vale do Paraíba e Litoral Norte e a de Sorocaba (FUNDAÇÃO SISTEMA ESTADUAL DE ANÁLISES DE DADOS, 2015).

O Estado de São Paulo detém o maior parque industrial químico da América Latina, exigindo uma reflexão maior sobre a atual contextualização do segmento, em razão do impacto ambiental, produzindo alteração no meio ambiente ou em algum de seus componentes por determinada ação ou atividade humana (SÃO PAULO (Estado), 2013a).

No caso específico do Estado de São Paulo há inúmeras evidências de que a urbanização e o crescimento econômico sem planejamento conduziram a uma complexa situação ambiental ultrapassando as capacidades de equilíbrio dos ecossistemas e da saúde da população.

Dentre esses impactos é inequívoco o reconhecimento nas últimas duas décadas dos agravos ao meio ambiente e a saúde da população fruto do surgimento de áreas contaminadas no Brasil, sobretudo no Estado de São Paulo.

De acordo com a CETESB, uma área contaminada pode ser definida como "área, local ou terreno onde há comprovadamente poluição ou contaminação causada pela introdução de quaisquer substâncias ou resíduos que nela tenham sido depositados, acumulados, armazenados, enterrados ou infiltrados de forma planejada, acidental ou até mesmo natural" (CETESB - COMPANHIA AMBIENTAL DO ESTADO DE SÃO PAULO, 2011a).

Dados da CETESB - Companhia Ambiental do Estado de São Paulo referentes à evolução da contabilização das áreas contaminadas e de sua distribuição por Região no Estado de São Paulo no final do ano de 2013 são apresentados nas FIG.10 e 11, respectivamente. 


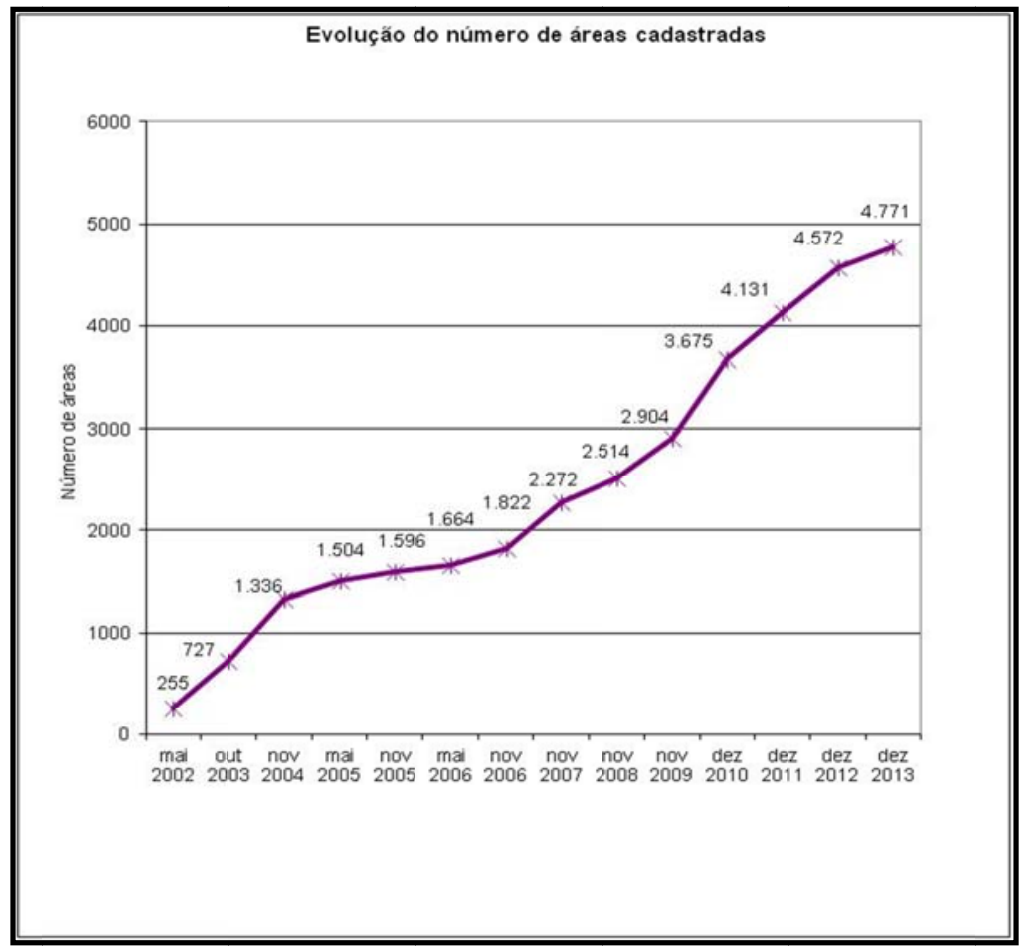

FIGURA 10 - Evolução das áreas contaminadas no Estado de São Paulo.

Fonte:(CETESB - COMPANHIA AMBIENTAL DO ESTADO DE SÃO PAULO,2013b)

A divulgação da lista de áreas contaminadas pela CETESB - Companhia Ambiental do Estado de São Paulo é realizada desde maio de 2002. Seus registros vêm aumentando sistematicamente devido a ações e esforços em fiscalização e licenciamento ambiental.

O gráfico da FIG. 11 evidencia que a RMSP e o município de São Paulo concentram a maioria dos casos de áreas contaminadas (52\%) onde também se observa o maior número de casos de descarte de resíduos químicos (97\%) quando comparado com os dados do SIEQ (FIG. 12). 


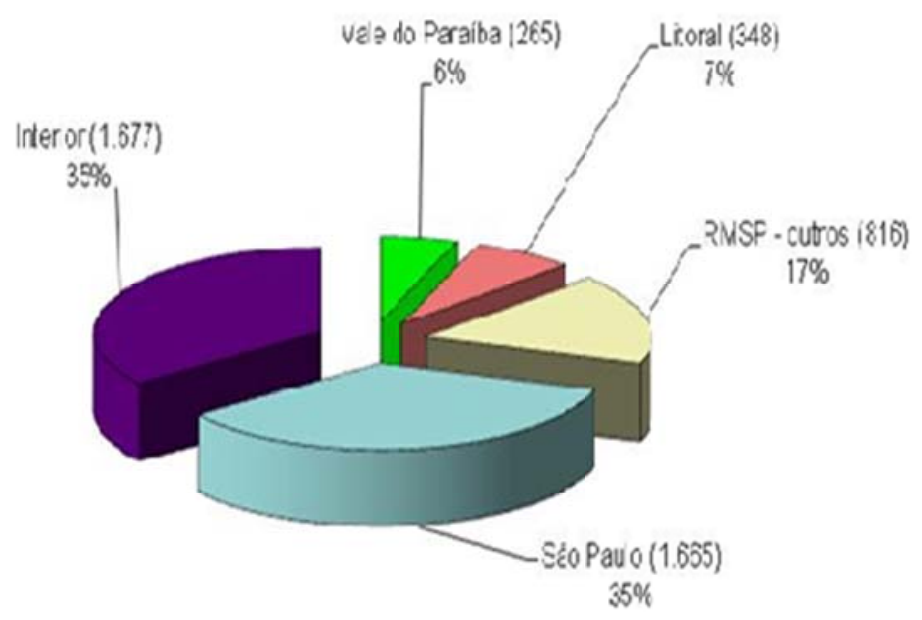

FIGURA 11 - Distribuição por Região das áreas contaminadas no Estado de São Paulo, segundo a CETESB.

Fonte: (CETESB - COMPANHIA AMBIENTAL DO ESTADO DE SIÃO PAULO, 2013b)

\section{Emergências Químicas atendidas pela CETESB} Região

\section{Descarte}

Período 2002 - 2013

Total de emergências $=316$

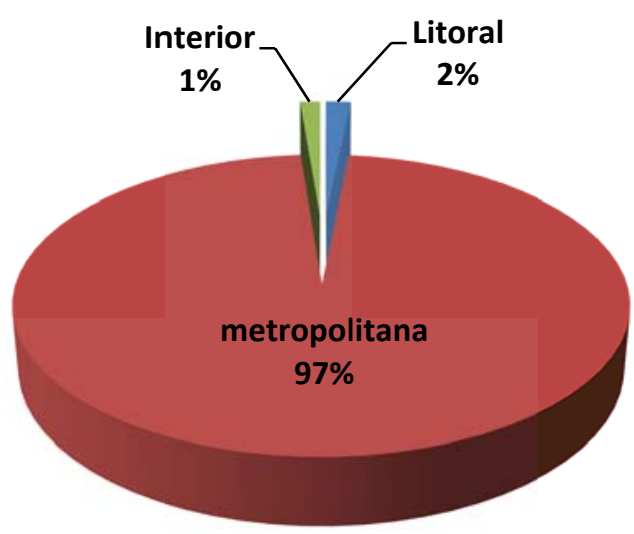

FIGURA 12 - Registro do descarte de resíduos químicos por Região, atendidos pela CETESB no período de 1984 a 2013. Fonte: (CETESB - COMPANHIA AMBIENTAL DO ESTADO DE SÃO PAULO,2013a, adaptado do SIEQ) 
Os casos de descartes de resíduos químicos e de áreas contaminadas impactam negativamente os recursos hídricos e a qualidade do solo como resultado direto do padrão de crescimento adotado sem a observância dos parâmetros de proteção ambiental. Em muitas situações os casos de descartes de resíduos químicos afetam zonas frágeis do ponto de vista ambiental como aquelas destinadas à proteção de mananciais e a preservação de vegetação natural.

As atividades que mais contribuem para os casos de áreas contaminadas podem ser visualizadas na FIG. 13.

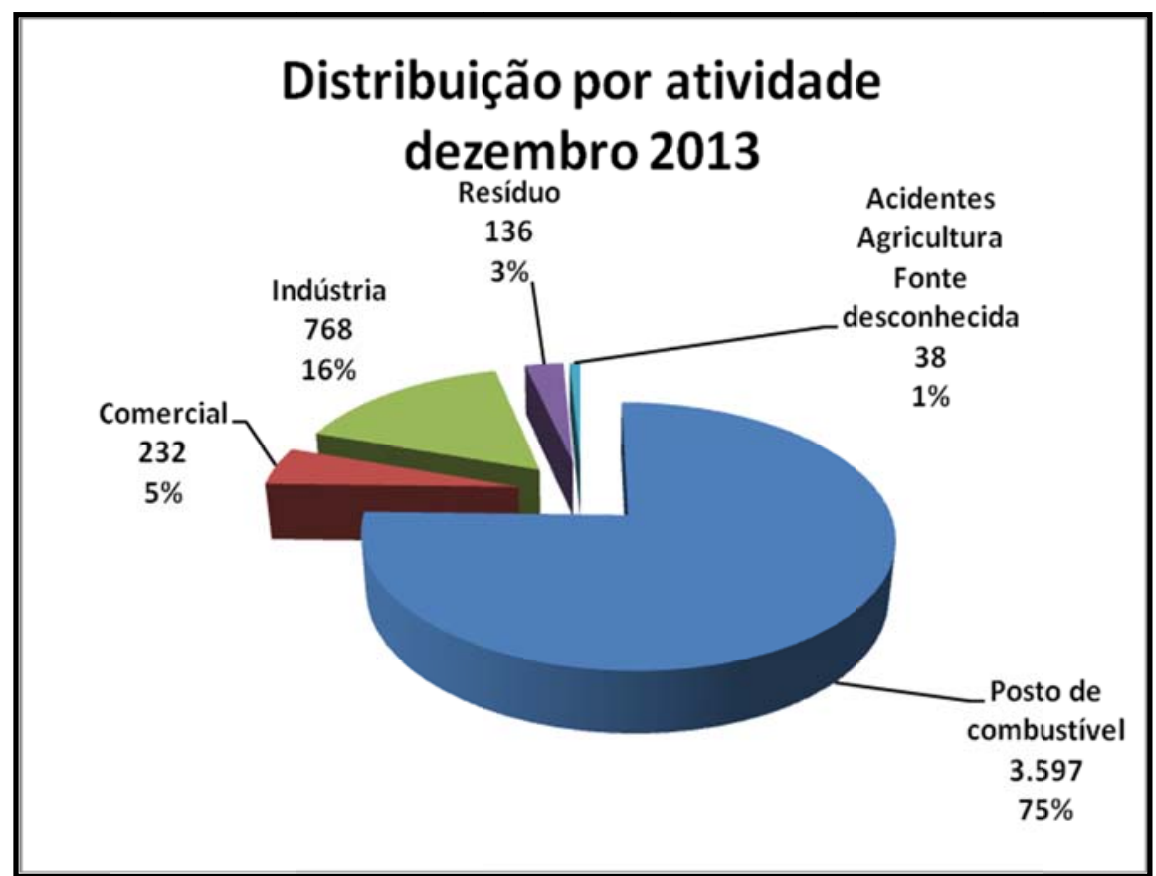

FIGURA 13 - Distribuição das atividades que resultam em áreas contaminadas no Estado de São Paulo.

Fonte: (CETESB - COMPANHIA AMBIENTAL DO ESTADO DE SÃO

PAULO, 2013b)

Em razão do trabalho de fiscalização realizado pela Agência Ambiental Paulista iniciado em 2001 a partir da publicação da Resolução CONAMA n 273 que estabelece diretrizes para o licenciamento ambiental de postos de combustíveis e serviços e dispõe sobre a prevenção e controle da poluição, foi possível identificar 3.597 áreas contaminadas (75\%) em razão dos postos e sistemas retalhistas de combustíveis. 
Quando observamos os $3 \%$ das atividades que geraram áreas contaminadas por resíduos, 136 casos, fica sem dúvida uma pergunta, esse percentual reflete de fato a realidade para o Estado de São Paulo? Isso porque a CETESB Companhia Ambiental do Estado de São Paulo atendeu de 1984 a 2013452 descartes de resíduos químicos.

É bem verdade que desse total, muitos não se enquadram nessa classificação de áreas contaminadas, mas certamente aqueles casos onde os resíduos ficaram dispostos diretamente sobre o solo e depois recolhidos não houve investigação de acordo com os procedimentos para gerenciamento de áreas contaminadas estabelecidos pela CETESB - Companhia Ambiental do Estado de São Paulo.

Apesar da melhoria das condições ambientais dos locais de disposição de resíduos sólidos nos últimos anos no estado de São Paulo, segundo o Inventário Estadual de Resíduos Sólidos Urbanos referente ao ano de 2013, (CETESB - COMPANHIA AMBIENTAL DO ESTADO DE SÃO PAULO, 2013d) ainda são dispostos de forma irregular cerca de 9.993 t/dia de resíduos sólidos urbanos de acordo com o Panorama de Resíduos Sólidos no Brasil publicado em 2014 pela Associação Brasileira de Empresas de Limpeza Pública e Resíduos Especiais (ASSOCIAÇÃO BRASILEIRA DAS EMPRESAS DE LIMPEZA PÚBLICA E RESÍDUOS ESPECIAIS, 2014).

Diante dessas informações pressupõe talvez um sub-registro do percentual das áreas contaminadas por resíduos como apresentado na FIG. 13. O que falta talvez para a questão dos resíduos seja o trabalho sistemático desenvolvido pela CETESB - Companhia Ambiental do Estado de São Paulo para identificação de possíveis áreas contaminadas por resíduos assim como ocorreu com os postos de combustíveis. 


\subsubsection{Descartes de resíduos químicos e as áreas contaminadas no estado do Rio de Janeiro}

O Estado do Rio de Janeiro possui 92 municípios e população de aproximadamente 16 milhões de habitantes (INSTITUTO BR'ASILEIRO DE GEOGRAFIA E ESTATÍSTICA, 2010b).

De acordo com o Instituto Estadual do Ambiente (INEA), durante o último século o desenvolvimento da industrialização ocorreu em diversas áreas do Estado do Rio de Janeiro sem os devidos cuidados ambientais. As atividades potencialmente poluidoras não possuíam uma política ambiental adequada e o uso e a ocupação do solo urbano e rural ocorria sem planejamento e controle. Isto ocasionou a contaminação de solo e água subterrânea em diversas áreas, limitando os possíveis usos do solo e induzindo restrições ao desenvolvimento urbano (INSTITUTO ESTADUAL DO AMBIENTE, 2014).

Ainda segundo o INEA foram contabilizadas 270 áreas contaminadas do seu cadastro de áreas contaminadas em sua $2^{\circ}$ edição do relatório. Destacam-se entre as atividades geradoras de áreas contaminadas no Estado, os postos de combustíveis, indústria, aterro de resíduos e viação, segundo dados da FIG.14.

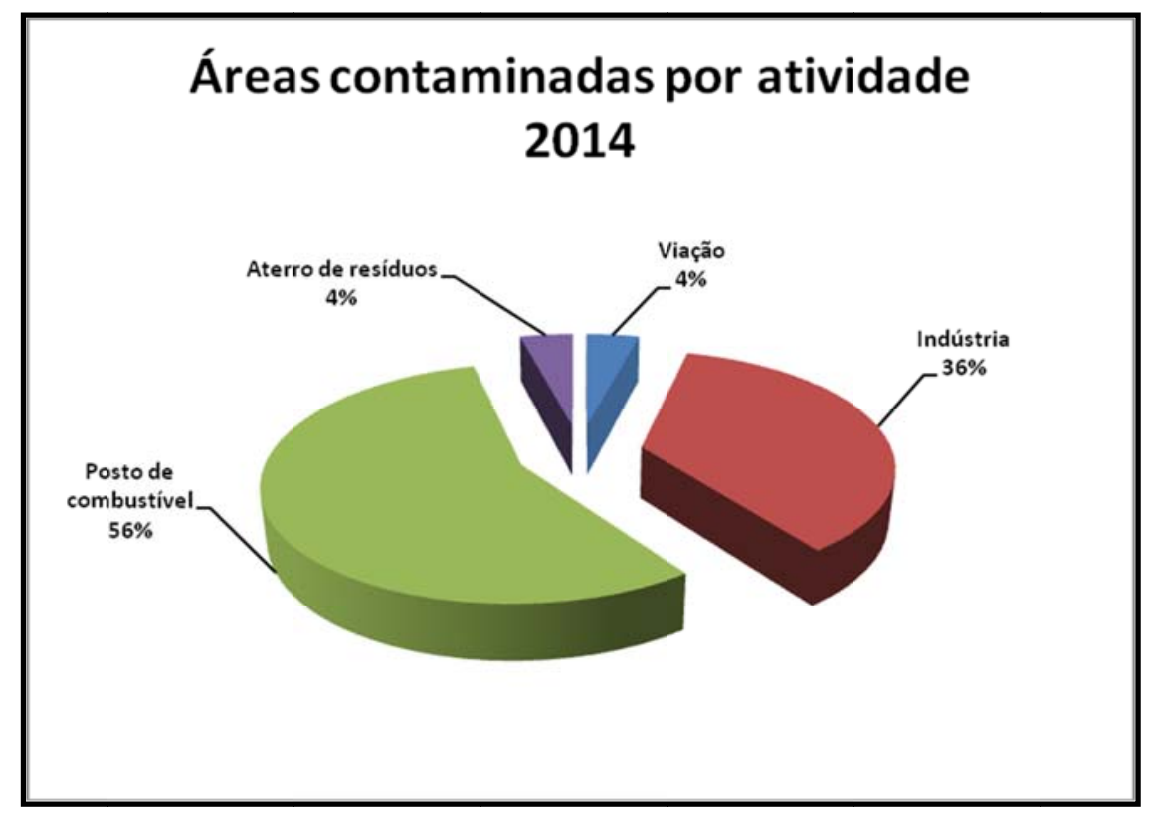

FIGURA 14 - Distribuição por atividade das áreas contaminadas no Estado do Rio de Janeiro.

Fonte: (INSTITUTO ESTADUAL DO AMBIENTE, 2014) 


\subsubsection{Descartes de resíduos químicos e as áreas contaminadas no estado de Minas Gerais}

A Fundação Estadual do Meio Ambiente (FEAM) publicou em dezembro de 2014, o Inventário de Áreas Contaminadas do Estado de Minas Gerais. O estudo reúne análises das informações da lista de áreas contaminadas e reabilitadas no Estado. Atualmente, existem 577 áreas registradas como Contaminadas do Estado de Minas Gerais. Em 2013, o número foi de 554 (FUNDAÇÃO ESTADUAL DO MEIO AMBIENTE, 2015).

Nas áreas gerenciadas pela FEAM o inventário de 2014 aponta que a principal atividade desenvolvida são os postos de combustíveis com 249 áreas identificadas. As atividades também identificadas como mais representativas são a indústria metalúrgica (49) e as ferrovias (40) (FUNDAÇÃO ESTADUAL DO MEIO AMBIENTE, 2015).

A distribuição de áreas contaminadas considerando as atividades causadoras, apresenta em Minas Gerais o maior número relacionado ao comércio varejista de combustíveis, revendedores de gasolina, álcool e diesel como apresentado na TAB. 2 (FUNDAÇÃO ESTADUAL DO MEIO AMBIENTE, 2015). 
TABELA 2 - Número de áreas contaminadas por atividades causadoras áreas acompanhadas pela FEAM - Ano 2014.

\begin{tabular}{l|c}
\hline \multicolumn{1}{c|}{ Atividade } & $\begin{array}{c}\text { Número de } \\
\text { Áreas Contaminadas }\end{array}$ \\
\hline Posto de combustível & 249 \\
\hline Indústria Metalúrgica & 49 \\
\hline Indústria Química & 12 \\
\hline Ferrovia & 40 \\
\hline Atividades Minerárias & 10 \\
\hline $\begin{array}{l}\text { Base de armazenamento e distribuição de derivados de petróleo e } \\
\text { álcool combustível }\end{array}$ & 10 \\
\hline Depósito de resíduos sólidos urbanos & 3 \\
\hline Rerrefino de óleo lubrificante usado & 2 \\
\hline Aeroporto & 1 \\
\hline Dutos para transporte de produtos químicos e oleodutos & 1 \\
\hline Reciclagem de pilhas, baterias e acumuladores & 1 \\
\hline Fonte: FEAM, 2015 &
\end{tabular}

Representa também importante impacto o número de áreas contaminadas relacionados à atividade de indústria metalúrgica e transporte terrestre e ferroviário (FUNDAÇÃO ESTADUAL DO MEIO AMBIENTE, 2015).

\subsection{Legislação aplicada}

De forma cronológica apresenta-se aqui nesse item da "revisão da literatura", uma abordagem dos principais instrumentos jurídicos, que visam à proteção do meio ambiente de forma genérica com o propósito específico para interrelacionar as questões de degradação/contaminação decorrentes de ações antrópicas motivada pelos descartes de resíduos químicos com reflexo nos aspectos socioambientais. 
Há de se destacar que a legislação ambiental brasileira é vasta sob o aspecto técnico jurídico, tem uma função não apenas de coibir práticas antiecológicas, mas também cumpre uma função de cunho pedagógico.

\subsubsection{Legislação Federal}

No Brasil, inicia-se ainda que de forma tímida a preocupação da proteção ambiental com o uso do solo por meio da Lei $n^{\circ} 6.803$ de 1980 que dispõe sobre as diretrizes básicas para o zoneamento industrial nas áreas críticas de poluição, e dá outras providências. Esse instrumento jurídico apresenta padrões e normas, consubstanciadas em disposições de observância pelos estados e municípios (BRASIL, 1980).

De acordo com esta Lei em seu Art. $2^{0}$, nas zonas de uso estritamente industrial fica permitida a instalação de empreendimentos industriais que possam por meio de resíduos sólidos, líquidos e gasosos mesmo após aplicação de métodos adequados de controle e tratamento de efluentes, nos termos da legislação vigente possam causar perigo à saúde, ao bem-estar e à segurança das populações (BRASIL, 1980).

O primeiro grande marco em termos de norma de proteção ambiental no Brasil é a Lei $n^{\circ} 6.938 / 81$, que dispõe sobre a Política Nacional do Meio Ambiente. A lei por meio de seus conceitos, princípios e instrumentos dar destaque especial para a vida e proteção do meio ambiente (BRASIL, 1981).

Em seu Art. 3, para fins nesta Lei, entende-se poluição, a degradação da qualidade ambiental resultante de atividades que direta ou indiretamente:
a) prejudiquem a saúde, a segurança e o bem-estar da população;
b) criem condições adversas às atividades sociais e econômicas;
c) afetem desfavoravelmente a biota;
d) afetem as condições estéticas ou sanitárias do meio ambiente; 
ambientais estabelecidos.

e) lancem matérias ou energia em desacordo com os padrões

Todas as alíneas do Art. $3^{0}$ abordam claramente os impactos ambientais negativos que se manifestam a partir de alterações ou de situações indesejáveis resultantes da ação antrópica daqueles que, de forma irresponsável, agridem o meio ambiente, às atividades sociais e econômicas e à saúde da população por meio do descarte ilegal de resíduos químicos perigosos.

Por padrões ambientais mencionado na alínea "e" do Art. 3 entendem-se como um limite - definido por leis, normas ou resoluções para as perturbações ambientais, em particular, da concentração de poluentes e resíduos, que determina a degradação máxima admissível do meio ambiente (INSTITUTO BRASILEIRO DO MEIO AMBIENTE E DOS RECURSOS NATURAIS RENOVÁVEIS, 2011).

Nesse sentido, resíduos químicos, via de regra, apresentam-se no estado sólido, líquido ou pastoso (matérias) e dependendo de suas características intrínsecas podem, por exemplo, reagir violentamente com a água liberando calor (energia). Nesse caso, configura-se a poluição pelo lançamento de matéria ou energia.

No Art. 14, parágrafo $1^{0}$, a Lei no 6.938 estabelece que "sem obstar a aplicação das penalidades previstas nesse artigo, é o poluidor obrigado, independentemente de existência de culpa, a indenizar ou reparar os danos causados ao meio ambiente e a terceiros, afetados por sua atividade" é a responsabilidade objetiva.

O Princípio do Poluidor-Pagador foi incorporado à Lei 6.938 quando se impõe ao poluidor e ao predador a obrigação de recuperar e ou indenizar os danos causados.

O Art. 15. Estabelece que poluidor que expuser a perigo a incolumidade humana, animal ou vegetal, ou estiver tornando mais grave situação de perigo 
existente, fica sujeito à pena de reclusão de 1 (um) a 3 (três) anos e multa de 100 (cem) a 1.000 (mil) MVR.

No parágrafo $(\S) 1^{0}$ deste Artigo inciso III está explicitado que a pena é aumentada até o dobro se o crime é praticado durante a noite, em domingo ou feriado. Destaca-se aqui que o descarte de resíduos químicos é, na maioria das vezes, praticado durante a noite, para obviamente evitar a identificação do veículo que comete o delito, o que configura o dolo.

A Constituição Federal de 1988 estabelece que todos têm direito ao meio ambiente ecologicamente equilibrado, bem de uso comum ao povo, essencial à sadia qualidade de vida, impondo-se ao Poder Público e à coletividade o dever de defendê-lo para as presentes e futuras gerações (Art. 225, caput) (BRASIL, 1988). Segundo BARBIERi (2001) a redação desse artigo foi influenciada pelo relatório, Nosso Futuro Comum, divulgado em 1987, período em que o Congresso Constituinte elaborava a atual constituição.

Como bem salientado no Art. 225, impõem-se ao Poder Público o dever de defender o meio ambiente o que possui indicadores que se refere aos casos de descarte de resíduos químicos, como medidas em caráter emergencial, para sua remoção, transporte e armazenamento temporário afastando o quanto antes da possibilidade de contaminação dos ecossistemas e da exposição da população de contaminantes químicos.

Ainda no Art. 225, $\S 3^{\circ}$ é previsto que "As condutas e atividades consideradas lesivas ao meio ambiente sujeitarão os infratores, pessoas físicas ou jurídicas, a sanções penais e administrativas, independentemente da obrigação de reparar os danos causados".

A Lei $n^{\circ} 9.605$ de 12 de fevereiro de 1998, mais conhecida como a "Lei de Crimes Ambientais", dispõe sobre as sanções penais e administrativas aplicáveis às condutas e atividades lesivas ao meio ambiente (BRASIL, 1998). É uma Lei com força suficiente para combater as transgressões ambientais como as que são cometidas por aqueles que promovem ilegalmente o descarte de resíduos químicos. 
Aquele que descarta resíduos químicos ilegalmente exerce conduta que ignora normas ambientais legalmente estabelecidas.

Está tipificado como crime ambiental no Art. 54 Causar poluição de qualquer natureza em níveis tais que resultem em danos à saúde humana, ou que provoquem a mortandade de animais ou a destruição significativa da flora.

É previsto no $\S 2^{\circ}$ alínea "V" ocorrer por lançamento de resíduos sólidos, líquidos ou gasosos, ou detritos, óleos ou substâncias oleosas em desacordo com as exigências estabelecidas em leis ou regulamentos.

O Art. 56. Produzir, processar, embalar, importar, exportar, comercializar, fornecer, transportar, armazenar, guardar, ter em depósito ou usar produto ou substância tóxica, perigosa ou nociva à saúde humana ou ao meio ambiente, em desacordo com as exigências estabelecidas em leis ou nos seus regulamentos:

Pena - reclusão, de um a quatro anos, e multa.

$\S 1^{\text {ㅇ }}$ Nas mesmas penas incorre quem

I - abandona os produtos ou substâncias referidos no caput ou os utiliza em desacordo com as normas ambientais ou de segurança

II - manipula, acondiciona, armazena, coleta, transporta, reutiliza, recicla ou dá destinação final a resíduos perigosos de forma diversa da estabelecida em lei ou regulamento

É importante aqui salientar que os que praticam o descarte de resíduos químicos prevêem o resultado lesivo de sua conduta e mesmo assim leva adiante produzindo como resultado um "crime doloso".

Nesse sentido, o Art. 58. Estabelece que nos crimes dolosos as penas serão aumentadas:

I - de um sexto a um terço, se resulta dano irreversível à flora ou ao meio ambiente em geral; 
II - de um terço até a metade, se resulta lesão corporal de natureza grave em outrem;

III - até o dobro, se resultar a morte de outrem.

O Decreto $n^{0} 6.514$, de 22 de julho de 2008 regulamentou a parte administrativa da Lei $n^{0}$ 9.605/98 e disciplinou as infrações administrativas no âmbito federal. As infrações administrativas estão previstas no Art. $2^{0}$ do Decreto $n^{0} 6.514$ como toda ação ou omissão que viole as regras jurídicas de uso, gozo, promoção, proteção e recuperação do meio ambiente. As penalidades passíveis de aplicação são advertência, multa simples, multa diária, embrago de obra ou atividade, entre outras (BRASIL, 2008).

Infrações ambientais em decorrência do descarte de resíduos químicos estão previstas no Art. 61 quando se prevê que causar poluição de qualquer natureza em níveis tais que resultem ou possa resultar em danos à saúde humana, ou que provoquem mortandade de animais ou a destruição significativa da biodiversidade está sujeito à multa de $\mathrm{R} \$ 5.000,00$ (cinco mil reais) a $\mathrm{R} \$$ $50.000 .000,00$ (cinquenta milhões de reais).

No Art. 62, alínea "V" está previsto que incorre nas mesmas multas do Art. 61 quem:

V - lançar resíduos sólidos, líquidos ou gasosos ou detritos, óleos ou substâncias oleosas em desacordo com as exigências estabelecidas em leis ou atos normativos;

A Lei Federal $n^{\circ}$ 11.445, de 05 de janeiro de 2007, institui a Política Nacional de Saneamento Básico e estabelece o manejo de resíduos sólidos urbanos como uma das quatro atividades do saneamento básico, de competência do município (BRASIL, 2007).

Os municípios adquirem assim por meio dessa nova Lei a titularidade dos serviços de saneamento básico e eles devem adotar o planejamento como ferramenta para alcançar a universalidade do acesso e a integralidade dos serviços. 
Exclui-se dessa Política os resíduos químicos de fonte geradora desconhecida e que possam afetar negativamente a saúde da população e o meio ambiente.

Ainda no âmbito federal, a Lei $n^{\circ} 12.305$, de 2 de agosto de 2010, institui a Política Nacional de Resíduos Sólidos e se apresenta como um instrumento jurídico para promoção da gestão integrada e o gerenciamento de resíduos sólidos, incluídos os perigosos, as responsabilidades dos geradores e do poder público (BRASIL, 2010a).

Destinação final é também apresentada na Lei $n^{\circ} 12.305:$

(...) destinação de resíduos que inclui a reutilização, a reciclagem, a compostagem, a recuperação e o aproveitamento energético ou outras destinações admitidas pelos órgãos competentes do Sisnama, do SNVS e do Suasa, entre elas a disposição final, observando normas operacionais específicas de modo a evitar danos ou riscos à saúde pública e à segurança e a minimizar os impactos ambientais adversos (artigo $3^{\circ}, \mathrm{VII}$ ).

Como se pode observar a destinação final não é apenas abandonar algo, como ocorre com os resíduos químicos, mas sim atender a legislação vigente com vistas a providenciar sua reutilização, reciclagem ou outra forma de aproveitamento.

Analisando o seu capítulo IV - Dos Resíduos Perigosos verifica-se no Art. 41 Parágrafo único que: "Se após descontaminação de sítio órfão realizada com recursos do Governo Federal ou de outro ente da Federação, forem identificados os responsáveis pela contaminação, estes ressarcirão integralmente o valor empregado ao poder público.

Observa-se aqui que pela primeira vez uma legislação federal faz citação à áreas contaminadas órfãs, um importante avanço na esfera jurídica.

Ressalta-se, entretanto, que como definido no Capítulo II a área órfã contaminada é aquela cujos responsáveis pela disposição não sejam identificáveis ou individualizáveis. 
Da mesma forma é também citado no Capítulo $V$ - Dos Instrumentos Econômicos em seu Art. 42 que estabelece que "O poder público poderá instituir medidas indutoras e linhas de financiamento para atender, prioritariamente, por exemplo, a descontaminação de áreas contaminadas, incluindo as áreas órfãs.

Aqui é mencionado que os recursos financeiros destinados à recuperação do sítio órfão poderão ser imputados aquele que causou esse dano ambiental caso seja possível essa identificação, mas não há citações sobre a remoção imediata dos resíduos do local como forma de se proteger não apenas o meio ambiente e a saúde da população exposta.

Cabe ao poder público atuar, subsidiariamente, com vistas a minimizar ou cessar o dano, logo que tome conhecimento de evento lesivo ao meio ambiente ou à saúde pública relacionado ao gerenciamento de resíduos sólidos como bem previsto na Art. 29 dessa Lei.

No estado de São Paulo, em especial na RMSP há casos em que esses "sítios órfãos" foram ocupados por famílias e que passam a conviver em área sabidamente contaminada. Nesses casos esses moradores se expõem ao lado de resíduos químicos deixados ali em embalagens de todas as espécies e já em estado avançado de degradação.

O Decreto Federal $n^{0} 7.404$ de 23 de dezembro de 2010 que regulamenta a Lei no 12.305, de 2 de agosto de 2010 não faz menção aos casos de descartes de resíduos químicos sem identificação (BRASIL, 2010b).

Entretanto, o Capítulo III é dedicado a Logística Reversa. A sua definição é encontrada no Art. 13.

"A logística reversa é o instrumento de desenvolvimento econômico e social caracterizado pelo conjunto de ações, procedimentos e meios destinados a viabilizar a coleta e a restituição dos resíduos sólidos ao setor empresarial, para reaproveitamento, em seu ciclo ou em outros ciclos produtivos, ou outra destinação final ambientalmente adequada". 
Indubitavelmente, a logística reversa contribuirá para a organização dos mais diversos setores produtivos da sociedade moderna, reduzindo assim, os casos de descarte de resíduos químicos perigosos e suas embalagens no meio ambiente.

Em seu Art. 15 é declarado que os sistemas de logística reversa serão implementados e operacionalizados por meio dos seguintes instrumentos:

I - acordos setoriais;

II - regulamentos expedidos pelo Poder Público; ou

III - termos de compromisso.

As responsabilidades para o agricultor, o revendedor e o fabricante de agrotóxicos já são exercidas no modelo da logística reversa muito antes da Política Nacional de Resíduos Sólidos, sendo modelo de sucesso em nosso País e na América Latina. Nesse modelo, a destinação final correta para as embalagens vazias dos agrotóxicos segue um procedimento complexo que requer a participação efetiva de todos os agentes envolvidos, diminuindo o risco para saúde da população e de contaminação do meio ambiente.

Também chama a atenção no Decreto Federal nº 7.404 o Art. 40:

Com relação ao Art.40 "O sistema de coleta seletiva de resíduos sólidos e a logística reversa priorizarão a participação de cooperativas ou de outras formas de associação de catadores de materiais reutilizáveis e recicláveis constituídas por pessoas físicas de baixa renda" vale observar o que se segue abaixo.

Sem prejuízo aos preceitos da sustentabilidade que trata $\circ$ Artigo supramencionado, importante citar que na Região Metropolitana de São Paulo, objeto de estudo desse trabalho, os catadores de materiais recicláveis tornamse vulneráveis aos riscos de intoxicação química quando encontram embalagens descartadas ilegalmente com resíduos químicos. Isso ocorre no momento em que se desfazem dos resíduos para reaproveitar as embalagens. 
Esse tema foi abordado por GÜNTHER (2008), em seu trabalho intitulado "Resíduos Sólidos no Contexto da Saúde Ambiental".

[...] em termos sociais a geração de resíduos sólidos mostra-se como uma questão dialética. Ao mesmo tempo em que o descarte de resíduos traz como decorrência a presença, cada vez maior, de catadores autônomos de materiais recicláveis trabalhando em condições precárias, representa também uma nova forma de inclusão social e de trabalho e renda em países em desenvolvimento. No primeiro caso, a reciclagem informal praticada pelos catadores, tem nos resíduos descartados o objeto de seu sustento, logo a atividade é realizada sem a mínima preocupação com as condições ocupacionais, de segurança ou sanitárias envolvidas. No segundo, a coleta seletiva e segregação de resíduos, atividades desenvolvidas por organizações de catadores, estabelecidas como associações ou cooperativas, têm despontado como uma alternativa de trabalho para um contingente de população sem qualificação profissional para a demanda de mercado.

No âmbito federal, a Câmara dos Deputados passou a discutir o tema por meio do Projeto de Lei $(P L) n^{\circ} 2.732 / 2011$, de autoria do Deputado Federal Arnaldo Jardim (PPS-SP). O Projeto Estabelece diretrizes para a prevenção da contaminação do solo, cria a Contribuição de Intervenção no Domínio Econômico sobre Substâncias Perigosas e o Fundo Nacional para a Descontaminação de Áreas Órfãs Contaminadas (BRASIL, 2011).

\subsubsection{Legislação no estado de São Paulo}

No Estado de São Paulo a Lei n 997, de 31 de maio de 1976, dispõe sobre a Prevenção e o Controle da Poluição do Meio Ambiente, prevê o licenciamento ambiental e confere penalidades por infrações à Lei (SÃO PAULO (Estado), 1976a).

O Decreto $n^{\circ} 8.468$ de 8 de setembro de 1976 regulamenta a Lei $n^{\circ} 997$, de 31 de maio de 1976, com 172 artigos e anexos cujas disposições representaram um instrumento de trabalho com mecanismos ajustados para operação e controle do meio ambiente (SÃO PAULO (Estado), 1976b). 
Sobre o descarte de resíduos químicos o Decreto $n^{0} 8.468$ prevê sanções administrativas uma vez que fica constatada poluição do solo, como previsto nos Artigos do Decreto abaixo especificados:

Art. 51 Não é permitido depositar, dispor, descarregar, enterrar, infiltrar ou acumular no solo resíduos, em qualquer estado material.

Art. 52 O solo somente poderá ser utilizado para destino final de resíduos de qualquer natureza, desde que sua disposição seja feita de forma adequada, estabelecida em projetos específicos de transporte e destino final.

Em se tratando de descarte de resíduos químicos a aplicação de sanções administrativas se configura na maioria dos casos como ineficaz, por não ser possível identificar o infrator.

O dano ambiental causado pelo descarte de resíduos químicos indubitavelmente ocorre por meio de transporte rodoviário até o local escolhido pelo infrator para "livrar-se" de produtos nos estados sólidos ou semi-sólidos normalmente de empreendimentos ou atividades de origem industrial, agrícola, serviços, laboratórios, fruto de roubo de carga, dentre outras.

Em alguns casos quando a identificação do veículo for denunciada pela população local ou detectada por meio de câmaras de segurança deverá o proprietário do veículo ser submetido as sanções administrativas previstas no Decreto $n^{\circ} 8.468$.

A Lei Estadual $n^{0} 12.300$, de 16 de março de 2006, instituiu a Política Estadual de Resíduos Sólidos definindo princípios e diretrizes, objetivos, instrumentos para a gestão integrada e compartilhada de resíduos sólidos, com vistas à prevenção e ao controle da poluição, à proteção e à recuperação da qualidade do meio ambiente, e à promoção da saúde pública, assegurando o uso adequado dos recursos ambientais no Estado de São Paulo (SÃO PAULO (Estado), 2006).

No Artigo $6^{\circ}$ Parágrafo único desta mesma lei está previsto: 
"Os resíduos gerados nas operações de emergência ambiental, em acidentes dentro ou fora das unidades geradoras ou receptoras de resíduo, nas operações de remediação de áreas contaminadas e os materiais gerados nas operações de escavação e dragagem deverão ser previamente caracterizados e, em seguida encaminhados para destinação adequada."

Artigo 31 - O gerenciamento dos resíduos industriais, especialmente os perigosos, desde a geração até a destinação final, será feito de forma a atender aos requisitos de proteção ambiental e de saúde pública, com base no Plano de Gerenciamento de Resíduos Sólidos de que trata esta lei.

Artigo 32 - Compete aos geradores de resíduos industriais a responsabilidade pelo seu gerenciamento, desde a sua geração até a sua disposição final:

O Decreto $n^{\circ} 54.645$ de 05 de agosto de 2009 que regulamenta a Política Estadual de Resíduos Sólidos no seu Art. 6 prevê que a Secretaria do Meio Ambiente, em conjunto com outros órgãos e entidades da Administração Direta e Indireta, elaborará o plano estadual de resíduos sólidos no prazo de até 8 (oito) meses, contados da data da publicação deste decreto incluindo entre outros a estratégia para integração e cooperação intermunicipal visando à solução conjunta dos problemas de gestão de resíduos sólidos, assegurada a participação da sociedade civil (SÃO PAULO (Estado), 2009a).

Isso permitiria o enfrentamento de acidentes ambientais decorrente de descarte de resíduos químicos em uma determinada região, contando, por exemplo, com locais predeterminados para recebimento temporário de resíduos químicos perigosos, afastando assim da ameaça de contaminação do meio ambiente e da população circunvizinha.

No Capítulo III - Das Responsabilidades na Seção II - Das Responsabilidades sobre Áreas Contaminadas e Áreas Degradadas, prevê no Art. 20 que os responsáveis pela degradação ou contaminação de áreas em decorrência de suas atividades econômicas, de acidentes ambientais ou pela disposição de resíduos sólidos deverão promover sua recuperação ou remediação, em conformidade com procedimentos específicos a serem estabelecidos pela 
Secretaria do Meio Ambiente, mediante resolução, no prazo de 1 (um) ano contado da data de publicação deste decreto (SÃO PAULO (Estado), 2009a).

Outra contribuição importante do Decreto Estadual n $n^{0}$ 54.645/2009 é a "responsabilidade pós-consumo" (RPC) que se refere à responsabilidade dos fabricantes, distribuidores ou importadores de uma série de produtos pela gestão dos resíduos gerados por estes após seu consumo (tais como embalagens, produtos usados, vencidos ou quebrados).

O Art. 19 do Decreto prevê que:

"Os fabricantes, distribuidores ou importadores de produtos que, por suas características, venham a gerar resíduos sólidos de significativo impacto ambiental, mesmo após o consumo desses produtos, ficam responsáveis (...) pelo atendimento das exigências estabelecidas pelos órgãos ambientais e de saúde, especialmente para fins de eliminação, recolhimento, tratamento e disposição final desses resíduos, bem como para a mitigação dos efeitos nocivos que causem ao meio ambiente ou à saúde pública".

Não há, portanto, previsto nesta Lei bem como em seu Regulamento as situações quando não for possível identificar os responsáveis pelo descarte de resíduos químicos em via pública ou a contaminação de sítios órfãos e, portanto, como deverão proceder as autoridades competentes que na maioria dos casos não possui estrutura para dar essa resposta e remover de imediato, quando assim, se fizer necessário, os resíduos químicos e destiná-los ainda que temporariamente em local seguro e apropriado.

$\mathrm{Na}$ questão emergente das áreas contaminadas, sua complexidade e interesse em diversos setores da sociedade há de se destacar o pioneirismo paulista com a publicação da Lei Estadual no 13.577de 8 de julho de 2009.

Sancionada em 8 de julho de 2009 a Lei Estadual n 13.577 dispõe sobre diretrizes e procedimentos para a proteção da qualidade do solo e gerenciamento de áreas contaminadas (SÃO PAULO (Estado), 2009b). 
A Lei $n^{0} 13.577$, permite que na prática sejam adotadas medidas de proteção da qualidade do solo e das águas subterrâneas, tanto para prevenção quanto para correção das áreas existentes.

Como objetivo previsto no Art. $2^{0}$ está previsto, garantir o uso sustentável do solo, protegendo-os de contaminações e prevenindo alterações nas suas características e funções.

Nesse sentido a alínea "l" prevê, medidas para proteção da qualidade do solo e das águas subterrâneas.

Merece atenção especial ao estabelecido no Capítulo III.

No Capítulo III Das Áreas Contaminadas na Seção I Das Responsabilidades no seu Art. 13 fica estabelecido que "São responsáveis legais e solidários pela prevenção, identificação e remediação de uma área contaminada":

I - o causador da contaminação e seus sucessores;

II - o proprietário da área;

III - o superficiário;

IV - o detentor da posse efetiva;

$V$ - quem dela se beneficiar direta ou indiretamente.

Também no Art. 14 fica estabelecido que "Havendo perigo à vida ou à saúde da população, em decorrência da contaminação de uma área, o responsável legal deverá comunicar imediatamente tal fato aos órgãos ambientais e de saúde e adotar prontamente as providências necessárias para elidir o perigo.

No $\S 1^{\circ}$ - Para fins deste artigo, consideram-se perigo à vida ou à saúde, dentre outras, as seguintes ocorrências:

1 - incêndios;

2 - explosões;

3 - episódios de exposição aguda a agentes tóxicos, reativos e corrosivos; 
4 - episódios de exposição e agentes patogênicos, mutagênicos e cancerígenos;

5 - migração de gases voláteis para ambientes confinados e semiconfinados, cujas concentrações possam excedam os valores estabelecidos em regulamento;

6 - comprometimento de estruturas em geral;

7 - contaminação das águas superficiais ou subterrâneas utilizadas para abastecimento público e dessedentação de animais;

8 - contaminação de alimentos.

Os descartes de resíduos químicos na RMSP apresentam pelo menos um desses perigos como aqueles indicados nos itens 1, 2, 3 e 4.

Também se prevê no $§ 2^{\circ}$ desta Lei que:

Na hipótese de o responsável legal não promover a imediata remoção do perigo, tal providência poderá ser adotada subsidiariamente pelo poder público, garantindo o direito de ressarcimento dos custos efetivamente despendidos pela administração pública, devidamente apurada mediante apresentação de planilha fundamentada que comprove que os valores gastos na remoção do perigo são compatíveis com o valor de mercado.

Observa-se aqui que igualmente como a Política Nacional de Resíduos Sólidos a Lei $n^{\circ} 13.577$ imputa ao Poder Público as ações de remoção do perigo para os casos de omissão dos responsáveis por área contaminadas.

No caso da Lei Estadual n 13.577 será possível contar com suporte financeiro do FEPRAC para destinação final ambientalmente adequada de resíduos químicos.

O FEPRAC é vinculado à Secretaria do Meio Ambiente e destina-se à proteção do solo contra alterações prejudiciais às funções, bem como à identificação e à remediação de áreas contaminadas. 
O Conselho Estadual de Meio Ambiente (CONSEMA), manifestou-se em sua $307^{a}$ Reunião Ordinária do Plenário em 21.05.13 (SÃO PAULO (Estado), 2013b) favorável (deliberação $n^{\circ}$ 08/2013) a Minuta de Decreto $n^{\circ} 59.263$, de 5 de junho de 2013 que regulamenta a Lei $n^{0} 13.577$ de 8 de julho de 2009, que dispõe sobre diretrizes e procedimentos para a proteção da qualidade do solo e gerenciamento de áreas contaminadas e dá outras providências correlatas (SÃO PAULO (Estado), 2013c). .

Vale então ressaltar que a CETESB - Companhia Ambiental do Estado de São Paulo já participou de 1984 a 2013 do atendimento de 452 acidentes envolvendo o descarte de resíduos químicos em todo o estado de São Paulo e 319 para a RMSP. São inúmeras as dificuldades para solução desse tipo de ocorrência, onde em cada caso se revela o despreparo e a falta de articulação entre os órgãos públicos envolvidos para a solução final do atendimento emergencial.

Diversos problemas surgem com o retardo na remoção de resíduos químicos em áreas periféricas da RMSP como, por exemplo, a reutilização de embalagens descartadas com resíduos químicos pela população local para armazenamento de água em suas residências ou para outros fins.

De acordo com FREIRIA (2011), a responsabilidade ambiental é compartilhada, é difusa, é de todos. Isso significa que em maior ou menor escala, todos somos ou deveremos ser operadores de políticas públicas ambientais. 


\section{MATERIAIS E MÉTODOS}

\subsection{Métodos}

"Pesquisa é sempre um elo entre o pesquisador e a comunidade científica, razão pela qual sua publicidade é elemento indispensável do processo de produção de conhecimento." (Sergio Vasconcelos de Luna).

Segundo GIL (2002), quanto aos objetivos gerais as pesquisas podem ser classificadas em: exploratórias, descritivas e explicativas.

Ainda segundo GIL (2002), a pesquisa de natureza exploratória cumpre três objetivos:

a) visa proporcionar maior familiaridade do pesquisador com o problema;

b) objetiva o aprimoramento de ideias ou a descoberta de intuições do pesquisador com relação ao problema estudado;

c) é flexível e possibilita a consideração dos mais variados aspectos ao fenômeno estudado.

SELLTIZ et al. (1987) citado por GIL (2002), relatam que as pesquisas exploratórias envolvem: (a) levantamento bibliográfico; (b) entrevistas com pessoas que tiveram experiências práticas com o problema pesquisado; e (c) análise de exemplos que "estimulem a compreensão".

A pesquisa descritiva tem como objetivo primordial a descrição das características de determinada população ou fenômenos ou, o estabelecimento de relações entre variáveis. Destacam-se aqui, técnicas padronizadas de coleta de dados, como questionários, e a observação sistemática (GIL, 2002).

As pesquisas explicativas têm como principal objetivo identificar fatores que determinam ou contribuem para a ocorrência de fenômenos. Esse tipo de pesquisa aprofunda o conhecimento da realidade, explicando a razão e o porquê das coisas (GIL, 2002). 
Diante do exposto, a pesquisa utilizou-se de métodos exploratório e descritivo.

O caráter exploratório desse trabalho está bem caracterizado pela pesquisa bibliográfica desenvolvida a partir de uma gama muito ampla de livros de referência, artigos científicos e a legislação afeta ao tema de estudo.

Quanto ao aspecto descritivo desse trabalho está a descrição de como ocorrem os descartes de resíduos químicos e as dificuldades para enfrentamento da situação emergencial pelos órgãos públicos competentes, especialmente quando não é possível identificar o responsável legal.

Para YIN (2001), o método de pesquisa que inclui estudos de caso, refere-se à investigação empírica e compreende uma abordagem abrangente, abarcando a lógica do planejamento, da coleta e da análise de dados e pode incluir tanto estudos de caso único quanto de casos múltiplos.

O estudo de caso como estratégia de pesquisa compreende um método que incorpora abordagens específicas à coleta e análise de dados.A pesquisa de estudos de caso pode incluir tanto estudos de caso único quanto de casos múltiplos (YIN, 2001).

No presente trabalho foram utilizados dois estudos de caso envolvendo descarte de resíduos químicos a partir dos seguintes critérios: a) apresentar descartes de resíduos químicos de natureza orgânica e inorgânica b) realização de análises químicas para caracterização de seus riscos à saúde da população eventualmente exposta e os potenciais riscos ao meio ambiente e c) estimar os custos necessários para a fase emergencial e de destinação final de um deles.

O objetivo do pesquisador ao apresentar os estudos de caso não representa uma "amostragem" e sim de expandir o conhecimento do tema estudado e não pretende enumerar frequências estatísticas.

\subsection{Materiais}

O presente trabalho foi desenvolvido por meio do desenvolvimento das ferramentas relacionadas a seguir. 


\subsubsection{Coleta de dados (fontes secundárias)}

O desenvolvimento do trabalho na modalidade documental considerou fontes diversificadas e dispersas como o SIEQ e a documentação fotográfica de atendimentos de descartes de resíduos químicos do Setor de Atendimento a Emergências da CETESB - Companhia Ambiental do Estado de São Paulo, referente ao período de 2005 a 2013, acrescidas de notícias de jornais e da "internet".

Os registros utilizados na pesquisa referem-se àqueles em que houve participação da CETESB - Companhia Ambiental do Estado de São Paulo, seja pela participação conjunta do Setor de Atendimento a Emergências e pela Agência Ambiental da região ou quando o atendimento ocorreu apenas pela Agência Ambiental.

A pesquisa documental constitui uma fonte rica e estável de dados, subsistem ao longo do tempo e tornam-se importante fonte de dados históricos GIL (2002).

A FIG. 15 representa uma visão da página da "internet" da CETESB Companhia Ambiental do Estado de São Paulo utilizada pelo pesquisador para elaboração dos diferentes gráficos apresentados ao longo desse trabalho sobre os descartes de resíduos químicos. 


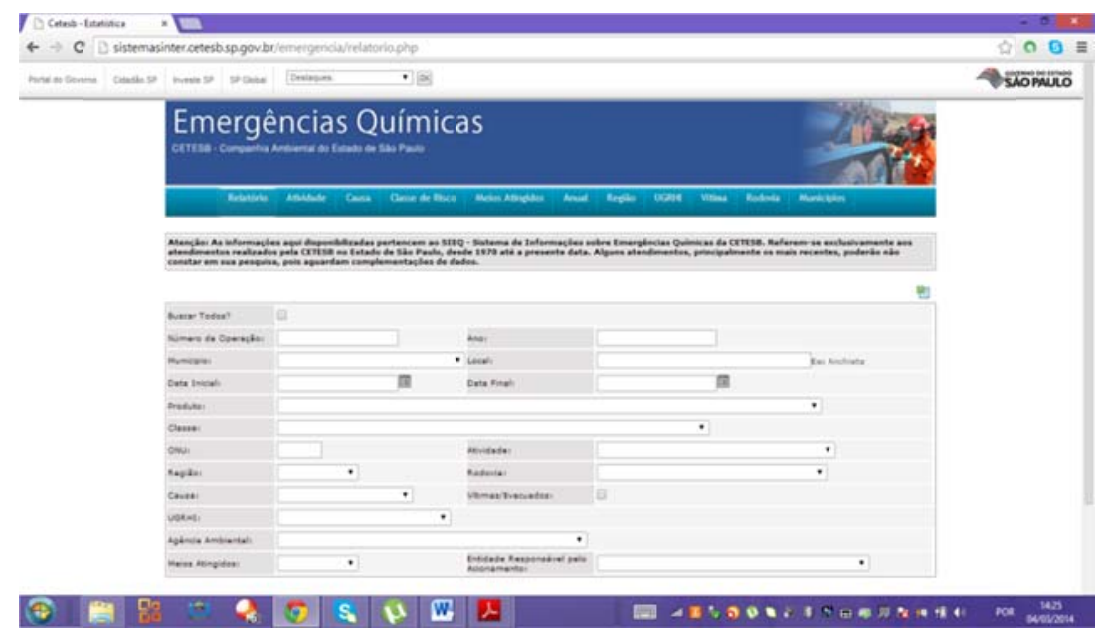

FIGURA 15 - Página "web" da CETESB para pesquisa sobre emergências químicas.

Fonte:(CETESB - COMPANHIA AMBIENTAL DO ESTADO DE SÃO PAULO, 2013a)

O levantamento dos Registros e Emergências Químicas - REQs a partir do SIEQ restringiu-se rigorosamente ao período objeto da pesquisa, ou seja, aquele compreendido pelo período de 2005 a 2013. As informações disponibilizadas pelo SIEQ referem-se exclusivamente aos atendimentos realizados pela CETESB - Companhia Ambiental do Estado de São Paulo.

A opção por iniciar a pesquisa a partir de 2005 se deve à melhoria na qualidade dos dados do SIEQ, que passou a contemplar dentre outros parâmetros, as coordenadas geográficas dos atendimentos e os compartimentos ambientais atingidos. Todos os dados, como tipo de emergência, natureza do resíduo, endereço, quantidade vazada, meios atingidos, foram organizados em planilhas Excel para facilitar os estudos e representação gráfica.

\subsubsection{Representação gráfica}

A partir dos dados obtidos foram gerados mapas com a colaboração da Geógrafa Cláudia Matos Fagundes, utilizando-se o "software" ArcGis 10.2.1 for Desktop (Licença de avaliação).

O ArcGis constitui um sistema de informação geográfica, produzido pela ESRI (Environmental Systems Research Institute), foi utilizado no gerenciamento de bases temáticas a partir de informações geográficas permitindlo uma análise 
espacial dos descartes de resíduos químicos em sete mapas, a partir da sobreposição de camadas com detalhamento de recursos hídricos, sistema viário, distritos da cidade de São Paulo e de bairros da cidade de Guarulhos.

A partir dos dados de coordenadas geográficas da base SIEQ, foram espacializados os pontos de descartes de resíduos químicos. Esses pontos permitiram correlações com as divisões geográficas (distritos da cidade de São Paulo e bairros da cidade de Guarulhos) que são apresentados nos mapas e nas tabelas geradas a partir destes cruzamentos.

As informações que serviram de base para a elaboração dos mapas foram extraídas do SIEQ por meio de um editor de planilhas, Microsoft Office Excel.

Utilizaram-se pontos obtidos em coordenadas geográficas (latitude e longitude) e sua transformação posterior para projeção Universal Transversa de Mercator (UTM).

Foram utilizadas as seguintes base cartográficas:

- malha Rodoviária do Estado de São Paulo. Dados levantados pelo Departamento de Estrada de Rodagem - (DER/SP) em 2012 e atualizado anualmente no SIRGeo/DER;o SIRGeo representa uma solução prática em termos de geoprocessamento aplicado a rodovias.

- detalhamento de recursos hídricos (Sistema Georreferenciado sobre os múltiplos usos da água no Estado de São Paulo). Base cartográfica digital do DAEE obtida a partir das especificações técnicas e imagens de fotolitos originais, fornecidas pelo IBGE.

\subsubsection{Análises químicas}

As análises químicas e respectivas metodologias aplicadas aos dois estudos de caso, visando a caracterização dos resíduos, foram realizadas nos seguintes laboratórios da CETESB - Companhia Ambiental do Estado de São Paulo:

\section{- Laboratório de Química Inorgânica}


Os métodos analíticos aplicados na caracterização dos parâmetros de interesse estão discriminados na TAB. 3.

TABELA 3 - Parâmetros analisados na amostra de resíduo (Boletim de Análises Nº EAAl/39393/2014).

\begin{tabular}{l|l}
\hline \multicolumn{1}{c|}{ Parâmetro } & \multicolumn{1}{c}{ Método } \\
\hline Alumínio Total & $\begin{array}{l}\text { Espectrometria ótica de emissão com plasma de } \\
\text { argônio - ICP/OES US-EPA, Método 6010C }\end{array}$ \\
\hline $\begin{array}{l}\text { Sól. Fixos, Sól. Voláteis totais, } \\
\text { Umidade }\end{array}$ & $\begin{array}{l}\text { Gravimetria - Standard Methods for the Examination } \\
\text { of Water and Wastewater - APHA - AWWA - WEF }\end{array}$ \\
\hline $\begin{array}{l}\text { Cloreto total,Nitrogênio-amônia, } \\
\text { total, Sulfato total, Fluoreto total }\end{array}$ & $\begin{array}{l}\text { Cromatografiaiônica - Standard Methods for the } \\
\text { Examination of Water and Wastewater - APHA - } \\
\text { AWWA - WEF }\end{array}$ \\
\hline Condutividade & $\begin{array}{l}\text { Standard Methods for the Examination of Water and } \\
\text { Wastewater - APHA - AWWA - WEF }\end{array}$ \\
\hline $\begin{array}{l}\text { Arsênio,Bário, Cádmio, Chumbo, } \\
\text { Cromo,Prata, Selênio, }\end{array}$ & $\begin{array}{l}\text { Espectrometriaótica de emissão com plasma de } \\
\text { argônio-ICP/OES - Standard Methods for the } \\
\text { Examination of Water and Wastewater - APHA - } \\
\text { AWWA - WEF }\end{array}$ \\
\hline Mercúrio & $\begin{array}{l}\text { Env. Protection Agency - USA-2007- método 7473 } \\
\text { - Mercury in Solids and Solutions by Thermal } \\
\text { Decomposition, Amalgamation, and Atomic } \\
\text { Absorption Spectrophotometry }\end{array}$ \\
\hline
\end{tabular}

Fonte: AMERICAN PUBLIC HEALTH ASSOCIATION, AMERICAN WATER WORKS ASSOCIATION \& WATER ENVIRONEMENTAL FEDERATION, 2012

Além dos métodos indicados na TAB. 3, foram também adotados os seguintes:

- Extrato solubilizado obtido segundo metodologia descrita na Norma Brasileira ABNT NBR 10006, segunda edição, 2004 (ABNT, 2004a).

○ O fluoreto total no solubilizado: determinação cancelada devido a problemas operacionais.

- Extrato lixiviado obtido segundo metodologia descrita na Norma Brasileira ABNT NBR 10005, segunda edição, 2004 (ABNT, 2004b).

- Laboratório de Química Orgânica

Os métodos de análises utilizados foram: 
Compostos Orgânicos Voláteis - SW 846 - Test Methods for Evaluating Solid Waste (1986) Método EPA 8270C - Semi Volatile Organic Compounds by Gas CromatographylMass Spectrometry (CGIMS);Capillary Column Technique - Rev. 3

Compostos Orgânicos Voláteis - SW 846 - Test Methods for Evaluating Solid Waste (1988) Método EPA 8260B - Volatile Organics Compounds by Gas CromatographylMass Spectrometry (CGIMS);Capillary Column Technique - Rev. 2.

\subsubsection{Equipamentos portáteis de detecção}

O equipamento portátil de deteç̧ão abaixo discriminado, devidamente calibrado, utilizado pelo pesquisador em um dos estudos, pertence ao Setor de Atendimento a Emergências da CETESB - Companhia Ambiental do Estado de São Paulo:

$\checkmark$ Fotoionizador portátil, modelo PGM 7320 Mini Rae 3000, marca Mini Rae, certificado de calibração $n^{\circ} 5969 / 2013$, emitido pela empresa Almont Brasil em 13 de novembro de 2013 (FIG. 16). O equipamento realiza medição de concentração na faixa de 0 a 15.000 ppm. A resolução para concentração na faixa entre 0 a $999,9 \mathrm{ppm}$, é de $0,1 \mathrm{ppm}$ e para concentrações de 1000 a 15.000 ppm é de 1 ppm (RAE SYSTEMS, 2014). Na calibração utilizou-se uma mistura padrão de isobutileno (Código CIL-PID, certificado 40714789, emitente White Martins, validade Março de 2016). 


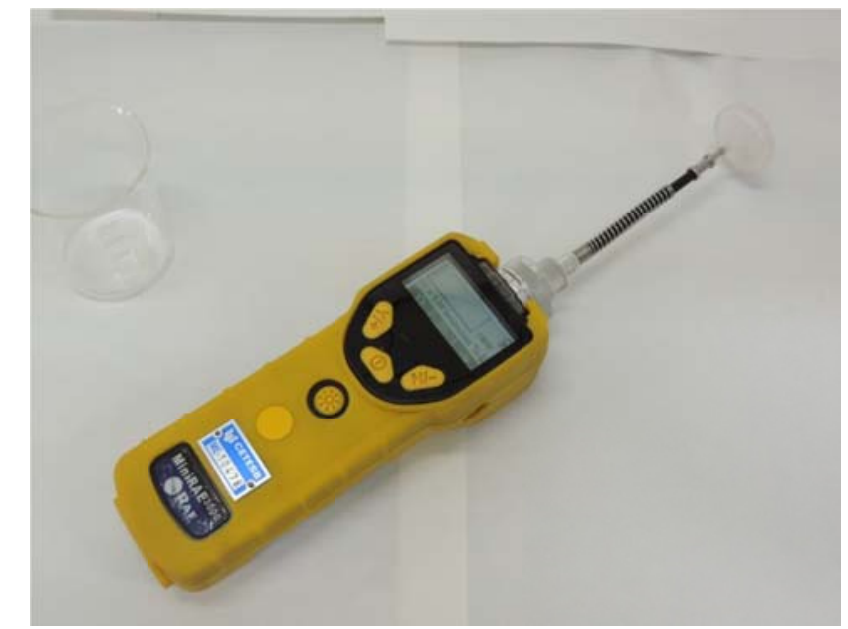

FIGURA 16 - Registro fotográfico do fotoionizador portátil utilizado para determinação de amônia anidra.

Fonte: CETESB - Companhia Ambiental do Estado de São Paulo, (Banco de Imagem).

\subsubsection{Elaboração de questionário (fonte primária de dados)}

A pesquisa empírica envolveu o acompanhamento de entrevistas com os principais atores que já participaram de atendimentos emergenciais a descarte de resíduos químicos. Os atores são representantes de órgãos públicos como órgãos ambientais nas esferas municipal e estadual, corpo de bombeiros, defesa civil e prefeitura municipal.

O objetivo dessa pesquisa foi avaliar o envolvimento de instituições públicas do estado de São Paulo no atendimento às emergências químicas que envolvem descarte de resíduos químicos, tendo como área de ocorrência a RMSP.

A pluralidade de abordagem da pesquisa buscou conhecer por meio de entrevistas com os principais atores intervenientes nos cenários acidentais, a sua capacidade de resposta, dificuldades e percepção dos danos ambientais causados pelos descartes de resíduos químicos.

Importante ressaltar que prevaleceu na resposta dos entrevistados sua percepção sobre a questão dos descartes de resíduos químicos. Segundo DAVIDOFF, 1983, citado por POFFO (2011), percepção é o processo de organizar e interpretar dados sensoriais recebidos, o qual é influenciado pelo 
meio no qual o indivíduo está inserido, por motivações, valores, expectativas, emoções e por suas experiências pessoais.

\subsubsection{Critérios de escolha adotados}

Os municípios visitados nesta pesquisa de campo foram aqueles nos quais o número de ocorrências com descarte de resíduos químicos atendidos pela CETESB - Companhia Ambiental do Estado de São Paulo, no período de 2005 a 2013, foram iguais ou superiores a 3 (três) registros, e onde foi possível identificar representantes nos órgãos públicos que participaram direta ou indiretamente de alguma emergência química.

\subsubsection{Composição da amostra}

A partir dos registros de emergências químicas da CETESB - Companhia Ambiental do Estado de São Paulo o estudo foi direcionado para 12 dos 23 municípios da RMSP, foram eles: Arujá, Barueri, Cajamar, Cotia, Guarulhos, Itaquaquecetuba, Mairiporã, Mogi das Cruzes, Santo André, São Paulo, São Bernardo do Campo e Suzano.

No município de Cajamar não foi localizado representante de órgãos públicos que tivesse atendido ao requisito da pesquisa, ou seja, ter participado em atendimentos emergenciais envolvendo descarte de resíduos químicos.

O questionário conta com 18 itens, sendo de 1 (um) a (seis) com informações factuais acerca do pesquisado, que dependem de pouca ou nenhuma interpretação. Os itens de 7 (sete) a 18 retratam informações não factuais ou opinativas, ou seja, perguntas propriamente ditas sobre o atendimento a emergências envolvendo descarte de resíduos.

De acordo com LUNA (1997) informações factuais são: sexo; idade; estado civil; série que cursa; empresa em que trabalha; renda; religião que pratica, etc. Por oposição, as informações não factuais ou opinativas são aquelas que exprimem a concepção de um indivíduo a respeito de si mesmo, de uma situação ou de outrem, envolvendo suas crenças, sentimentos, valores, opiniões, etc. 
As entrevistas realizadas pelo pesquisador seguiram o modelo descrito por MINAYO (1992) como sendo semi estruturado ou não estruturado, que combina perguntas fechadas (ou estruturadas) e abertas, onde o entrevistado tem a possibilidade de discorrer sobre o tema proposto, sem respostas ou condições prefixadas pelo pesquisador.

Nas perguntas fechadas o principal objetivo foi obter um panorama geral sobre a situação do descarte de resíduos na RMSP, apresentado por meio de figuras retratando aspectos da resposta a emergências por parte das instituições dos entrevistados. As perguntas abertas foram examinadas à luz da categorização e da análise subjetiva.

As pesquisas do tipo exploratórias têm como principal finalidade desenvolver, esclarecer e modificar conceitos, com vistas à formulação de problemas ou hipóteses pesquisáveis. Este tipo de pesquisa é realizado especialmente quando o tema escolhido é pouco explorado e torna-se difícil sobre ele formular hipóteses precisas e operacionalizáveis. O produto final deste processo é um problema mais esclarecido, passível de investigação mediante procedimentos sistematizados (GIL, 1991).

O questionário foi inicialmente aplicado a 6 (seis) técnicos do Setor de Atendimento a Emergências da CETESB - Companhia Ambiental do Estado de São Paulo, no mês de dezembro de 2011, com a finalidade de promover ajustes em seu conteúdo.

Os temas abordados no questionário (Apêndice 1) foram:

1. perfil do pesquisado e experiência profissional, sendo observado:
a. faixa etária;
b. grau de instrução;
c. tempo de atuação na empresa.

2. número de atendimentos emergenciais envolvendo descarte de resíduos químicos, sendo avaliados: 
a. quantidade de atendimentos emergenciais envolvendo descarte de resíduos químicos no qual o entrevistado participou ou atendeu;

3. impactos decorrentes dos acidentes ambientais relacionados ao descarte de resíduos químicos, sendo observados:

a. principal meio físico afetado (água, ar, solo, residência, rua/rodovia, rio/córrego) pelo descarte de resíduos químicos;

b. principais consequências observadas pelo entrevistado devido à omissão ou retardo das autoridades públicas em atender prontamente uma emergência envolvendo descarte de resíduos químicos;

4. capacitação técnica das equipes de resposta a acidentes ambientais envolvendo descarte de resíduos químicos, sendo observadas:

a. realização de treinamento/capacitação baseado em conhecimentos técnicos e práticos sobre aspectos de segurança, com ênfase no atendimento a emergências com produtos químicos;

5. perfil da instituição na qual o pesquisado atua:

a. disponibilidade e rapidez no atendimento a situações emergenciais envolvendo descarte ilegal de resíduos químicos;

b. disponibilidade de EPIs;

C. registro dos atendimentos em Banco de Dados;

6. informações sobre o Atendimento emergencial em si:

a. identificação dos responsáveis pelo descarte de resíduos químicos;

b. tempo médio despendido para o atendimento emergencial;

c. participação em grupos de trabalhos na fase pós-emergencial para tratar da questão dos descartes de resíduos químicos como forma de se preparar para novas situações emergenciais;

d. notificação à Autoridade Policial sobre 0 atendimento emergencial; 
Para esta pesquisa qualitativa responderam ao questionário 32 representantes de diferentes instituições públicas, que já participaram de pelo menos 1 (um) atendimento emergencial envolvendo atividades irregulares e/ou ilegais com o descarte de resíduos químicos em áreas inseridas na RMSP.

Foi utilizado, nesta avaliação, o método qualitativo, estabelecendo o significado de um fenômeno a partir do ponto de vista de um público alvo. Os resultados da pesquisa são apresentados e discutidos no item 7.6. 


\section{6 ÁREA DE ESTUDO}

A área de estudo do presente trabalho foi a RMSP, uma região primordialmente urbana com áreas arruadas e efetivamente ocupadas por uso residencial, comercial, industrial e de serviços.

A RMSP ilustrada por meio de mapa na FIG.17, é o maior pólo de riqueza nacional. Seu Produto Interno Bruto (PIB) atingiu, em 2008, algo em torno de $\mathrm{R} \$ 572$ bilhões, o que corresponde a cerca de $20 \%$ do total brasileiro (EMPRESA PAULISTA DE PLANEJAMENTO METROPOLITANO, 2012).

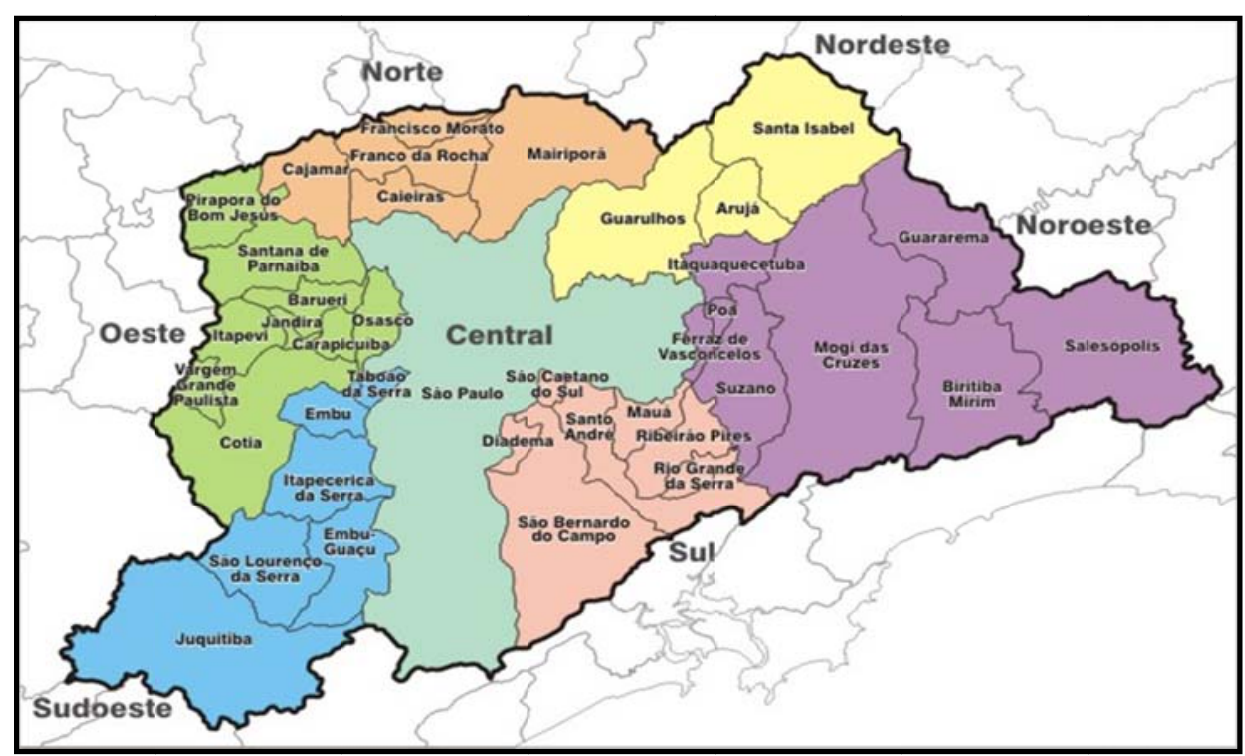

FIGURA 17 - Mapa da Região Metropolitana de São Paulo.

Fonte: Secretariados Transportes Metropolitanos.

http://www.stm.sp.gov.br/index.php/rmas-de-sao-paulo/rm-de-sao-paulo

A metrópole detém a centralização do comando do grande capital privado: nela estão as sedes brasileiras dos mais importantes complexos industriais, comerciais e principalmente financeiros, que controlam as atividades econômicas no País (EMPRESA PAULISTA DE PLANEJAMENTO METROPOLITANO, 2012).

A RMSP segundo dados de 2010 da EMPLASA, conta com 19.700.000habitantes. A FIG. 18 ilustra a distribuição territorial da população na RMSP. 


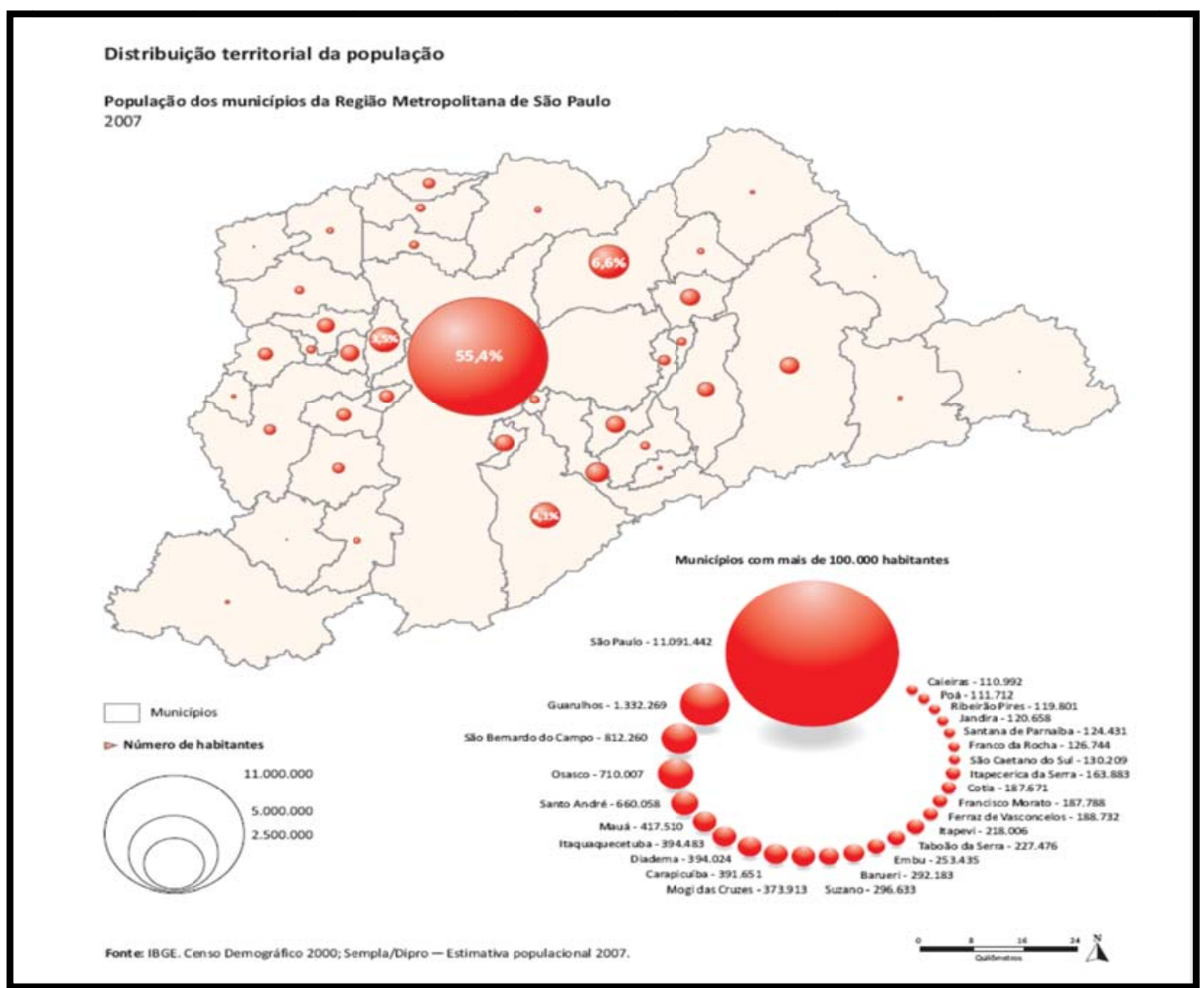

FIGURA 18 - Distribuição territorial da população na Região Metropolitana de São Paulo. Fonte: Prefeitura Municipal de São Paulo, 2014

A FIG. 19 apresenta as 22 Unidades de Gerenciamento de Recursos Hídricos (UGRHIs) que compõem o Estado de São Paulo e a sua classificação por vocação, conforme designado pelo Anexo III da lei Estadual n ${ }^{0} 9.034$ de 1994 Plano Estadual de Recursos Hídricos (CETESB - COMPANHIA AMBIENTAL DO ESTADO DE SÃO PAULO, 2013c). 


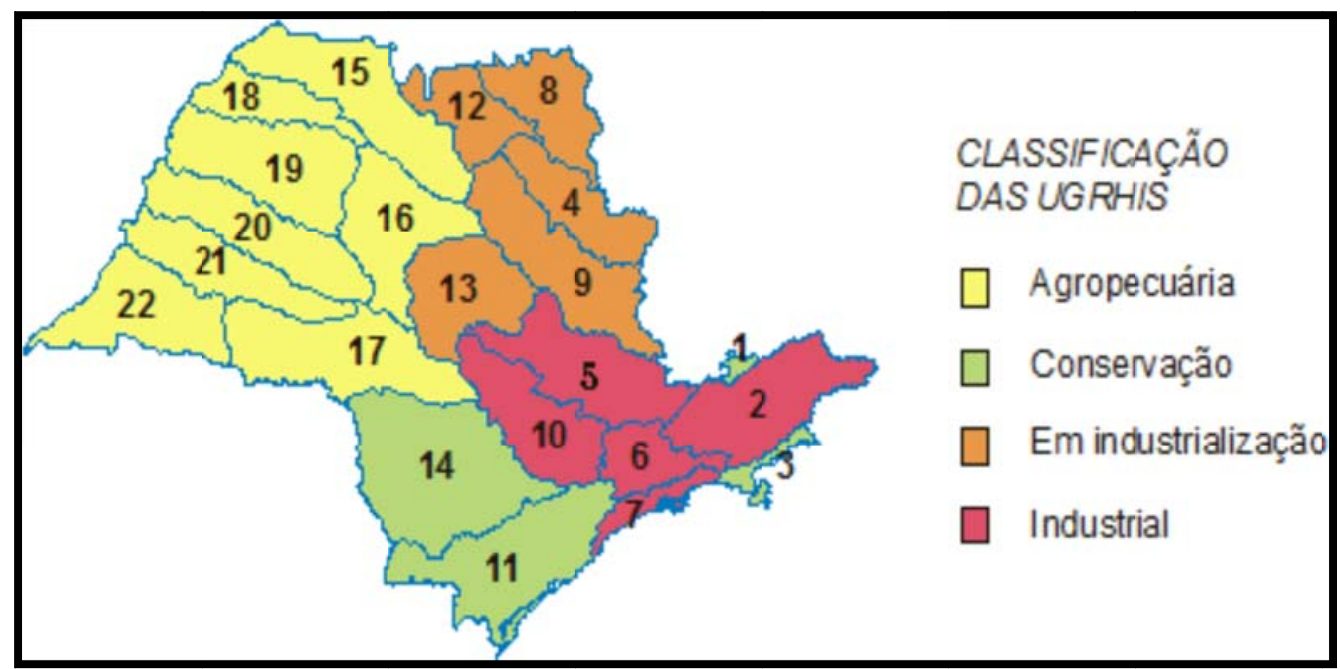

FIGURA 19 - Classificação das 22 Unidades de Gerenciamento de Recursos Hídricos - UGRHI - por vocação.

Fonte: CETESB - COMPANHIA AMBIENTAL DO ESTADO DE SÃO PAULO, 2013c.

A área de estudo está inserida na UGRHI6, com perfil industrial, caracterizada no cenário estadual pela complexa estrutura econômica. Segundo o Relatório de Emergências Químicas atendidas pela CETESB - Companhia Ambiental do Estado de São Paulo em 2010 apesar de ser uma Região predominantemente urbana, possui vegetação remanescente, unidades de conservação de proteção integral e de uso sustentável.

A vegetação natural presente nesta UGRHI corresponde a $27,2 \%$ de sua área total, com remanescentes da Floresta Ombrófila Densa ${ }^{2}$, que ocorre de forma contínua principalmente em sua porção sul, sudeste, centro-norte e sudoeste e de forma fragmentada por toda a área da bacia. Essas características tornam a região vulnerável aos casos de descartes de resíduos químicos (CETESB COMPANHIA AMBIENTAL DO ESTADO DE SÃO PAULO, 2013 c).

${ }^{2} \dot{E}$ uma mata perenifólia, ou seja, sempre verde com árvores emergentes de até 40 metros de altura. Possui densa vegetação arbustiva, composta por samambaias, arborescentes,bromélias e palmeiras. 
Entre alguns fatores que contribuíram para a opção de estudo na RMSP está o fato de ser a RMSP a área com maior incidência de emergências químicas envolvendo o descarte de resíduos químicos e por tratar-se de uma área densamente ocupada e segundo a EMPLASA possui $8.051 \mathrm{~km}^{2}$ e população, segundo estimativas de 2010 , de 19,7 milhões de habitantes. 


\section{RESULTADOS E DISCUSSÃO}

Nesse Capítulo serão apresentados e discutidos os resultados obtidos com a pesquisa no que se refere aos 07 (sete) mapas temáticos elaborados a partir dos REQs georreferenciados, da pesquisa de campo aplicada por meio de questionário e dos dois estudos de caso.

No período avaliado (FIG. 20) foram atendidos 189 Registros de Emergências Químicas (REQs) referentes aos descartes de resíduos químicos na RMSP.

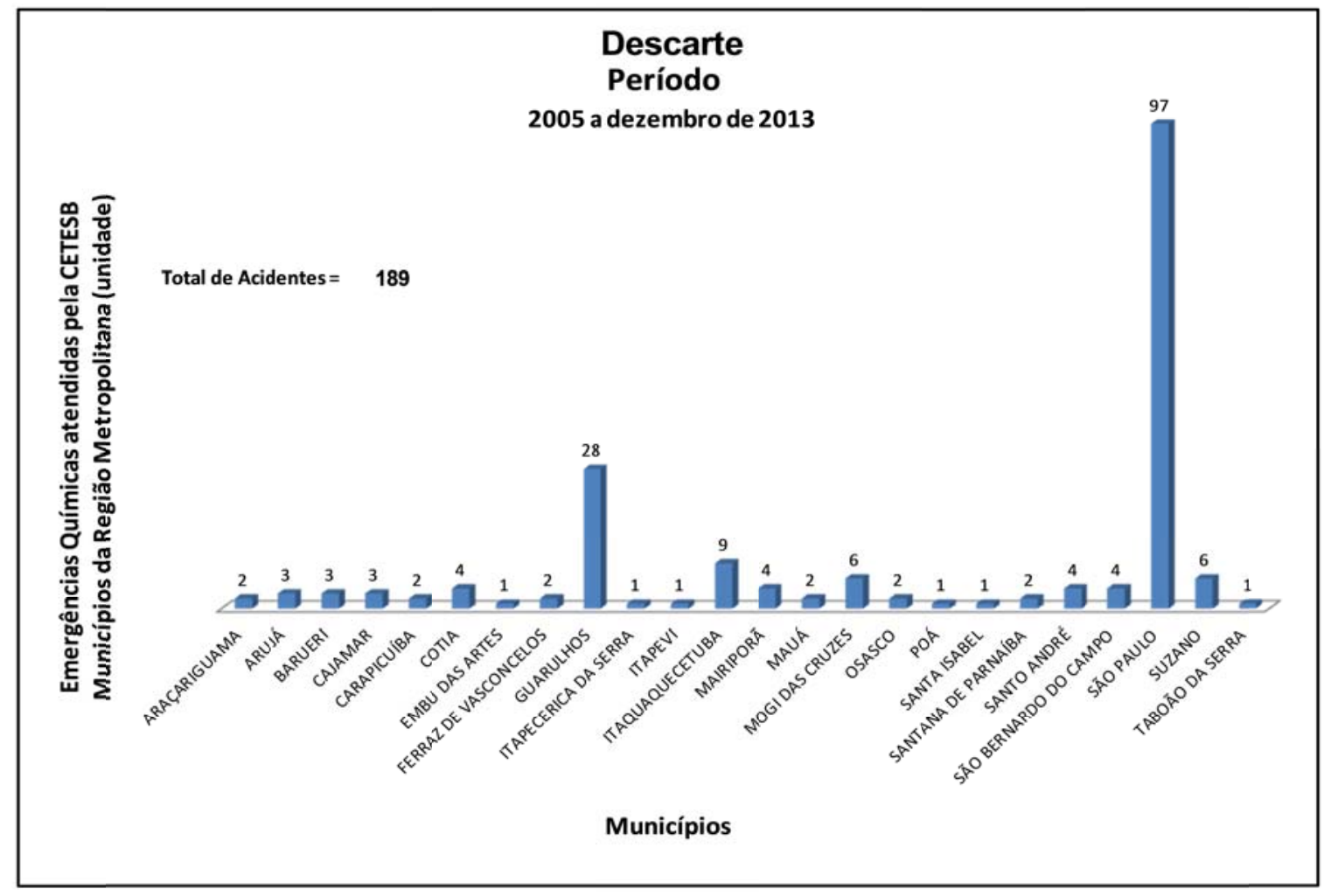

FIGURA 20 - Distribuição das emergências químicas atendidas pela CETESB por municípios da RMSP envolvendo descartes de resíduos químicos. Fonte: (CETESB - COMPANHIA AMBIENTAL DO ESTADO DE SÃO PAULO 2013a, adaptado do SIEQ)

Os resultados demonstram que em 24 dos 39 municípios da RMSP foram atendidas pela CETESB - Companhia Ambiental do Estado de São Paulo emergências químicas envolvendo descarte de resíduos químicos. A maior incidência dessas emergências ocorreu nos municípios de São Paulo com 97 registros, seguida por Guarulhos, com 28 ocorrências; Itaquaquecetuba com 
9ocorrências, Mogi das Cruzes e Suzano com 6 registros cada, São Bernardo, Santo André, Mairiporã e Cotia com 4 registros cada.

\subsection{Diagnóstico ambiental quanto à distribuição espacial dos descartes de resíduos químicos no estado de São Paulo com detalhamento de recursos hídricos}

A FIG. 21 apresenta o mapa do Estado de São Paulo com destaque para os locais onde foram registrados os descartes de resíduos químicos sobrepostos ao detalhamento de recursos hídricos.

Segundo dados do SIEQ da CETESB - Companhia Ambiental do Estado de São Paulo no período de 2005 a 2013 foram 189 REQs na RMSP, sendo que em 24 casos ficou constatada a contaminação de algum corpo d'água diretamente ou porque o sistema de drenagem de águas pluviais foi o meio de contaminação de nascentes, córregos, rios (Pinheiros, Tietê e Tamanduateí) e represas (Billings e Guarapiranga).

Observando a distribuição pontual no mapa da FIG 21 é possível visualizar o elevado número de descarte de resíduos químicos na RMSP (189 casos) com destaque a Unidade de Gerenciamento de Recursos Hídricos do Alto Tietê, UGRHI 6 - Alto Tietê. 
Figura 21 - Descarte de Resíduos Químicos no Estado de São Paulo com Detalhamento de Recursos Hídricos Período 2005 - 2013

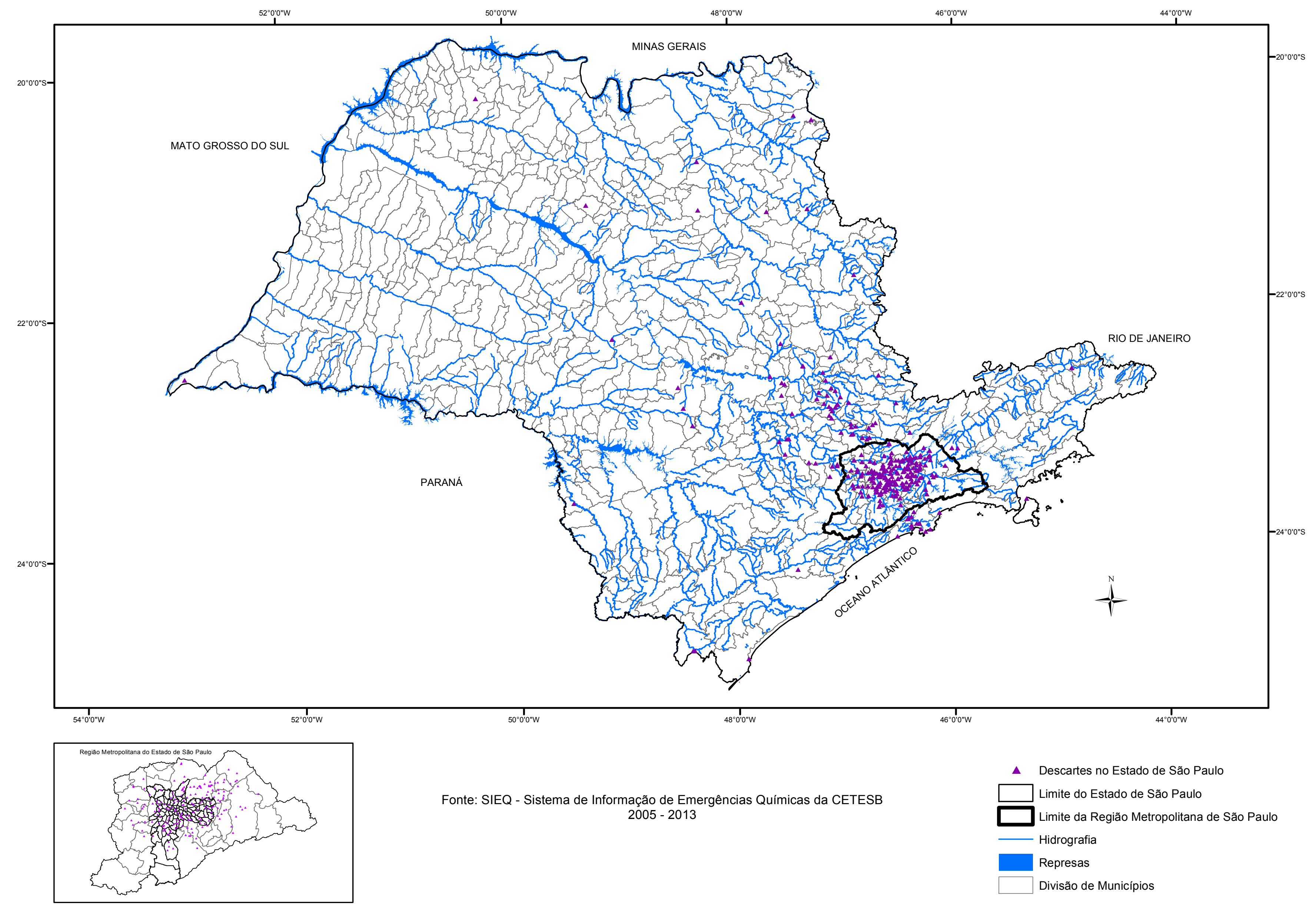


No extremo sul, o Distrito de Grajaú, pertencente à Subprefeitura de Capela do Socorro, possui como limites os distritos de Pedreira, Cidade Dutra, Parelheiros e o município de São Bernardo do Campo às margens da Represa Billings. É o terceiro e mais populoso distrito da cidade. Uma das vulnerabilidades ambientais do distrito de Grajaú é por está inserido em área de proteção aos mananciais, responsável pelo abastecimento de $30 \%$ da população da RMSP (SÃO PAULO (Cidade), 2014).

Na FIG. 22 encontram-se representados os 4 (quatro) casos de descartes de resíduos no Distrito de Grajaú. 
Figura 22 - Distribuição das ocorrências de descarte de resíduos químicos no Distrito de Grajaú, com destaque para as Áreas de Proteção e Recuperação de Mananciais

Período 2005 - 2013
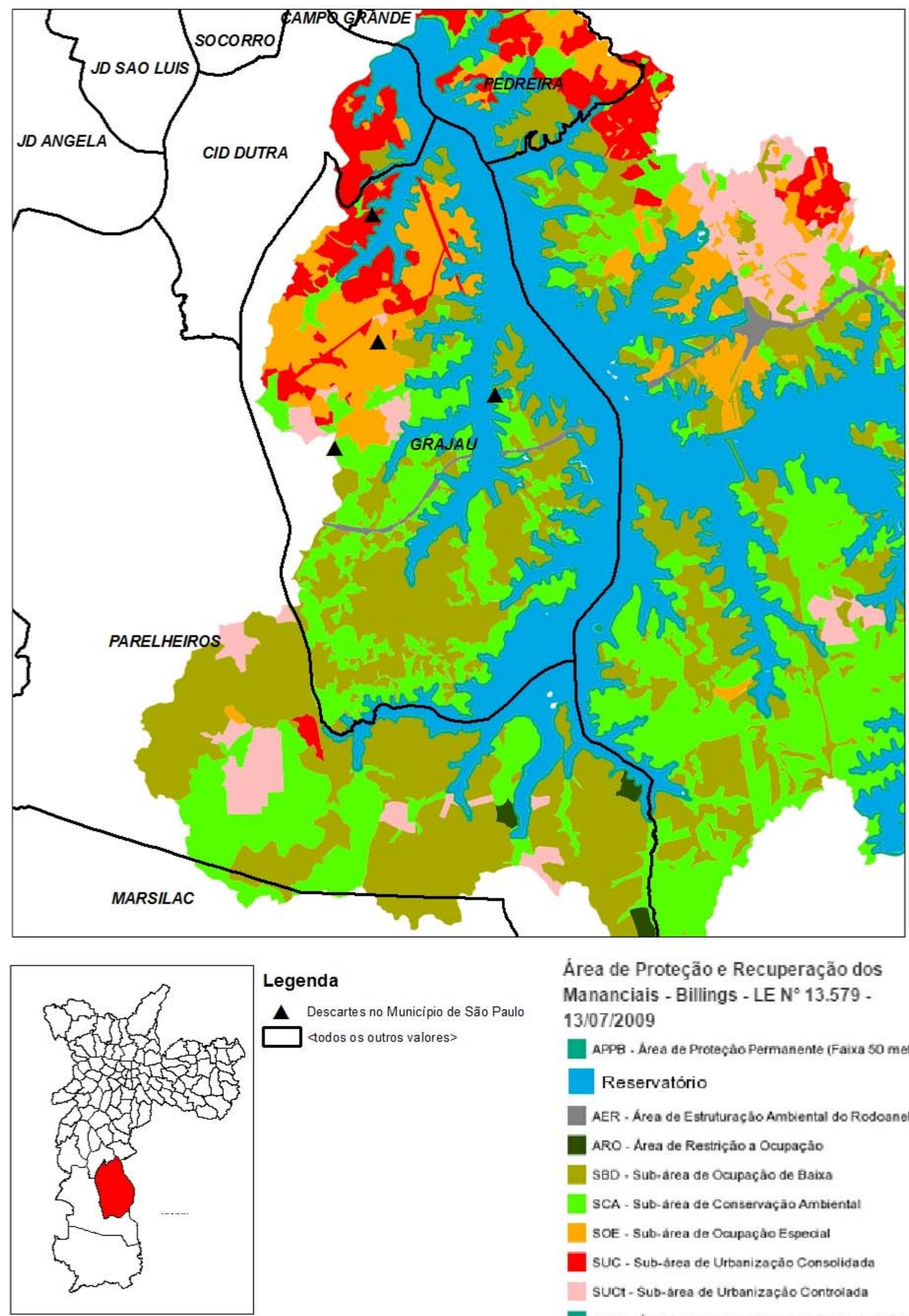

Área de Proteção e Recuperação dos Mananciais - Billings - LE N ${ }^{\circ} 13.579$ 13/07/2009

APPB - Afea de Proteçào Permanente (Faixa 50 metros) Reservatório

AER - Area de Estruturaçáo Ambiental do Rodoanel ARO - Area de Restrição a Ocupação

SBD - Sub-area de Ocupaçăo de Baixa

SCA - Sub-årea de Conservação Ambiental

SOE - Sub-arrea de Ocupaçào Especial

SUC - Sub-ârea de Urbanização Consolidada Suct - Sub-area de Urbanizaçâo Controlada 
É também característica do distrito de Grajaú, a expansão desenfreada dos loteamentos clandestinos e de favelas, localizadas em grande parte ao longo dos córregos contribuintes das represas (SÃO PAULO (Cidade), 2014).

A prática ilícita daqueles que descartam resíduos químicos ocorre preferencialmente no período noturno e em áreas periféricas dos municípios e em algumas situações em margens de córregos, rios e represas tornando-se uma séria ameaça à qualidade da água.

MICKLIN (1999) inclui a qualidade da água e a degradação dos ambientes urbanos entre os maiores desafios para a América Latina.

As situações em que resíduos químicos são descartados nas proximidades de um corpo d'água desafiam aqueles que participam do atendimento emergencial na mobilização de recursos humanos e materiais para promover sua remoção no menor tempo possível.

Dependendo do uso a que se destina o corpo d'água afetado há que se adotar providências imediatas como informar as empresas que operam diretamente os serviços de tratamento e distribuição de água, ou no caso do uso de água para fins recreativos, informar as autoridades municipais sobre a proibição ou limitação dos usos.

É indispensável comunicar a Vigilância Sanitária do município, caso seja constatada a contaminação de corpos d'água. A avaliação de saúde pública é fundamental nesses casos, a fim de se determinar até que ponto as pessoas foram, estão sendo ou podem ser expostas a substâncias perigosas associadas a um descarte de resíduos químicos.

\subsection{Diagnóstico ambiental quanto à distribuição espacial dos descartes de resíduos químicos no estado de São Paulo com detalhamento do sistema viário}

A FIG. 23 apresenta o mapa do Estado de São Paulo com o detalhamento do sistema viário e a localização dos pontos onde ocorreram os registros de emergências químicas. 
Figura 23 - Descarte de Resíduos Químicos no Estado de São Paulo com Detalhamento do Sistem a Viário Período 2005 - 2013
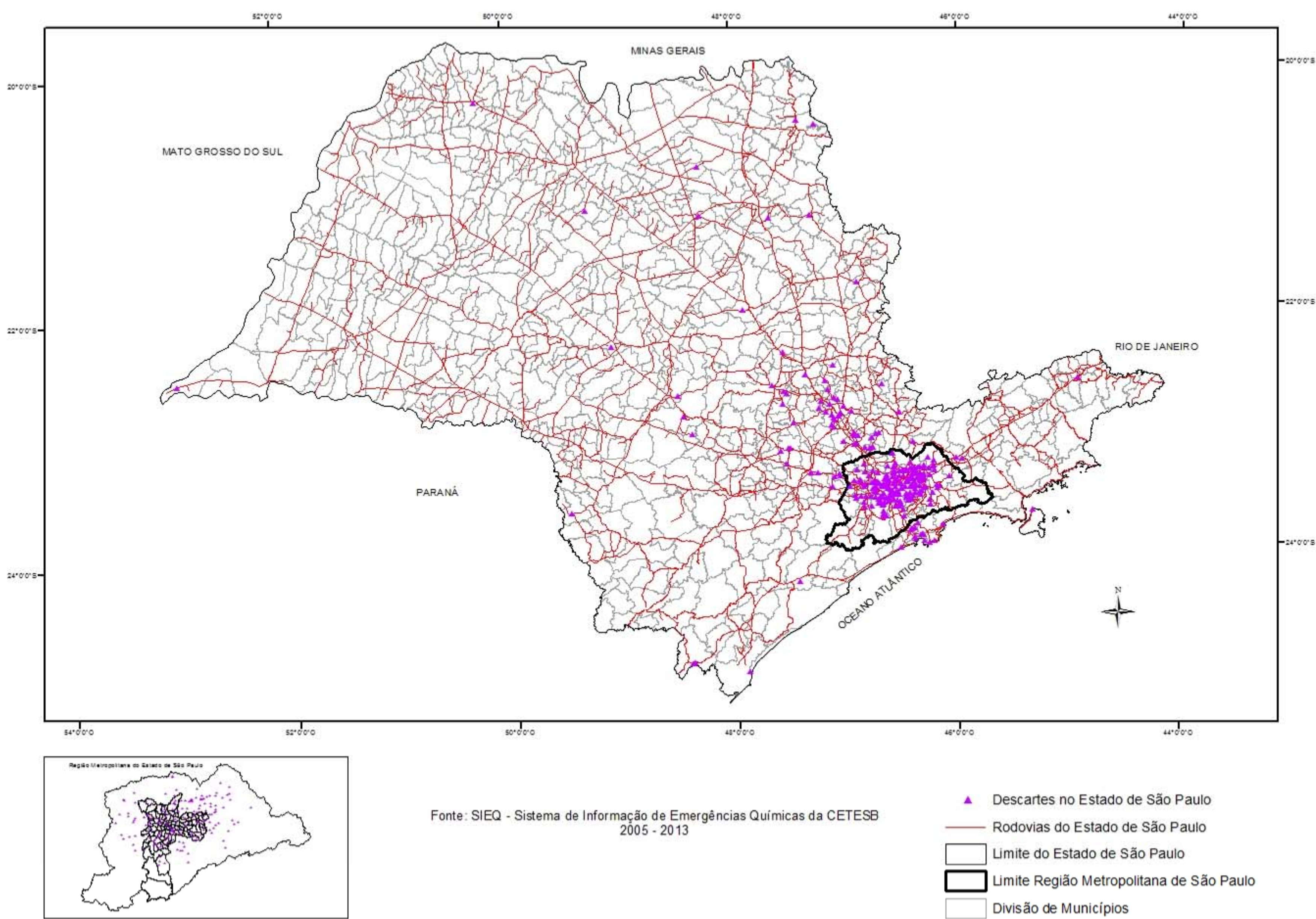

Fonte: SIEQ - Sistema de Informação de Emergências Químicas da CETESB $2005 \cdot 2013$
- Descartes no Estado de São Paulo - Rodovias do Estado de São Paulo Limite do Estado de São Paulo

Limite Região Metropolitana de São Paulo Divisão de Municipios 
A malha rodoviária pavimentada do estado de São Paulo ultrapassa 37.000 km, dos quais $1.055 \mathrm{~km}$ são de rodovias federais, cerca de $14.000 \mathrm{~km}$ de rodovias municipais e os restantes 22.000 km são de rodovias estaduais (81\%) (SÃO PAULO (Estado), 2014b).

Pela importância da economia do Estado de São Paulo no desenvolvimento econômico e social do país, esse complexo sistema viário do estado reflete o perfil de sua atividade econômica fortemente concentrada na movimentação de cargas, em geral como produtos e insumos para a atividade industrial (SÃO PAULO (Estado), 2014b).

A elevada concentração de pólos industriais no Estado de São Paulo, bem como a centralização da RMSP como região de passagem e interligação entre as diferentes malhas rodoviárias e pólos industriais, acarretam na intensa movimentação de produtos químicos (SÃO PAULO (Estado), 2014b).

É nesse contexto que se apresentam os desafios socioambientais em consequência do transporte rodoviário já bem conhecidos, uma vez que no Brasil e no âmbito do MERCOSUL (Mercado Comum do Sul), o modal rodoviário se sobressai a todos os demais, como o transporte hidroviário, ferroviário e por dutos.

Nesse sentido, a ação de descarte de resíduos químicos é invariavelmente também realizada por meio do transporte rodoviário. A FIG. 23 apresenta os principais cruzamentos rodoviários no Estado de São Paulo e os pontos onde foram registrados descartes de resíduos químicos e que em alguns casos cortam corpos d’água que abastecem importantes mananciais.

A intencionalidade dos descartes de resíduos químicos obtidos por meio do modal rodoviário difere substancialmente da casualidade dos acidentes rodoviários de produtos perigosos.

Enquanto uma emergência química causada pelo transporte rodoviário mobiliza rápido apoio dos responsáveis, seja do transportador, do expedidor ou do destinatário para obtenção de recursos necessários para minimização aos 
eventuais danos ao meio ambiente, em atendimentos que envolvam o descarte de resíduos químicos ao longo dos chamados corredores de transporte, como rodovia, rua ou avenida, todas as dificuldades estarão presentes em razão da não identificação do causador desse ato ilícito, sobretudo porque assim agiu com a intenção de ocultar provas.

As rodovias que lideraram as estatísticas de descartes de resíduos químicos no período de 2005 a 2013 foram: Anchieta (3), Regis Bittencourt (3), Dutra (3), Castello Branco (3), Ayrton Senna (2), D. Pedro (2), Fernão Dias (1), Santos Dummont (1) e Índio Tibiriçá (1).

\subsection{Distribuição espacial dos descartes de resíduos químicos na Região Metropolitana de São Paulo}

A FIG. 24 apresenta o mapa dos descartes de resíduos químicos na RMSP.

O elevado número de descartes de resíduos na RMSP é dentre tantos fatores, como a importância econômica da Região para o Brasil e o resultado do espraiamento urbano ${ }^{3}$, que a torna atraente para a prática ilícita do descarte de entulhos, pneus inservíveis, materiais diversos e como tema desse trabalho o descarte de resíduos químicos.

Do total de 287 descartes de resíduos ocorridos no estado de São Paulo no período de 2005 a 2013, 189 (66\%) ocorreram na RMSP.

A interconectividade urbana verificada na RMSP e o fluxo intenso de veículos são fatores que estimulam a prática ilegal do descarte de resíduos químicos. É comum que os que cometem esse crime ambiental tenham como origem e destino municípios distintos, principalmente da RMSP.

\footnotetext{
${ }^{3}$ Espraiamento urbano. O espraiamento urbano é o crescimento urbano desconcentrado, não denso e que deixa vazios urbanos dentro da mancha urbana. O fenômeno pode ser indesejável caso essas metrópoles não estejam crescendo naturalmente e sim crescendo mais do que deveriam. Extraído do Texto Para Discussão $n^{0} 1481$ Evolução Urbana e Espraiamento na Região Metropolitana de São Paulo. IPEA (Instituto de Pesquisa Econômica Aplicada).
} 
Figura 24 - Descartes de Resíduos Quím icos na Região Metropolitana de São Paulo Período 2005 - 2013
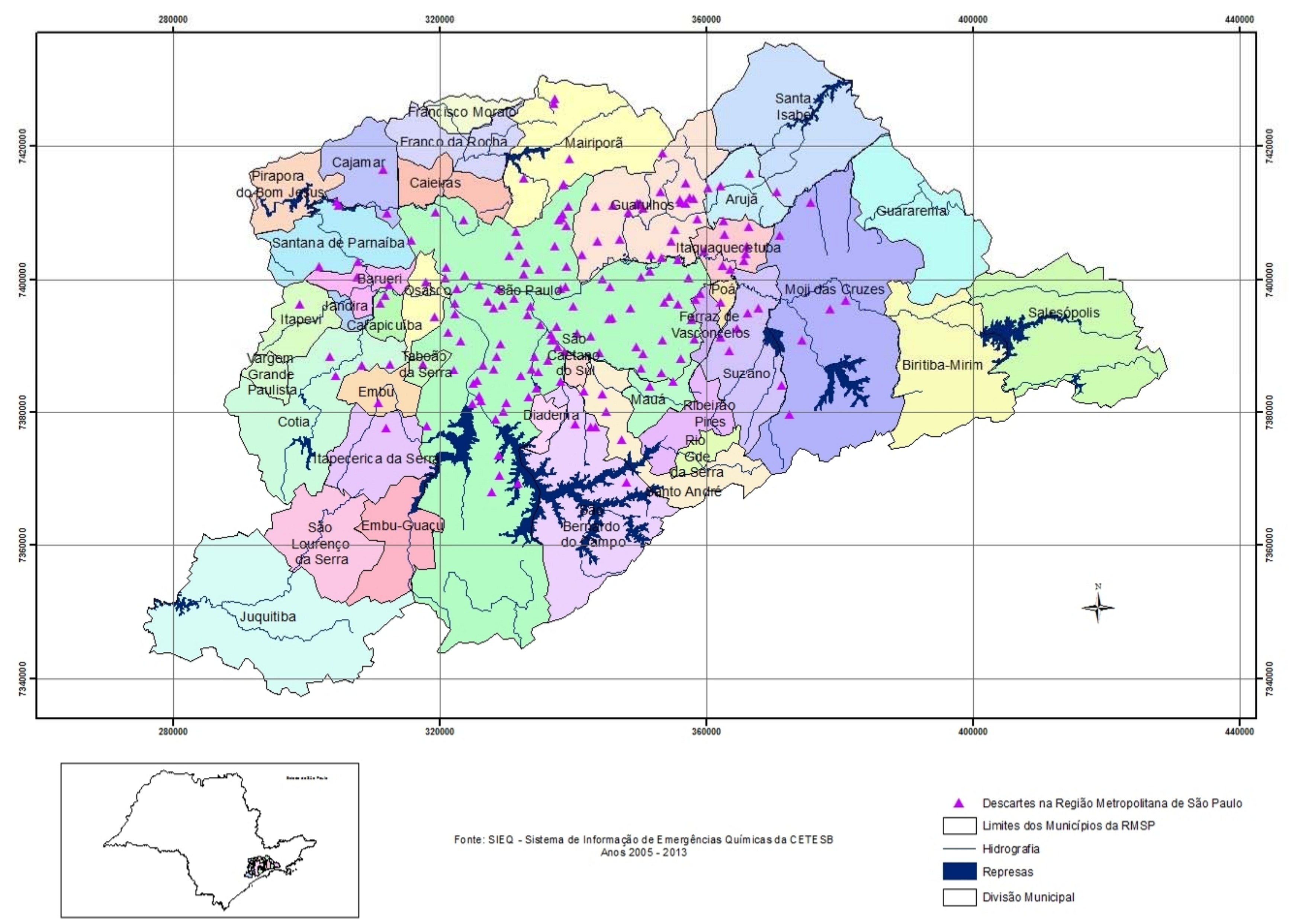

Fonte: SIEQ - Sistema de Informa çăo de E mergências Quimicas da CETE SB Anos $2005-2013$ 
Outro aspecto desfavorável do espraiamento urbano são os espaços vazios deixados na RMSP, mais pronunciados nas bordas dos municípios, como pode ser observado, por exemplo, na distribuição dos pontos de descarte no mapa da FIG. 24, o que ocorre entre os municípios de Barueri/Santana de Parnaíba e Cajamar, São Paulo e Guarulhos, São Paulo e Osasco, São Paulo e Ferraz de Vasconcelos, São Paulo e Mauá, Santo André e São Bernardo do Campo e Santo André e São Paulo.

Nesse sentido, a cidade de São Paulo registrou no período desse trabalho (2005 - 2013) o maior número de casos de descarte de resíduos químicos (97), pois corrobora para esse fenômeno o fato de ser um ponto de entroncamento e articulação regional entre os demais municípios da Região.

Importante também ressaltar os registros de descartes de resíduos químicos em área vizinha aos dois grandes reservatórios de água da porção sul da RMSP (represas Billings e Guarapiranga).

\subsection{Diagnóstico socioambiental quanto à distribuição espacial dos} descartes de resíduos químicos nos distritos da cidade de São Paulo

A cidade de São Paulo com 11.253 .503 hab. e área de $1.521,11 \mathrm{~km}^{2}$ (INSTITUTO BRASILEIRO DE GEOGRAFIA E ESTATÍSTICA, 2014), constitui o núcleo central da mais importante região metropolitana do Brasil e sua área de influência tem um alcance que ultrapassa o âmbito regional e mesmo o nacional, colocando-a como um dos pólos de destaque entre as denominadas cidades globais (SÃO PAULO (Cidade), 2004a).

Seu desenvolvimento urbano, relativamente recente, pois data de pouco mais de cem anos, esteve estreitamente relacionado à ocupação do território paulista desencadeada pela expansão das atividades agroexportadoras, especialmente o cultivo do café e, ao longo do século $X X$, ao processo de industrialização brasileiro. Este último teve seu principal foco em São Paulo e em alguns de seus municípios vizinhos (região do $A B C$ ), impulsionando o crescimento da cidade e determinando a formação de uma área metropolitana 
que comanda ampla e diversificada rede urbana hierarquicamente estruturada a partir da capital (SÃO PAULO (Cidade), 2004a).

Com um PIB de $\mathrm{R} \$$ 477.005.597.000,00 em 2011 (INSTITUTO BRASILEIRO DE GEOGRAFIA E ESTATíSTICA, 2011), São Paulo destaca-se como o principal pólo econômico entre os municípios brasileiros e constitui o núcleo dinâmico da maior região metropolitana do país. É o quarto PIB entre as Unidades Federativas do Brasil após SP, RJ e MG. Sua divisão administrativa contempla 32 subprefeituras e 96 distritos (SÃO PAULO (Cidade), 2004b).

A FIG. 25 ilustra o mapeamento por meio do Sistema de Informações Geográficas (GIS) dos 97 descartes de resíduos químicos na cidade de São Paulo distribuídos geograficamente em seus 96 distritos, estabelecidos pela Lei municipal $n^{\circ} 11.220$ de 20 de maio de 1992 (SÃO PAULO (cidade), 1992). A divisão geográfica da área da cidade de São Paulo, instituída pela presente lei, passa a ser referência obrigatória para a administração pública municipal direta e indireta. 
Figura 25 - Descartes de Resíduos Químicos nos distritos da Cidade de São Paulo Período 2005 - 2013

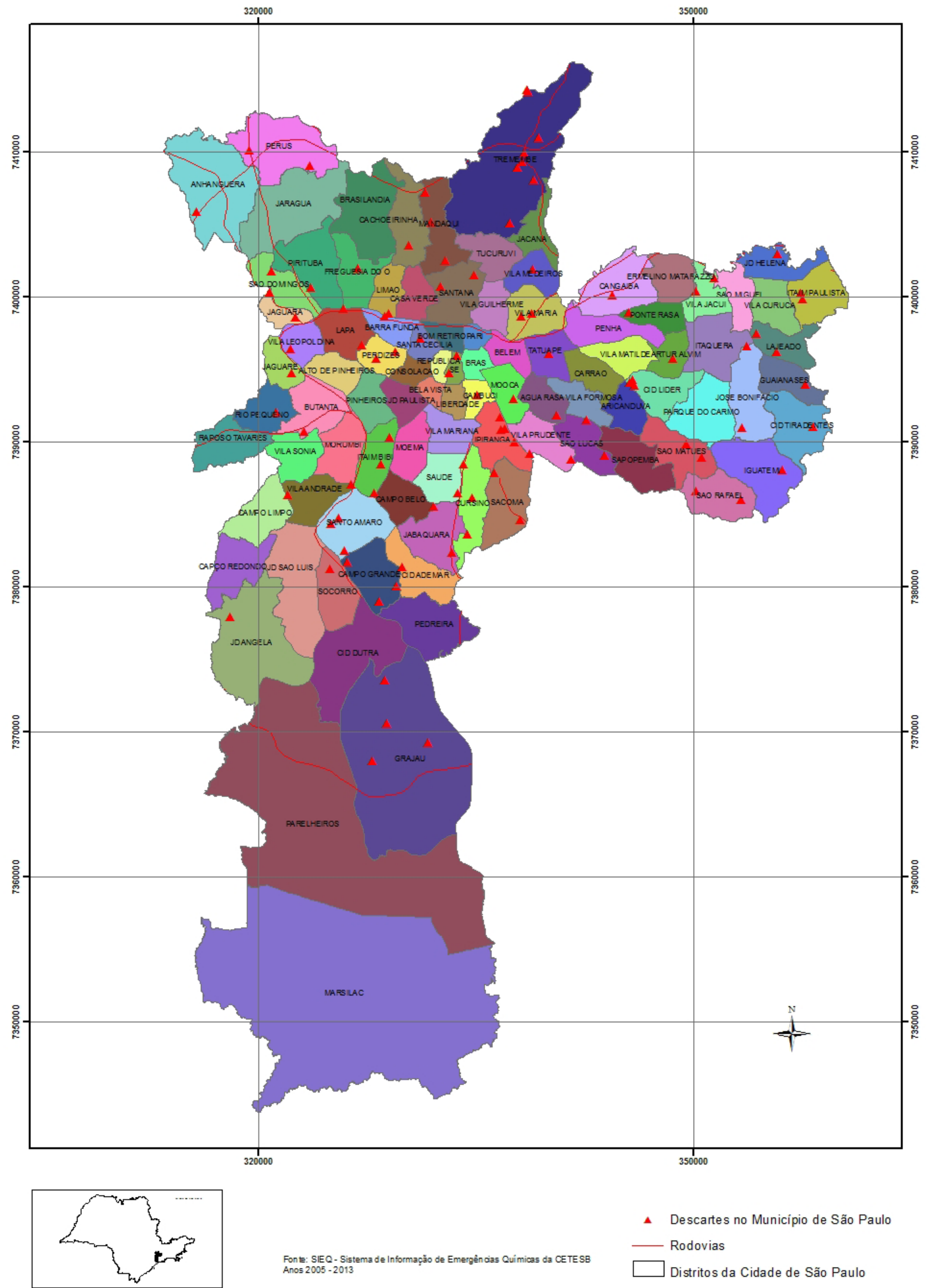


A FIG. 26 apresenta as informações referentes ao número de ocorrências por distrito, facilitando a visualização do mapa apresentado na FIG. 25.

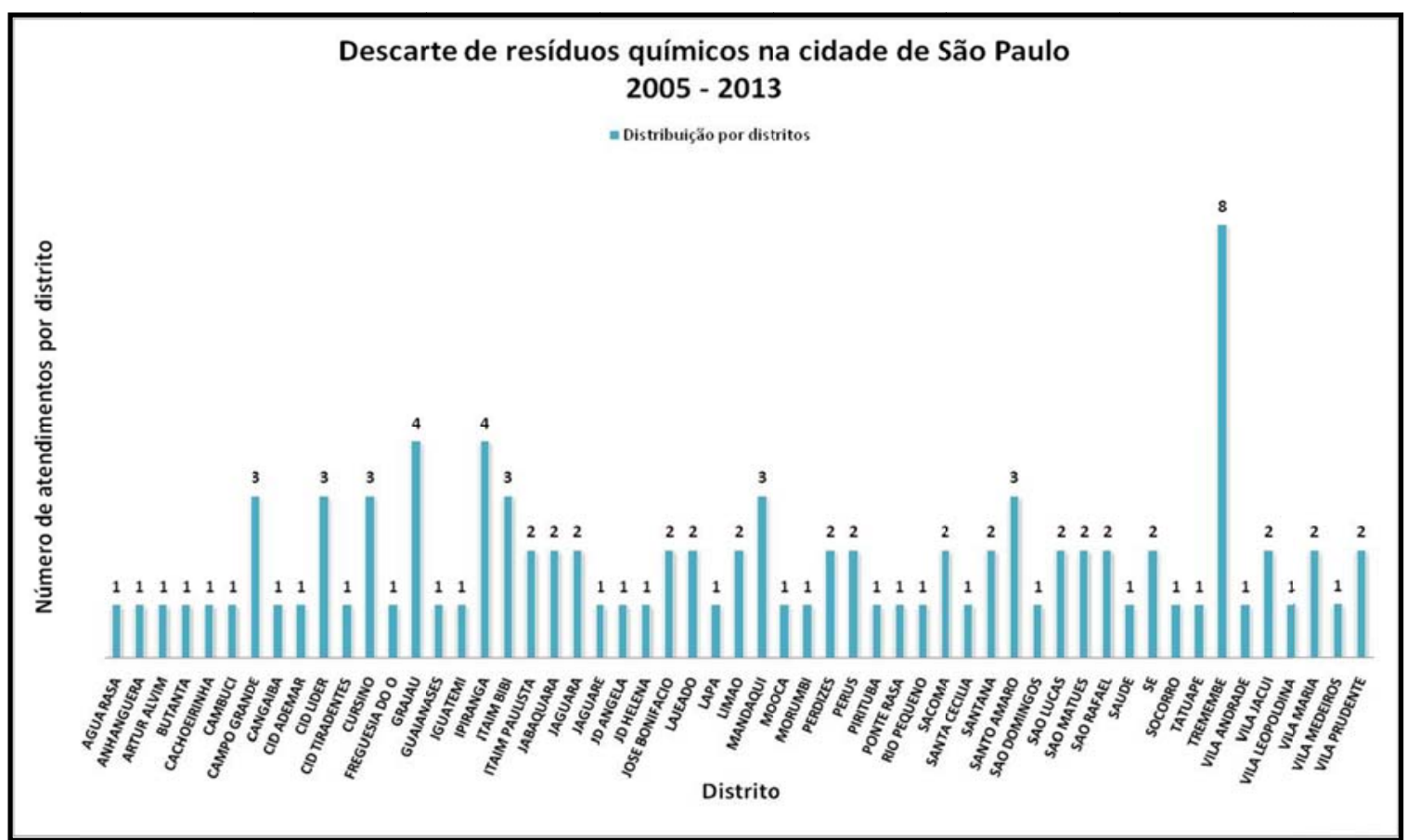

FIGURA 26 - Distribuição dos registros de descarte de resíduos químicos por distritos na cidade de São Paulo.

Fonte:(CETESB - Companhia Ambiental do Estado de São Paulo 2013a, adaptado do SIEQ)

A FIG 27 apresenta o mapa da cidade de São Paulo com os descartes de resíduos químicos por distritos e a estimativa das quantidades totais vazadas. A quantidade da estimativa de vazamento de resíduos foi obtida a partir da consulta dessa pesquisa aos REQs atendidos pela CETESB - Companhia Ambiental do Estado de São Paulo. 
Figura 27 - Distribuição das ocorrências de descarte de resíduos químicos nos distritos da cidade de São Paulo

Estimativa de vazamento de resíduos

Período 2005 - 2013
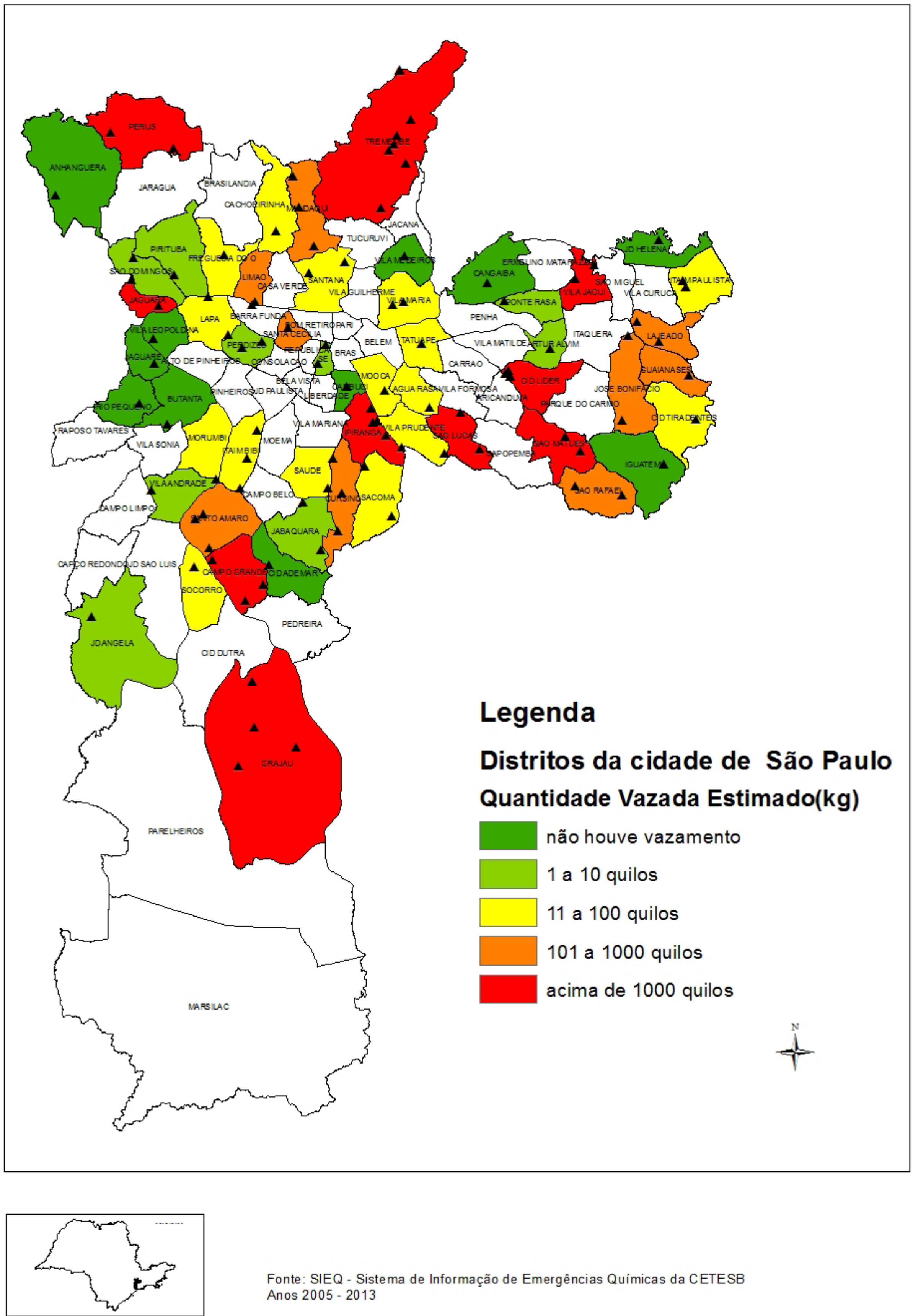
Avaliando as informações e os resultados apresentados a partir das FIG. 25 e 27 foi possível realizar e propor uma análise das condições socioambientais na cidade de São Paulo com relação aos descartes de resíduos químicos associado às quantidades vazadas.

Uma leitura inicial da FIG. 25 nos leva a crer que há uma desconcentração da prática dos descartes de resíduos químicos se considerarmos apenas os seus registros localizados espacialmente no mapa.

Entretanto, quando analisarmos a correlação entre o risco ambiental e a condição social, características sócio-demográficas e econômicas da população, associado às quantidades de resíduos descartados nas regiões centrais e periféricas (FIG. 27), concluiremos que há diferenças marcantes na capacidade da população e o meio ambiente para se auto-proteger.

Assim como as demais metrópoles mundiais, São Paulo apresenta em sua parte mais central, uma extensa área ocupada por residências horizontais e verticais, na qual os indicadores socioeconômicos reforçam a presença de um padrão de vida associada às camadas médias e altas da população nesses distritos (SÃO PAULO (Cidade), 2004b).

Os demais distritos, na medida em que se distanciam dessa grande área, vão progressivamente apresentando queda no padrão socioeconômico da população residente, atingindo os piores índices nos distritos limítrofes, que acabam por formar extensas áreas de pobreza no território municipal (SÃO PAULO (Cidade), 2004b).

Nesses distritos limítrofes muitas vezes regiões notadamente onde se observa uma maior exclusão social é também onde se constata difícil acesso aos serviços públicos e à maior vulnerabilidade ambiental.

Entre as deficiências de serviços públicos verificadas nessas regiões que favorecem a prática do descarte de resíduos químicos nas áreas periféricas da cidade, destacam-se a deterioração da iluminação pública e a falta de 
segurança, além de acesso limitado do serviço de saneamento básico, incluindo tratamento de esgoto, coleta e disposição final de lixo.

O quadro abaixo resume o conjunto de fatores que são decisivos para a escolha do local para a prática do descarte de resíduos químicos, segundo a experiência do autor nos 23 anos de atuação no Setor de Atendimento a Emergências da CETESB.

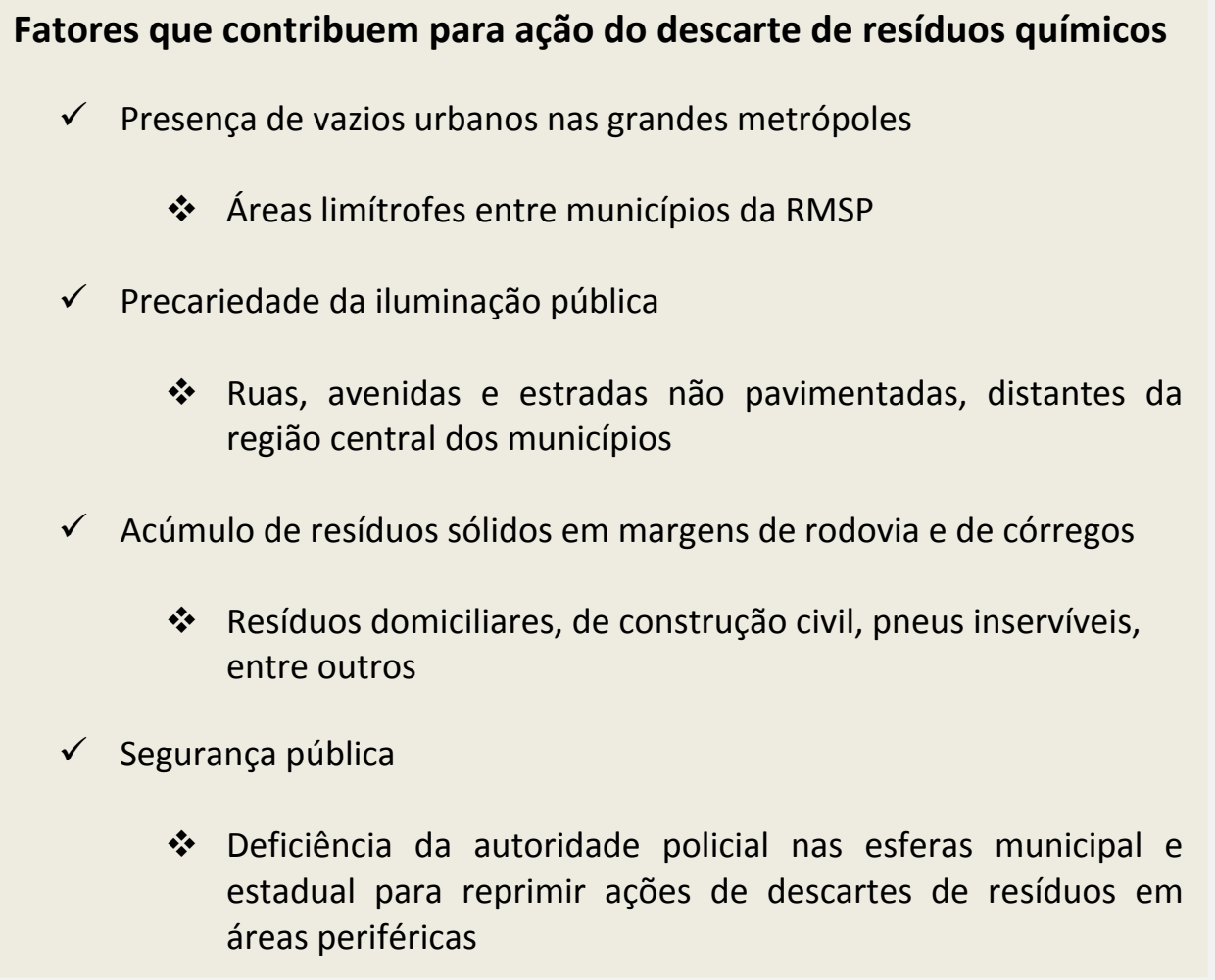

Os fatores aqui elencados são também citados no Guia de Prevenção de Descartes de Resíduos da Agência de Proteção Ambiental dos Estados Unidos (ENVIRONMENTAL PROTECTION AGENCY, 1998).

As populações mais vulneráveis à ação do descarte de resíduos químicos são aquelas que residem em áreas de baixo poder econômico, normalmente em favelas, cortiços e moradias improvisadas e possuem baixo nível de percepção de risco quando se deparam, por exemplo, com embalagens contendo resíduos químicos.

São nos distritos mais periféricos da metrópole que residem os que ocupam a parte inferior da pirâmide social. 
Em determinados distritos das áreas mais periféricas da cidade as equipes de atendimento a emergência são advertidas pela própria população local sobre a questão da segurança, pois muitas vezes, tratam-se de áreas dominadas pelo tráfico de drogas. Isso de fato interfere na permanência dessas equipes de emergência para desempenharem o trabalho de avaliação ambiental.

O Índice Paulista de Vulnerabilidade Social (IPVS), calculado pela Fundação Sistema Estadual de Análises de Dados (SEADE), é uma das formas de medir as condições de vida da população paulistana. O IPVS informa ao gestor público e à sociedade uma visão mais detalhada das condições de vida do seu município, com a identificação e a localização espacial das áreas que abrigam os segmentos populacionais mais vulneráveis à pobreza (FUNDAÇÃO SISTEMA ESTADUAL DE ANÁLISES DE DADOS, 2014).

Este índice possui alta desagregação. Sua composição advém da combinação entre a condição socioeconômica e a demográfica, definidas a partir de 8 (oito) variáveis (refletindo renda, escolaridade e ciclo de vida familiar).

Avaliando a distribuição das informações na FIG. 27 observa-se como característica marcante de ocorrências em distritos mais periféricos a predominância da maior quantidade de resíduos químicos descartados. Em alguns casos o descarte pode ter sido ocasionado por furto de carga.

Esse fato pode ser observado na FIG. 27 quando distritos periféricos da Zona Norte como Perus, Tremembé e Jaguara registraram quantidades de resíduos descartados acima de $1000 \mathrm{~kg}$.

O mesmo ocorreu em distritos periféricos da Zona Leste como Vila Jacuí, São Lucas, São Mateus e Cidade Líder apresentaram quantidades de resíduos descartados acima de $1000 \mathrm{~kg}$.

Também em distritos periféricos da Zona Leste foram registrados volumes significativos de resíduos descartados (de 11 a 1000 kg) são eles: Lajeado, Guaianazes, São Rafael, Cidade Tiradentes, Itaim Paulista e Vila Prudente. 
No extremo sul da Capital surgem os Distritos de Campo Grande e Grajaú com quantidades de resíduos descartados acima de $1000 \mathrm{~kg}$.

É exatamente nessas regiões mais carentes, onde se concentram as maiores dificuldades para obterem-se recursos materiais para sua remoção e armazenamento temporário.

O retardo na mobilização de recursos nesses casos pode significar no aproveitamento por parte da população das embalagens que contém os resíduos e, por conseguinte, expô-los aos mais diversos riscos de contaminação.

Da mesma forma a permanência dos resíduos no ambiente por mais tempo, algumas vezes dispostos diretamente no solo, pode implicar em maior risco de contaminação do solo e da água subterrânea.

Já nas Regiões Central e Oeste predominam os casos de descarte de resíduos que ocorreram sem vazamento ou em quantidades menores (de 1 a $10 \mathrm{~kg}$ ), exceção feita a uma ocorrência no distrito de Santa Cecília $(500 \mathrm{~kg})$ e no distrito da Lapa (50 kg).

A seguir são apresentados, por meio das TAB.4,5,6,7 e 8 de modo detalhado os registros de descartes de resíduos químicos por distritos nas Regiões Norte, Sul, Leste, Oeste e Central. Os dados compilados trazem informações sobre a ocorrência de vazamento, os danos causados e meios afetados, liberação de gás /vapor, a identificação dos resíduos e se ocorreu em via pública. 
TABELA 4 - Registros de descartes de resíduos químicos por distritos na Zona Norte de São Paulo

\begin{tabular}{|c|c|c|c|c|c|c|c|c|c|c|c|}
\hline \multirow{2}{*}{$\begin{array}{l}\text { Distritos da Zona } \\
\text { Norte de São } \\
\text { Paulo }\end{array}$} & \multirow[t]{2}{*}{ REQ/Ano } & \multicolumn{3}{|c|}{ Identificação/Natureza do Resíduo Químico } & \multicolumn{2}{|c|}{$\begin{array}{c}\text { Houve } \\
\text { vazamento? }\end{array}$} & \multicolumn{5}{|c|}{ Danos/meios afetados } \\
\hline & & $\begin{array}{l}\text { Produtos } \\
\text { identificados }\end{array}$ & $\begin{array}{c}\text { Não } \\
\text { Identificado }\end{array}$ & $\begin{array}{l}\text { Liberação de } \\
\text { Gás/Vapor }\end{array}$ & SIM & NÃO & $\mathrm{Ar}$ & Solo & Água & $\begin{array}{c}\text { Via } \\
\text { Pública }\end{array}$ & $\begin{array}{c}\text { Rede de } \\
\text { esgoto/pluviais }\end{array}$ \\
\hline ANHANGUERA & $288 / 2009$ & & $\mathrm{x}$ & & & $\mathrm{x}$ & & & & $\mathrm{x}$ & \\
\hline $\begin{array}{l}\text { FREGUESIA DO } \\
\text { O }\end{array}$ & $051 / 2006$ & & $x$ & & & $\mathrm{x}$ & & & & $\mathrm{x}$ & \\
\hline \multirow[t]{2}{*}{ JAGUARA } & $359 / 2008$ & & $x$ & & & $x$ & & & & $\mathrm{x}$ & \\
\hline & $199 / 2013$ & & $\mathrm{x}$ & $\mathrm{x}$ & $\mathrm{x}$ & & $\mathrm{x}$ & & & $\mathrm{x}$ & \\
\hline LIMAO & $187 / 2010$ & & $\mathrm{x}$ & $x$ & $\mathrm{x}$ & & $x$ & $x$ & & & \\
\hline \multirow[t]{3}{*}{ MANDAQUI } & $400 / 2009$ & Resina de poliéster & & $x$ & $x$ & & $x$ & $x$ & & $x$ & \\
\hline & $393 / 2010$ & & $x$ & & $x$ & & & $x$ & & $x$ & \\
\hline & $160 / 2011$ & & $\mathrm{x}$ & & $\mathrm{x}$ & & & $\mathrm{x}$ & & & \\
\hline \multirow[t]{2}{*}{ PERUS } & $045 / 2006$ & Carbonato de bário & & & $\mathrm{x}$ & & & $\mathrm{x}$ & & $\mathrm{x}$ & \\
\hline & 076/2009 & & $x$ & $x$ & $x$ & & $\mathrm{x}$ & $x$ & & $x$ & $x$ \\
\hline SANTANA & $138 / 2013$ & & $x$ & $x$ & $x$ & & $x$ & & & & $x$ \\
\hline SAODOMINGOS & $078 / 2007$ & & $x$ & $x$ & $x$ & & $x$ & $x$ & & $x$ & \\
\hline \multirow[t]{8}{*}{ TREMEMBE } & $317 / 2007$ & & $\mathrm{x}$ & & & $\mathrm{x}$ & & & & $\mathrm{x}$ & \\
\hline & $100 / 2008$ & Chorume & & $x$ & $x$ & & $x$ & $x$ & & $x$ & \\
\hline & $123 / 2008$ & & $x$ & $x$ & $x$ & & $x$ & $x$ & & $x$ & \\
\hline & $276 / 2008$ & Formol & & & & $\mathrm{x}$ & & & & $\mathrm{x}$ & \\
\hline & $017 / 2009$ & & $x$ & & $x$ & & & $x$ & & $x$ & \\
\hline & $233 / 2010$ & & $x$ & $\mathrm{x}$ & $\mathrm{x}$ & & $\mathrm{x}$ & $\mathrm{x}$ & & $\mathrm{x}$ & \\
\hline & $443 / 2010$ & Thinner & & $x$ & $x$ & & $x$ & & & & $x$ \\
\hline & $049 / 2013$ & & $x$ & & & $x$ & & & & $x$ & \\
\hline \multirow[t]{2}{*}{ VILA MARIA } & $168 / 2012$ & & $x$ & $x$ & $\mathrm{x}$ & & $x$ & & $x$ & & $\mathrm{x}$ \\
\hline & $371 / 2013$ & & $x$ & & & $x$ & & & & & \\
\hline VILA MEDEIROS & $116 / 2011$ & Hidroquinona & & & & $\mathrm{x}$ & & & & $\mathrm{x}$ & \\
\hline TOTAL & 27 & 7 & 20 & 13 & 18 & 9 & 13 & 13 & 1 & 21 & 4 \\
\hline
\end{tabular}


TABELA 5 - Registros de descartes de resíduos químicos por distritos na Zona Leste de São Paulo

\begin{tabular}{|c|c|c|c|c|c|c|c|c|c|c|c|}
\hline \multirow{2}{*}{$\begin{array}{l}\text { Distritos da } \\
\text { Zona Leste de } \\
\text { São Paulo }\end{array}$} & \multirow[t]{2}{*}{ REQ/Ano } & \multicolumn{3}{|c|}{ Identificação/Natureza do Resíduo Químico } & \multicolumn{2}{|c|}{ Houve vazamento? } & \multicolumn{5}{|c|}{ Danos/meios afetados } \\
\hline & & $\begin{array}{l}\text { Produtos } \\
\text { identificados }\end{array}$ & $\begin{array}{c}\text { Não } \\
\text { Identificado }\end{array}$ & $\begin{array}{l}\text { Liberação de } \\
\text { Gás/Vapor }\end{array}$ & SIM & NÃO & $\operatorname{Ar}$ & Solo & Água & Via Pública & $\begin{array}{c}\text { Rede de } \\
\text { esgoto/pluviais }\end{array}$ \\
\hline AGUA RASA & $278 / 2008$ & & $\mathrm{x}$ & $x$ & $x$ & & $x$ & & & & $\mathrm{x}$ \\
\hline $\begin{array}{l}\text { ARTUR } \\
\text { ALVIM }\end{array}$ & $148 / 2009$ & & $x$ & $x$ & $x$ & & $x$ & & & & $x$ \\
\hline CANGAIBA & $312 / 2005$ & Mercaptanas líquidas & & $\mathrm{x}$ & $\mathrm{x}$ & & $\mathrm{x}$ & & & & \\
\hline \multirow[t]{3}{*}{ CID LIDER } & $281 / 2009$ & & $\mathrm{x}$ & $\mathrm{x}$ & $\mathrm{x}$ & & $\mathrm{x}$ & $\mathrm{x}$ & & & \\
\hline & $219 / 2013$ & Resina de Poliéster & & $\mathrm{x}$ & $\mathrm{x}$ & & $\mathrm{x}$ & $\mathrm{x}$ & & & \\
\hline & $237 / 2013$ & & $x$ & $x$ & $x$ & & $x$ & $x$ & & & \\
\hline $\begin{array}{l}\text { CID } \\
\text { TIRADENTES }\end{array}$ & $248 / 2009$ & & $x$ & & $x$ & & & $x$ & & $x$ & \\
\hline GUAIANASES & $081 / 2012$ & Parafina & & & $\mathrm{x}$ & & & $\mathrm{x}$ & & & \\
\hline IGUATEMI & $148 / 2013$ & Resina de Poliéster & & & & $x$ & & & & & \\
\hline \multirow{2}{*}{$\begin{array}{l}\text { ITAIM } \\
\text { PAULISTA }\end{array}$} & $252 / 2009$ & & $x$ & & $x$ & & & & & $x$ & $x$ \\
\hline & $254 / 2009$ & & $x$ & & & $\mathrm{x}$ & & & & $x$ & \\
\hline JD HELENA & $087 / 2012$ & $\begin{array}{l}\text { Ác Oxálico, Glicerina, Ác } \\
\text { acético, Ácsulfônico }\end{array}$ & & & & $\mathrm{x}$ & & & & & \\
\hline \multirow{4}{*}{$\begin{array}{l}\text { JOSE } \\
\text { BONIFACIO } \\
\text { LAJEADO }\end{array}$} & $196 / 2007$ & & $x$ & & $x$ & & & $x$ & $x$ & & \\
\hline & $336 / 2008$ & & $\mathrm{x}$ & & & $\mathrm{x}$ & & & & & \\
\hline & $383 / 2008$ & & $\mathrm{x}$ & $\mathrm{x}$ & $\mathrm{x}$ & & $\mathrm{x}$ & & & & \\
\hline & $327 / 2013$ & Formol & & & & $\mathrm{x}$ & & & & $\mathrm{x}$ & \\
\hline MOOCA & $316 / 2011$ & & $x$ & & $x$ & & & & & & $x$ \\
\hline PONTE RASA & $043 / 2009$ & Percloroetileno & & $x$ & $x$ & & $x$ & & & & \\
\hline \multirow[t]{2}{*}{ SAO LUCAS } & $033 / 2005$ & $\begin{array}{l}\text { Óleo para motores Óleos } \\
\text { lubrificantes }\end{array}$ & & $x$ & $x$ & & $x$ & & & & $x$ \\
\hline & $053 / 2006$ & & $\mathrm{x}$ & & & $\mathrm{x}$ & & & & $\mathrm{x}$ & \\
\hline \multirow[t]{2}{*}{ SAO MATEUS } & $380 / 2008$ & & $x$ & & $x$ & & & $x$ & & $x$ & \\
\hline & $109 / 2011$ & & $\mathrm{x}$ & & & $\mathrm{x}$ & & & & $\mathrm{x}$ & \\
\hline \multirow[t]{2}{*}{ SAO RAFAEL } & $278 / 2005$ & & $\mathrm{x}$ & & & $\mathrm{x}$ & & & & & \\
\hline & $011 / 2012$ & Óxido de alumínio & & & $x$ & & & $x$ & & & \\
\hline TATUAPE & $357 / 2012$ & & $\mathrm{x}$ & $\mathrm{x}$ & $\mathrm{x}$ & & $\mathrm{x}$ & & & & $\mathrm{x}$ \\
\hline \multirow[t]{2}{*}{ VILA JACUI } & $406 / 2005$ & & $x$ & & $x$ & & & $x$ & & & \\
\hline & $081 / 2009$ & & $\mathrm{x}$ & & $\mathrm{x}$ & & & $\mathrm{x}$ & & & \\
\hline VILA & $150 / 2012$ & Trióxido de cromo & & & $x$ & & & & & $x$ & \\
\hline PRUDENTE & $179 / 2013$ & & $x$ & $x$ & $x$ & & $\mathrm{x}$ & & & $x$ & \\
\hline TOTAL & 29 & 10 & 19 & 11 & 21 & 8 & 11 & 10 & 1 & 9 & 6 \\
\hline
\end{tabular}


TABELA 6 - Registros de descartes de resíduos químicos por distritos na Zona Sul de São Paulo

\begin{tabular}{|c|c|c|c|c|c|c|c|c|c|c|c|}
\hline \multirow[t]{2}{*}{$\begin{array}{l}\text { Distritos da Zona Sul de } \\
\text { São Paulo }\end{array}$} & \multirow[t]{2}{*}{$\begin{array}{c}\mathrm{REQ} / \mathrm{An} \\
\mathrm{o}\end{array}$} & \multicolumn{3}{|c|}{ Identificação/Natureza do Resíduo Químico } & \multicolumn{2}{|c|}{$\begin{array}{c}\text { Houve } \\
\text { vazamento? }\end{array}$} & \multicolumn{5}{|c|}{ Danos/meios afetados } \\
\hline & & $\begin{array}{l}\text { Produtos } \\
\text { identificados }\end{array}$ & $\begin{array}{l}\text { Não } \\
\text { Identificado }\end{array}$ & $\begin{array}{l}\text { Liberação de } \\
\text { Gás/Vapor }\end{array}$ & SIM & NÃO & $\operatorname{Ar}$ & Solo & Água & $\begin{array}{l}\text { Via } \\
\text { Pública }\end{array}$ & $\begin{array}{c}\text { Rede de } \\
\text { esgoto/pl } \\
\text { uviais }\end{array}$ \\
\hline \multirow[t]{3}{*}{ CAMPO GRANDE } & $258 / 2007$ & & $\mathrm{x}$ & & & $x$ & & & & & \\
\hline & $413 / 2010$ & & $x$ & $\mathrm{x}$ & $x$ & & $\mathrm{x}$ & $\mathrm{x}$ & & $\mathrm{x}$ & \\
\hline & $399 / 2012$ & & $\mathrm{x}$ & $x$ & $\mathrm{x}$ & & $\mathrm{x}$ & $x$ & $\mathrm{x}$ & $x$ & \\
\hline CID ADEMAR & $231 / 2013$ & Polímeros granuladosIsocianato de polimetileno & & & & $x$ & & & & $\mathrm{x}$ & \\
\hline \multirow[t]{3}{*}{ CURSINO } & $340 / 2005$ & & $x$ & & & $\mathrm{x}$ & & & & & \\
\hline & 097/2006 & & $\mathrm{x}$ & & $\mathrm{x}$ & & & & & $\mathrm{x}$ & \\
\hline & $382 / 2007$ & & $x$ & & $x$ & & & & & $\mathrm{x}$ & \\
\hline \multirow[t]{4}{*}{ GRAJAU } & $377 / 2008$ & & $x$ & & $\mathrm{x}$ & & & $x$ & & $x$ & \\
\hline & $073 / 2013$ & & $x$ & $x$ & $x$ & & $x$ & $x$ & & $x$ & \\
\hline & $081 / 2013$ & & $\mathrm{x}$ & & $\mathrm{x}$ & & & $\mathrm{x}$ & & $\mathrm{x}$ & \\
\hline & $084 / 2013$ & & $x$ & & $x$ & & & $x$ & & $\mathrm{x}$ & \\
\hline \multirow[t]{4}{*}{ IPIRANGA } & $169 / 2009$ & & $x$ & $x$ & $x$ & & $\mathrm{x}$ & $x$ & & $x$ & \\
\hline & $171 / 2009$ & $\begin{array}{l}\text { Carbonato de cálcio Bicarbonato de sódioLauril } \\
\text { éter sulfato de sódio }\end{array}$ & & $x$ & $x$ & & $\mathrm{x}$ & $x$ & & $x$ & \\
\hline & $272 / 2009$ & & $\mathrm{x}$ & & $\mathrm{x}$ & & & $\mathrm{x}$ & & $\mathrm{x}$ & $\mathrm{x}$ \\
\hline & $457 / 2010$ & & $x$ & & $x$ & & & & $x$ & & $x$ \\
\hline \multirow[t]{3}{*}{ ITAIM BIBI } & $170 / 2010$ & Limalha de ferro & & & $\mathrm{x}$ & & & $\mathrm{x}$ & & $\mathrm{x}$ & \\
\hline & $384 / 2010$ & & $x$ & $x$ & $x$ & & $x$ & & & $x$ & $x$ \\
\hline & $226 / 2012$ & Percloroetileno & & & & $x$ & & & & $x$ & \\
\hline \multirow[t]{2}{*}{ JABAQUARA } & $211 / 2012$ & Clorodifluor metano & & & & $x$ & & & & & \\
\hline & $383 / 2013$ & & $x$ & $x$ & $x$ & & $x$ & & & & $x$ \\
\hline JD ANGELA & $105 / 2006$ & & $\mathrm{x}$ & $x$ & $\mathrm{x}$ & & $\mathrm{x}$ & $x$ & & & \\
\hline MORUMBI & $358 / 2008$ & & $\mathrm{x}$ & $x$ & $\mathrm{x}$ & & $\mathrm{x}$ & & $x$ & & $\mathrm{x}$ \\
\hline \multirow[t]{2}{*}{ SACOMA } & $119 / 2005$ & & $\mathrm{x}$ & $\mathrm{x}$ & $\mathrm{x}$ & & $\mathrm{x}$ & & & $x$ & \\
\hline & $397 / 2009$ & Fungicida "Priori Xtra" & & & $\mathrm{x}$ & & & $\mathrm{x}$ & & $\mathrm{x}$ & \\
\hline \multirow[t]{3}{*}{ SANTO AMARO } & $080 / 2008$ & Inseticida carbamato & & $x$ & $x$ & & $\mathrm{x}$ & $x$ & & & \\
\hline & $098 / 2008$ & & $\mathrm{x}$ & $x$ & $\mathrm{x}$ & & $\mathrm{x}$ & & & & \\
\hline & $160 / 2010$ & Carbureto de cálcio & & & & $\mathrm{x}$ & & & & $\mathrm{x}$ & \\
\hline SAUDE & $035 / 2006$ & Metassilicato & & & $\mathrm{x}$ & & & & & $x$ & \\
\hline SOCORRO & $371 / 2008$ & & $x$ & $x$ & & $x$ & $\mathrm{x}$ & & & $\mathrm{x}$ & \\
\hline VILA ANDRADE & $338 / 2005$ & Sódio metálico & & & $\mathrm{x}$ & & & $x$ & & & \\
\hline
\end{tabular}


TABELA 7- Registros de descartes de resíduos químicos por distritos na Zona Oeste de São Paulo

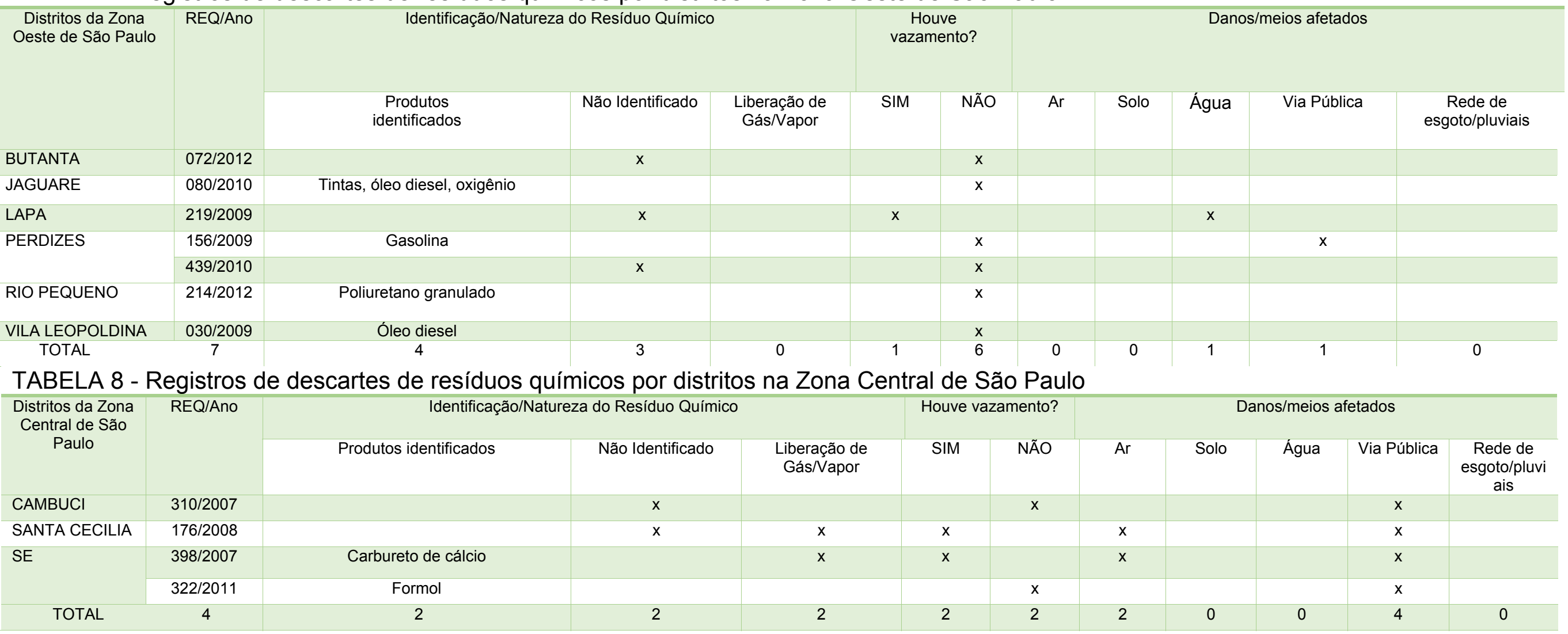


Os dados apresentados na FIG. 28,sobre registros de descarte de resíduos químicos na cidade de São Paulo, foram extraídos das TAB.4,5,6,7 e 8.

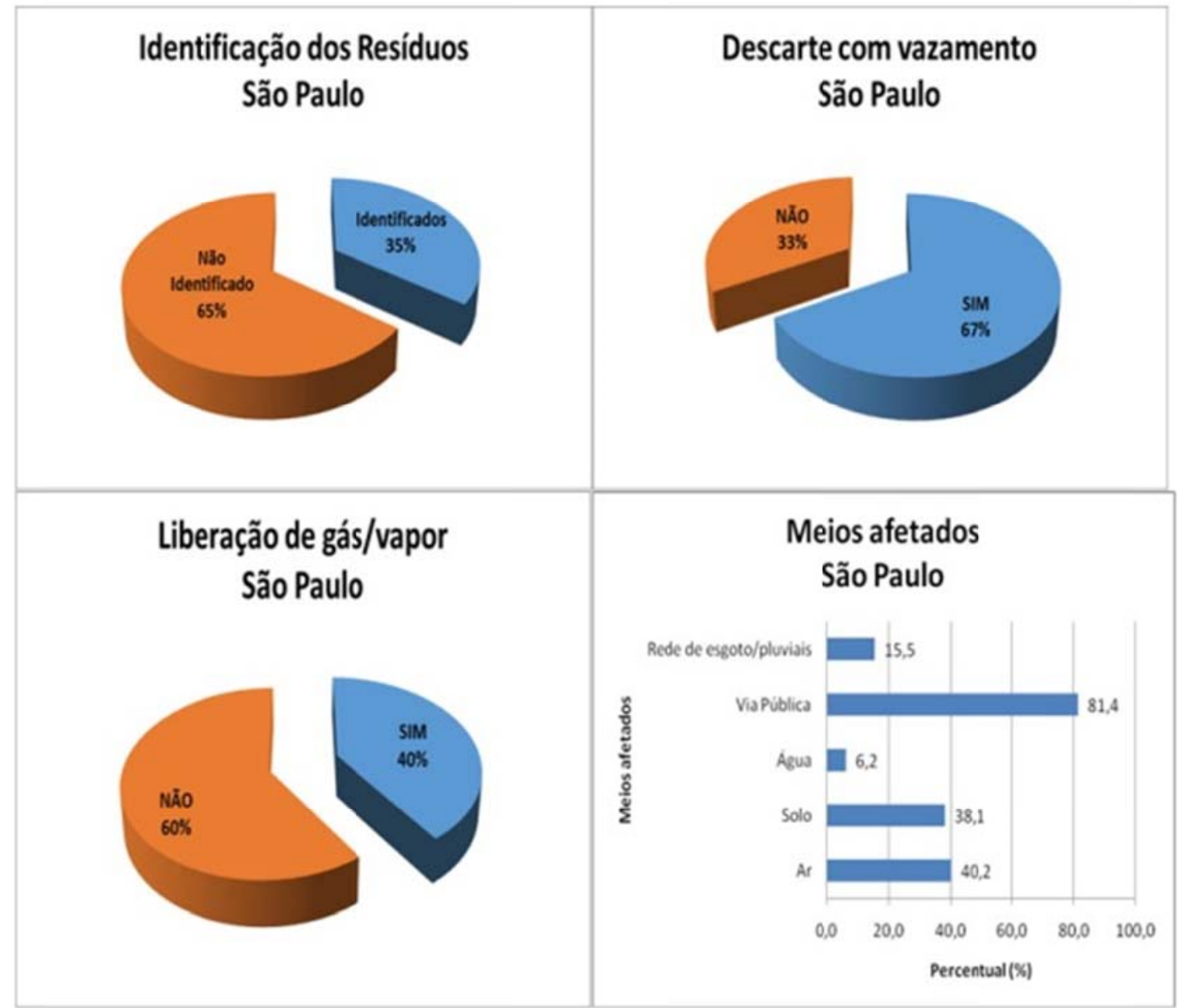

FIGURA 28 - Informações sobre registros de descarte de resíduos químicos na cidade de São Paulo.

Analisando a FIG.28 conclui-se que um dos maiores problemas que envolve as equipes que participam dos atendimentos emergenciais causados por descartes de resíduos químicos é o desconhecimento, na maioria dos casos $(65 \%)$, de sua origem.

No item "Danos/Meios Afetados" pode-se observar que o percentual não totaliza $100 \%$, porque um único caso de descarte pode atingir diversos meios (água, ar e solo) simultaneamente, incluindo a via pública e a rede de esgoto/ águas pluviais. Observa-se nesse caso que o ar $(40,2 \%)$ e o solo $(38,1 \%)$ estão entre os meios naturais mais afetados. 
O ar como meio afetado, refere-se a uma questão pontual e localizada, que de alguma forma causou o incômodo à população local e/ou foi percebido pelas equipes que participaram do atendimento emergencial.

O solo atingido pelos descartes de resíduos pode representar em muitos casos uma das formas de contaminação das águas subterrâneas.

Uma quantidade expressiva dos descartes de resíduos químicos ocorre em via pública $(81,4 \%)$, em margem de estradas, ruas e avenidas. Quando não são descartados em via pública os resíduos são abandonados em terrenos baldios. Esse elevado percentual dos descartes em via pública demonstra claramente os riscos a que estão expostos a população local e o meio ambiente.

Com relação ao meio hídrico, a ação de descarte de resíduos se dá diretamente em córregos, rios e nascentes $(6,2 \%)$ ou indiretamente pela rede pública de esgoto/águas pluviais $(15,5 \%)$ que pode atingir importantes rios e córregos da cidade.

É também uma informação importante da FIG.28 o fato de que a maioria dos casos de descartes de resíduos químicos ocorreu com vazamento (67\%). Desse total, 40\% envolveram substâncias voláteis (liberação de gás e/ou vapor). Esse fato pode representar para a população local e aqueles que participam do atendimento emergencial uma ameaça à saúde pela inalação direta dessas substâncias.

Analisando os dados da TAB.4 se observa o elevado registro de descartes de resíduos no Distrito de Tremembé 8 (oito) casos. Segundo dados do SIEQ,esses registros estão inseridos no Núcleo do Engordador no Parque Estadual da Cantareira ou na suas imediações.

Na FIG. 29 encontram-se representados os 8 (oito) casos de descartes de resíduos no Distrito de Tremembé e os 3 (três) no Distrito de Mandaqui localizados próximos do Parque Estadual da Cantareira e do Sistema Cantareira. 


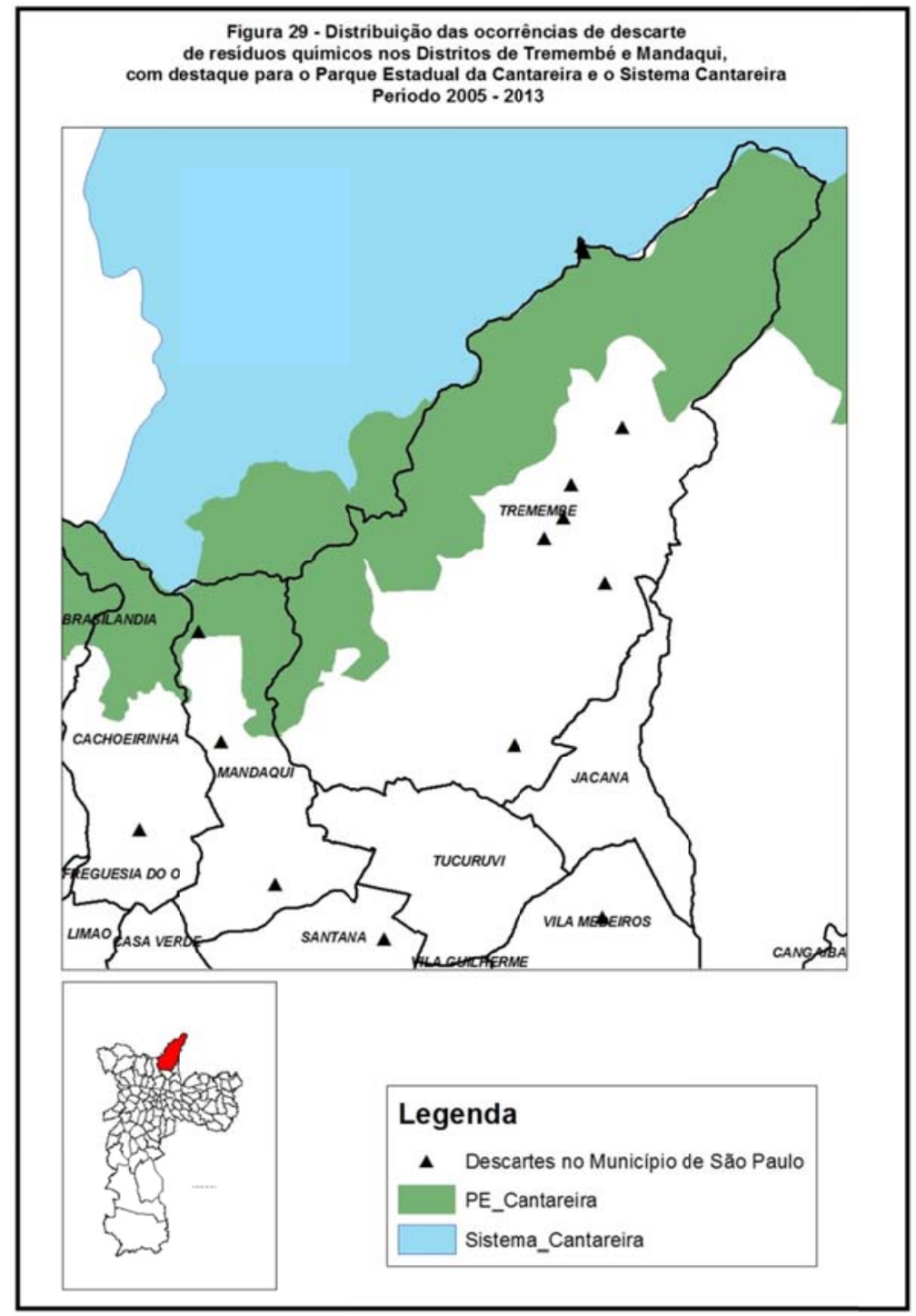

FIGURA 29 -Distribuição das ocorrências de descarte de resíduos químicos nos Distritos de Tremembé e Mandaqui com destaque para o Parque Estadual da Cantareira e o Sistema Cantareira.

O Parque Estadual da Cantareira abrangendo parte dos municípios de São Paulo, Caieiras, Mairiporã e Guarulhos, vem sofrendo diversas ações de degradação ambiental, principalmente por conta de loteamentos clandestinos. $O$ fato de situar-se nas bordas de importantes municípios da RMSP tem sido utilizado como local de desova de entulhos, carcaças de veículos roubados e pontos de descarte de resíduos químicos. E, por vezes, infratores aproveitamse das dificuldades de fiscalização dos órgãos públicos para reprimirem essa prática. 
Dos 8 (oito) casos de descarte no Distrito de Tremembé, 4 (quatro) ocorreram na Avenida Cel. Sezefredo Fagundes, o que significa $50 \%$ das ocorrências registradas no período nesse distrito.

Também na Avenida Cel. Sezefredo Fagundes, nº 7555 encontra-se um "botafora", (FIG.30) inserido na APA do Parque da Serra da Cantareira, pertencente a microbacia do Rio Piqueri, sub-bacia Cabuçu de Cima e Bacia do Tietê Centro.

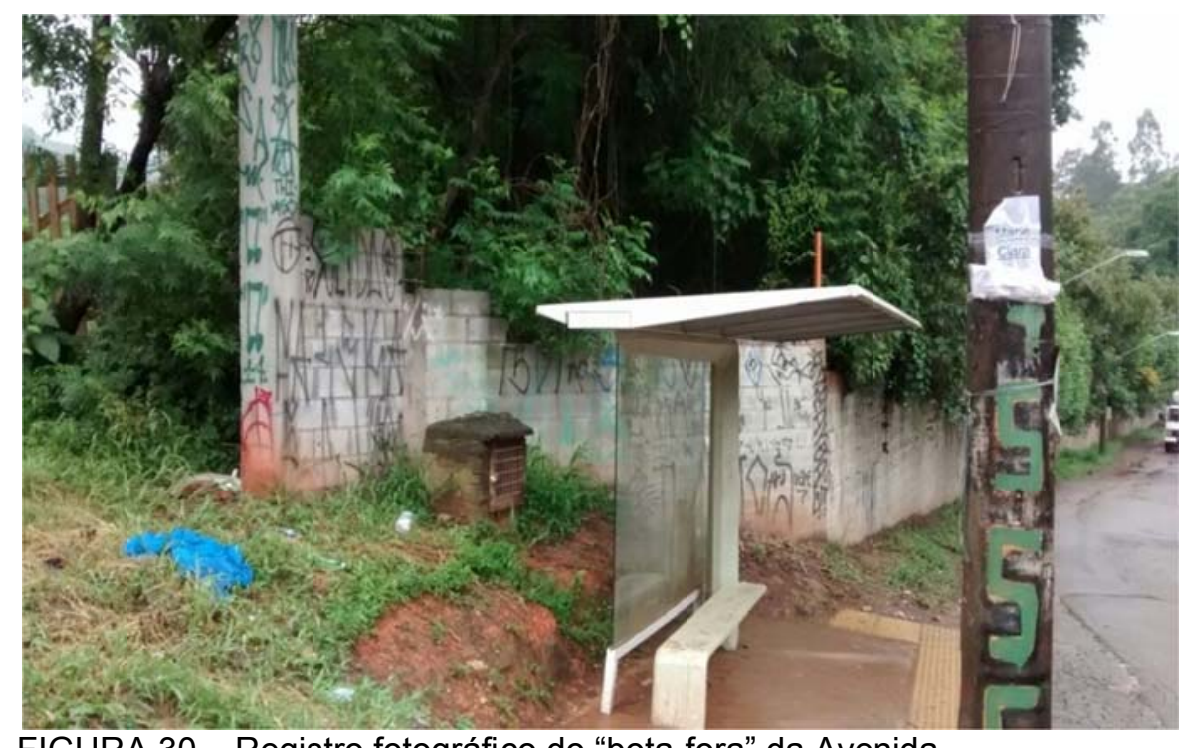

FIGURA 30 - Registro fotográfico do "bota-fora" da Avenida Sezefredo Fagundes.

CETESB - Companhia Ambiental do Estado de São Paulo (Banco de Imagem).

Segundo consulta realizada em 22 de janeiro de 2015 na Pasta Administrativa (PA/29/00332/09) na Agência Ambiental de Santana da CETESB - Companhia Ambiental do Estado de São Paulo, o empreendimento de propriedade da Prefeitura do Município de São Paulo, ocupa uma área de 426.115,92 m².

De acordo com a caracterização geológica realizada por meio de sondagens, verificou-se que, além dos materiais comuns normais de entulho (tijolos, pedra, terra, concreto e madeira) foram encontrados também algum lixo, constituído por plásticos, papéis e panos. Em alguns casos teria sido constatado odor geral de óleo, de resto de asfalto e de muito lixo doméstico, inclusive orgânico, sob a superfície da área. Há fortes evidências de que no local foram depositados resíduos químicos perigosos. 
A área é declarada contaminada sob investigação e atualmente encontra-se sob avaliação da CETESB - Companhia Ambiental do Estado de São Paulo a viabilidade técnica do projeto de recuperação ambiental do "bota-fora" sob responsabilidade da Prefeitura do Município de São Paulo.

Segundo RODRIGUES (2011) a Avenida. Cel. Sezefredo Fagundes, que tem início no distrito de Tucuruvi, atravessa o distrito de Tremembé e segue até a divisa do município de Mairiporã, tem trechos problemáticos, onde não há calçadas para os pedestres e a partir do $n^{\circ} 16.000$ existem alguns pontos de acúmulo de lixo, com excesso de entulho, galhos de árvores, madeiras, papelão e lixo orgânico até a divisa com Mairiporã.

Certamente a recorrência de descartes de resíduos químicos na Avenida. Cel. Sezefredo Fagundes guarda relação direta com o que se noticia pelo "Jornal a Gazeta da Zona Norte".

As 4 (quatro) ocorrências de descarte de resíduos químicos na Avenida. Cel. Sezefredo Fagundes (REQs 123/2008, 276/2008, 17/2009 e 049/2013), envolveram grandes quantidades de embalagens ou dos resíduos descartados sendo o solo o principal meio afetado.

\subsection{Diagnóstico socioambiental quanto à distribuição espacial dos descartes de resíduos químicos nos bairros da cidade de Guarulhos}

Guarulhos é o segundo maior município paulista em população, com mais de 1.221.979 habitantes (INSTITUTO BRASILEIRO DE GEOGRAFIA E ESTATÍSTICA, 2010c). Localizada na Região Metropolitana de São Paulo, a cidade tem uma área de $319,19 \mathrm{~km}^{2}$.

Guarulhos ocupa a segunda posição na composição do PIB da região metropolitana com 5,4\%, seguida de São Bernardo do Campo e Barueri, com $5,0 \%$, e Osasco com 4,8\%. A capital concentra 62,8\%, mesmo sendo São Paulo o grande detentor do PIB da RMSP, a representatividade de Guarulhos demonstra a importância econômica do município no contexto metropolitano (GUARULHOS (Cidade), 1997). 
Distante apenas $17 \mathrm{~km}$ do centro da maior metrópole da América Latina, o município encontra-se estrategicamente localizado entre duas das principais rodovias nacionais: a Via Dutra, eixo de ligação São Paulo - Rio de Janeiro, e Rodovia Fernão Dias, que liga São Paulo a Belo Horizonte. Conta ainda com a Rodovia Ayrton Senna, uma das mais modernas do país, que facilita a ligação de São Paulo ao Aeroporto Internacional de Guarulhos, e está a 108 km do Porto de Santos (GUARULHOS (Cidade), 1997).

A cobertura vegetal primitiva é representada pela Mata Atlântica, também denominada Floresta Cantareira e, pela Mata Planaltina ou de Transição. Com a expansão populacional e industrial essa cobertura sofreu grande desgaste. Restam atualmente o Parque Estadual Cantareira (Núcleo Cabuçu) com 2.550 ha, a fazenda Itaverava, algumas áreas localizadas na Tapera Grande, além de pequenos redutos de mata existentes na cidade, Bosque Maia, Parque Fracalanza e Aeroporto Internacional, entre outros, preservados pela Legislação de Proteção Permanente (GUARULHOS (Cidade), 2014a).

O acelerado e desordenado processo de crescimento da cidade de Guarulhos teve como consequência o surgimento de diversos problemas sócioambientais, entre os quais se destaca a drástica redução de sua área florestada (GUARULHOS (Cidade), 2014a).

Guarulhos recebe as rodovias federais Dutra (liga São Paulo e Rio de Janeiro), Ayrton Senna (São Paulo e Vale do Paraíba) e Fernão Dias (São Paulo e Minas Gerais) e está próxima dos portos de Santos e São Sebastião, possui portos secos e entrepostos aduaneiros. Abriga o Aeroporto Internacional de São Paulo/ Guarulhos - Governador André Franco Montoro (GUARULHOS (Cidade), 2014b).

A FIG. 31 apresenta o mapa dos descartes de resíduos químicos nos bairros da cidade de Guarulhos. 
Figura 31 - Distribuição das ocorrências de descarte de resíduos químicos nos bairros da cidade de Guarulhos

Período 2005 - 2013

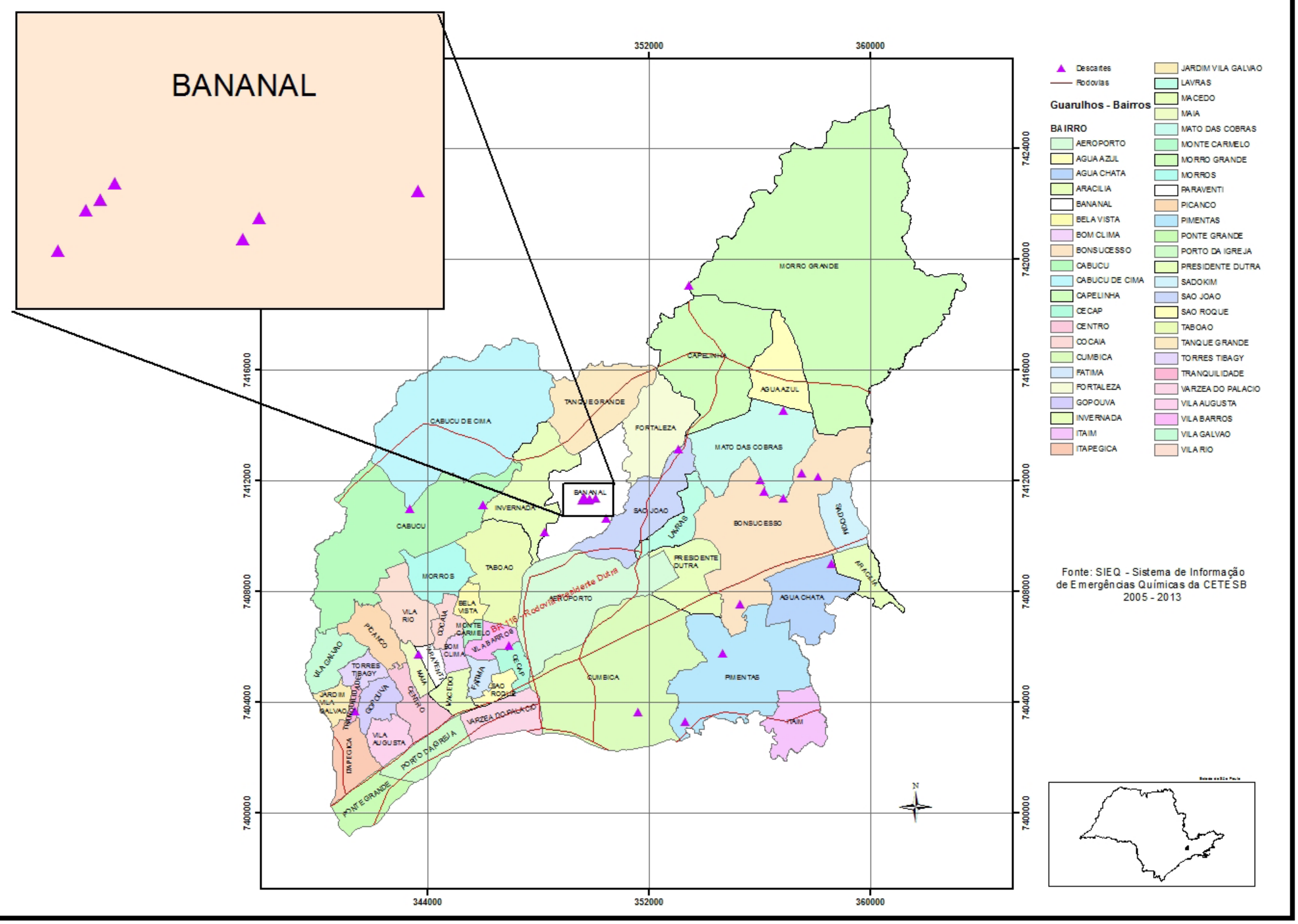


A FIG. 32 abaixo apresenta a distribuição dos registros de descartes de resíduos químicos por bairros da cidade de Guarulhos, de forma auxiliar a visualização do número de registros do mapa apresentado na Fig. 31.

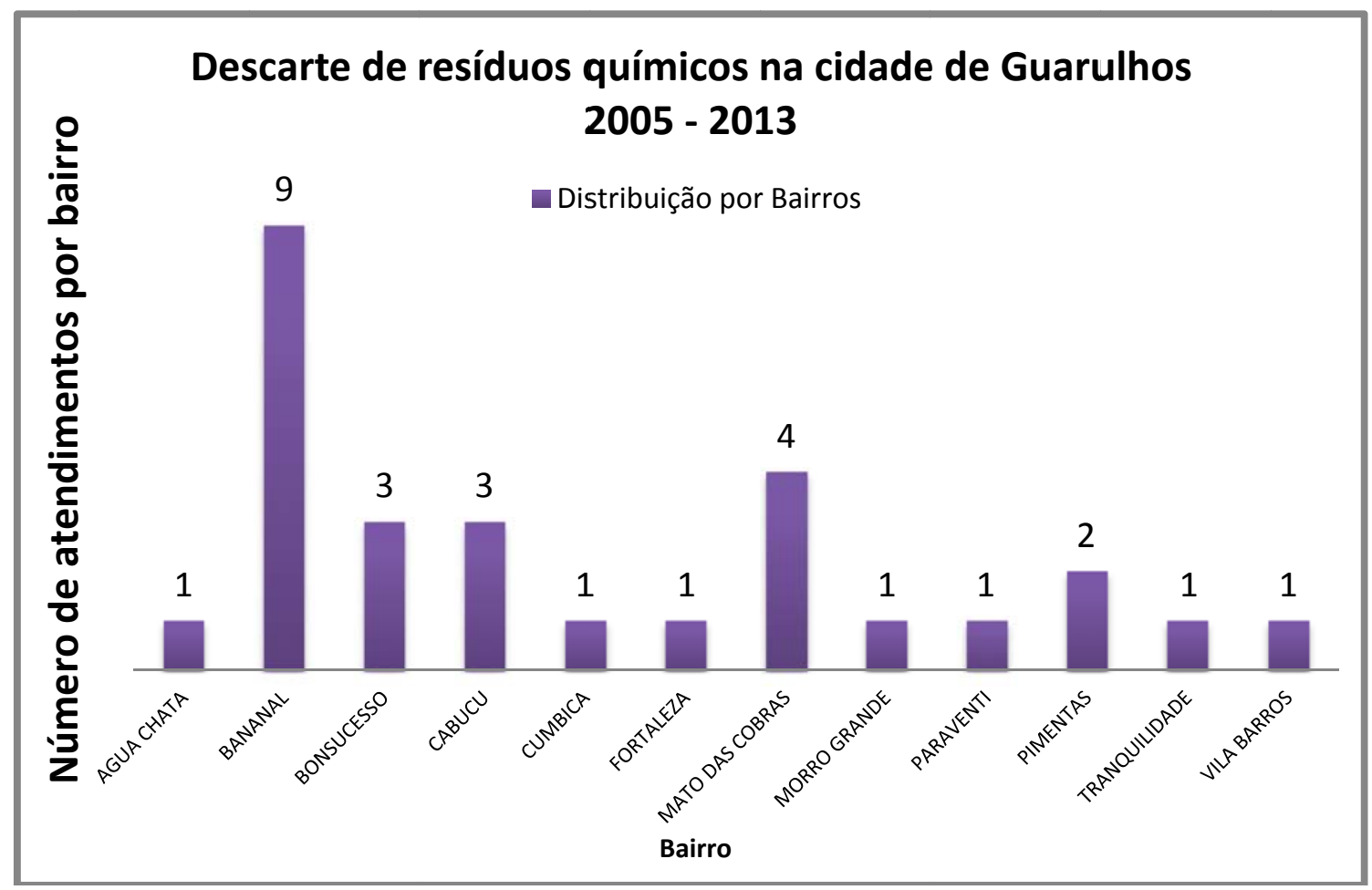

FIGURA 32 - Distribuição dos registros de descarte de resíduos químicos por bairros da cidade de Guarulhos.

Fonte:(CETESB - COMPANHIA AMBIENTAL DO ESTADO DE SÃO PAULO, 2013a, adaptado do SIEQ)

A FIG. 33 apresenta o mapa da cidade de Guarulhos com os descartes de resíduos químicos por bairro e a estimativa das quantidades totais vazadas. As quantidades estimadas de resíduos químicos foram extraídas a partir da consulta feita aos REQs por bairro.

A análise socioambiental dos descartes de resíduos químicos será feita tomando-se como referência as Unidades de Planejamento Regional (UPRs).

As UPRs são divisões territoriais da cidade previstas pela legislação municipal, Decreto $n^{\circ} 25.303 / 2008$, com o fim de alimentar o Sistema de Informações e Planejamento (GUARULHOS (Cidade), 2008). 


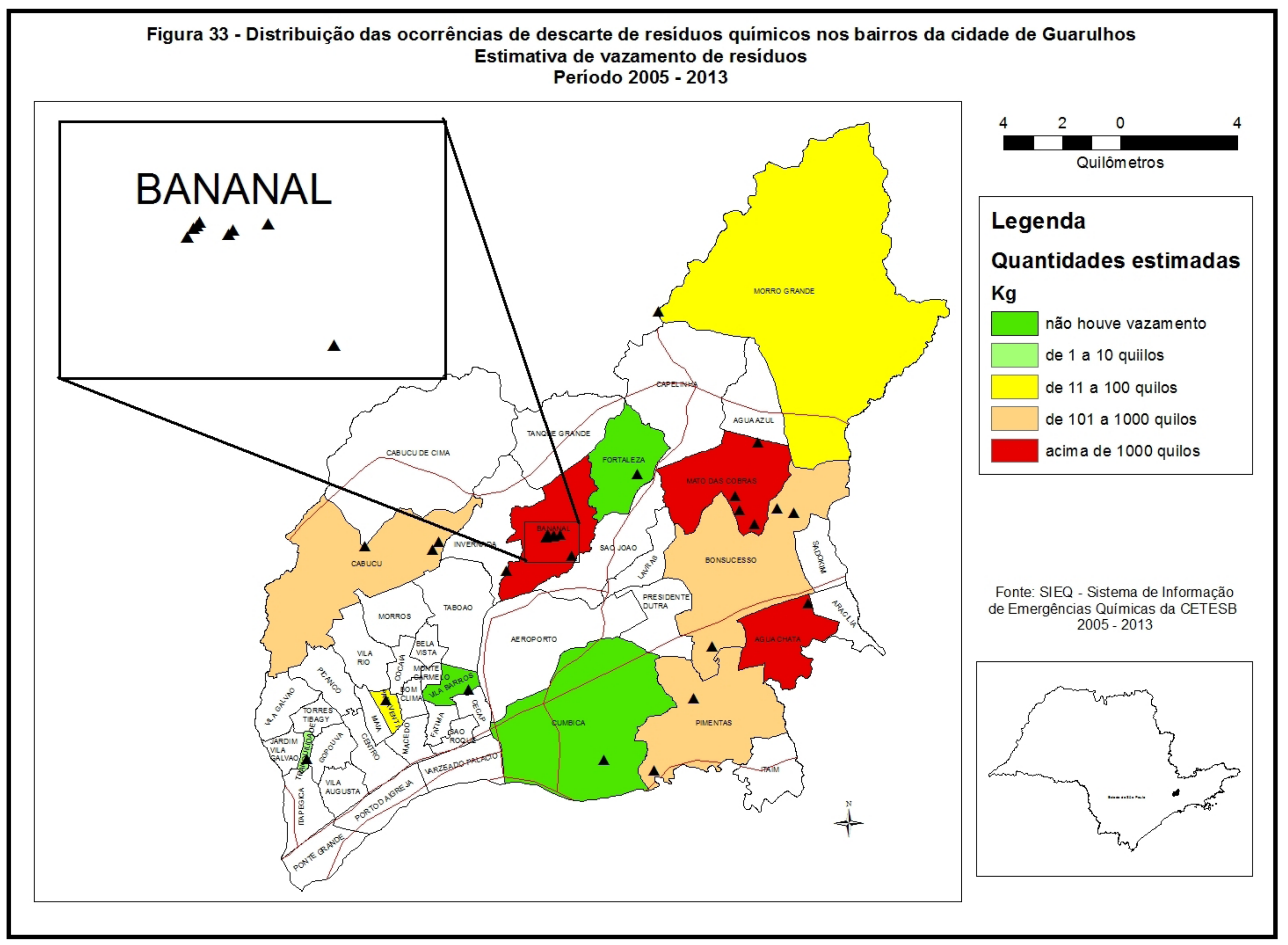


As UPRs englobam um ou mais bairros da cidade. O território municipal fica subdividido em 11 UPRs, a saber: Centro, Vila Galvão, Taboão, São João, Bonsucesso, Cumbica, Pimentas, Cabuçu, Tanque-Grande, Capelinha e Jaguari (GUARULHOS (Cidade), 2011).

Considerando as divisões territoriais das UPRs e reconhecendo a diversidade urbana encontrada no território de Guarulhos, a análise realizada nesse trabalho levará em consideração algumas questões socioambientais relevantes para a análise das áreas onde foram registrados descartes de resíduos químicos.

Nos bairros periféricos de Mato das Cobras, Bananal e Água Chata (bairro limítrofe) foram registrados descartes de resíduos químicos com quantidades acima de $1000 \mathrm{~kg}$.

Com quantidades de 101 a 1000 kg estão bairros limítrofes do município como Pimentas, Bonsucesso, Cabuçu.

No bairro de Fortaleza há registro de um único caso de descarte de resíduo, no entanto, sem vazamento.

Predominam-se na Região das UPRs de Bonsucesso (bairros de Mato das Cobras e Bonsucesso), de Pimentas (bairros de Água Chata e Pimentas)e São João (bairros de Bananal e Fortaleza)famílias com renda entre 3 a 5 salários mínimos, além de baixo índice de coleta de esgoto quando comparado com outros bairros do município. Os equipamentos de educação e saúde encontram-se uniformemente espacializados sendo que suas condições são precárias (GUARULHOS (Cidade), 2011).

É nesse contexto de degradação da infraestrutura urbana e de espaços segregados exclusivamente para populações de baixa renda e em zonas geograficamente periféricas, que se insere o perfil dos bairros de Bonsucesso, Mato das Cobras, Pimentas, Água Chata, Bananal e Fortaleza (GUARULHOS (Cidade), 2011). 
O bairro dos Pimentas, segundo a Leitura Técnica e Comunitária do Plano Diretor, além de ser uma das regiões mais carentes de equipamentos públicos, se comparada com a região oeste da cidade, ainda apresenta um contínuo crescimento de sua população, que se encontra majoritariamente nas classes D e E(GUARULHOS (Cidade), 2011).

A UPR de Cabuçu (bairro de Cabuçu) é descrita como uma região heterogênea cuja principal característica é o conflito entre a expansão urbana, a geografia e as áreas de proteção ambiental da Serra da Cantareira (GUARULHOS (Cidade), 2011).

No bairro de Cabuçu foram registrados três casos de descartes de resíduos químicos com quantidades estimadas entre 101 e $1000 \mathrm{~kg}$, numa área de proteção ambiental.

A UPR Jaguari possui assentamento irregular com características de área rural e sua localização corresponde estritamente à área de Proteção Ambiental (GUARULHOS (Cidade), 2011).

Encontra-se inserida na UPR Jaguari, o bairro de Morro Grande, com um único registro de descarte de resíduo estimado em $100 \mathrm{~kg}$.

Situada na porção sudoeste da cidade, a UPR Centro (bairros de Vila Barros e Paraventi) é muito bem provida de equipamentos públicos de educação e saúde, que estão uniformemente distribuídos no território. De acordo com o mapa de inclusão e exclusão feito para a cidade, esta é a região com os maiores índices de qualidade de vida e desenvolvimento humano, tendo consequentemente taxas de exclusão social próximas de zero (GUARULHOS (Cidade), 2011).

O único descarte de resíduo registrado no bairro central de Vila Barros ocorreu sem vazamento. Também na região central da cidade o único registro de descarte de resíduo no bairro de Paraventi ocorreu com vazamento de aproximadamente $50 \mathrm{~kg}$. 
As condições socioeconômicas da UPR Vila Galvão que inclui o bairro de Tranquilidade mostram-se um pouco acima da média do município. Embora a região possua um bom quadro de equipamentos públicos de educação e saúde, eles se concentram na porção onde se localizam famílias de alta renda, a oeste do território (GUARULHOS (Cidade), 2011).

No bairro de Tranquilidade o único registro de descarte de resíduo teve como consequência vazamento estimado em $10 \mathrm{~kg}$.

Ao sul de Guarulhos, região limítrofe da cidade de São Paulo, a UPR Cumbica é formada por um único bairro de mesmo nome. O desenvolvimento da região ocorreu concomitante ao centro da cidade, caracterizada como uma área bastante adensada desde o final da década de 1950. A UPR tem a Rodovia Presidente Dutra como eixo principal e de certa forma determinante de seu uso e ocupação do solo (GUARULHOS (Cidade), 2011).

No bairro de Cumbica também foi registrado um único caso de descarte de resíduo sem vazamento.

A seguir a TAB. 9apresenta de modo detalhado os registros de descartes de resíduos químicos ocorridos no período de 2005 a 2013 nos diversos bairros da cidade de Guarulhos. Os dados compilados trazem informações sobre a existência de vazamento, os danos causados e meios afetados, a identificação dos resíduos e se ocorreu em via pública. 
TABELA 9 - Registros de descartes de resíduos químicos por bairros em Guarulhos

\begin{tabular}{|c|c|c|c|c|c|c|c|c|c|c|c|}
\hline \multirow[t]{2}{*}{ Bairros de Guarulhos } & \multirow[t]{2}{*}{ REQ/Ano } & \multicolumn{3}{|c|}{ Identificação/Natureza do Resíduo Químico } & \multicolumn{2}{|c|}{ Houve vazamento? } & \multicolumn{5}{|c|}{ Danos/meios afetados } \\
\hline & & $\begin{array}{l}\text { Produtos } \\
\text { identificados }\end{array}$ & Não Identificado & $\begin{array}{l}\text { Liberação de } \\
\text { Gás/Vapor }\end{array}$ & SIM & NÃO & $\mathrm{Ar}$ & Solo & Água & Via Pública & $\begin{array}{c}\text { Rede de } \\
\text { esgoto/pluviais }\end{array}$ \\
\hline AGUA CHATA & $307 / 2009$ & & $\mathrm{x}$ & & $\mathrm{x}$ & & & $\mathrm{x}$ & & $\mathrm{x}$ & \\
\hline \multirow{9}{*}{ BANANAL } & $393 / 2005$ & & $\mathrm{x}$ & & $\mathrm{x}$ & & & $\mathrm{x}$ & & $\mathrm{x}$ & \\
\hline & $047 / 2006$ & & $\mathrm{x}$ & & $\mathrm{x}$ & & & $\mathrm{x}$ & & $\mathrm{x}$ & \\
\hline & $049 / 2006$ & & $x$ & & $\mathrm{x}$ & & & $\mathrm{x}$ & & $\mathrm{x}$ & \\
\hline & $126 / 2006$ & & $\mathrm{x}$ & & & $\mathrm{x}$ & & & & $\mathrm{x}$ & \\
\hline & $172 / 2006$ & & $\mathrm{x}$ & & $\mathrm{x}$ & & & $\mathrm{x}$ & & $\mathrm{x}$ & \\
\hline & $173 / 2006$ & & $x$ & & $x$ & & & $x$ & & $x$ & \\
\hline & $114 / 2008$ & & $\mathrm{x}$ & $\mathrm{x}$ & $\mathrm{x}$ & & $\mathrm{x}$ & $\mathrm{x}$ & & $\mathrm{x}$ & \\
\hline & $203 / 2008$ & $\begin{array}{l}\text { Hidroxpropil metil } \\
\text { celulose }\end{array}$ & & $x$ & $x$ & & $x$ & $x$ & & $x$ & \\
\hline & $223 / 2008$ & & $\mathrm{x}$ & $\mathrm{x}$ & $\mathrm{x}$ & & $\mathrm{x}$ & $\mathrm{x}$ & & $\mathrm{x}$ & \\
\hline \multirow[t]{3}{*}{ BONSUCESSO } & $135 / 2006$ & & $\mathrm{x}$ & & $\mathrm{x}$ & & & $\mathrm{x}$ & & & \\
\hline & $236 / 2009$ & & $\mathrm{x}$ & $x$ & $\mathrm{x}$ & & $\mathrm{x}$ & $\mathrm{x}$ & & $\mathrm{x}$ & \\
\hline & $239 / 2009$ & & $x$ & & $x$ & & & $x$ & & $x$ & \\
\hline \multirow[t]{3}{*}{ CABUCU } & $069 / 2008$ & & $x$ & & $x$ & & & $x$ & $x$ & $x$ & \\
\hline & $166 / 2008$ & & $\mathrm{x}$ & $\mathrm{x}$ & $\mathrm{x}$ & & $\mathrm{x}$ & $\mathrm{x}$ & & & \\
\hline & $231 / 2008$ & & $\mathrm{x}$ & $\mathrm{x}$ & $\mathrm{x}$ & & $\mathrm{x}$ & $\mathrm{x}$ & & & \\
\hline CUMBICA & $185 / 2009$ & Solução de baterias & & & $\mathrm{x}$ & & & $\mathrm{x}$ & & $\mathrm{x}$ & \\
\hline FORTALEZA & $407 / 2007$ & & $\mathrm{x}$ & & $\mathrm{x}$ & & & $\mathrm{x}$ & $\mathrm{x}$ & $\mathrm{x}$ & \\
\hline \multirow{4}{*}{ MATO DAS COBRAS } & $077 / 2010$ & & $x$ & $x$ & $x$ & & $x$ & $x$ & & $x$ & \\
\hline & $020 / 2011$ & & $x$ & $x$ & $x$ & & $x$ & $x$ & $x$ & $x$ & \\
\hline & $088 / 2013$ & & $x$ & & $x$ & & & $\mathrm{x}$ & & $\mathrm{x}$ & \\
\hline & $251 / 2013$ & & $\mathrm{x}$ & & $x$ & & & $x$ & & & \\
\hline MORRO GRANDE & $093 / 2013$ & & $\mathrm{x}$ & & $\mathrm{x}$ & & & $x$ & & $\mathrm{x}$ & \\
\hline PARAVENTI & $454 / 2010$ & & $x$ & $x$ & $x$ & & $x$ & $x$ & $x$ & & \\
\hline \multirow[t]{2}{*}{ PIMENTAS } & $283 / 2009$ & Lodo de ETE & & $x$ & $x$ & & $\mathrm{x}$ & $x$ & & $x$ & \\
\hline & $307 / 2011$ & & $\mathrm{x}$ & & $x$ & & & $\mathrm{x}$ & & $x$ & \\
\hline TRANQUILIDADE & $350 / 2009$ & & $\mathrm{x}$ & $\mathrm{x}$ & $\mathrm{x}$ & & $\mathrm{x}$ & & $x$ & & $x$ \\
\hline VILA BARROS & $074 / 2010$ & $\begin{array}{l}\text { Estanho, composto } \\
\text { orgânico líquido }\end{array}$ & & & & $\mathrm{x}$ & & & & $\mathrm{x}$ & \\
\hline TOTAL & 28 & 4 & 24 & 11 & 26 & 2 & 11 & 25 & 5 & 22 & 1 \\
\hline
\end{tabular}


Os dados apresentados na FIG.34 extraídos da TAB. 9 mostram informações sobre registros de descarte de resíduos químicos na cidade de Guarulhos.

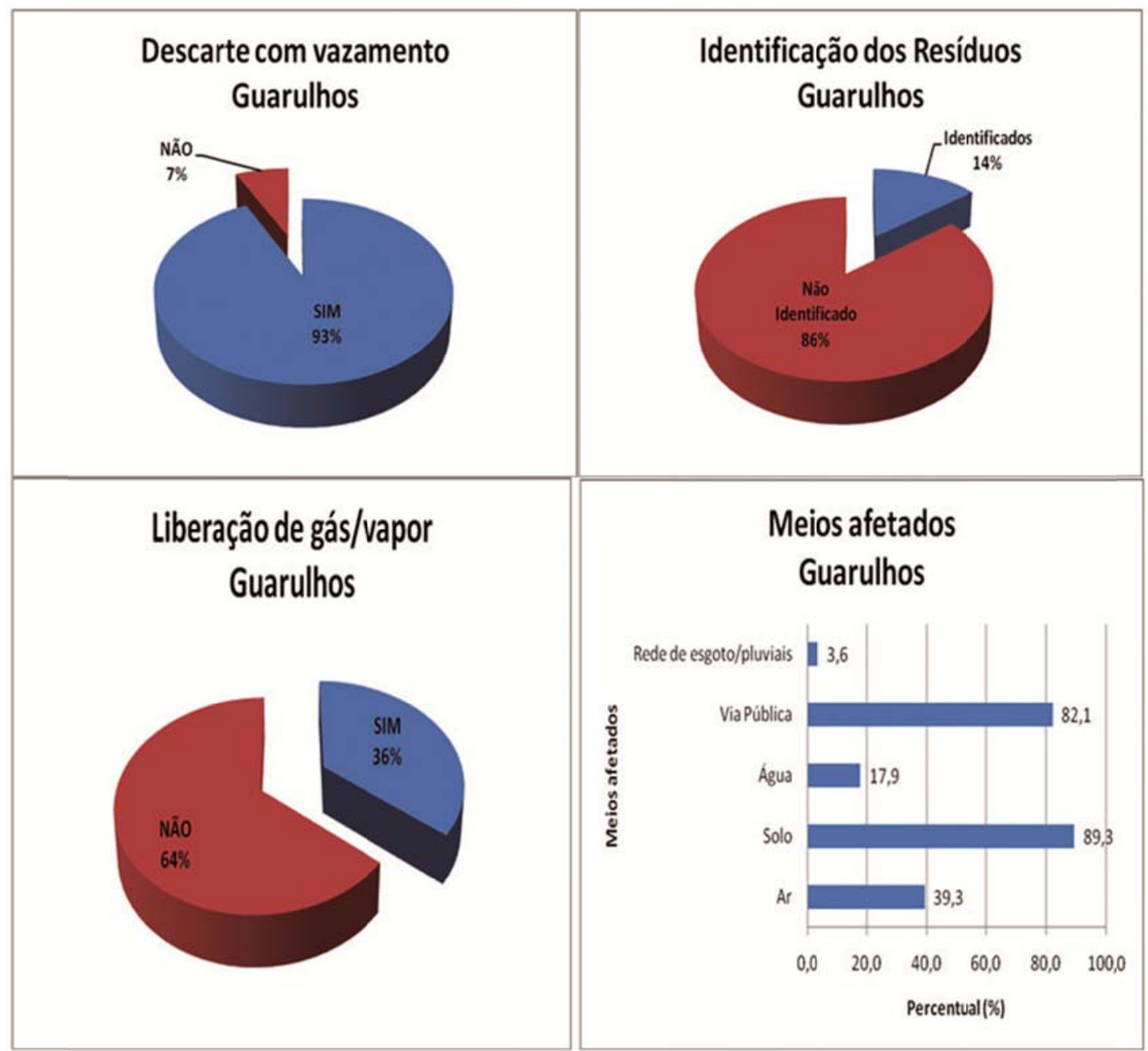

FIGURA 34 - Informações sobre registros de descarte de resíduos químicos Na cidade de Guarulhos.

Analisando a FIG.34 pode-se concluir que uma das maiores preocupações das equipes que participam dos atendimentos emergenciais causados por descartes de resíduos químicos é o desconhecimento, na maioria dos casos $(86 \%)$ de sua origem.

Dos dados apresentados na FIG.34 observa-se que a maioria dos casos de descartes de resíduos químicos ocorreu com vazamento (93\%). Em 36\% dos casos envolveu substâncias voláteis (liberação de gás e/ou vapor). Esse fato pode representar para a população local e aqueles que participam do 
atendimento emergencial uma ameaça à saúde pela inalação direta dessas substâncias.

No item "Danos/Meios Afetados" pode-se observar que o percentual não totaliza $100 \%$, porque um único caso de descarte pode atingir diversos meios (água, ar e solo) simultaneamente, incluindo a via pública e a rede de esgoto/ águas pluviais. Observa-se, nesse caso, que o solo $(89,3 \%)$ e o ar $(39,3 \%)$ estão entre os meios naturais mais afetados.

O solo pode representar em muitos casos uma fonte de contaminação da água subterrânea. $\mathrm{O}$ ar como meio afetado, refere-se a uma questão pontual e localizada que de alguma forma causou o incômodo à população local e foi percebido pelas equipes que participaram do atendimento emergencial.

Uma quantidade expressiva dos descartes de resíduos químicos ocorre em via pública $(82,1 \%)$ em margem de estradas, ruas e avenidas. Quando não são descartados em via pública os resíduos são abandonados em terrenos baldios. Esse elevado percentual dos descartes de resíduos em via pública demonstra claramente os riscos a que estão expostos a população local e o meio ambiente.

$\mathrm{Na}$ cidade de Guarulhos as ocorrências em via pública se deram principalmente em áreas periféricas, como na Estrada do Taboão, Estrada Albino Martelo, Estrada Velha Guarulhos para Nazaré Paulista e Estrada do Saboó. Entre as vias aqui referenciadas algumas não possuem pavimentação.

Uma característica comum aos descartes de resíduos ocorridos na Estrada do Taboão foi a expressiva quantidade de tambores metálicos descartados, de 20 a 30 , em geral com embalagens apresentando vazamento

Com relação ao meio hídrico a ação de descarte de resíduos se dá diretamente em córregos, rios e nascentes $(17,9 \%)$ ou indiretamente pela rede pública de esgoto/águas pluviais (3,6\%) que pode atingir importantes rios e córregos. 


\subsection{Pesquisa de campo aplicada por meio de questionário a representantes de instituições públicas que participam de atendimentos emergenciais envolvendo descarte de resíduos químicos}

\subsubsection{Análise dos resultados da pesquisa}

A seguir são apresentados os resultados da avaliação dos diferentes atores envolvidos nos atendimentos emergenciais a descarte de resíduos químicos, as dificuldades e providências tomadas. Os atores são representantes de órgãos públicos, como órgãos ambientais nas esferas municipal e estadual, corpo de bombeiros, defesa civil e prefeitura municipal. As informações foram agrupadas por temas que guardam relação entre si, sendo os resultados descritos com a mesma sequência/numeração do questionário apresentado no item 5 - Materiais e Métodos.

A análise dos resultados contemplou não apenas as respostas de múltipla escolha aos questionários, mas também a descrição obtida dos entrevistados.

O estudo foi realizado com 32 indivíduos de 05 instituições distintas, com o envolvimento de representantes do Corpo de Bombeiros (06); Defesa Civil (07); Órgão ambiental do estado - CETESB (07); órgão municipal (03) e prefeitura municipal (09).

Nas FIG.35 a 38 são apresentados os indicadores do resultado da pesquisa quanto ao perfil do pesquisado e experiência profissional; quanto à faixa etária, grau de instrução, tempo de atuação na empresa e número de atendimento emergenciais envolvendo descarte de resíduos químicos. 


\section{Perfil do pesquisado e experiência profissional}

a. Faixa etária

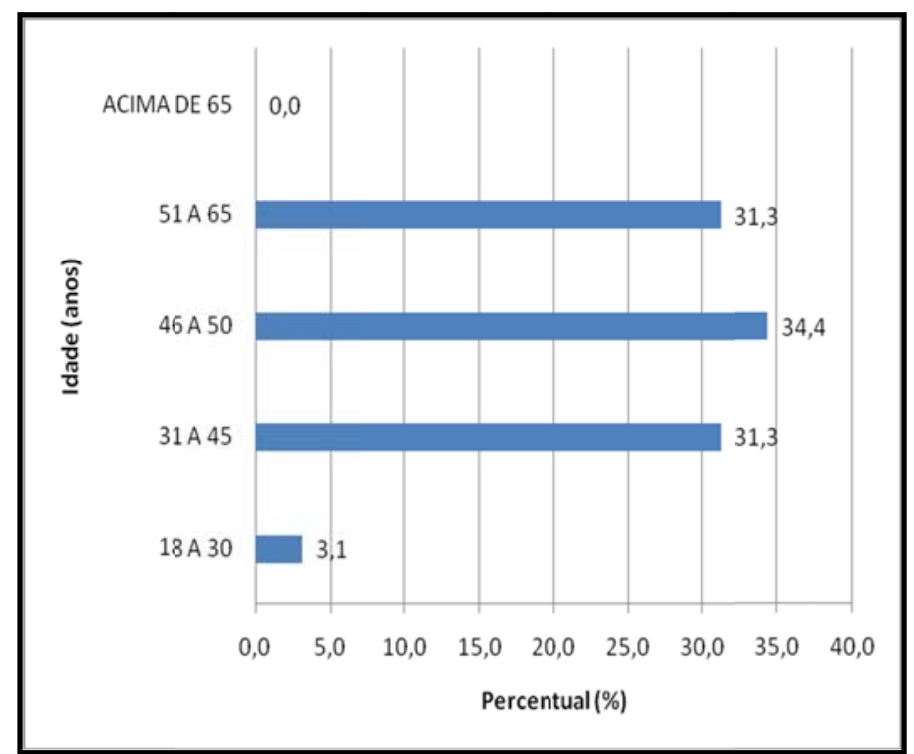

FIGURA 35 - Informações do perfil do pesquisado quanto à faixa etária.

b. Grau de instrução

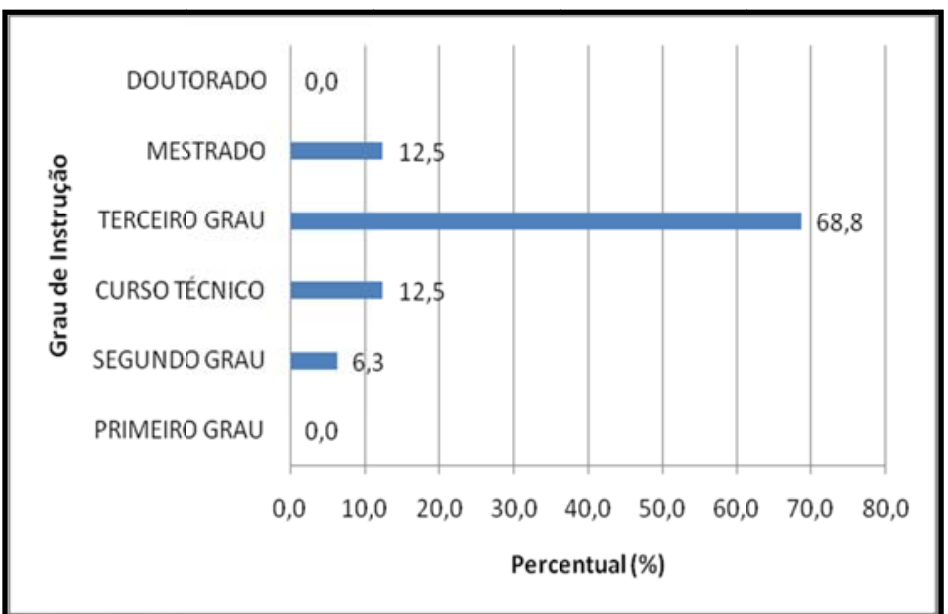

FIGURA 36 - Informações do perfil do pesquisado quanto ao grau de instrução(escolaridade).

O resultado desta pesquisa demonstrou que (81,3\%), dos atores envolvidos nos atendimentos de emergência tem ensino superior. Este fato atribui às respostas do questionário qualidade técnica, possibilitando assim, estabelecer 
com a pesquisa o melhor entendimento do real "status" das questões relativas ao descarte de resíduos químicos na RMSP.

c . Tempo de atuação na empresa

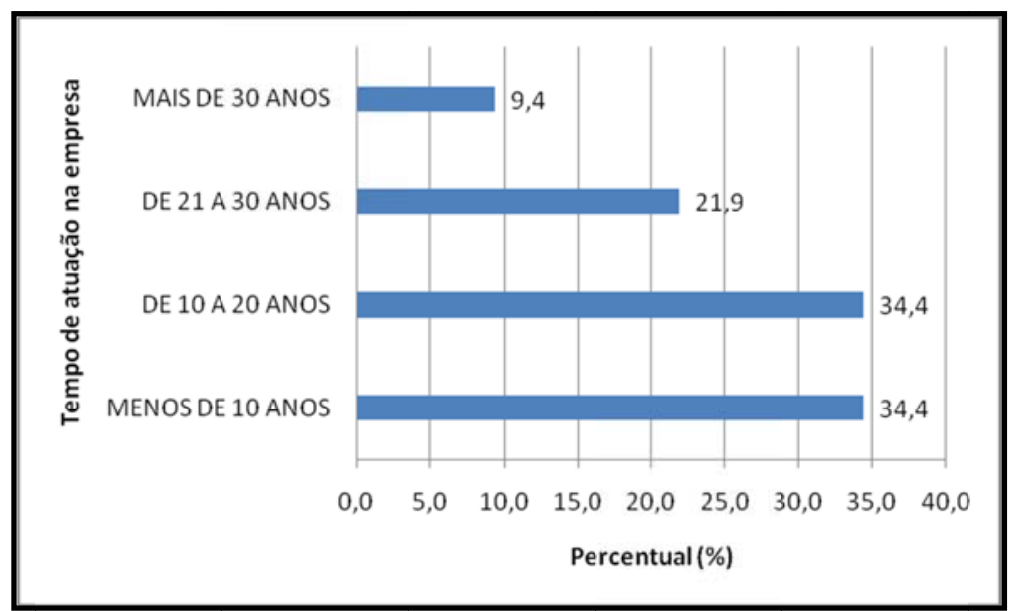

FIGURA 37 - Informações sobre o tempo de atuação do pesquisado na empresa.

Avaliando as respostas quanto ao tempo de atuação do profissional envolvido, foi observado que $65,7 \%$ dos entrevistados desempenham suas atividades na instituição há mais de 10 anos. Isso reflete em experiência profissional adquirida ao longo do tempo.

2. Número de atendimentos emergenciais envolvendo descarte de resíduos químicos.

a. Quantidade de atendimentos emergenciais envolvendo descarte de resíduos químicos que o entrevistado atendeu "in loco" ou participou à distância.

A FIG.38 apresenta o resultado da pesquisa quanto ao número de atendimento emergenciais envolvendo descarte de resíduos químicos. 


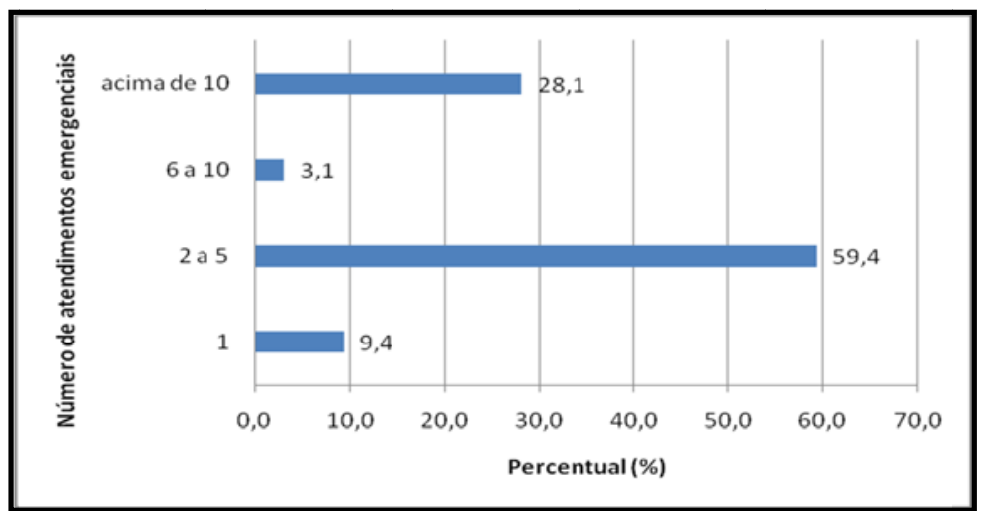

FIGURA 38 - Número de atendimentos emergenciais envolvendo descarte de resíduos químicos.

O resultado da pesquisa revelou que $59,4 \%$ dos profissionais entrevistados participaram de 2 a 5 emergências envolvendo o descarte de resíduos químicos. Ressalta-se aqui os agentes da Defesa Civil, Corpo de Bombeiros e técnicos do Órgão Ambiental estadual e municipal.

Dos $28,1 \%$ dos entrevistados que participaram em mais de 10 eventos dessa natureza destacam-se os técnicos do órgão ambiental estadual. Esses resultados revelam que os entrevistados tiveram a oportunidadle de participar da resposta emergencial a descarte de resíduos químicos e que, portanto, puderam dar sua contribuição ao objetivo dessa pesquisa.

\section{Impactos decorrentes dos atendimentos emergenciais rellacionados ao descarte de resíduos químicos segundo a percepção dos entrevistados}

a. Principal meio físico/estrutura afetada (água, ar, solo, residência, rua/rodovia, rio/córrego) pelo descarte de resíduos químicos.

A FIG. 39 apresenta os resultados quanto os Impactos decorrentes dos atendimentos emergenciais relacionados ao descarte de resíduos químicos segundo a percepção dos entrevistados. 


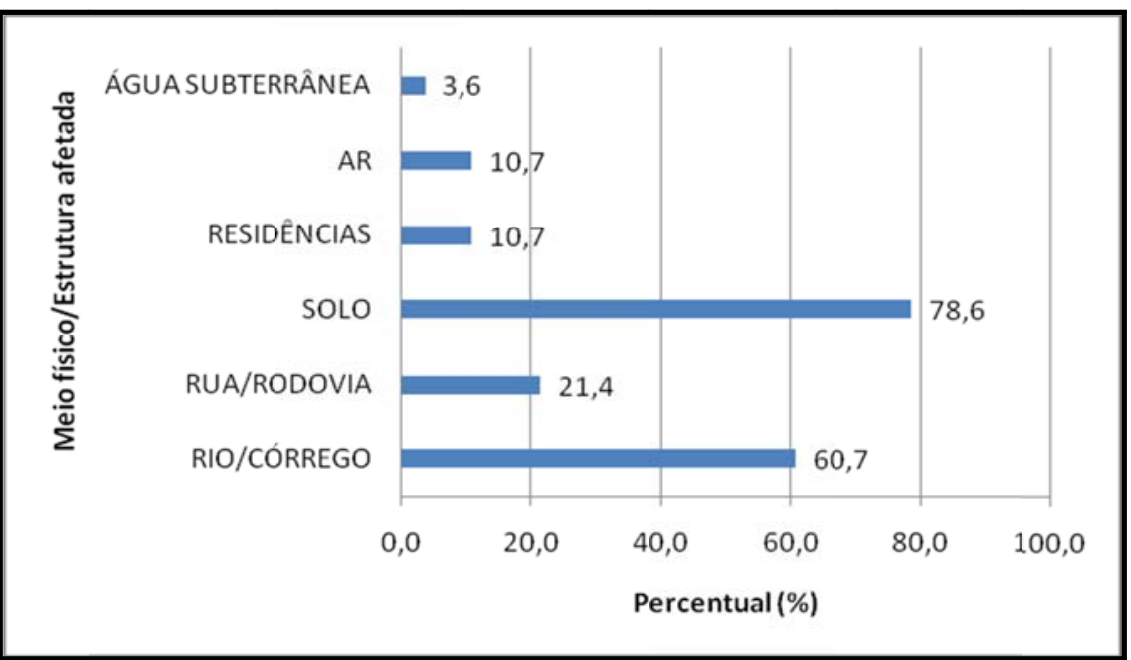

FIGURA 39 - Resultado da pesquisa quanto ao meio físico/estrutura afetada.

Ressalta-se aqui, que esse item considerou respostas múltiplas e, portanto, o percentual não totaliza $100 \%$.

Vale inicialmente ressaltar que os entrevistados responderam esse item com base na percepção adquirida ao longo de sua experiência profissional a partir dos atendimentos realizados, portanto, puderam optar por mais de uma alternativa.

Uma única emergência química pode desencadear diversos danos simultaneamente, incluindo o solo, o ar, a água subterrânea e a água superficial aqui tipificada como rio ou córrego. Além dos meios físicos como ar, água e solo foram incluídos na pesquisa residências e rua/rodovia.

Na FIG. 39 pode-se observar que $78,6 \%$ dos entrevistados responderam que o solo foi o meio físico mais afetado. Esses resultados da pesquisa corroboram com os dados da CETESB - Companhia Ambiental do Estado de São Paulo que apontam o solo como o meio físico mais atingido pelos descartes de resíduos químicos, como demonstrado na Fig. 40. 


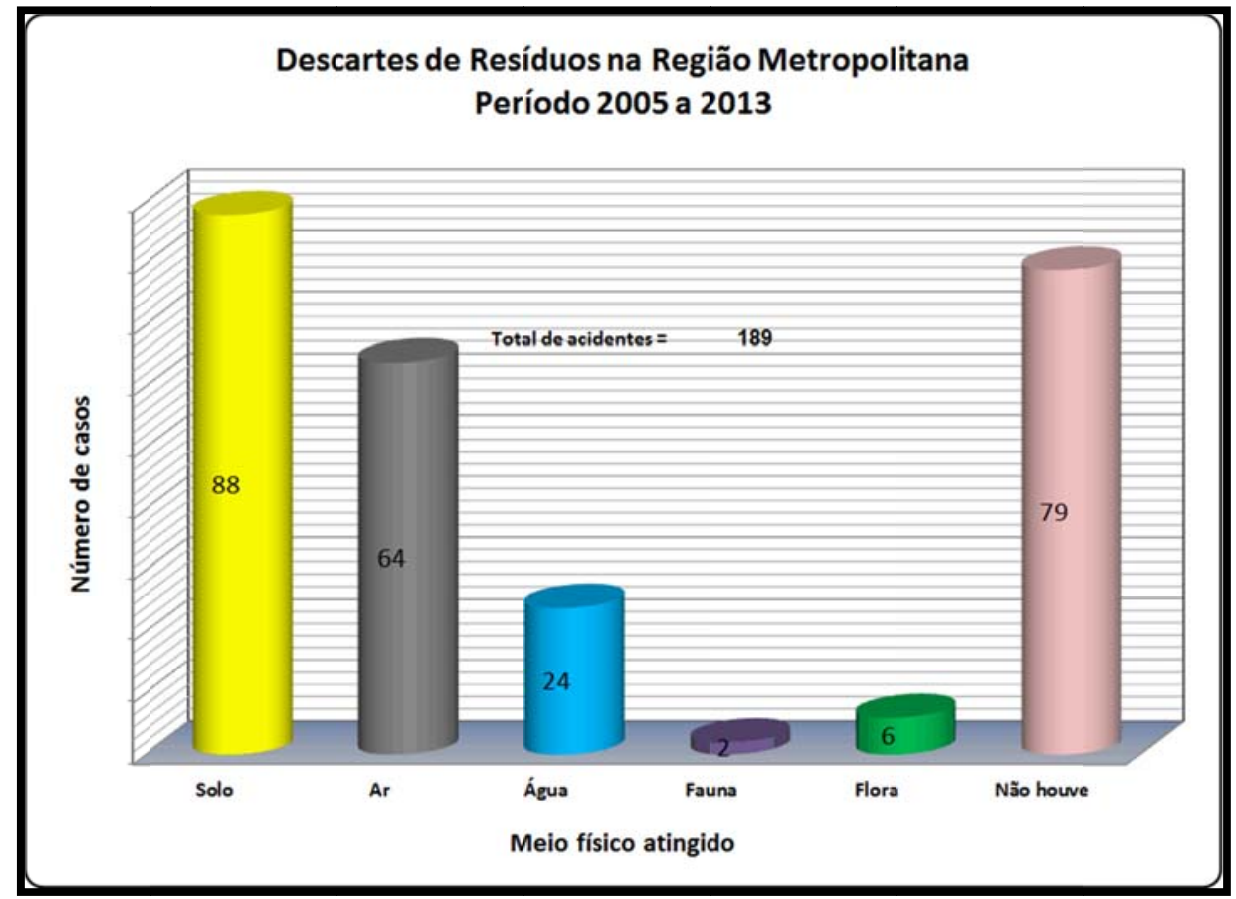

FIGURA 40 - Meios atingidos pelos descartes de resíduos químicos nas emergências atendidas pela CETESB - Companhia Ambiental do Estado de São Paulo.Fonte:(CETESB - Companhia Ambiental do Estado de São Paulo 2013a, adaptado do SIEQ).

A experiência dos representantes do órgão ambiental revela que é comum que as embalagens (sacos, tambores, cilindros, bombonas e barricas) contendo resíduos químicos sejam depositadas diretamente sobre o solo e em muitas situações apresentando vazamento.

Importante também que em alguns casos os resíduos são depositados diretamente no solo. Esse ato atinge contornos de grande gravidade, sobretudo quando ocorre precipitação pluviométrica, o que pode ampliar a contaminação do meio ambiente. As águas de chuva podem carrear resíduos químicos, ampliando assim, a contaminação do solo, podendo inclusive atingir corpos d'água próximo do local do descarte.

Dentre os inúmeros casos atendidos pela CETESB - Companhia Ambiental do Estado de São Paulo onde se constatou a contaminação do solo, a FIG.41, exemplifica essa situação conforme descrição do REQ 276/2004, de 24 de julho de 2004, na Estrada Velha de Santos, São Bernardo do Campo. Nesse caso a Polícia Ambiental encontrou diversas embalagens contendo resíduos 
químicos, algumas das quais algumas estavam rompidas e o produto em contato direto com o solo. Causou preocupação às equipes de emergência o fato do local do descarte está próximo de um pesqueiro e área de plantações.

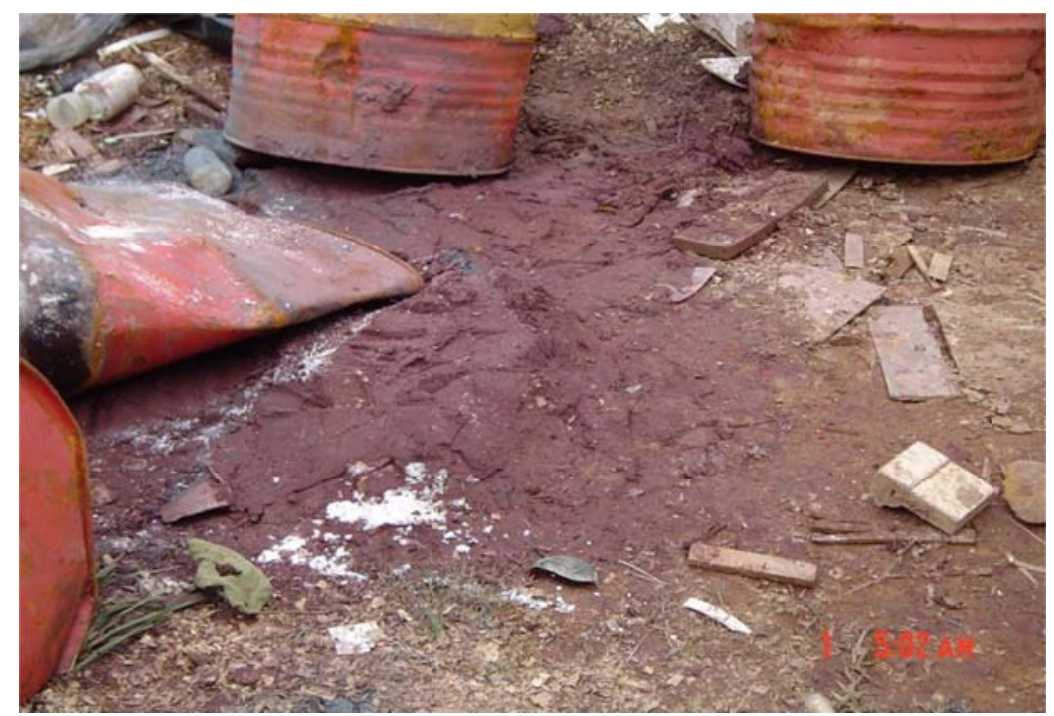

FIGURA 41 - Registro fotográfico de descarte de resíduos químicos com contaminação direta do solo.

Fonte: CETESB - Companhia Ambiental do Estado de São Paulo (Banco de Imagem).

Muitas das ocorrências de descarte ilegal de resíduos químicos ocorrem em áreas onde se encontram presentes resíduos inertes, "Não Perigosos e Inertes, Classe II B", segundo a Norma Brasileira NBR 10004:2004. Entre esses resíduos estão entulhos de construção civil que podem agravar a contaminação do meio, uma vez que exigirá das autoridades competentes o acompanhamento da remoção, transporte e destino final não apenas dos resíduos químicos depositados, mas também dos demais resíduos que ali se encontravam.

A contaminação de recursos hídricos, como rios e córregos, citado por $60,7 \%$ dos entrevistados aparece como a segunda maior incidência de contaminação. Pelos dados da FIG.40, o meio físico água, que inclui córregos e rios, surge em terceiro lugar, o que difere um pouco da percepção dos entrevistados.

Na maioria dos casos atendidos pela CETESB - Companhia Ambiental do Estado de São Paulo, o descarte de resíduos químicos ocorre em áreas 
afastadas dos centros urbanos, em especial em margens de corpos d'água, podendo em alguns casos afetar importantes mananciais de abastecimento de água da RMSP.

O atendimento emergencial realizado pela CETESB - Companhia Ambiental do Estado de São Paulo em 01 de dezembro de 2011 na Estrada do Corta Rabicho, bairro dos Correias, município de Arujá, REQ 380/2011, ilustra bem o descarte de resíduos químicos em margem de córrego. Neste caso 05 (cinco) tambores emanando forte odor característico de solvente foram ali depositados, tendo um deles atingido as águas de um córrego, como ilustrado na FIG.42.

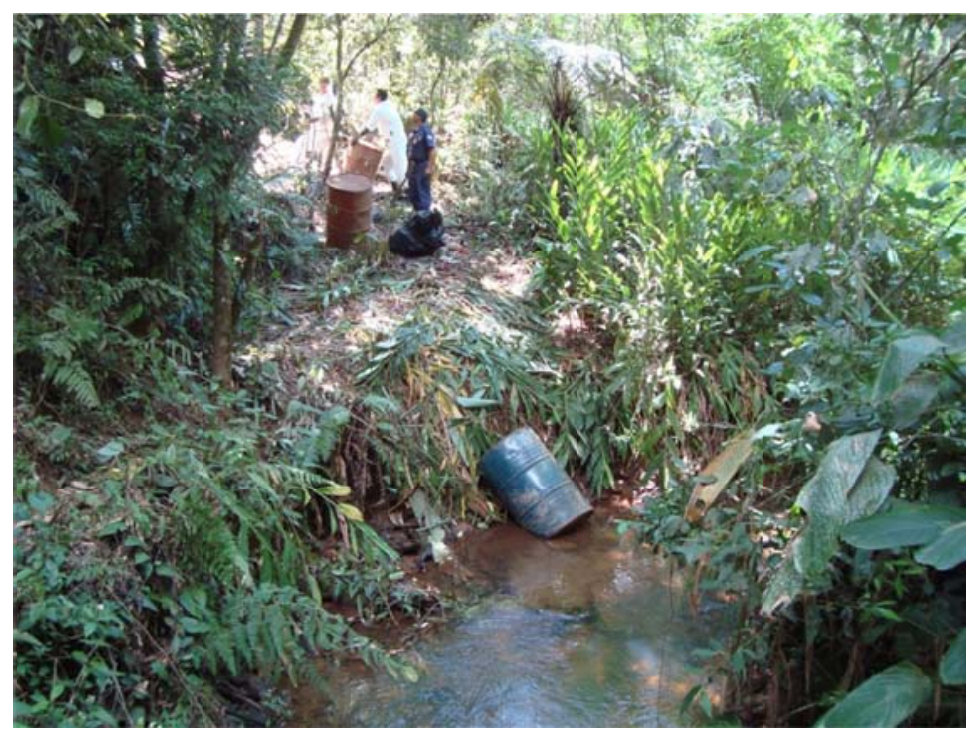

FIGURA 42 - Registro fotográfico de descarte de resíduos químicos com ocorrência de contaminação direta de corpo d'agua. Fonte: CETESB - Companhia Ambiental do Estado de São Paulo (Banco de Imagem).

O percentual dos entrevistados equivalente a 3,6\% que responderam que os resíduos químicos oferecem risco de contaminação à água subterrânea devese à baixa percepção que os componentes de tais resíduos podem migrar através do solo e, por fim, atingir o lençol freático. De fato, o que se observa na prática é a presença de contaminantes químicos resultantes dos resíduos químicos na superfície do solo. Entretanto, é sim possível que os resíduos químicos tenham sido depositados sobre o solo por longo período de tempo podendo atingir a água subterrânea. 
Representando $10,7 \%$ das respostas estão aquelas ocorrências em que se constatou odor característico de substâncias químicas, como por exemplo, de solventes industriais, resinas fenólicas, borras de tintas e vernizes nas imediações de residências. Essas ocorrências de alguma forma causaram incômodo à população local, colocando em risco a sua saúde e eventualmente a segurança, uma vez que muitos desses resíduos podem liberar vapores tóxicos e inflamáveis.

Uma situação de descarte de resíduos, FIG. 43, cujo principal impacto constatado foi o incômodo à população, está registrado no REQ 400/2009, de 23 de dezembro de 2009 (ocorrência na Rua Alice Blanche 23, Mandaqui, São Paulo), onde um tambor metálico foi deixado em frente a uma residência exalando forte odor característico de resina de poliéster além de apresentar vazamento.

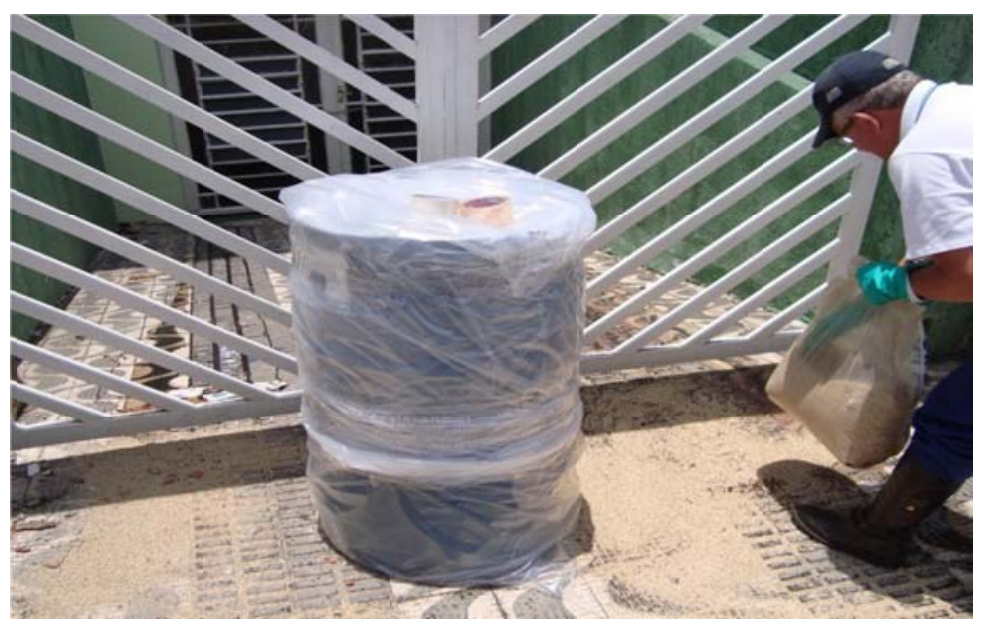

FIGURA 43 - Registro fotográfico de ação emergencial decorrente de descarte de tambor contendo resíduo químico em frente à residência. Fonte: CETESB - Companhia Ambiental do Estado de São Paulo(Banco de Imagem).

Percentual semelhante $(10,7 \%)$ menciona o ar como um dos meios físicos afetados. Este fato está associado a eventuais incômoidos do odor característico ou em uma situação ainda mais grave como exemplo, o efeito da fumaça e dos vapores resultantes da combustão espontânea dos resíduos, ou provocada por terceiros, causando incômodo ou efeitos adversos à saúde. 
$21,4 \%$ dos entrevistados consideram que ruas e rodovias são importantes meios afetados nos descartes de resíduos químicos uma vez que estes afetam a população diretamente. Nesses casos, a grande dificuldade enfrentada é que as prefeituras não dispõem de infraestrutura compatível para a sua remoção, transporte, armazenamento e, principalmente, de recursos para destinação final adequada que atendam aos requisitos legais da legislação ambiental vigente.

Situações de descarte de resíduos químicos em logradouros públicos requerem sempre intervenções imediatas em face da possibilidade de contaminação da população, que nesse caso é o principal motivo de preocupação. O REQ 171/2009, de 17 de junho de 2009, descreve o atendimento emergencial envolvendo o descarte de diversas embalagens contendo resíduos químicos na Av. Presidente Wilson e suas imediações, Vila Independência, Ipiranga, São Paulo, como ilustrado na FIG.44.

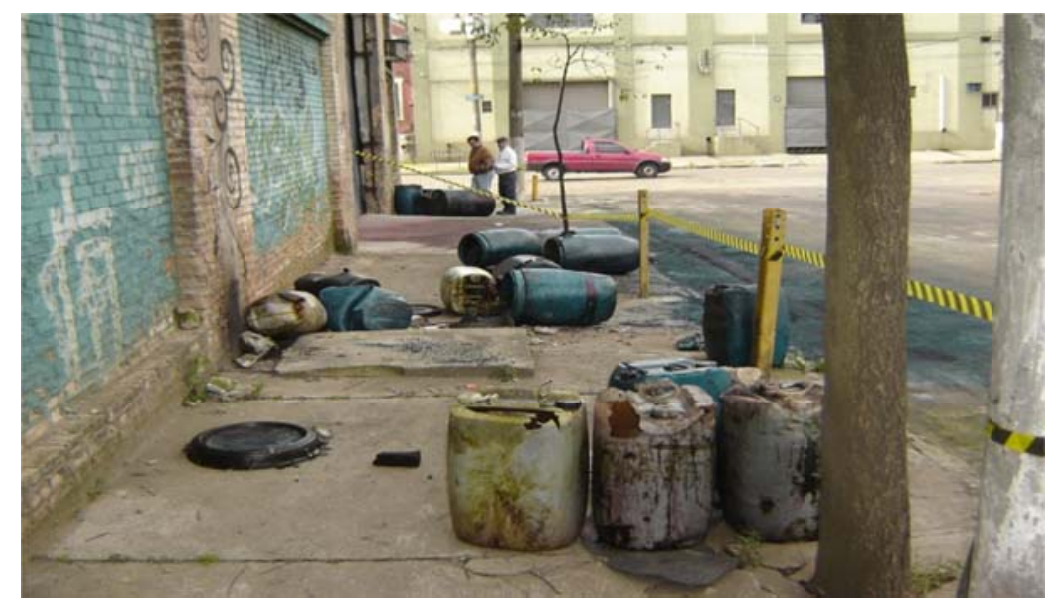

FIGURA 44 - Registro fotográfico do descarte de diversas embalagens contendo resíduos químicos em via pública (Av.Presidente Wilson).

Fonte: CETESB - Companhia Ambiental do Estado de São Paulo, 2009 (Banco de Imagem).

Em relação às rodovias, deve-se observar em primeiro lugar se os resíduos estão inseridos na faixa de domínio da concessionária. Em caso positivo, fica sob responsabilidade da concessionária providenciar os recursos necessários para realizar 0 atendimento emergencial, incluindo a remoção, transporte, armazenamento temporário e destinação final, com acompanhamento do órgão 
ambiental. Em caso negativo, faz-se necessário o acionamento do responsável pela área onde foram depositados os resíduos, ou comunicar os responsáveis pelas embalagens caso estejam identificadas.

Na FIG.45 observa-se a ocorrência do descarte de produto/resíduo na margem da Rod Anhanguera, km 34, município de Cajamar. Segundo dados do REQ 045/2012, o fato ocorreu em 09 de fevereiro de 2012, quando funcionários da CCR AutoBan, empresa que administra a rodovia, constataram a presença de aproximadamente $300 \mathrm{~kg}$ de um pó branco, sem odor e sem identificação, sendo acionados a CETESB - Companhia Ambiental do Estado de São Paulo e o Corpo de Bombeiros.

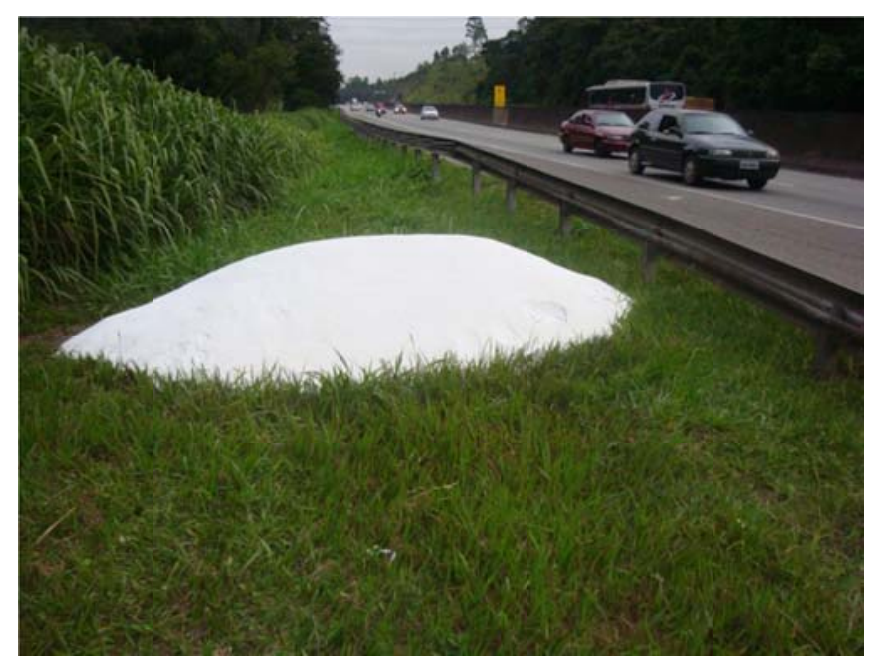

FIGURA 45 - Registro fotográfico da ocorrência do descarte de resíduo químico na margem da Rodovia Anhanguera. Fonte: CETESB - Companhia Ambiental do Estado de São Paulo (Banco de Imagem).

b. Principais consequências observadas segundo a percepção dos entrevistados devido à omissão ou retardo das autoridades públicas em atender prontamente emergências envolvendo descarte de resíduos químicos.

A FIG. 46 mostra os resultados da pesquisa relativa às consequências da omissão ou do retardo das autoridades públicas em atender prontamente emergências envolvendo descarte de resíduos químicos. 


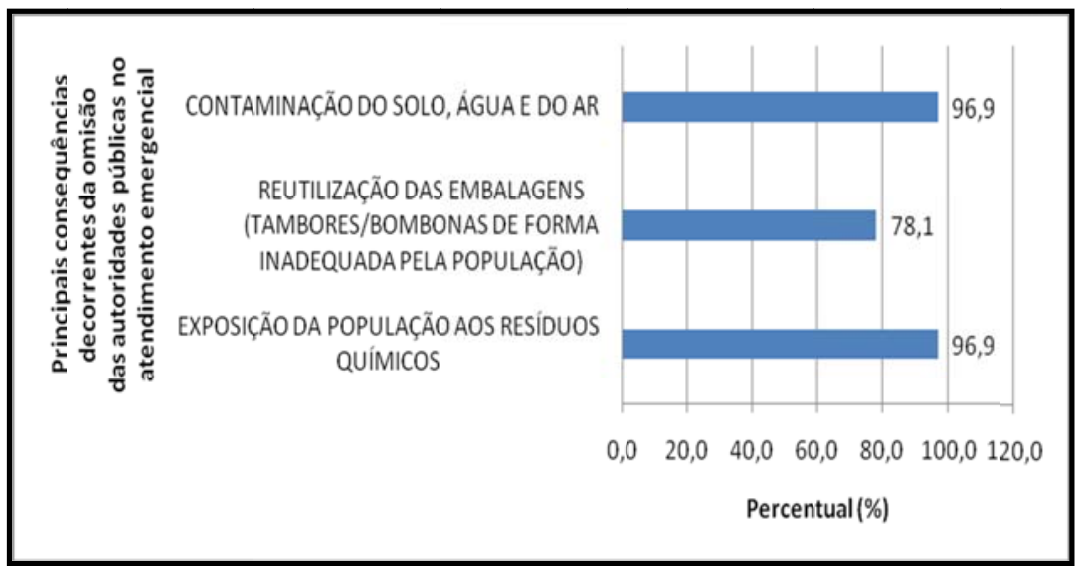

FIGURA 46 - Avaliação da percepção dos entrevistados quanto à omissão ou retardo das autoridades públicas em atender prontamente emergências envolvendo descarte de resíduos químicos. Fonte: CETESB - Companhia Ambiental do Estado de São Paulo (Banco de Imagem).

Ressalta-se aqui, que esse item considerou respostas múltiplas e, portanto, o percentual não totaliza $100 \%$.

O resultado desse item da pesquisa evidencia as múltiplas consequências negativas de ordem socioambiental e de saúde pública provocada pelo descarte de resíduos químicos, em especial quando há retardo na resposta emergencial.

Quanto aos aspectos ambientais merece atenção a possibilidade de contaminação do solo, da água e do ar, como ilustrado no item anterior com os casos de atendimentos emergenciais realizados pela CETESB - Companhia Ambiental do Estado de São Paulo.

Um dos principais efeitos adversos à saúde pública é a possibilidade da população residente próxima da área afetada inalar gases ou vapores provenientes das inúmeras substâncias químicas, ou mesmo, o contato direto com essas substâncias, podendo causar desde irritação da pele, até mesmo, nos casos mais graves, queimaduras químicas. 
Nesse sentido, chama atenção para a possibilidade de que crianças e adultos tenham contato direto com os resíduos e venham a se intoxicar. É comum em áreas periféricas das regiões metropolitanas do país que crianças desenvolvam atividades recreativas nas ruas e em terrenos baldios, o que nesses casos as tornam mais vulneráveis à exposição aos agentes químicos.

Um caso de ampla repercussão sobre intoxicação química é mencionado por MILLER (2007) acerca de resíduos químicos, com pelo menos 200 tipos de compostos, armazenados em barris de aço, enterrados em um canal situado em Niagara Falls, no estado de Nova York, pela empresa Hooker Chemicals and Plastics entre 1942 e 1953. Em 1976, os moradores passaram a reclamar para as autoridades municipais do cheiro forte e das queimaduras em crianças que brincavam na área do Canal. Essa área ficou internacionalmente conhecido como "Love Canal" em homenagem a seu construtor William Love.

Nesse contexto se insere a preocupação da exposição de crianças às substâncias químicas presentes nos resíduos descartados em vias públicas. As crianças se expõem mais às toxinas ambientais do que os adultos (NATIONAL RESEARCH COUNCIL, 1993).

No REQ 288/2009, referente à ocorrência atendida em 26 de setembro de 2009 na Rua Solidariedade $n^{\circ} 113$, Morro Doce, município de São Paulo, foi constatado que diversas embalagens contendo resíduos químicos haviam sido abandonadas em via pública por um morador residente naquela rua.

Na FIG. 47 observa-se a vulnerabilidade da população local ao transitar próximo das embalagens supostamente contaminadas. 


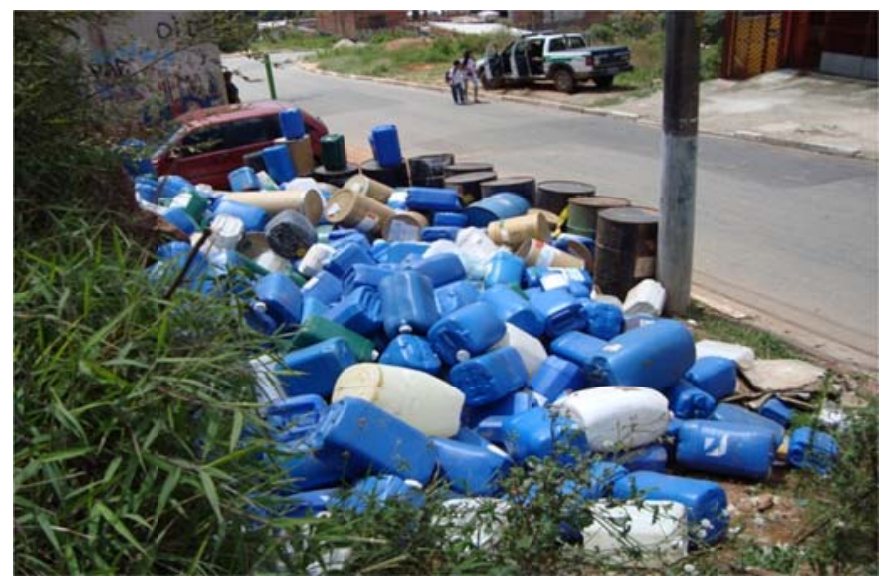

FIGURA 47 - Registro fotográfico de diversas bombonas plásticas e tambores metálicos de 200 litros, contendo resíduos químicos deixados em via pública. Fonte: CETESB - Companhia Ambiental do Estado de São Paulo (Banco de Imagem).

Quanto aos aspectos socioeconômicos, o resultado da pesquisa demonstra pelas respostas dos entrevistados e entidades envolvidas, que a reutilização de embalagens de resíduos químicos pela população, principalmente tambores e bombonas, é uma ameaça à saúde. Há registro de casos atendidos pela CETESB - Companhia Ambiental do Estado de São Paulo em que a população enxergou nessas embalagens uma forma de reaproveitá-las para armazenar água para consumo humano.

Outro interesse que essas embalagens metálicas podem despertar em catadores autônomos é a possibilidade de sua revenda para sucateiros. A situação nesse caso se agrava durante a manipulação dos resíduos químicos na operação de esvaziamento dessas embalagens, expondo essas pessoas a riscos significativos de contaminação química por inalação ou contato dérmico.

Essa situação é ainda mais preocupante do ponto de vista de saúde pública quando a operação de reaproveitamento de embalagens com substâncias químicas se dá no interior de residências, evidenciando assim a baixa percepção de risco daqueles que executam essa operação, dada a possibilidade de contaminação. 
Um exemplo de reutilização de embalagens de resíduos químicos pela população ocorreu no atendimento descrito no REQ 077/2010, na Estrada Albino Martelo s/n, Vila Nova Bonsucesso, em Guarulhos, em 14 de fevereiro de 2010. Foi observado que existiam 40 tambores com resíduos sólidos e líquidos descartados numa extensão de quatrocentos metros da Estrada Albino Martelo. Consta desse registro de atendimento que alguns munícipes descartaram os resíduos na pista e levaram o tambor.

Ao chegar ao local os técnicos do Setor de Operações de Emergência da CETESB, iniciaram prontamente o processo de destombamento dos tambores que estavam deitados, deixando-os na posição vertical e impedindo assim que o resíduo viesse a atingir o solo.

Os dados aqui referenciados enfatizam a necessidade de um pronto atendimento emergencial quando da notificação de casos de descarte de resíduos químicos pelas autoridades competentes. Esse pronto atendimento deve vir acompanhado de capacitação do corpo técnico para que se avaliem com profundidade as eventuais consequências de emergências químicas envolvendo descarte de resíduos químicos.

\section{Capacitação técnica das equipes de resposta a acidentes ambientais envolvendo descarte de resíduos químicos}

a. A realização de treinamento/capacitação sobre aspectos de segurança com ênfase no atendimento a emergências com produtos químicos.

A FIG.48 apresenta a capacitação técnica das equipes quanto à resposta às emergências químicas. 


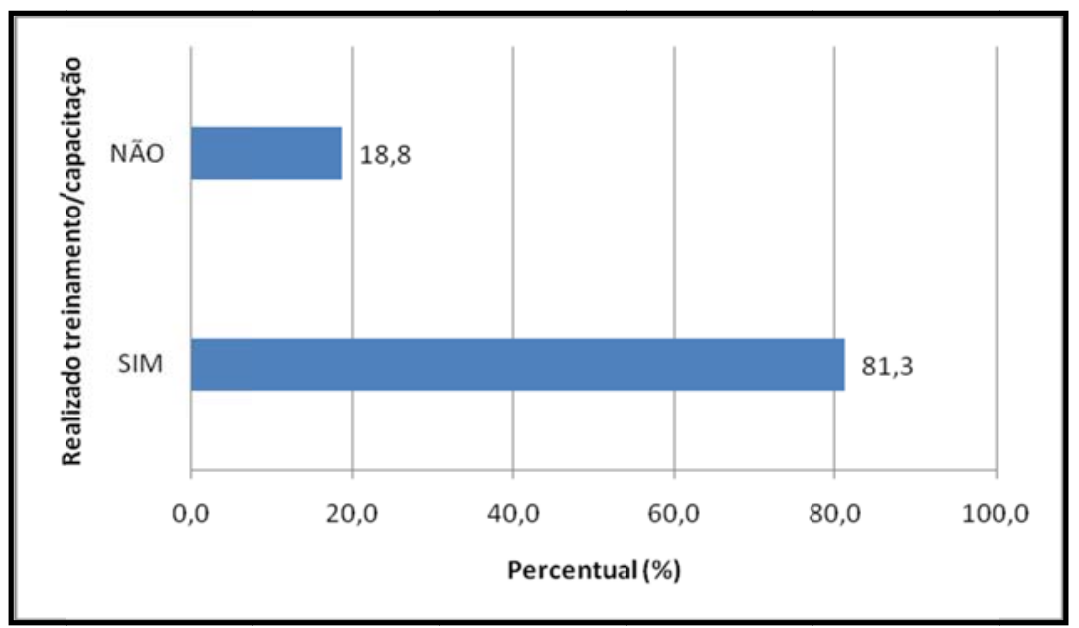

FIGURA 48 - Realização de treinamento/capacitação sobre aspectos de segurança com ênfase para atendimento a emergências com produtos químicos.

A pesquisa demonstrou que $81,3 \%$ dos entrevistados receberam pelo menos um treinamento específico sobre atendimento a emergências com produtos químicos. Dos que receberam esse treinamento estão em sua totalidade os bombeiros e técnicos da CETESB - Companhia Ambiental do Estado de São Paulo. Faz parte também desses técnicos que receberam treinamento alguns agentes de Defesa Civil e das Secretarias de Meio Ambiente. O percentual dos 18,8\% que nunca receberam qualquer treinamento nessa área são também alguns agentes de Defesa Civil e de Secretarias municipais.

Os treinamentos mencionados pelos entrevistados na área de emergências químicas foram aqueles oferecidos pela Escola Superior de Bombeiros de Franco da Rocha, da CETESB - Companhia Ambiental do Estado de São Paulo e de empresas especializadas em atendimento a emergências químicas.

Manter equipes técnicas de órgãos públicos como, Defesa Civil, Corpo de Bombeiros e Órgãos Ambientais treinados e capacitados nos mais diversos temas que atuam diariamente é sempre um grande desafio. Isso porque esse programa de capacitação dever ser continuado. Importante também mencionar que a capacitação dessas equipes proporciona entrosamento prévio o que facilita a coordenação das operações de emergência. 
A relevância desse item da pesquisa se justifica pela importância que a competência técnica adquirida por meio de capacitação/treinamento na temática de atendimento a emergências com produtos químicos exerce naqueles profissionais designados por suas instituições para realizarem o atendimento emergencial envolvendo descarte de resíduos químicos.

Outra vantagem da capacitação está na aproximação e troca de conhecimentos dos atores durante os treinamentos, o que favorece 0 relacionamento pessoal durante as emergências que são normalmente situações de grande estresse.

É sem dúvida motivo de preocupação que profissionais que nunca receberam treinamento na área de emergências químicas estejam presentes nesses cenários. Não apenas por não terem recebido informações básicas sobre riscos químicos, sistemas de classificação e identificação de produtos químicos, proteção pessoal e descontaminação, mas também pela falta de elementos básicos importantes para avaliação dos cenários acidentais.

\section{Perfil da instituição em que o pesquisado atua}

a. disponibilidade e rapidez no atendimento a situações emergenciais envolvendo descarte de resíduos químicos (FIG. 49).

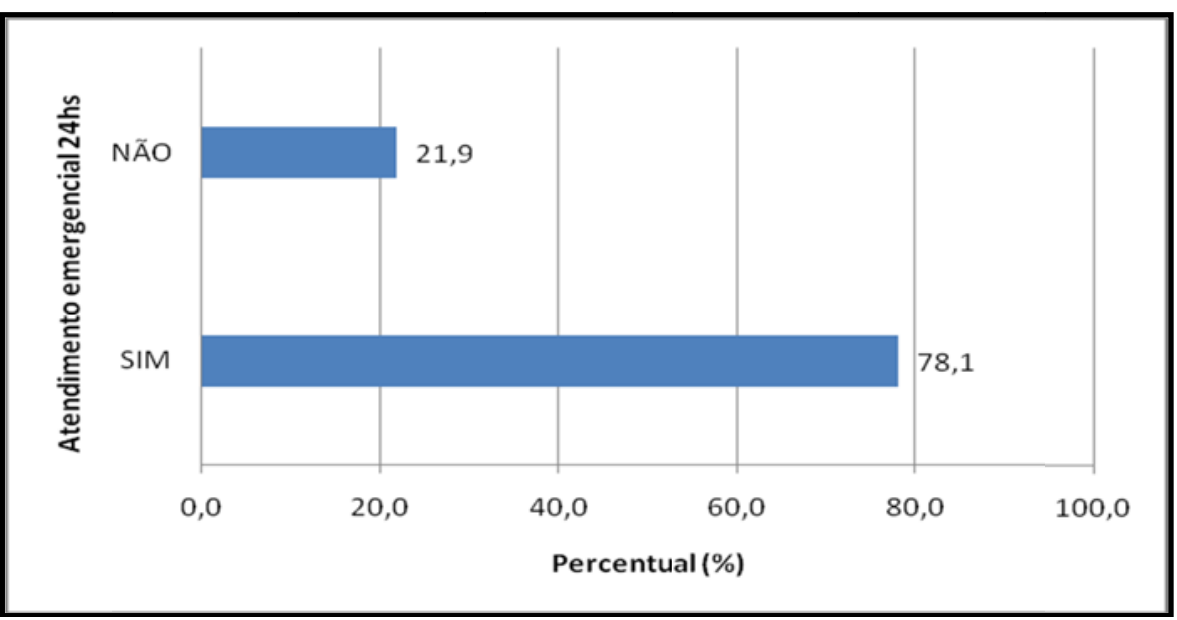

FIGURA 49 - Disponibilidade para atendimento emergencial 24hs em casos de descarte de resíduos químicos. 
A FIG. 49 indica que $78,1 \%$ dos entrevistados responderam que sua instituição possui disponibilidade para atendimento 24 horas por dia, incluindo o Corpo de Bombeiros, a CETESB e a Defesa Civil.

No Estado de São Paulo, a CETESB - Companhia Ambiental do Estado de São Paulo, participa dos atendimentos emergenciais em caráter permanente e é, via de regra, acompanhada pelo Corpo de Bombeiros, agentes de defesa civil e, dependendo do município e da gravidade da situação, pelas secretarias de meio ambiente municipal ou estadual.

Outros $21,9 \%$ responderam que não estão disponíveis 24 horas. Incluem-se nesse caso os técnicos da Secretaria de Meio Ambiente de alguns municípios que prestam o atendimento em horário administrativo, sendo representados aos sábados, domingos, feriados e fora de horário administrativos pela Defesa Civil do município.

A pesquisa revela que na grande maioria das instituições visitadas $(78,1 \%) \circ$ atendimento às emergências químicas envolvendo descarte de resíduos químicos é realizado ininterruptamente.

É inegável o aspecto positivo da participação efetiva de instituições com distintas competências como da área de segurança, representada pelo Corpo de Bombeiros, e da área ambiental como a CETESB - Companhia Ambiental do Estado de São Paulo e pela Defesa Civil, representando a prefeitura municipal, desempenhando um papel crucial na fase emergencial, podendo intervir rapidamente nas ações de combate que são decisivas para o controle da situação e redução de danos à segurança e saúde da população e ao meio ambiente.

No Estado de São Paulo as competências e atribuições dos Setores de Segurança Pública, Saúde e Meio Ambiente foram consolidadas em outubro de 2012 por meio de um "Protocolo Unificado de Atendimento a Emergências Químicas no Estado de São Paulo". As responsabilidades podem e devem ser 
compartilhadas, assim como as potencialidades e deficiências de cada setor para o enfrentamento de situações de emergência, devem ser já previamente conhecidas por todos os integrantes do poder público (SÃO PAULO (Estado), 2012).

Esse protocolo tem como principal objetivo integrar as atividades dos órgãos públicos buscando ações de respostas eficientes para atender da melhor forma as demandas geradas pela população. A implantação do Protocolo junto aos órgãos públicos competentes será de responsabilidade da Coordenadoria Estadual de Defesa Civil.

b.Disponibilidade de Equipamentos de Proteção Individual (EPIs) (FIG. 50).

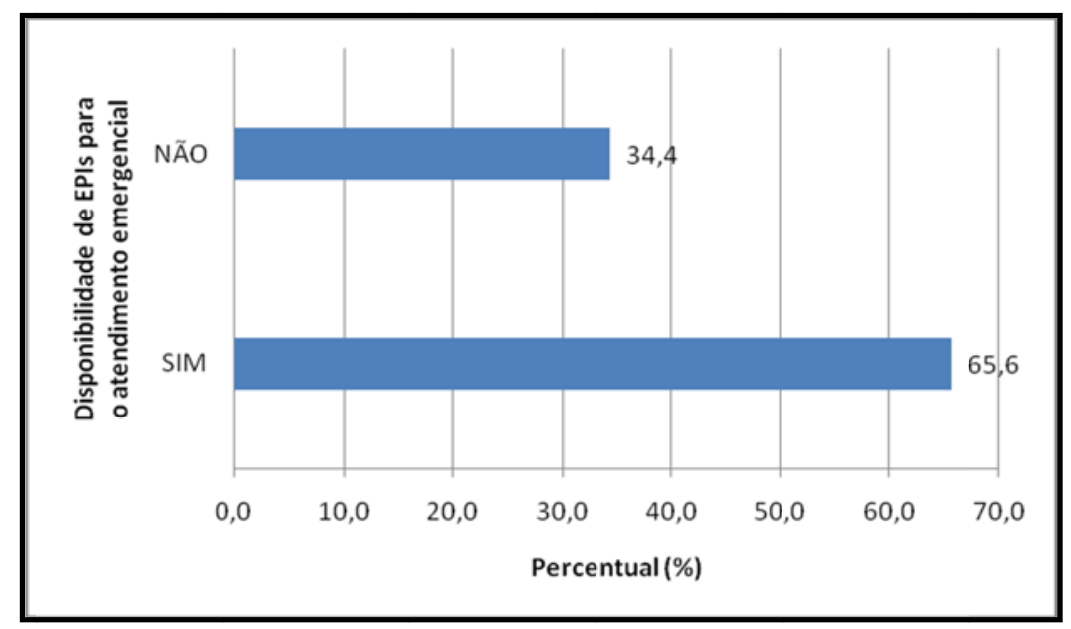

FIGURA 50 - Disponibilidade de Equipamentos de Proteção Individual (EPIs) para atendimento emergencial.

O resultado desse item da pesquisa demonstra que a maioria dos entrevistados $(65,6 \%)$ respondeu que há disponível em sua instituição EPls para o atendimento emergencial. Entretanto, restam ainda aqueles $(34,4 \%)$ que não possuem tais equipamentos.

É de fundamental importância para proteção pessoal e o sucesso do atendimento emergencial que as equipes estejam devidamente protegidas, reduzindo o risco de acidente de trabalho. 
Os EPIs são considerados dispositivos de uso individual destinados a proteger a integridade física e a saúde do trabalhador (COMISSÃO INTERNA DE PREVENÇÃO DE ACIDENTES, 1992).

Importante mencionar o fato da instituição disponibilizar EPIs para os atendimentos, e ser comum deparar-se com situações em que os técnicos subestimam os riscos químicos e deixam de utilizar luvas, botas, roupas de proteção química e respiradores faciais dotados de filtro químico. Tais equipamentos, dependendo do cenário acidental e gravidade da situação, são indispensáveis.

O uso de EPIs deve ser obrigatório, em especial na fase inicial de avaliação dos riscos químicos. A obrigatoriedade dos EPIs deve ser não somente para os técnicos que representam as instituições, mas também para os trabalhadores que efetivamente recolherão as embalagens, quer seja de forma manual ou mecânica, e os condutores de veículos pesados, muito comuns nessas situações, como retroescavadeira, pá carregadeira e caminhões.

No âmbito internacional a Occupational Safety and Health Administration (OSHA) define os EPls que devem ser utilizados para olhos, cabeça, extremidades, as roupas de proteção, os dispositivos de respiração e outros.

De acordo com a Norma Regulamentadora $n^{\circ} 6$ do Ministério do Trabalho e Emprego (MTE), os empregados são obrigados a usar os EPls e responsabilizarem-se pela guarda e pela conservação deles (BRASIL, 1978). 
c. Registros dos atendimentos em Banco de Dados (FIG. 51).

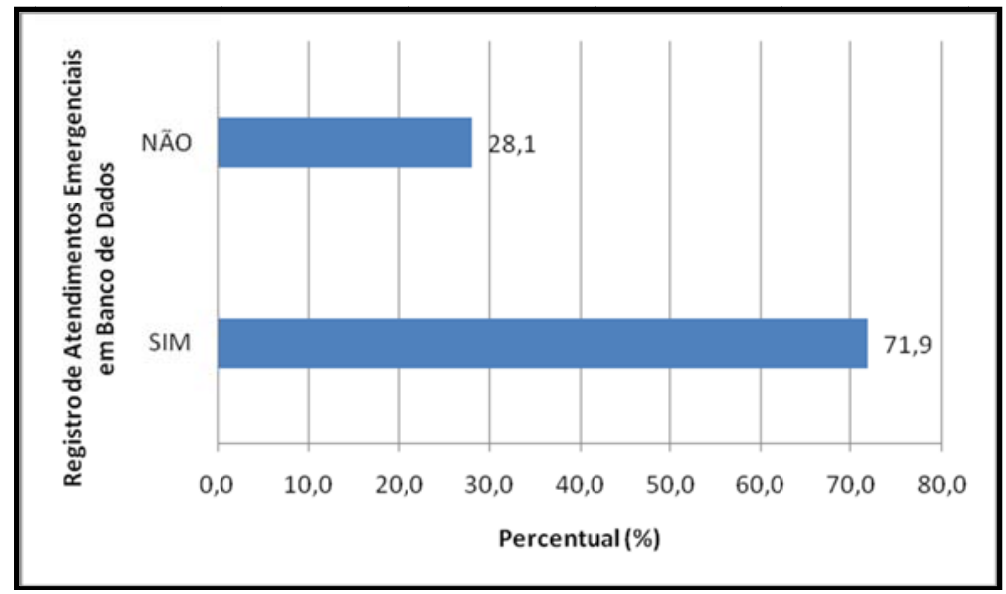

FIGURA 51 - Resposta da pesquisa quanto ao registro dos atendimentos emergenciais em Banco de dados.

A resposta de $71,9 \%$ dos entrevistados, de que em sua instituição há Banco de Dados de atendimentos emergenciais, retrata a possibilidade de conhecimento detalhado de sua distribuição espacial no âmbito da RMSP, facilitando a análise em termos de eventuais efeitos danosos da prática lesiva caracterizada aqui pelos descartes de resíduos químicos.

De todos os entrevistados que responderam positivamente a esse item estão a CETESB - Companhia Ambiental do Estado de São Paulo e o Corpo de Bombeiros. A CETESB disponibiliza seu Banco de Dados na "internet" com possibilidade de consulta da atividade "descarte de resíduos químicos" com acesso pelo endereço eletrônico http://sistemasinter.CETESB.sp.gov.br/emergencia/relatorio.php e o Corpo de Bombeiros cuja consulta pode ser feita pelo seu Anuário Estatístico.

Daqueles que responderam negativamente a esse item estão entre eles alguns representantes das Secretarias de Meio Ambiente na esfera municipal e da Defesa Civil.

\section{Informações sobre o atendimento emergencial em si}

a. Identificação dos responsáveis pelo descarte de resíduos químicos (FIG. 52) 


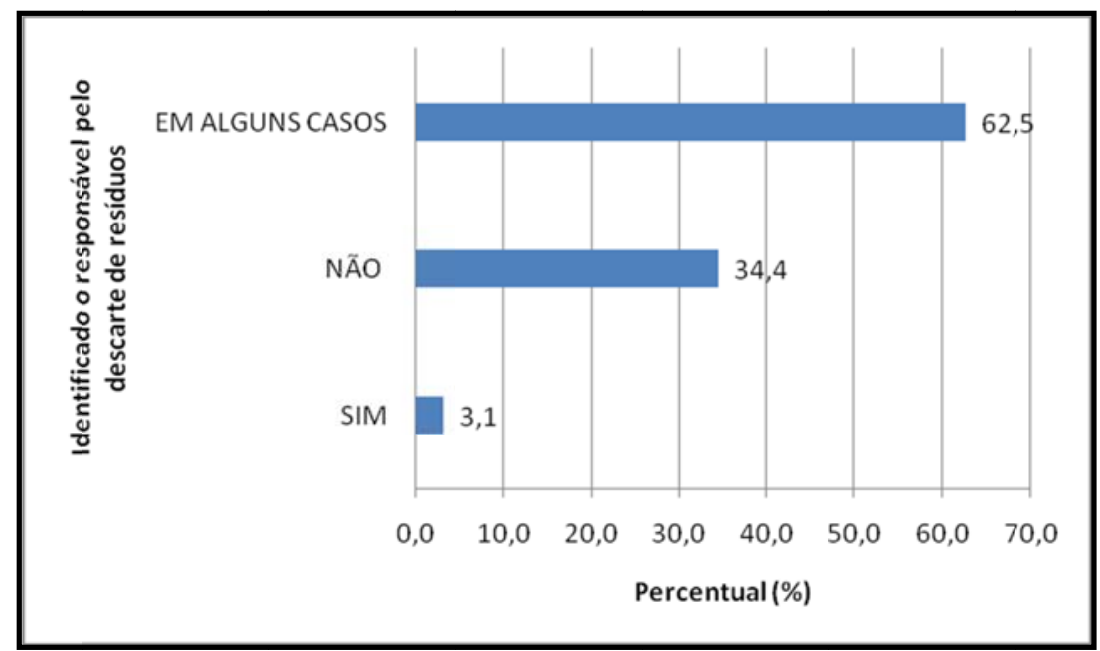

FIGURA 52 - Resultado da pesquisa quanto à identificação dos responsáveis pelo descarte de resíduos químicos.

Esta avaliação foi um dos itens da pesquisa que revela uma das principais dificuldades no atendimento emergencial, ou seja, a falta de identificação dos responsáveis pela ação de descarte de resíduos químicos na RMSP.

A grande maioria $(62,5 \%)$ respondeu que em alguns casos dos atendimentos em que participou foi possível identificar o responsável.

Durante a entrevista este pesquisador observou a partir das respostas dos entrevistados que a opção por "em alguns casos" se deu porque, pelo menos, em um dos atendimentos por eles realizados foi possível identificar os responsáveis.

A seguir serão relatados na TAB.10 alguns atendimentos avaliados nos REQs onde foi possível a identificação dos responsáveis pela ação do descarte ou de seus corresponsáveis. 
TABELA 10 - Resumo das ocorrências onde foi possível a identificação dos responsáveis ou de seus corresponsáveis pela ação do descarte.

\begin{tabular}{|c|c|c|c|c|c|c|}
\hline REQ/Ano & Data & Localização & $\begin{array}{l}\text { Ocorrência } \\
\text { de vazamento } \\
\text { no solo? }\end{array}$ & $\begin{array}{c}\text { Quantidade } \\
\text { vazada }\end{array}$ & $\begin{array}{l}\text { Aspectosl } \\
\text { natureza dos } \\
\text { resíduos }\end{array}$ & $\begin{array}{c}\text { Tipo de } \\
\text { embalagens }\end{array}$ \\
\hline $036 / 2005$ & 11.02 .05 & $\begin{array}{l}\text { Estrada do } \\
\text { Campo Limpo X } \\
\text { Estrada São } \\
\text { Bento, Jd } \\
\text { Moraes, } \\
\text { Itaquaquecetuba }\end{array}$ & Sim. & $\begin{array}{l}\text { Não } \\
\text { estimada }\end{array}$ & $\begin{array}{l}\text { Material em pó } \\
\text { de coloração } \\
\text { rosa e } \\
\text { esverdeado }\end{array}$ & big bags \\
\hline $372 / 2008$ & 17.10 .08 & $\begin{array}{l}\text { Rua Imirim, s/n, } \\
\text { Chácara Marcos, } \\
\text { Barueri }\end{array}$ & Sim. & $\begin{array}{l}\text { Não } \\
\text { estimada }\end{array}$ & $\begin{array}{l}\text { Resíduos } \\
\text { sólidos e } \\
\text { líquidos, com } \\
\text { forte odor }\end{array}$ & $\begin{array}{l}\text { Sacos } \\
\text { plásticos, } \\
\text { bombonas }\end{array}$ \\
\hline $249 / 2011$ & 01.08 .11 & $\begin{array}{l}\text { Av. Presidente } \\
\text { Campos Sales, } \\
5510 \text {, Morada do } \\
\text { Sol, Mogi das } \\
\text { Cruzes }\end{array}$ & Não. & $\begin{array}{l}\text { Não houve } \\
\text { vazamento }\end{array}$ & $\begin{array}{l}\text { Ác Clorídrico, Ác } \\
\text { Fosfórico, Ác } \\
\text { Nítrico, Amônia } \\
\text { em solução, } \\
\text { Hidróxido de } \\
\text { sódio }\end{array}$ & Bombonas \\
\hline
\end{tabular}

No REQ 036/2005, foi possível identificar entre os resíduos documentos contendo o nome de duas empresas que atuam na Região de Itaquaquecetuba. A Prefeitura de Itaquaquecetuba providenciou a remoção dos resíduos e seu armazenamento provisório no próprio caminhão, utilizado para transporte no interior de galpão de manutenção da própria prefeitura.

A CETESB - Companhia Ambiental do Estado de São Paulo promoveu vistorias nas empresas responsáveis pelos resíduos descartados e os seus representantes foram notificados da necessidade da remoção dos resíduos armazenados temporariamente pela prefeitura.

No REQ 372/2008 foram identificados vários EPIs contaminados como luvas e máscaras, em um terreno distante cerca de 100 metros do Rio Tietê ilustrado na FIG.53. 


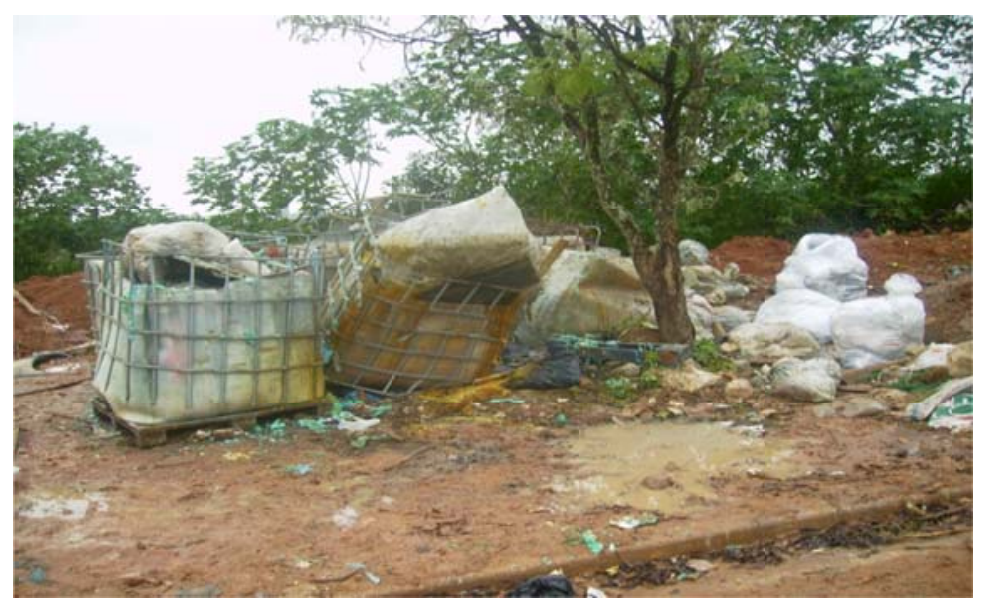

FIGURA 53 - Registro fotográfico da ocorrência de Descarte de diversas embalagens contendo resíduos químicas. Fonte: CETESB - Companhia Ambiental do Estado de São Paulo (Banco de Imagem).

Nesse caso o que chamou atenção das equipes de atendimento a emergência e contribuiu para identificar o possível responsável foram uniformes deixados juntos aos resíduos, contendo a identificação de uma empresa da região que trabalha com superfícies metálicas, como ilustra a FIG.54.

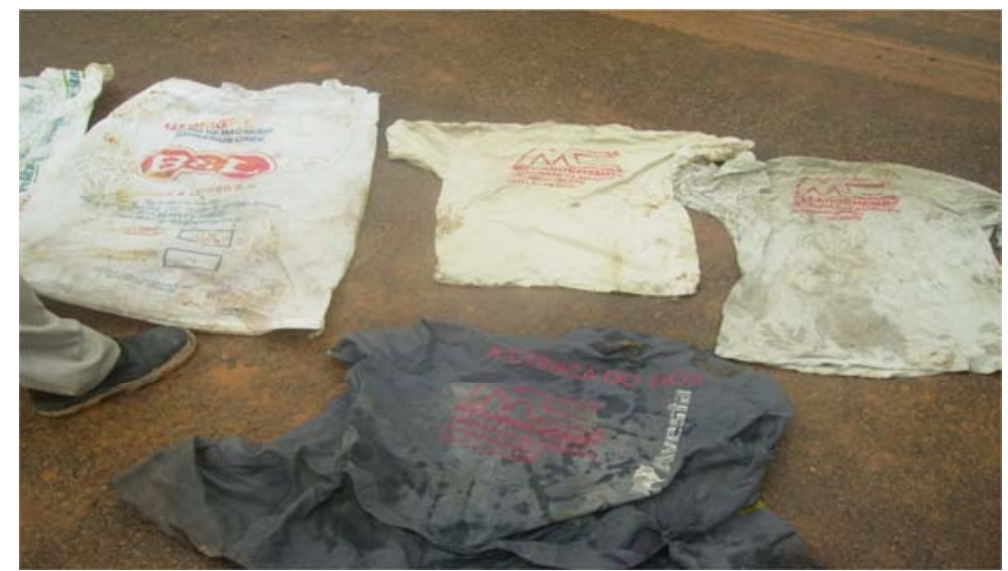

FIGURA 54 - Registro fotográfico de uniformes descartados juntos com os resíduos químicos.

Fonte: CETESB - Companhia Ambiental do Estado de São Paulo (Banco de Imagem).

Esse atendimento contou com a importante participação da Defesa Civil e da Guarda Municipal de Barueri que, juntamente com a Polícia Ambiental, passaram a investigar o caso. Diante dos fatos, o caso foi levado ao 
conhecimento da autoridade competente (Delegacia de Polícia de Barueri) que compareceu ao local do evento.

$\mathrm{Na}$ vistoria realizada pela autoridade policial na empresa suspeita, foram encontradas bombonas semelhantes àquelas deixadas no local dos fatos. Diante das fortes evidências, o representante legal da empresa, ainda que tenha declarado não ter determinado a colocação do material no local do sinistro, afirmou que por meios próprios providenciaria a remoção de todo o material para o seu pátio, onde adotaria providências para caracterizar os resíduos químicos e encaminhá-los sob orientação da CETESB - Companhia Ambiental do Estado de São Paulo a destinação final adequada.

No REQ 249/2011, verificou-se durante o atendimento no local que se tratava de desmanche de caminhões roubados.

Nesse atendimento foi possível identificar a empresa responsável por meio dos rótulos que constavam de algumas embalagens. Ao ser comunicada, a empresa responsável comprometeu-se de imediato em promover sua remoção. Esse caso ilustra bem as situações de roubo de carga seguido de seu abandono, por não ser de interesse dos infratores os produtos químicos.

As lições aprendidas desses atendimentos evidenciam a necessidade de uma avaliação minuciosa na área do descarte na busca de dados relevantes, como a existência de rótulos nas embalagens, notas fiscais ou qualquer outro documento que possam levar ao infrator, poupando assim, recursos públicos para promoção da limpeza da área impactada com os resíduos químicos.

Fato é, que casos como esses aqui relatados se não permitiram a identificação clara do responsável, apontaram circunstâncias que no mínimo merecem a investigação policial. 
Daqueles que responderam não ter sido possível identificar os responsáveis pelo descarte ilegal de resíduos químicos $(34,4 \%)$ resultou certamente em maiores dificuldades para encerrar a fase emergencial, pois foi necessária a mobilização de recursos humanos e materiais, em geral fornecidos pela prefeitura.

Vale aqui ressaltar, ser comum as autoridades públicas responsáveis pelo atendimento emergencial solicitarem a presença no local de representantes de empresas sempre que for constatada sua identificação em rótulos ou inscrição gravada no corpo das embalagens dos resíduos.

b. Tempo médio despendido para atendimento emergencial (FIG. 55)

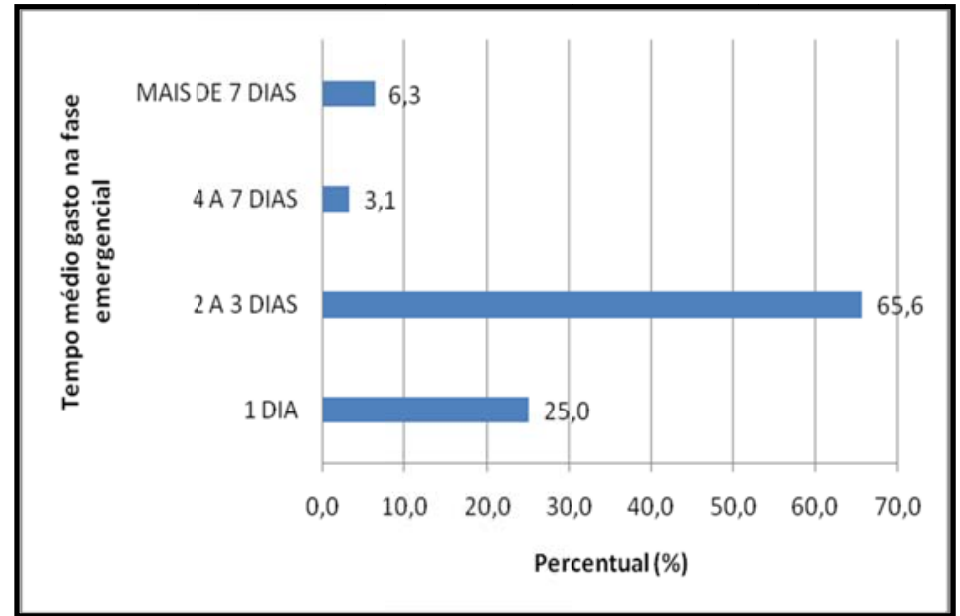

FIGURA 55 - Tempo médio utilizado para encerrar a fase emergencial.

Fonte: CETESB - Companhia Ambiental do Estado de São Paulo (Banco de Imagem).

Foi identificado que a maioria dos atendimentos $(65,6 \%)$ levou em média de 2 (dois) a 3 (três) dias para o encerramento da fase emergencial.

Esse tempo médio se deve às dificuldades normalmente encontradas pelas autoridades em obterem veículos, embalagens e máquinas compatíveis ao trabalho a ser realizado, muitas vezes em áreas de difícil acesso, como áreas 
de encosta de alta declividade, e o mais importante, o local a ser providenciado para destinar os resíduos no seu armazenamento temporário.

Um atendimento emergencial que ilustra bem o tempo médio de três dias para seu encerramento é o do REQ 123/2008, atendido em 10 de abril de 2008, quando 37 tambores foram descartados, em sua maioria em local de difícil acesso, nas proximidades da Av. Sezefredo Fagundes, altura do $n^{\circ} 25.000$, bairro Vila Cachoeira, município de São Paulo. Nesse caso, foram envolvidos inúmeros recursos materiais necessários para remoção, acondicionamento, logística para o atendimento e transporte dos resíduos químicos.

Na FIG. 56 é apresentada a complexidade no resgate dos tambores do local onde foram abandonados.

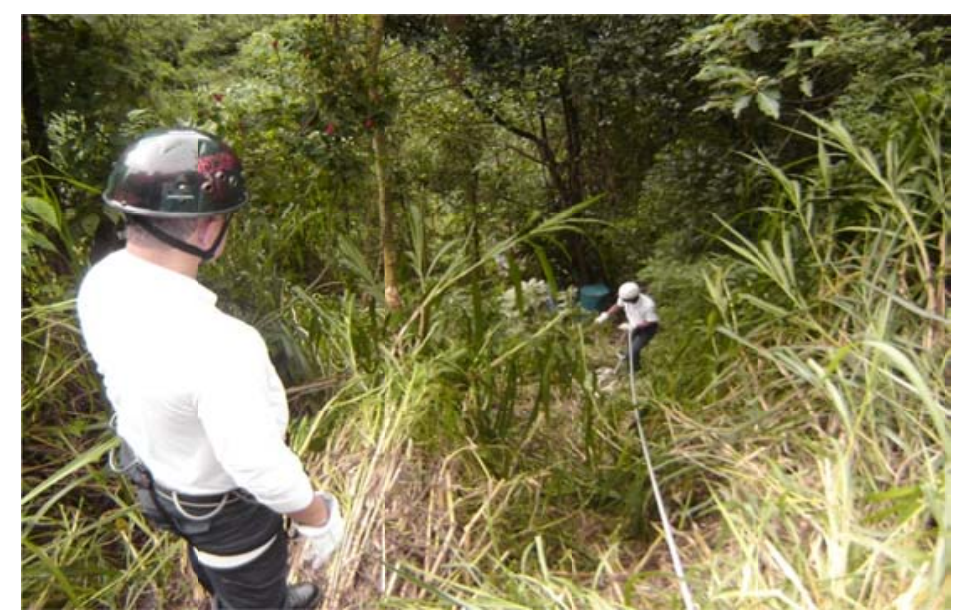

FIGURA 56 - Registro fotográfico da retirada dos tambores utilizando-se técnicas de "Rapel".

Fonte: CETESB - Companhia Ambiental do Estado de São Paulo (Banco de Imagem).

Operações dessa magnitude são necessariamente interrompidas durante a noite, por questões de segurança. A mobilização de equipes técnicas de órgãos públicos e de veículos dedicados envolveu:

Corpo de Bombeiros: 4 viaturas; 10 pessoas;

Defesa Civil Municipal: 6 viaturas; 1 máquina retro-escavadeira; 4 caminhões carroceria;2 caminhões "munck"; 1 guincho; aproximadamente 50 pessoas, 
entre agentes de defesa civil e funcionários;outros: luvas, botas, cordas, cintas, areia, pranchas de madeira, barraca de campanha e alimentos;

CETESB: 2 viaturas;5 técnicos; roupas de proteção química;luvas de proteção mecânica;máscaras de proteção respiratória facial e semi-facial;equipamentos de monitoramento;sacos plásticos para remoção de resíduos; rádios comunicadores;

Polícia Militar: 3 viaturas; 6 Policiais;

CET: 2 viaturas; 3 técnicos.

Pela FIG. 57 é possível visualizar veículos da Defesa Civil e do Corpo de Bombeiros mobilizados para resposta à emergência.

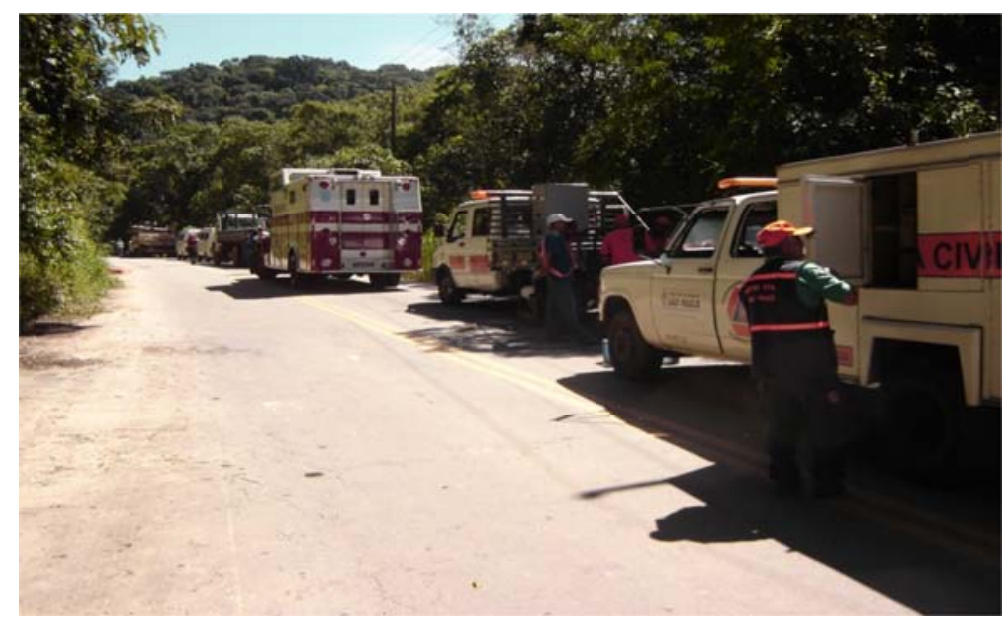

FIGURA 57 - Registro fotográfico de veículos mobilizados para remoção dos tambores contendo resíduos químicos. Fonte: CETESB - Companhia Ambiental do Estado de São Paulo (Banco de Imagem).

Das dificuldades encontradas nesse atendimento estão os 37 tambores restantes, dos quais 29 encontravam-se espalhados em um barranco com um declive de aproximadamente 85 metros de altura e em uma extensão de 123 metros. Desses tambores, 14 estavam na parte intermediária do declive e os 15 restantes em sua parte mais extrema.

Quando os entrevistados respondem que a fase emergencial se encerra com mais de 7 (sete) dias $(6,3 \%)$, certamente esse fato assume uma dimensão 
ainda mais preocupante, considerando-se haver nesse período uma maior probabilidade de chuvas e agravamento dos riscos de contaminação, além de expor ainda mais a população a riscos de intoxicação.

Isso se torna mais grave quando os resíduos são lançados a granel diretamente sob o solo. Esse tempo demasiado para encerramento da fase emergencial se acentua quando estão envolvidos grandes volumes de resíduos, dificuldades de acesso para sua remoção e pelos motivos já discutidos aqui anteriormente.

Idealmente, o que se espera é que a fase emergencial se encerre no primeiro dia do atendimento, como respondido por $25 \%$ dos entrevistados.

Nesses casos foram consideradas as situações onde estiveram envolvidas pequenas quantidades de resíduos, o acionamento das equipes emergenciais ocorreu em horário administrativo, os resíduos foram encontrados em áreas de fácil acesso para remoção e transporte, havia possibilidade dos resíduos serem armazenados temporariamente em áreas da prefeitura ou removidos pelas empresas responsáveis, identificadas que estavam nas embalagens dos resíduos. Todos esses fatos conjugados concorrem para o êxito do atendimento.

A situação aqui relatada pode ser demonstrada pelas FIG.58 e 59 durante atendimento emergencial dos registros REQ 252/2009, de 23 de agosto de 2009, quando um tambor contendo resíduo químico foi deixado na Rua Juraraterê, $n^{\circ} 10$, Itaim Paulista. Com intervenção do Corpo de Bombeiros, Defesa Civil e CETESB - Companhia Ambiental do Estado de São Paulo, o tambor foi envelopado com saco duplo de plástico resistente e levado pela Defesa Civil para área da Prefeitura até a destinação final adequada. 


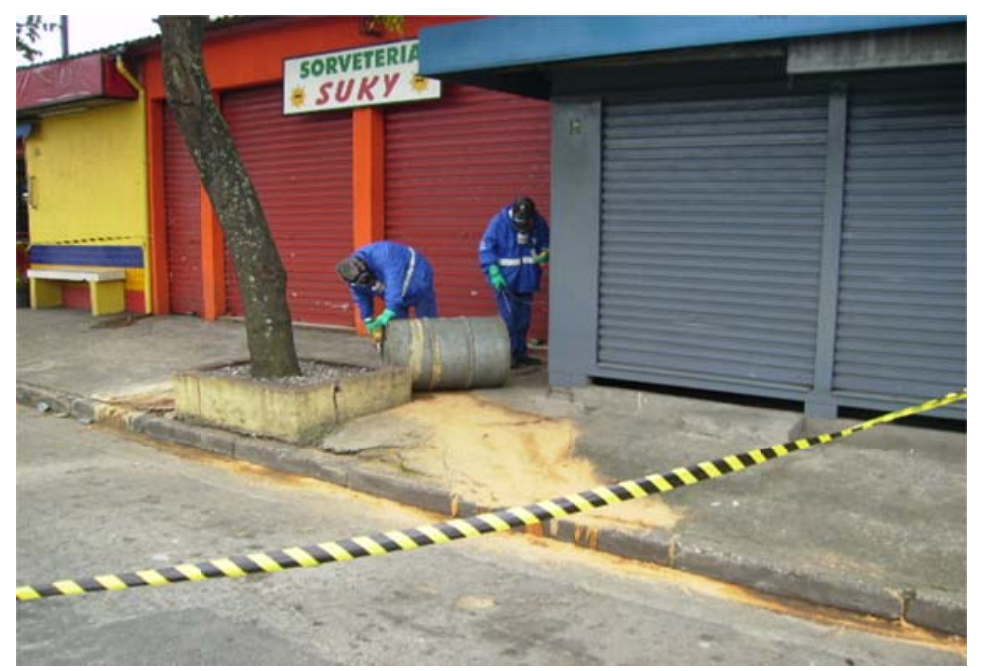

FIGURA 58 - Registro fotográfico da avaliação de

riscos químicos por técnicos da CETESB.

Fonte: CETESB - Companhia Ambiental do Estado de São Paulo (Banco de Imagem)

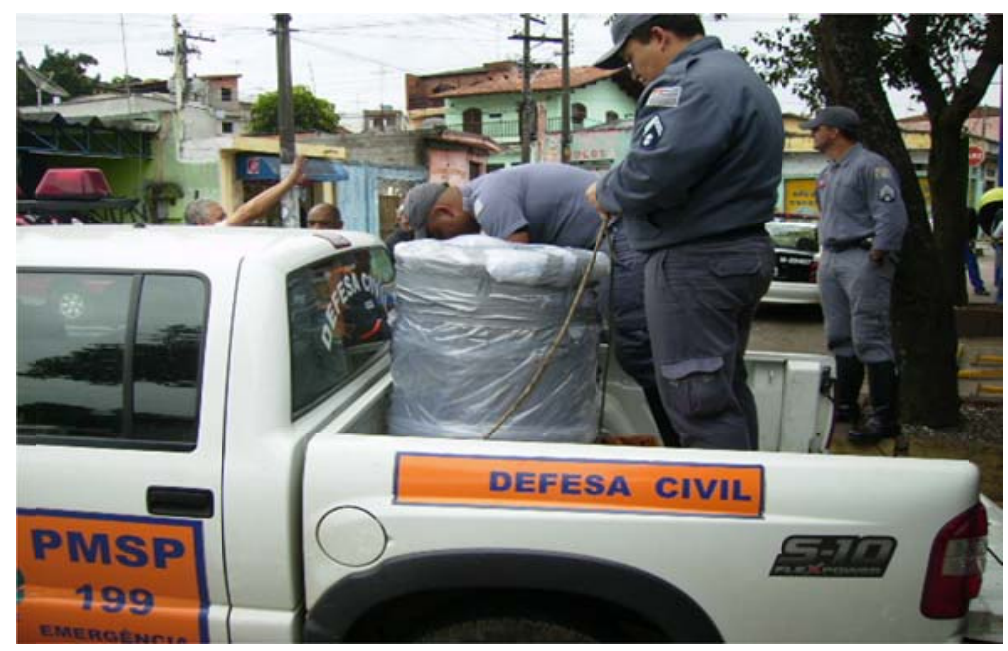

FIGURA 59 - Registro fotográfico da operação de transporte de tambor com resíduo químico.

Fonte: CETESB - Companhia Ambiental do Estado de São Paulo (Banco de Imagem). 
c. Participação em grupos de trabalhos na fase pós-emergencial para tratar da questão dos descartes de resíduos químicos (FIG.60).

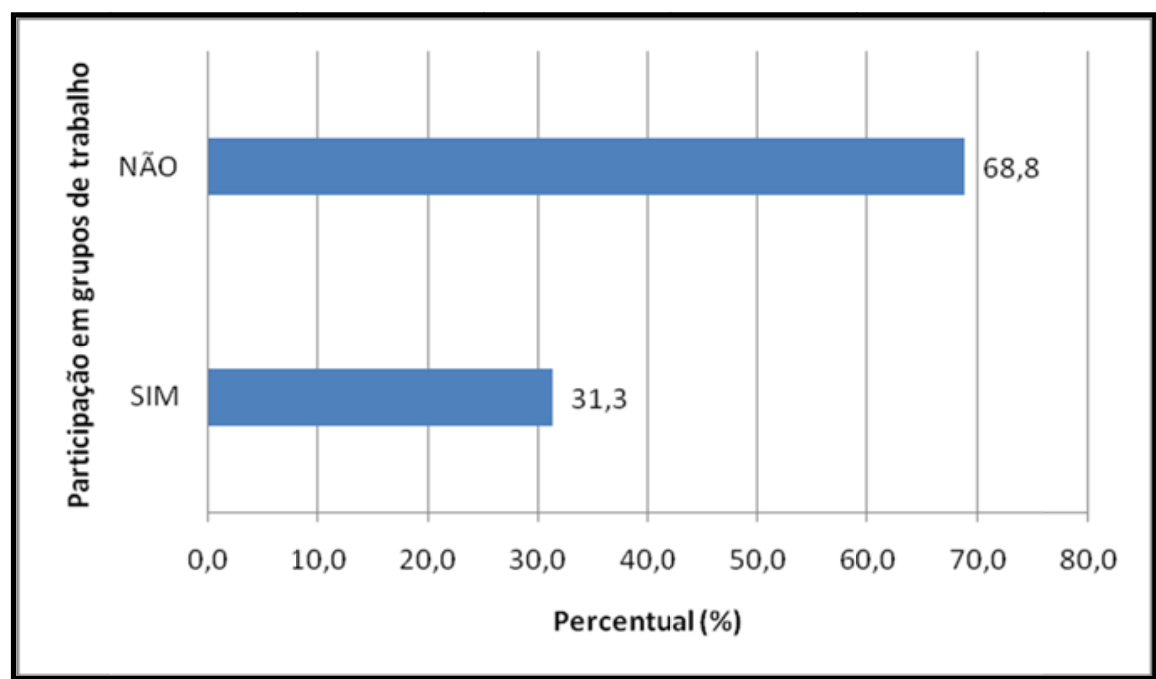

FIGURA 60 - Participação em grupos de trabalho para tratar das questões relacionadas ao descarte de resíduos químicos.

De acordo com os resultados desse item da pesquisa, verifica-se em $31,3 \%$ dos entrevistados a preocupação com a adoção de medidas preventivas que venham a colaborar com eventuais situações envolvendo descarte de resíduos químicos em seu município. Nessa situação, adotar medidas preventivas como, por exemplo, grupos de trabalho para discutir o assunto, significa antecipar-se a outros eventos e saber como enfrentá-los, uma vez que são situações que exigirão esforços conjugados de órgãos públicos nas esferas municipais e estadual.

Os conflitos entre instituições durante os atendimentos emergenciais são quase sempre inevitáveis, principalmente quanto à remoção dos resíduos da via pública e o seu armazenamento temporário em local seguro. Essas são algumas das razões para que esse tema não seja mais protelado e que venha a ser tratado por todos, reduzindo-se assim o tempo de resposta da fase emergencial e mitigando possíveis efeitos deletérios à saúde e segurança da população e ao meio ambiente. 
Os fatos acima expostos denotam a complexidade do tema e reforçam a necessidade de soluções coletivas e previamente tratadas entre instituições e que não sejam resolvidas de forma isolada, dependendo de ações pessoais, mas sim solucionadas a partir de uma atuação integradora, utilizando-se critérios técnicos e legais.

Nesse sentido, destaca-se a iniciativa da Prefeitura de São Paulo, em agosto de 2011, por meio da Coordenadoria Municipal de Defesa Civil ao criar grupo de trabalho multi-institucional para discussão e proposição de ações com relação aos riscos tecnológicos envolvendo emergências químicas relativas ao descarte de resíduos químicos no município de São Paulo.

A iniciativa da Prefeitura de São Paulo, com a criação desse grupo de trabalho, é de fato uma das poucas medidas que se tem notícia para enfrentar o problema do descarte ilegal de resíduos químicos, pois dos $31,3 \%$ que responderam positivamente a esse item estão incluídas reuniões realizadas muito mais com o objetivo de solucionar atendimentos emergenciais já ocorridos.

d. Notificação à Polícia sobre o atendimento emergencial (FIG. 61).

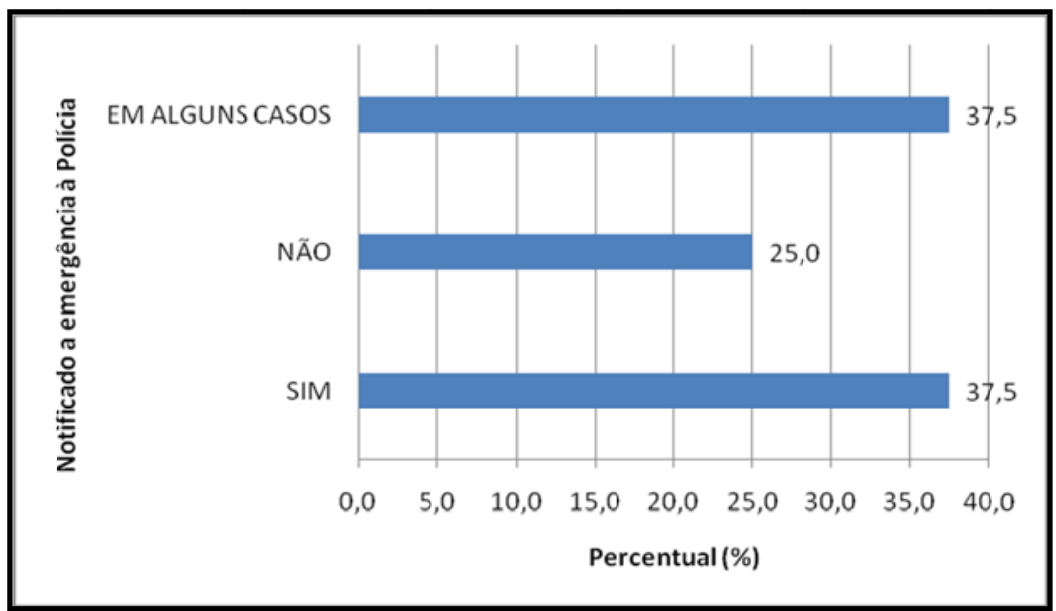

FIGURA 61 - Notificação à Polícia em decorrência do descarte de resíduos químicos. 
A pesquisa identificou que $37,5 \%$ dos entrevistados realizou notificação à Polícia, igualmente outros $37,5 \%$ respondeu que apenas "em alguns casos" ocorreu essa notificação policial e $25 \%$ respondeu não ter realizado nenhuma comunicação à Polícia.

É importante destacar que, sob a óptica legal, os descartes de resíduos químicos constituem crime ambiental previsto na Lei de Crimes Ambientais, $n^{\circ}$ 9.605, de 12 de fevereiro de 1998, na Subseção III - Das Infrações Relativas à Poluição e outras Infrações Ambientais, em seu Art. 62 "É passível de multa quem lançar resíduos sólidos, líquidos ou gasosos, ou detritos, óleos ou substâncias oleosas em desacordo com as exigências estabelecidas em leis ou atos normativos".

Pela gravidade que situações envolvendo descarte de resíduos podem resultar como riscos à saúde humana e depreciação da qualidade ambiental, a comunicação dos fatos à autoridade policial deveria ser procedimento adotado por todos aqueles que participam dessas situações emergenciais e não apenas em algumas situações.

\subsection{Estudos de casos}

Nesta seção da tese serão apresentados dois atendimentos emergenciais inseridos na RMSP e na UGRHI 6 visando abordar todos os indicadores dessas ações e também com o objetivo de estimar o custo da operação de avaliação ambiental.

A escolha das ocorrências, REQs276/2013 e 017/2009, inseridas na RMSP como estudos de casos pautou-se pelas especificidades de suas características como aqui descritas: 1) a grande quantidade de resíduos descartados; 2) a forma de disposição direta sobre o solo, condição que implica a existência de um maior potencial de contaminação do solo e das águas subterrâneas; 3) o tempo em que permaneceram dispostos no solo sem a devida remoção; 4) a natureza química predominantemente inorgânica para o REQ 276/2013 e orgânica para o REQ 017/2009 e 5) o grau de complexidade 
que envolveu o desencadeamento das ações para remoção e transporte dos resíduos.

Os dois casos representam bem a natureza química de resíduos químicos que trazem sempre a preocupação das autoridades públicas para promoverem sua remoção, armazenamento temporário e destinação final adequada, condição que implica a existência de um maior potencial de contaminação do solo e das águas subterrâneas.

Em ambos os casos foram realizadas análises químicas nos laboratórios da CETESB - Companhia Ambiental do Estado de São Paulo na busca por sua caracterização e identificação da forma adequada de disposição final.

Em especial para o REQ 017/2009 foi estimado o custo da operação de avaliação ambiental realizada pela CETESB - Companhia Ambiental do Estado de São Paulo, análises químicas, emissão de parecer técnico, remoção, transporte e destinação final adequada.

Os casos aqui descritos e avaliados buscam contextualizar e discutir a complexidade de se realizar atendimentos emergenciais, quando se desconhece os infratores pelo descarte de resíduos químicos e o desafio pela busca de uma solução integrada em caráter emergencial com diversos atores governamentais nas suas diferentes áreas de competência.

\subsubsection{Descarte de resíduo inorgânico: escória de fundição}

Em 25 de setembro de 2013, a CETESB - Companhia Ambiental do Estado de São Paulo foi notificada de descarte de resíduo químico na Estrada do Caracol, Bairro do Taboão em Mogi das Cruzes, conforme localização detalhada na FIG. 62. 


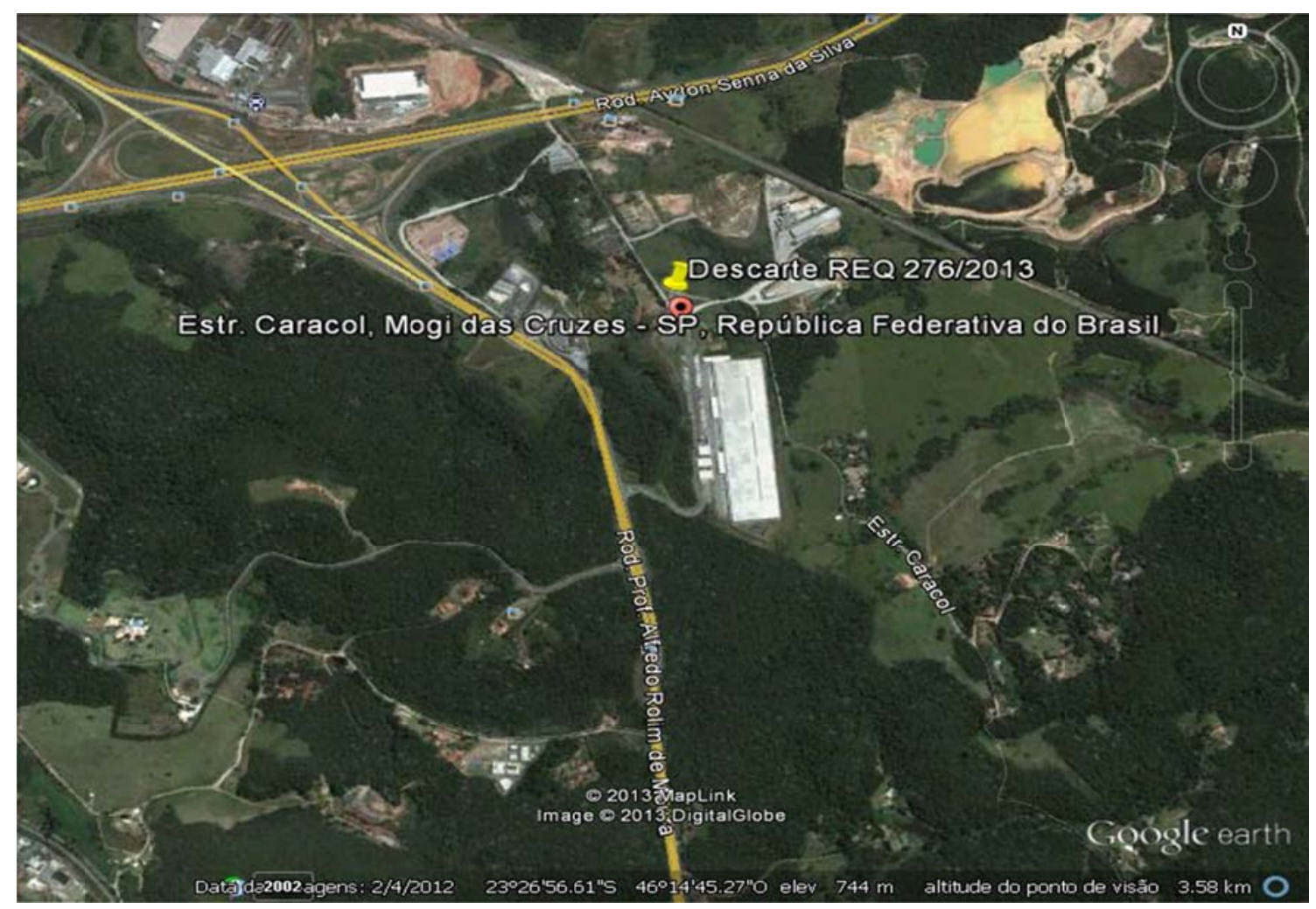

FIGURA 62 - Mapa de localização do registro de emergência química REQ 276/2013.

Fonte: Google Earth

$O$ atendimento emergencial da CETESB - Companhia Ambiental do Estado de São Paulo foi realizado exclusivamente pela Agência Ambiental de Mogi das Cruzes (REQ 276/2013).

No local verificou-se que o veículo responsável pelo descarte dos resíduos foi flagrado por câmara de segurança pertencente a uma empresa situada nas proximidades.

A estimativa da quantidade de resíduos descartados irregularmente foi de $8 \mathrm{~m}^{3}$ de resíduo industrial aparentemente resultante de borra de fundlição de sucata de alumínio. Com auxílio de uma retro escavadeira de uma empresa localizada nas imediações, foi possível remover o resíduo disposto no meio da via e depositá-lo no acostamento.

A FIG. 63 apresenta como os resíduos foram descartados diretamente sob o solo, na Estrada do Caracol. 


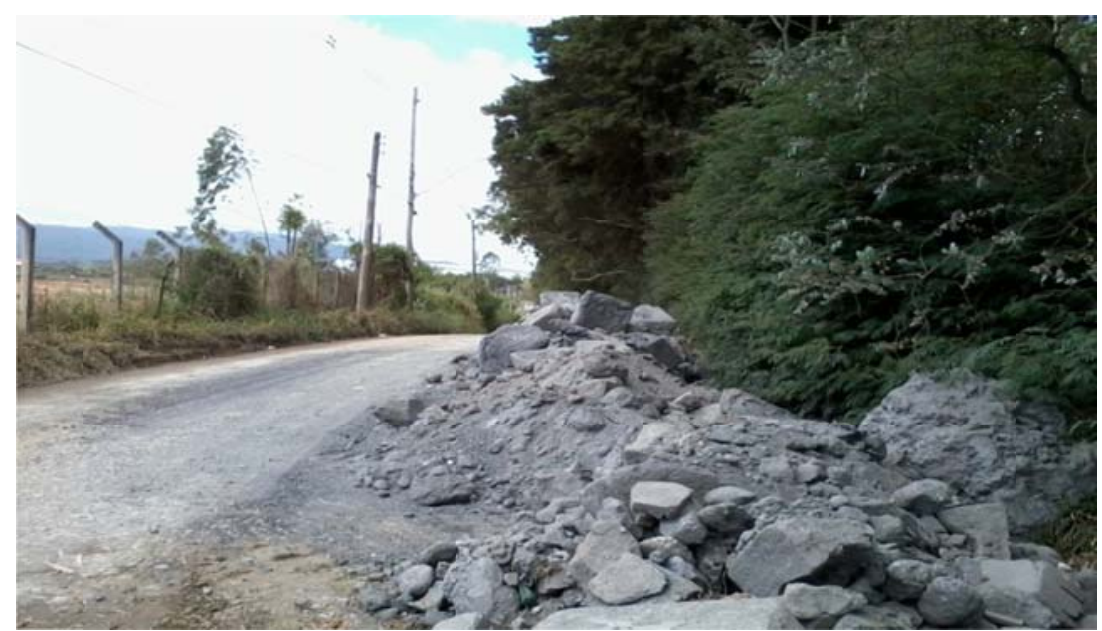

FIGURA 63 - Registro fotográfico dos resíduos químicos

Descartados na Estrada do Caracol.

Fonte: CETESB - Companhia Ambiental do Estado de São Paulo

(Banco de Imagem)

O resíduo granulado de coloração acinzentada causou forte incômodo de odor na população que circulava por aquela via. Segundo relato do técnico da Agência Ambiental de Mogi das Cruzes que realizou o atendimento percebia-se odor característico de amônia anidra $\left(\mathrm{NH}_{3}\right)$.

Em 26 de novembro de 2013, técnicos do Setor de Atendimento a Emergências da CETESB - Companhia Ambiental do Estado de São Paulo em conjunto com a Agência Ambiental de Mogi das Cruzes realizaram vistoria no local e constataram que os resíduos ainda ali permaneciam.

Em seguida, portando EPIs apropriados como luva de proteção, roupas de proteção química e respirador facial do tipo panorâmico, procederam a coleta de amostra do resíduo segundo o Guia Nacional de Coleta e Preservação de Amostras (CETESB - COMPANHIA AMBIENTAL DO ESTADO DE SÃO PAULO, 2011b) para análise de parâmetros inorgânicos com a finalidade de se conhecer algumas características do material ali depositado, por tratar-se de resíduo de origem desconhecida.

A FIG. 64 retrata o momento da coleta de amostra realizada em 26.11.13. 


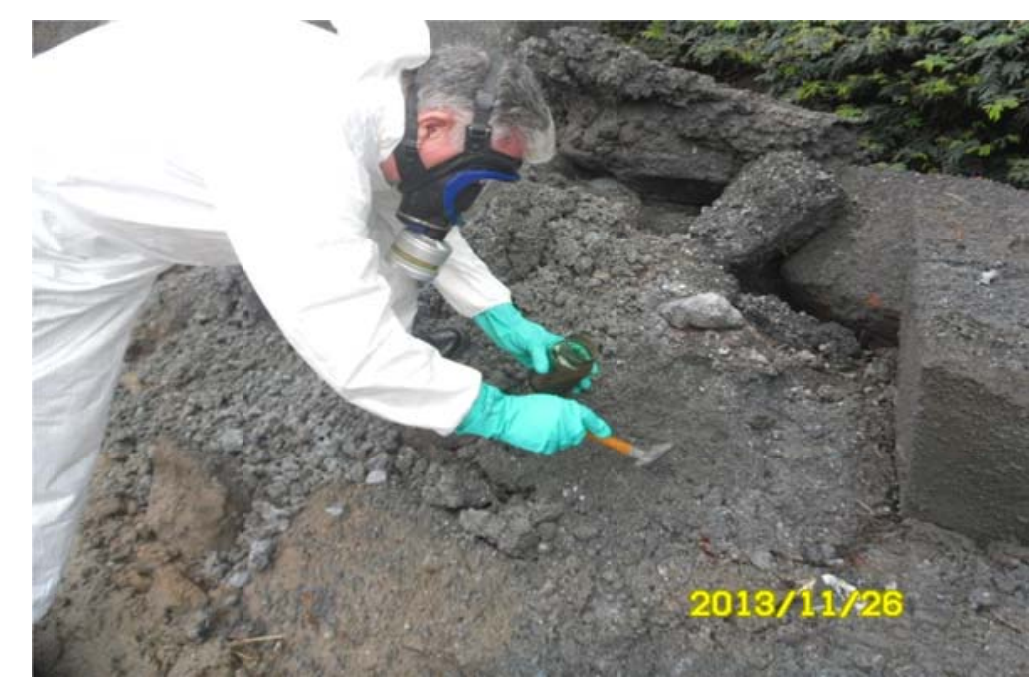

FIGURA 64 - Registro fotográfico da coleta do resíduo descartado na Estrada do Caracol.

Fonte: CETESB - Companhia Ambiental do Estado de São Paulo (Banco de Imagem)

A coleta de amostra, cerca de 500 gramas, foi realizada em pote de vidro (borossilicato), de cor âmbar. Após a coleta a amostra foi refrigerada a $4^{\circ} \mathrm{C} \mathrm{e}$ enviada no mesmo dia ao Laboratório de Química Inorgânica da CETESB Companhia Ambiental do Estado de São Paulo com solicitação de análise para atendimento à NBR 10004, em atendimento aos seguintes parâmetros:

- na massa bruta: alumínio, resíduo total/fixo e volátil, umidade.

- no solubilizado: pH, condutividade, nitrato, nitrito, cloreto, fluoreto, sulfato, nitrogênio amoniacal.

- no lixiviado: arsênio, bário, cádmio, chumbo, cromo total, fluoreto, mercúrio, prata e selênio.

Os resultados das análises químicas encontram-se sumariados nas TAB.11, 12 e 13. 
TABELA 11 - Resultados analíticos dos ensaios na massa bruta (Boletim de Análises Nº (EAAI/39393/2014).

\begin{tabular}{l|c|c}
\hline \multicolumn{1}{r|}{ Amostra } & No $^{\circ} \mathbf{1 3 3 1 7 9 2}$ & Unidade \\
\hline Parâmetro & 247.841 & $\mathrm{mg} \mathrm{Al} / \mathrm{kg}$ \\
\hline Alumínio & 11 & $\%$ \\
\hline Sólidos Voláteis Totais & 89 & $\%$ \\
\hline Sólidos Fixos Totais & 70 & $\%$ \\
\hline Sólidos Totais & 26,4 & $\%$ \\
\hline Umidade & & $\%$ \\
\hline
\end{tabular}

Os resultados analíticos da TAB.11 demonstram o caráter essencialmente inorgânico da amostra, 89\% são sólidos fixos e com elevada concentração de alumínio, cerca de $25 \%$ de seu total.

TABELA 12 - Resultados analíticos do solubilizado (Boletim de Análises No EAAI/39343/2014).

\begin{tabular}{l|c|l}
\hline Parâmetro $\quad$ Amostra & $\mathbf{N}^{\mathbf{0}} \mathbf{1 3 3 8 2 2 8}$ & \multicolumn{1}{c}{ Unidade } \\
\hline Cloreto Total & 48,8 & $\mathrm{mg} \mathrm{Cl} / \mathrm{L}$ \\
\hline Condutividade & 698 & $\mu \mathrm{S} / \mathrm{cm}$ \\
\hline Nitrogênio nitrato & 0,44 & $\mathrm{mg} \mathrm{NO}_{3} \mathrm{~N} / \mathrm{L}$ \\
\hline Nitrogênio amoniacal & 0,31 & $\mathrm{mg} \mathrm{NO}_{2} \mathrm{~N} / \mathrm{L}$ \\
\hline pH (solubilizado) & 9,49 & $\mathrm{mg} \mathrm{SO}_{4} / \mathrm{L}$ \\
\hline Sulfato Total & 75,1 & \\
\hline
\end{tabular}

Observando-se os resultados da TAB. 12, verifica-se que o $\mathrm{pH}$ da amostra de 9,49 , medido a partir do ensaio de solubilização com água deionizada e o teor de nitrogênio amoniacal $\left(0,31 \mathrm{mgNH}_{3} / \mathrm{L}\right)$ determinado no solubilizado, guarda relação direta com o forte odor de amônia anidra $\left(\mathrm{NH}_{3}\right)$ não ionizada percebida pela população que circulava próximo ao descarte do resíduo no momento do atendimento emergencial. 
TABELA 13 - Resultados analíticos do lixiviado (Boletim de Análises $N^{\circ}$ EAAI/39413/2014).

\begin{tabular}{|l|c|c|c}
\hline \multicolumn{1}{c|}{ Amostra } & No $\mathbf{1 3 3 8 2 2 8}$ & Unidade & $\begin{array}{c}\text { Limite } \\
\text { Máximo do lixiviado } \\
\text { ABNT NBR 10004:2004 }\end{array}$ \\
\hline Arsênio Total & $<0,05$ & $\mathrm{mg} \mathrm{As} / \mathrm{L}$ & $1,0 \mathrm{mg} / \mathrm{L}$ \\
\hline Bário Total & 8,51 & $\mathrm{mgBa} / \mathrm{L}$ & $70,0 \mathrm{mg} / \mathrm{L}$ \\
\hline Cádmio Total & $<0,03$ & $\mathrm{mgCd} / \mathrm{L}$ & $0,5 \mathrm{mg} / \mathrm{L}$ \\
\hline Chumbo Total & $<0,25$ & $\mathrm{mgPb} / \mathrm{L}$ & $1,0 \mathrm{mg} / \mathrm{L}$ \\
\hline Cromo Total & $<0,10$ & $\mathrm{mgCr} / \mathrm{L}$ & $5,0 \mathrm{mg} / \mathrm{L}$ \\
\hline Fluoreto Total & $<5,00$ & $\mathrm{mgF} / \mathrm{L}$ & $150 \mathrm{mg} / \mathrm{L}$ \\
\hline Mercúrio Total & $<0,001$ & $\mathrm{mgHg} / \mathrm{L}$ & $0,1 \mathrm{mg} / \mathrm{L}$ \\
\hline pH (lixiviado) & 5,35 & & \\
\hline Prata Total & $<0,02$ & $\mathrm{mgAg} / \mathrm{L}$ & $5,0 \mathrm{mg} / \mathrm{L}$ \\
\hline Selênio Total & $<0,05$ & $\mathrm{mgSe} / \mathrm{L}$ & $1,0 \mathrm{mg} / \mathrm{L}$ \\
\hline Sólidos Secos & 73 & $\%$ & \\
\hline Volume de lixiviado & 2,00 & $\mathrm{Litros}$ & \\
\hline
\end{tabular}

Os resultados da TAB. 13 indicam que se excetuando o elemento bário, os demais metais apresentaram-se abaixo do limite de quantificação ${ }^{4}$.

Em 28 de novembro de 2013 foi realizado na amostra $n^{\circ} 1331792$ (FIG. 65) um teste no Laboratório de Química Inorgânica da CETESB - Companhia Ambiental do Estado de São Paulo para se avaliar a sua reatividade com água e a concentração de gases e vapores resultante dessa reação.

\footnotetext{
${ }^{4}$ Limite de quantificação: o limite de quantificação é definido como sendo a menor quantidade de um analito que pode ser determinada quantitativamente, utilizando um determinado procedimento experimental com adequada precisão e exatidão.
} 


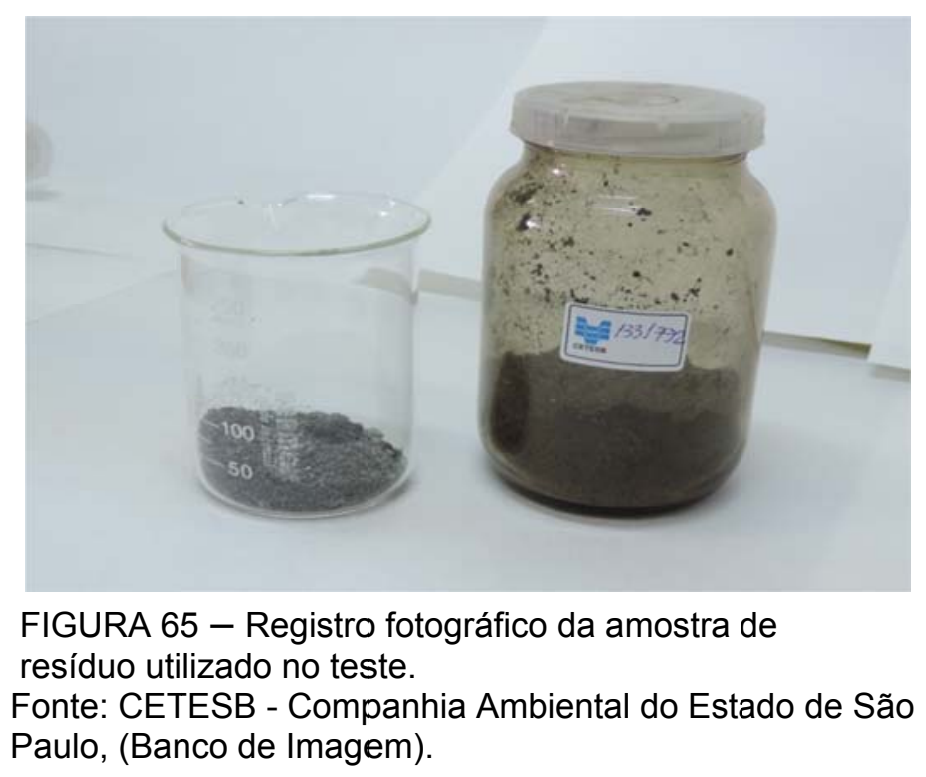

O equipamento utilizado para determinação de gases e vapores foi um fotoionizador portátil, modelo PGM 7320 Mini Rae 3000, marca RAE Systems.

Apesar da fotoionização ser preferencialmente utilizada para avaliação de COV, é também possível por meio dessa técnica determinar alguns compostos inorgânicos, como fosfina $\left(\mathrm{PH}_{3}\right)$ e amônia anidra $\left(\mathrm{NH}_{3}\right)$. Especificamente a amônia anidra apresenta PI (Potencial de lonização) de 10,18 eV, portanto inferior ao PI da lâmpada utilizada pelo equipamento $(\mathrm{PI}=10,6 \mathrm{eV})$, condição necessária para sua ionização.

O teste foi realizado em quatro etapas: 1) Avaliação com fotoionizador da atmosfera do interior da capela; 2) Avaliação com fotoionizadlor da amostra seca; 3) Aplicação de água sobre a amostra 4) Avaliação com fotoionizador da amostra úmida.

Na primeira etapa uma medição da atmosfera do interior da capela foi realizada com o fotoionizador (FIG. 66), a fim de se verificar eventuais contaminações por outros gases e vapores. Não foi detectada concentração de outros contaminantes. 


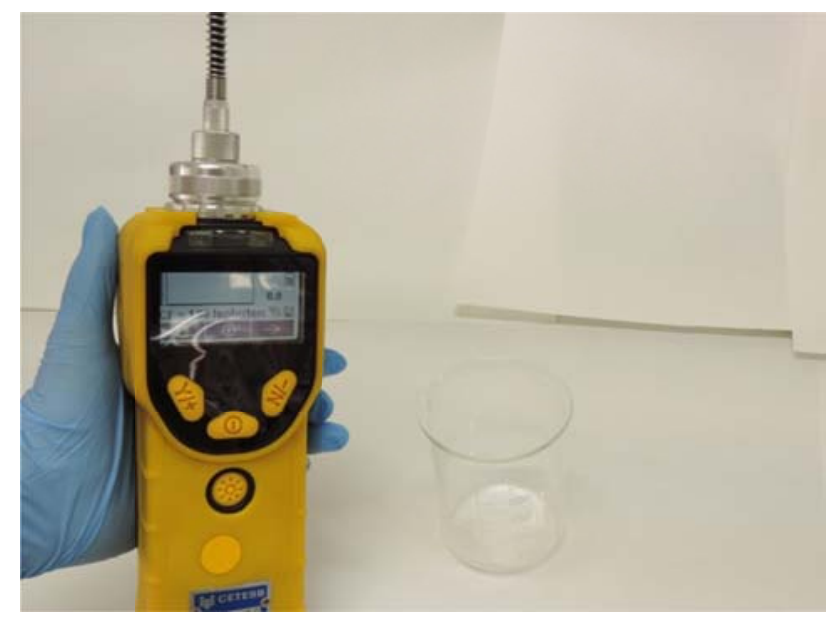

FIGURA 66 - Avaliação da concentração de gases e vapores no interior da capela do Laboratório de Química Inorgânica da CETESB, antes do início do teste.Fonte: CETESB - Companhia Ambiental do Estado de São Paulo (Banco de Imagem)

Diante da ausência de interferentes no interior da capela, segundo os resultados obtidos pelo fotoionizador utilizado no teste, partiu-se para a segunda etapa, aproximando-se o fotoionizador sobre uma porção da amostra seca de resíduo (FIG. 67).

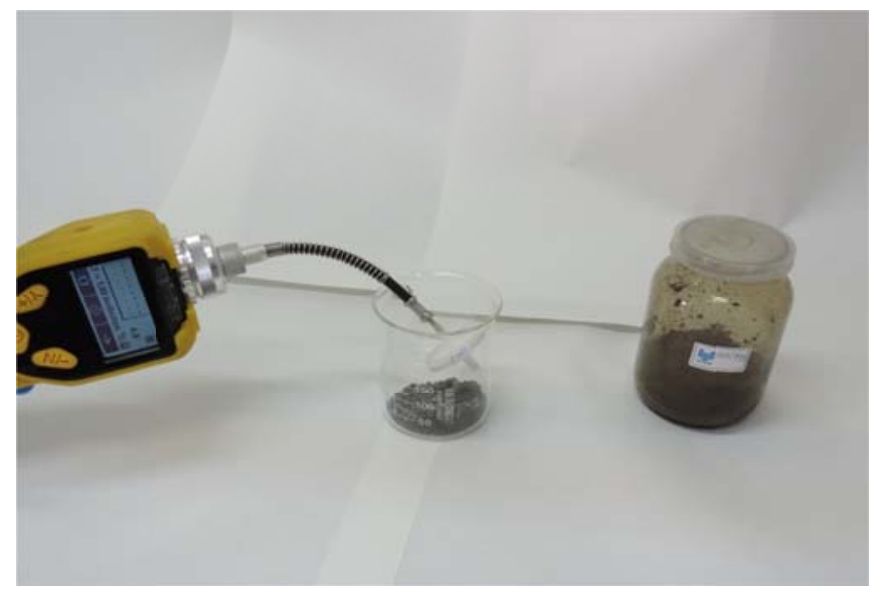

FIGURA 67 - Avaliação da concentração de gases e vapores sobre a amostra seca.

Fonte: CETESB - Companhia Ambiental do Estado de São Paulo(Banco de Imagem)

Observou-se a partir desse ensaio, concentração máxima de 5,4 ppm de COV e de outros gases ionizáveis até 10,6 eV. O valor real obtido após aplicação do fator de correção para amônia anidra ( $F c=9,4$, utilizando-se lâmpada de 10,6 
eV) foi de $\mathbf{5 2 , 3 8} \mathbf{p p m}$. Utilizou-se o fator de correção para amônia anidra, por ser esta, a principal substância volátil resultante da reação da borra de alumínio com a umidade do ar.

$\mathrm{Na}$ terceira etapa do teste adicionou-se água deionizada sobre uma porção da amostra, conforme ilustrado na FIG.68.

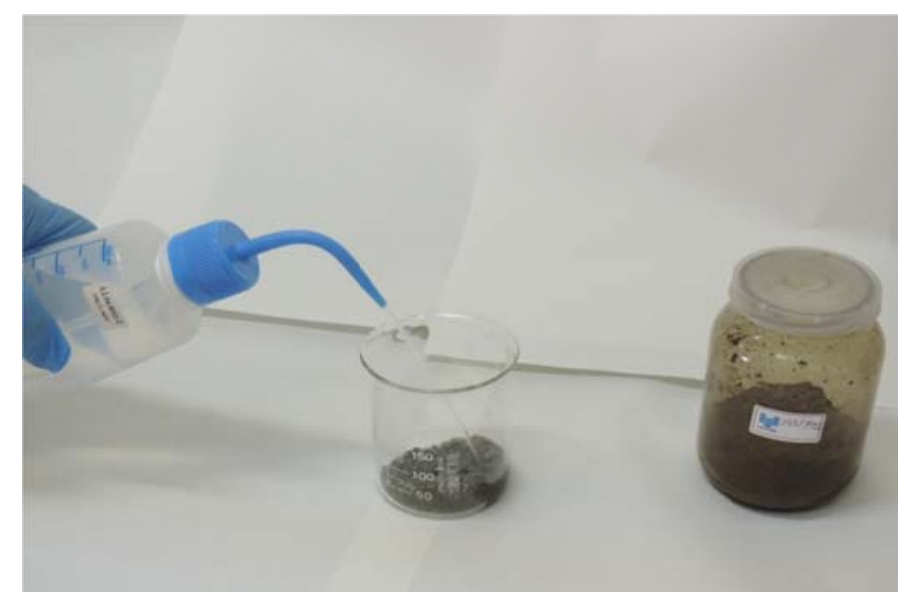

FIGURA 68 - Aplicação de água deionizada sobre a amostra de resíduo.

Fonte: CETESB - Companhia Ambiental do Estado de São Paulo (Banco de Imagem)

Como resultado acima observado destaca-se ausência de reação violenta com a água. Entretanto, foi percebido odor amoniacal após aplicação de água sobre a amostra. A quarta e última etapa do teste consistiu em aproximar o fotoionizador sobre a amostra umedecida (FIG.69).

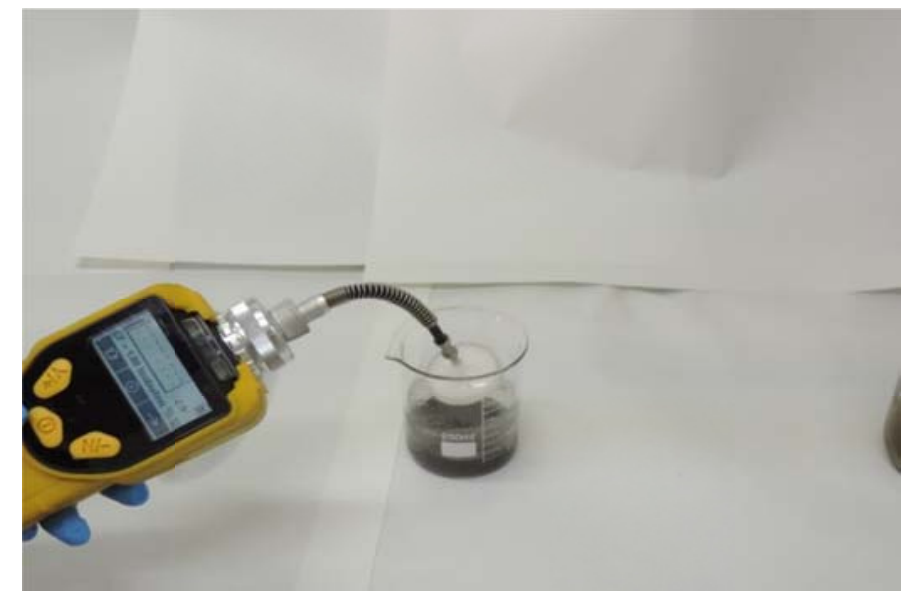

FIGURA 69 - Avaliação da concentração de gases e vapores sobre a amostra úmida.

Fonte: CETESB (Banco de Imagem). 
Observou-se a partir dessa medição, concentração máxima de 10,1ppm de COV e de outros gases ionizáveis até 10,6 eV. O valor real obtido após aplicação do fator de correção para amônia anidra ( $F c=9,4$, utilizando-se lâmpada de 10,6 eV) foi de 94,94 ppm.

Segundo a Associação Brasileira do Alumínio ( $A B A L)$,a escória de alumínio contém nitreto de alumínio (AIN), que em contato com a umidade do ambiente gera amônia anidra $\left(\mathrm{NH}_{3}\right)$.Os nitretos reagem com água produzindo o hidróxido do metal e amônia segundo a reação:

$\mathrm{AIN}+3 \mathrm{H}_{2} \mathrm{O} \longrightarrow \mathrm{Al}(\mathrm{OH})_{3(\mathrm{aq})}+\mathrm{NH}_{3(\mathrm{~g})}$

A amônia anidra além do odor irritante, em doses excessivas, pode ser letal.

Dessa forma, levando em conta a reação com geração de amônia, é importante que a escória de alumínio seja estocada em ambiente coberto e livre de intempéries. Segundo dados da ABAL, uma estocagem inadequada de nitreto de alumínio em uma fundição, próxima a área urbana, provocou grande liberação de $\mathrm{NH}_{3(\mathrm{~g})}$, causando pânico entre os moradores (ASSOCIAÇÃO BRASILEIRA DO ALUMÍNIO, 2007).

No caso da $\mathrm{NH}_{3(\mathrm{~g}) \text {, o valor limite de percepção olfativa }}{ }^{5}$ (LPO) é de 46,8 ppm, conforme o Manual de Produtos Químicos da CETESB (CETESB COMPANHIA AMBIENTAL DO ESTADO DE SÃO PAULO, 2013e) e da WISER (Wireless Information System for Emergency Responders) (US NATIONAL LIBRARY OF MEDICINE, 2014a).

Segundo dados do WISER, da Biblioteca Nacional de Medicina dos Estados Unidos, os vapores de amônia anidra são irritantes mesmo em baixas concentrações para a pele, olhos e sistema respiratório (US NATIONAL LIBRARY OF MEDICINE, 2014b).

\footnotetext{
${ }^{5}$ Limite de Percepção Olfativa (LPO) como existe uma grande variação individual na capacidade olfativa das pessoas, a informação acerca do limiar de odor é dado para uma faixa de concentração do menor valor (para as pessoas mais sensíveis) até o maior valor, e a média geométrica da população testada.
} 
Ainda segundo a WISER, a amônia anidra reage com a umidade das membranas da mucosa para produzir uma solução alcalina (hidróxido de amônio). Exposições à amônia anidra podem resultar em injúrias corrosivas às membranas oculares, pulmonares, do trato gastrointestinal devido ao seu $\mathrm{pH}$ de caráter alcalino e sua natureza higroscópica ${ }^{6}$ (US NATIONAL LIBRARY OF MEDICINE, 2014c).

De acordo com o "Bonn Agreement" uma referência para se avaliar os efeitos nocivos de gases tóxicos para a saúde humana de um trabalhador pode ser a comparação de limites de tolerância como o "Short Term Exposure Limit" (STEL) de 35 ppm para a amônia anidra, indicado no WISER (US NATIONAL LIBRARY OF MEDICINE, 2014d).

Segundo o "Bonn Agreement", se a concentração de um gás tóxico for menor do que $10 \%$ da máxima concentração permitida, como por exemplo, o STEL, a situação pode ser considerada segura.

${ }^{6}$ Capacidade de uma substância em absorver umidade do ar.

${ }^{7}$ Bonn Agreement é um acordo de cooperação estabelecido em 1983 para tratar de poluição por óleo e outras substâncias químicas no Mar do Norte

${ }^{8}$ Short Term Exposure Limit (STEL) é a concentração na qual os trabalhadores podem se expor, por um curto período, sem apresentar efeitos adversos. O tempo máximo de exposição aos valores do TLV (Threshold Limit Value) - STEL é de 15 minutos, podendo ocorrer, no máximo, 4 vezes durante a jornada, sendo o intervalo de tempo entre cada ocorrência de pelo menos 60 minutos. 
Por esse critério, a amostra submetida ao teste em laboratório revelou que o resíduo de borra de alumínio libera concentração de gases tóxicos nocivos à saúde humana. Tal afirmação se deve à concentração de 52,38 ppm de amônia anidra quando o fotoionizador foi aproximado da amostra seca e de 94,94 ppm quando a amostra foi umedecida. Em ambos os casos a concentração de amônia anidra excedeu os 10\% do STEL (3,5 ppm).

Os resíduos de borra de alumínio descartados irregularmente em via pública foram considerados como Resíduo Perigoso Classe I, por apresentar característica de reatividade, segundo o item 4.2.1.3 da Norma ABNT NBR 10.004:2004 "Gerar gases, vapores e fumos tóxicos em quantidades suficientes para provocar danos à saúde pública ou ao meio ambiente".

$\mathrm{Na}$ vistoria realizada em 27.06.14 ficou constatado que os resíduos permaneciam no local. Somente em 13.10.14 em nova vistoria realizada pela Agência Ambiental de Mogi das Cruzes foi observado que os resíduos haviam sido removidos pelo proprietário do veículo identificado por meio de câmeras de segurança.

Os resíduos foram enviados para o Aterro Resicontrol de Tremembé, com licença ambiental para recebimento e disposição de Resíduo Classe I.

7.7.2 Descrição de atendimento emergencial envolvendo descarte de resíduos químicos orgânicos e estimativa de custos da operação para remoção e destinação dos resíduos químicos

A seguir é apresentada uma descrição de um atendimento emergencial, bem como a estimativa de custos da operação para a fase emergencial envolvendo o descarte de resíduos químicos ocorrido no Parque Estadual da Cantareira, Av. Cel. Sezefredo Fagundes, altura do $n^{0} 19.100$, bairro Cachoeira, Núcleo do Engordador.

$\mathrm{O}$ atendimento realizado foi identificado pelo Registro de Emergência Química REQ 017/2009, sua localização pode ser visualizada na FIG.70 (“Google Earth"). 


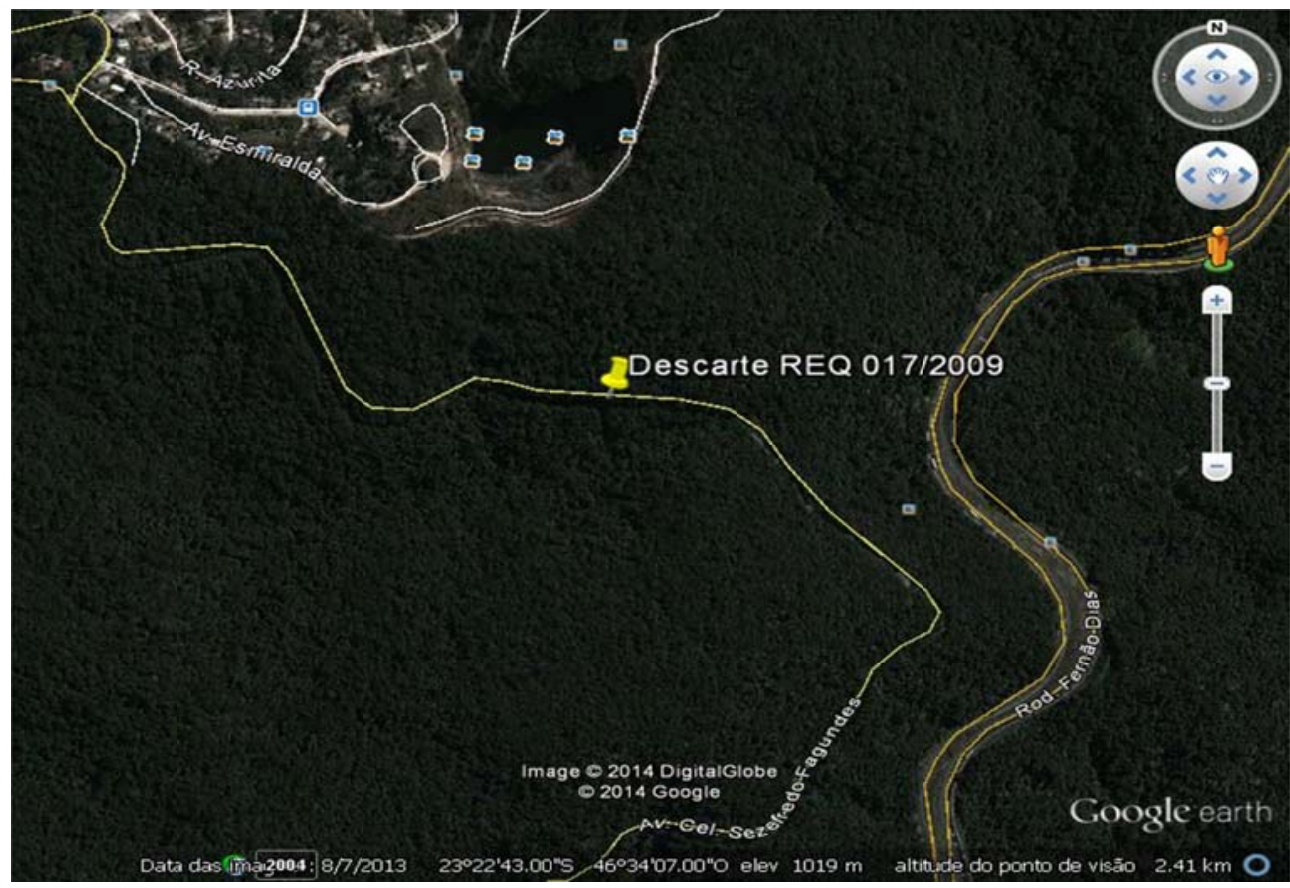

FIGURA 70 - Mapa de localização do registro REQ 017/2009.

Fonte: Googleearth

O local onde ocorreu o descarte de material pertence ao Parque Estadual da Cantareira, o qual é uma Unidade de Conservação criada através do decreto $\mathrm{n}^{\circ}$ 41.626/63. Possuindo 7.916,52 ha, este parque abrange parte dos municípios de São Paulo, Caieiras, Mairiporã e Guarulhos. Trata-se de um fragmento de Mata Atlântica que abriga diversas espécies de fauna e flora, além de mananciais com água de excelente qualidade.

Em 17 de janeiro de 2009 uma equipe de plantão do Setor de Atendimento a Emergências e da Agência Ambiental de Santana, da CETESB - Companhia Ambiental do Estado de São Paulo, realizaram avaliação inicial e constataram que se tratava de resíduos com aparência "esponjosa e pegajosa" de resina de aspecto relativamente homogêneo. A coloração variava de cinza a cinza azulado e notava-se forte odor de solvente junto ao local do descarte.

A FIG. 71demonstra as condições em que se encontravam dispostos os resíduos, em terreno de acentuada declividade e área estimada de $8 \mathrm{~m} \times 60 \mathrm{~m}$. 


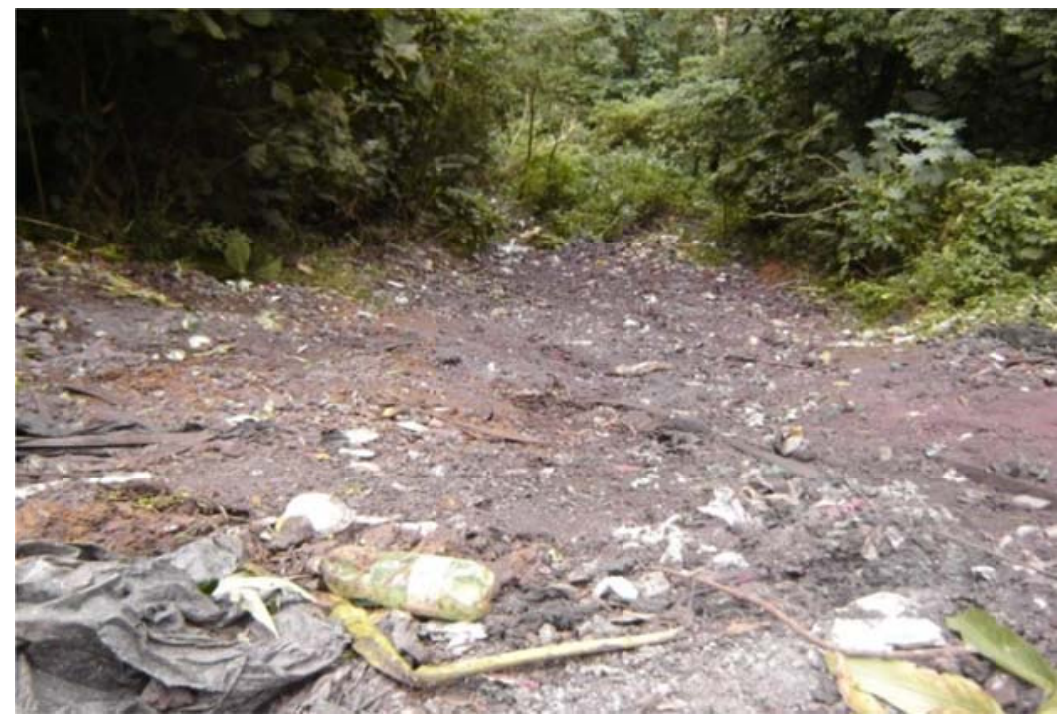

FIGURA 71 - Registro fotográfico de resíduos dispostos em área do Parque Estadual da Cantareira.

Fonte: CETESB - Companhia Ambiental do Estado de São

Paulo (Banco de Imagem)

A partir do atendimento emergencial iniciou-se uma série de tratativas por parte da CETESB - Companhia Ambiental do Estado de São Paulo e da Direção do Parque Estadual da Cantareira para mobilização de recursos materiais para a operação de remoção dos resíduos.

Diante da impossibilidade de se obterem recursos para promover a retirada dos resíduos, optou-se pelo recobrimento dos resíduos com sacos plásticos fornecidos pela Defesa Civil da cidade de São Paulo.

A FIG. 72 apresenta a ação em caráter emergencial para reduzir a possibilidade de infiltração do material no solo. 


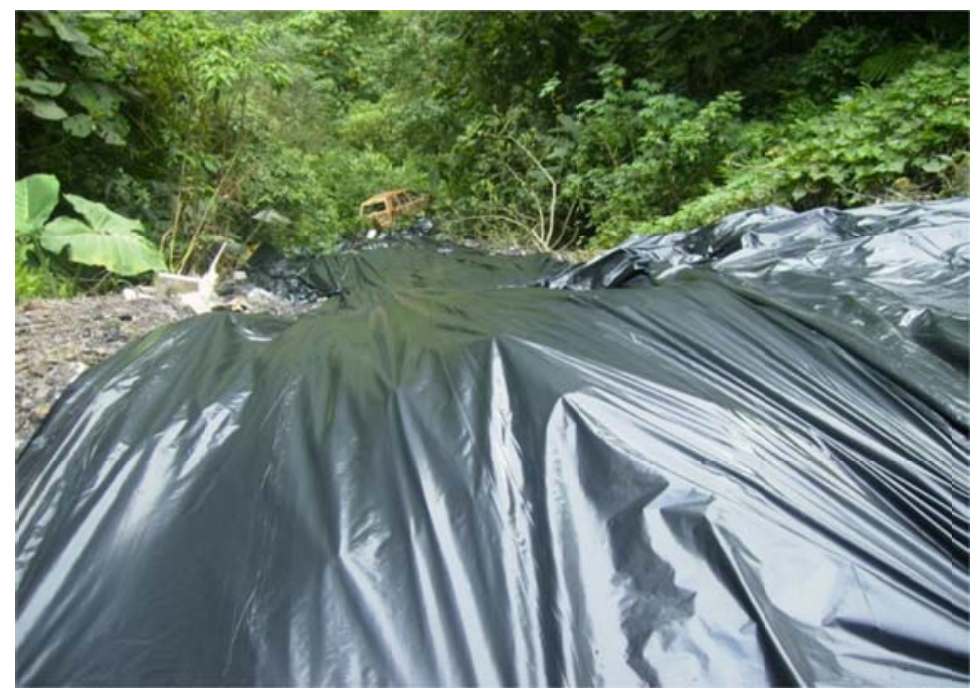

FIGURA 72 - Registro fotográfico do atendimento emergencial para reduzir ação de água de chuva sobre os resíduos.Fonte: CETESB - Companhia Ambiental do Estado de São Paulo (Banco de Imagem)

Pela necessidade de se conhecer a natureza química dos resíduos ali depositados, a CETESB - Companhia Ambiental do Estado de São Paulo realizou uma nova inspeção no local, cinco dias após o inicio da ocorrência, com apoio do Setor de Resíduos Sólidos Industriais. Uma amostra do material foi coletada pelos técnicos da CETESB - Companhia Ambiental do Estado de São Paulo com o objetivo de realizar uma análise química tendo como base a NBR 10.004 .

Os resultados das análises desse resíduo efetuados nos laboratórios de Química Orgânica e Inorgânica da CETESB - Companhia Ambiental de São Paulo estão sumariados na TAB.14. 
TABELA 14 - Resultados das análises químicas da amostra de resíduo.

Identificação da amostra № 909822

\begin{tabular}{|c|c|c|}
\hline Parâmetro (unidade) & Concentração & $\begin{array}{l}\text { Identificação do Boletim } \\
\text { de Análises da CETESB }\end{array}$ \\
\hline \multicolumn{3}{|c|}{ Identificação dos Compostos Orgânicos Voláteis ( $\left.{ }^{*}\right)$} \\
\hline Benzeno (mg/kg) & 26,4 & \\
\hline n-Butilbenzeno (mg/kg) & 109 & \\
\hline Sec-Butilbenzeno (mg/kg) & 42,5 & \\
\hline Etilbenzeno (mg/kg) & 12.900 & \\
\hline Isopropibenzeno (mg/kg) & 226 & \\
\hline p-Isopropiltolueno (mg/kg) & 54,6 & \\
\hline n-propilbenzeno (mg/kg) & 597 & No EAAQ/09920/2009 \\
\hline Tetracloroeteno (mg/kg) & 7,08 & \\
\hline Tolueno $(\mathrm{mg} / \mathrm{kg})$ & 16.500 & \\
\hline 1,2,4 -Trimetilbenzeno $(\mathrm{mg} / \mathrm{kg})$ & 6.800 & \\
\hline 1,3,5 - Trimetilbenzeno $(\mathrm{mg} / \mathrm{kg})$ & 1060 & \\
\hline $\mathrm{m}, \mathrm{p}$-Xileno (mg/kg) & 17.600 & \\
\hline o-Xileno (mg/kg) & 5.570 & \\
\hline \multicolumn{3}{|l|}{ Composição da Massa bruta } \\
\hline Semi-Voláteis (\%) & 76 & \\
\hline Sólidos Fixos (\%) & 24 & $N^{\circ}$ EAAI/10948/2009 \\
\hline Umidade (\%) & 37 & \\
\hline \multicolumn{3}{|c|}{ Identificação dos compostos Semi-voláteis (*) } \\
\hline Azobenzeno (mg/kg) & 751 & \\
\hline Bis(2-etilexil)ftalato (mg/kg) & 4.580 & No EAAQ/09920/2009 \\
\hline Dibutilftalato (mg/kg) & 1.590 & \\
\hline Naftaleno (mg/kg) & 686 & \\
\hline \multicolumn{3}{|l|}{ Metais e Fenóis } \\
\hline Bário (mg/kg) & 7.410 & \\
\hline Chumbo (mg/kg) & 96,4 & \\
\hline Cromo $(\mathrm{mg} / \mathrm{kg})$ & 527 & $N^{\circ}$ EAAl/10948/2009 \\
\hline Mercúrio (mg/kg) & 0,36 & \\
\hline $\begin{array}{l}\text { Fenóis (Outros orgânicos) }(\mathrm{mg} / \mathrm{kg}) \\
\left({ }^{*}\right) \text { Os resultados das análises para os }\end{array}$ & 106 & \\
\hline
\end{tabular}

No Brasil a caracterização de resíduos obedece a Norma da ABNT 10004/2004 - Resíduos Sólidos - Classificação, que além de listar as características que conferem periculosidade a um resíduo, apresenta listagens de resíduos, descritos pelos processos que thes deram origem.

Não há procedimentos padronizados no Brasil para caracterização de resíduos de origem desconhecida ou para análise. É de fato uma tarefa difícil efetuar a identificação de um resíduo de origem desconhecida em razão das inúmeras 
substâncias orgânicas e inorgânicas que podem estar ali presentes, muitos das quais sem limites estabelecidos para saúde humana.

Sob o aspecto de riscos toxicológicos das substâncias químicas, as palavras de SANTOS (2008) acrescentam as incertezas sobre essa temática.

A (eco)toxicidade de substâncias químicas é uma atual preocupação
mundial. Muitas substâncias não foram avaliadas quanto à toxicidade,
e os resultados das avaliações anteriormente feitas, podem não ser
conclusivos, exigindo uma constante atualização (e gestão) da
informação toxicológica (SANTOS, 2008, p.31).

O que se faz na prática, em alguns casos, é solicitar aos laboratórios ensaios do tipo "screening" objetivando assim reduzir os custos analíticos, mas isso somente é possível quando se dispõe de laboratórios com excelente capacidade analítica.

$\mathrm{Na}$ amostra ( $\mathrm{n}^{\circ}$ 909822) do resíduo coletado pela CETESB - Companhia Ambiental do Estado de São Paulo foi possível observar-se a partir de uma avaliação preliminar de campo que os resíduos depositados possuíam características de resíduos de resina misturados com descarte de oficina. Foi possível constatar que o resíduo possui elevado teor de sólidos voláteis $(76 \%$ da amostra).

Os resultados analíticos (TAB. 14) evidenciaram a presença de inúmeras substâncias orgânicas que conferem periculosidade ao resíduo como: fenóis, xilenos, tolueno, benzeno, tetracloroeteno, bis(2-etilexil)ftalato, dibutilftalato e naftaleno.

Foram identificados por cromatografia gasosa com detector de espectrometriade massa - CG/MS os seguintes compostos: 1,3 bis (1-metiletil)benzeno, metiletil cetona (MIK), acetato de etila, acetato de butila, 4-etil-1,2dimetilbenzeno,benzaldeído e cis-2,6-dimetil-2-nitrociclohexanona

Observa-se nos resultados analíticos obtidos (TAB. 14) a concentração de benzeno na amostra, de $26,4 \mathrm{mg} / \mathrm{kg}$, considerada ambientalmente significativa dada a sua elevada toxicidade. Entretanto, não há limite na massa bruta para a classificação desse resíduo. 
Das substâncias orgânicas identificadas nos Boletins de Análises ( $\mathrm{N}^{\circ}$ EAAQ/09920/2009) algumas constam da Lista Nacional de Agentes Cancerígenos para Humanos (LINACH) publicada na Portaria Interministerial No 9, de 7 de outubro de 2014 (BRASIL, 2014b). São elas:

- Grupo I - Agentes confirmados como carcinogênicos para humanos; benzeno e isopropil benzeno (cumeno);

- Grupo II A - Agentes provavelmente carcinogênicos para humanos;

Tetracloroetileno;

- Grupo II B - Agentes possivelmente carcinogênicos para humanos naftaleno e etilbenzeno.

Com relação aos metais tóxicos analisados o bário apresentou concentração mais elevada $(7.410 \mathrm{mg} / \mathrm{kg})$, seguido pelo cromo $(527 \mathrm{mg} / \mathrm{kg})$ e chumbo $(96,4$ $\mathrm{mg} / \mathrm{kg})$.

Com base nos resultados analíticos da CETESB - Companhia Ambiental do Estado de São Paulo, o Setor de Resíduos Sólidos Industriais, considerando a origem desconhecida dos resíduos, dos elevados teores de sólidos voláteis, das baixas concentrações de metais e tendo identificado a presença de composto organoclorado (tetracloroeteno) e de outras substâncias consideradas perigosas, recomendou que os resíduos fossem removidos do local e que preferencialmente o destino final fosse o tratamento térmico de alto desempenho.

Uma recomendação para este caso foi de que após a retirada dos resíduos se promovesse a raspagem do solo e a remoção da vegetação que teve contato com o material.

Após essa etapa de avaliação preliminar dos contaminantes presentes nos resíduos, iniciaram-se as ações de planejamento para o desencadeamento da remoção dos resíduos depositados em área de difícil acesso. Levando-se em conta a quantidade de resíduo depositada, condições de compactação do 
material, inclinação do terreno e os fatores de segurança a que estariam expostos os trabalhadores para a operacionalização desse trabalho, optou-se pelo uso de uma escavadeira, caminhão "munck", "big bags" (recipientes confeccionados de polietileno, oferecendo segurança e resistência para acomodação dos resíduos), recursos humanos e materiais de apoio à atividade.

Durante essa fase do planejamento constatou-se a necessidade de solicitar à concessionária de energia elétrica - AES Eletropaulo - para remanejamento de uma seção da rede elétrica a fim de propiciar os trabalhos de movimentação da máquina a ser utilizada na remoção dos resíduos. Outra providência envolveu a comunicação ao CET, para efetuar a paralisação temporária do tráfego durante a movimentação de máquinas no local do descarte.

Todo esse trabalho para mobilização de recursos enfrentou algumas dificuldades, pois dependiam de recursos financeiros e dos esforços conjuntos, envolvendo a Defesa Civil do município de São Paulo (SubPrefeitura de Jaçanã e Tremembé), CET, AES Eletropaulo, CETESB (Setor de Atendimento a Emergências e Agência Ambiental de Santana), Diretoria do Parque Estadual da Serra da Cantareira - Núcleo Engordador, Guarda Civil Metropolitana e Polícia Militar.

Vencida a longa etapa inicial de planejamento e de mobilização de recursos, foi agendado para o dia 09 de junho de 2009 o início previsto para os trabalhos de remoção dos resíduos.

Nos dias 09, 10, 11 e 12 de junho de 2009 foram desenvolvidos os trabalhos de remoção dos resíduos químicos que se encontravam depositados no barranco.

Os trabalhos foram realizados da seguinte forma:

1. A escavadeira puxava o resíduo do barranco e depositava na pista da Av. Sezefredo Fagundes; 
2. A escavadeira realizava a colocação dos resíduos da pista em "big bags" com o auxílio de trabalhadores cedidos pela Defesa Civil (FIG. 73);

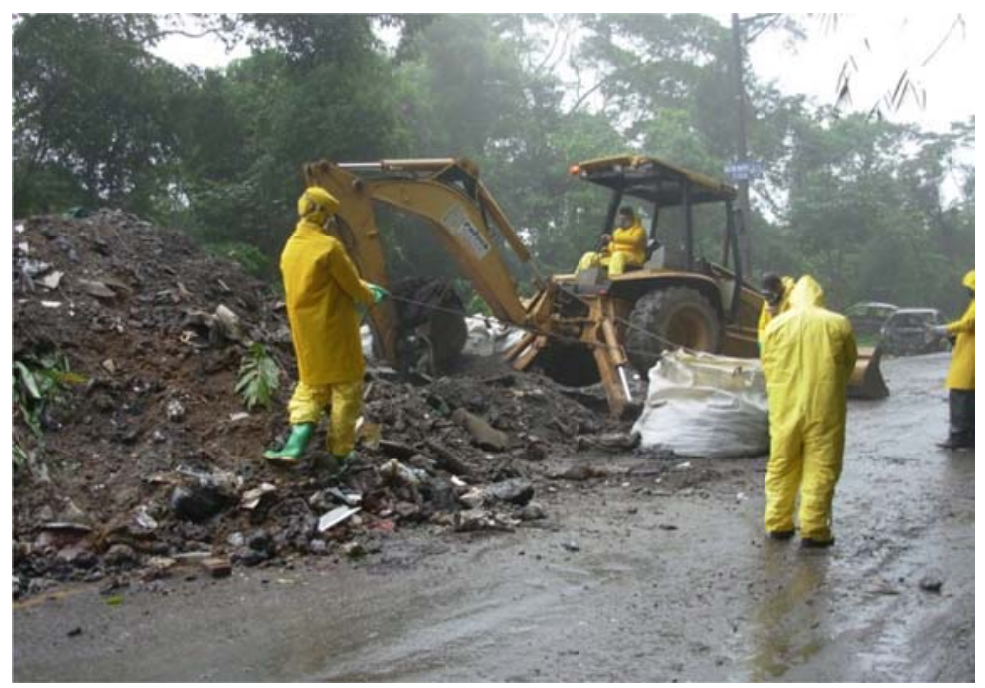

FIGURA 73 - Registro fotográfico da colocação dos resíduos em "big bags".

Fonte: CETESB - Companhia Ambiental do Estado de São

Paulo (Banco de Imagem)

3. Um caminhão "munck" realizava a coleta dos "big bags" e seu transporte para o pátio do Almoxarifado da Sub-Prefeitura Jaçanã Tremembé (FIG. 74).

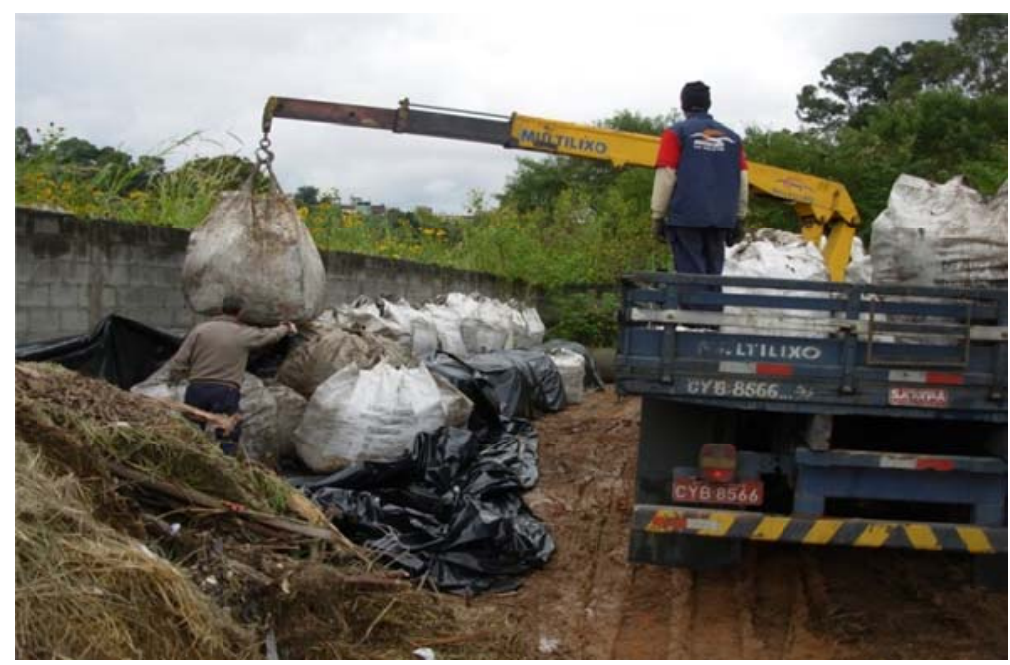

FIGURA 74 - Registro fotográfico do armazenamento temporário dos "big bags" na Sub-Prefeitura Jaçanã Tremembé. Fonte: CETESB - Companhia Ambiental do Estado de São Paulo (Banco de Imagem) 
Durante os quatro dias de trabalho removeu-se 100 "big bags" com cerca de $800 \mathrm{~kg}$ cada.

Além dos resíduos químicos foram também retiradas carcaças de caixas eletrônicos e de automóveis, como ilustrado na FIG. 75.

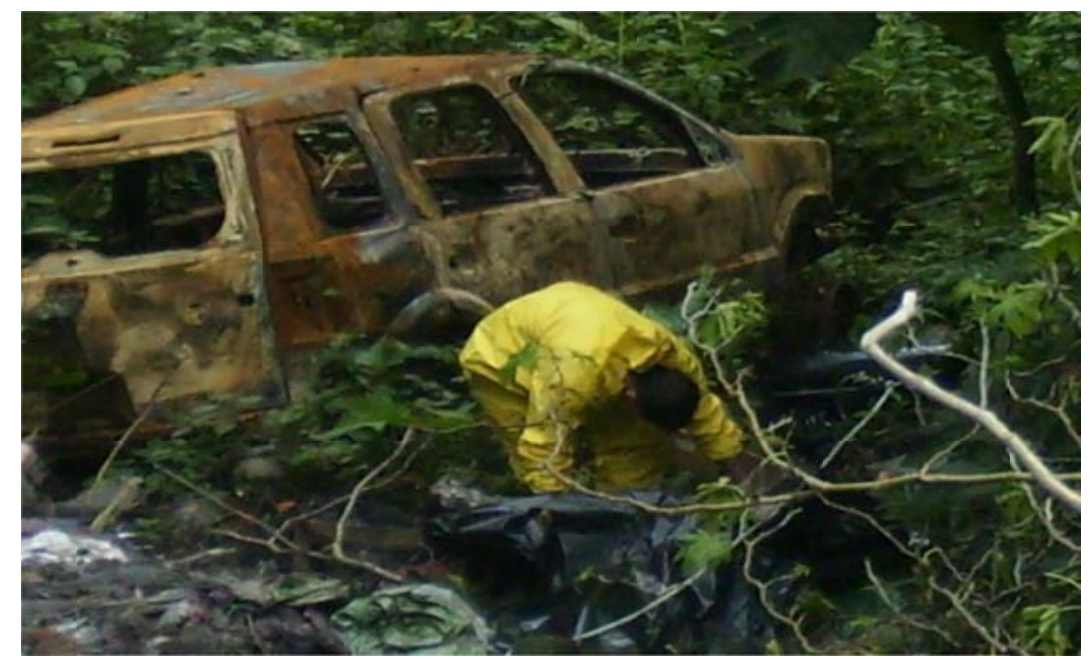

FIGURA 75 - Registro fotográfico da operação de remoção de carcaça de caixas eletrônicos e automóveis.

Fonte: CETESB - Companhia Ambiental do Estado de São Paulo (Banco de Imagem)

O fato de se identificar além dos resíduos químicos outros tipos de material ali descartado denota que o local já se apresenta como um ponto viciado de descarte de material e que certamente deverá ser melhor monitorado pela segurança do Parque.

Os aspectos de segurança da operação foram acompanhados por técnicos da CETESB - Companhia Ambiental do Estado de São Paulo, que identificaram previamente os EPIs necessários para preservar a saúde dos trabalhadores

A Associação Internacional de Direito Pontíficio "Arautos do Evangelho", que além de sua missão religiosa desenvolve trabalho de preservação ambiental na Serra da Cantareira, ofereceu apoio a essa operação alugando a escavadeira utilizada na remoção dos resíduos.

A FIG. 76 ilustra o recorte da página "web" dos Arautos do Evangelho noticiando a operação de retirada dos resíduos químicos. 


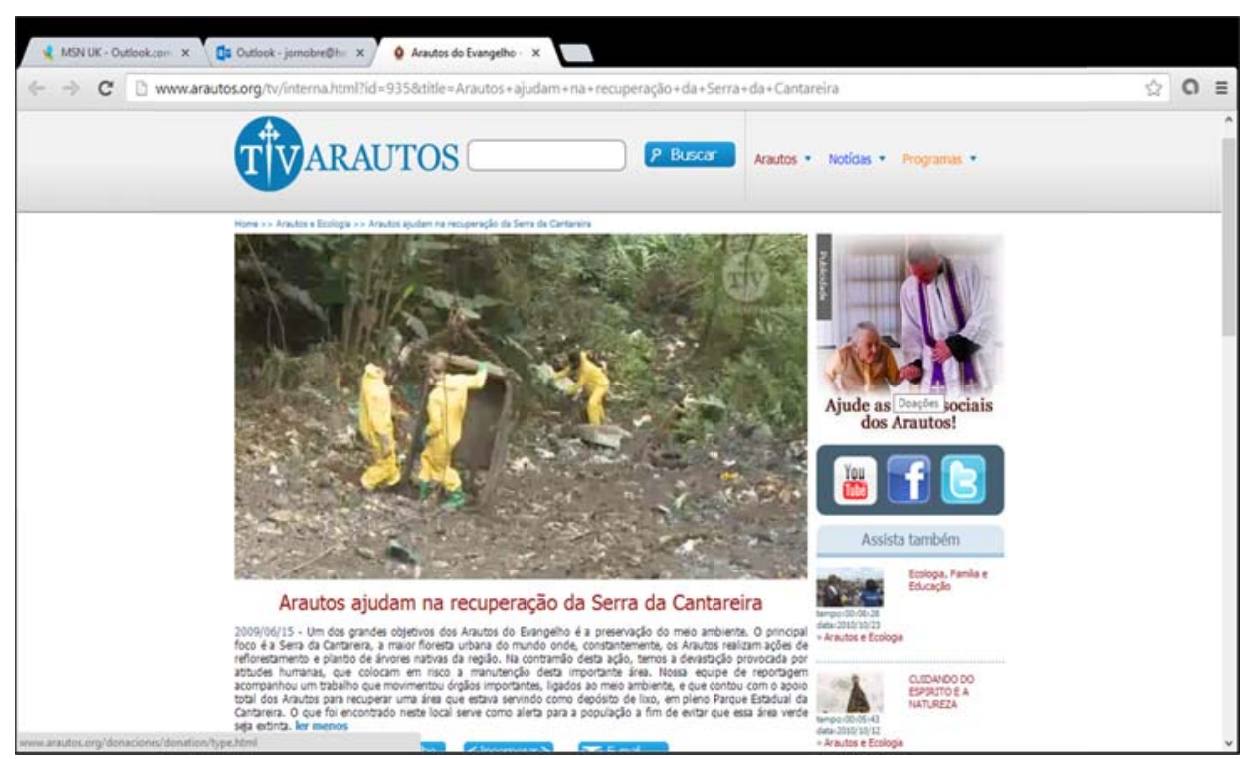

FIGURA 76 - Notícia na página "web" dos Arautos do Evangelho sobre a remoção dos resíduos.

Fonte:

http://www.arautos.org/tv/interna.html?id=935\&title=Arautos+ajudam+na+recupera\%C3\%A7 \%C3\%A30+da+Serra+da+Cantareira)

O CDR Pedreira (Centro de Disposição de Resíduos Ltda), uma empresa do Grupo Estre, em apoio ao Instituto Florestal e ao Parque Estadual da Cantareira ofereceu apoio no transporte dos resíduos da Av. Sezefredo Fagundes até a Defesa Civil, no Bairro de Jaçanã e daí até a empresa Resincontrol para a sua destruição pele técnica de Co-processamento, nos dias 07 e 17 de dezembro de 2009.

\section{Planilha com Estimativa de Custos Operacionais}

Os custos aqui referenciados foram corrigidos em maio de 2015 pelo Índice de Preços ao Consumidor do Município de São Paulo (IPC) a partir da recuperação das informações disponibilizadas pelos órgãos públicos e privados que participaram dessa operação.

Estão contabilizados os custos operacionais dos técnicos da CETESB Companhia Ambiental do Estado de São Paulo, das análises laboratoriais, dos EPIs, das máquinas e equipamentos utilizados na remoção, transporte e destruição dos resíduos. 
A TAB. 15 apresenta um resumo das ações e instituições/órgãos envolvidos no processo bem como indicadores e custos operacionais.

TABELA 15- Estimativa de custo de uma operação para atendimento de emergência. Estudo de caso.

\begin{tabular}{|c|c|c|c|c|c|}
\hline $\begin{array}{l}\text { Instituição } \\
\text { envolvida }\end{array}$ & Atividade & Descrição da Ação & Quantidade & Unidade & $\begin{array}{l}\text { Valor Total } \\
\text { (R\$) }\end{array}$ \\
\hline $\begin{array}{l}\text { CDR Pedreira } \\
\text { Ltda }\end{array}$ & Transporte & $\begin{array}{l}\text { Transporte de material } \\
\text { da Av. Sezefredo } \\
\text { Fagundes até a Defesa } \\
\text { Civil (bairro do Jaçanã) }\end{array}$ & 12 & Viagens & $14.962,94$ \\
\hline \multirow[t]{2}{*}{$\begin{array}{l}\text { CDR Pedreira } \\
\text { Ltda } \\
\text { E Defesa civil e } \\
\text { Resincontrol }\end{array}$} & $\begin{array}{l}\text { Transporte/ } \\
\text { Coprocessa } \\
\text { mento }\end{array}$ & $\begin{array}{l}\text { Transporte do material } \\
\text { da Defesa Civil para a } \\
\text { empresa de } \\
\text { Coprocessamento na } \\
\text { Resicontrol }\end{array}$ & 46,95 & Toneladas & $42.280,71$ \\
\hline & & & & Sub -Total & $57.243,65$ \\
\hline $\begin{array}{l}\text { Arautos do } \\
\text { Evangelho }\end{array}$ & $\begin{array}{l}\text { Locação e } \\
\text { transporte }\end{array}$ & $\begin{array}{l}\text { Locação e transporte } \\
\text { de ida e volta da } \\
\text { Escavadeira Mecânica } \\
\text { do Tipo Bucyrus22B }\end{array}$ & & & $10.950,81$ \\
\hline \multirow{3}{*}{ CETESB } & $\begin{array}{l}\text { Operação } \\
\text { técnica }\end{array}$ & Custo operacional & 212 horas & 09 técnicos & $15.539,50$ \\
\hline & $\begin{array}{l}\text { Análises } \\
\text { químicas }\end{array}$ & $\begin{array}{l}\text { Análises químicas } \\
\text { realizadas pelos } \\
\text { laboratórios da } \\
\text { CETESB }\end{array}$ & & & $4.263,87$ \\
\hline & EPI & Gastos com EPI $\left({ }^{*}\right)$ & & & $5.243,81$ \\
\hline \multirow[t]{2}{*}{$\begin{array}{l}\text { CET- Companhia } \\
\text { de Engenharia de } \\
\text { Tráfego - }\end{array}$} & & Custo operacional & & & $12.230,74$ \\
\hline & & & & Total & $105.472,38$ \\
\hline
\end{tabular}

${ }^{*}$ ) Custo dos EPIs utilizados por técnicos da CETESB e fornecidos aos trabalhadores que participaram da remoção e acondicionamento dos resíduos. Os EPIs fornecidos pela CETESB incluíram Respirador facial com cartucho, filtro químico contra vapores orgânicos e gases ácidos para máscara facial do tipo panorama, macacão em polietileno de alta densidade Tyvek 1422 amarelo com costura simples dotado de abertura frontal com zíper elástico nos punhos e luvas de segurança em borracha nitrílica.

O total geral estimado para a operação de remoção, transporte, análises químicas e destruição final dos resíduos químicos dispostos irregularmente no Parque Estadual da Cantareira foi de $\mathrm{R} \$ 105.472,38$.

Os resíduos foram destinados para a Unidade de Coprocessamento Resicontrol em Sorocaba. A Resicontrol trabalha com o conceito de "blend", onde os resíduos são misturados, tratados e transformados em lotes 
homogêneos. O produto dessa mistura é aproveitado como combustível na indústria cimenteira.

Os custos aqui mencionados não incluíram as ações de investigação do solo e água subterrânea e eventual necessidade de remediação da área afetada. Nesta ação estiveram envolvidas 05 instituições ou empresas diferentes. Apesar de todos os esforços e a urgência da situação emergencial, somente foi possível promover a remoção, transporte e armazenamento temporário dos resíduos químicos após 05 meses da disposição irregular dos resíduos.

A demora para a finalização da ação emergencial decorreu exatamente da necessidade de articulação entre diversas instituições e as dificuldades de mobilização de recursos humanos e materiais. 


\section{CONCLUSÕES E RECOMENDAÇÕES}

\subsection{Conclusões}

O estudo permitiu avaliar o impacto socioambiental decorrente das emergências químicas ocorridas na Região Metropolitana de São Paulo (RMSP) com descarte de resíduos químicos, visando conhecer os atores envolvidos (agencia ambiental, defesa civil e corpo de bombeiros) e qual o diagnóstico da situação.

É no momento da descrição minuciosa de uma situação de emergência química, quando não é possível identificar os responsáveis por esse ato lesivo ao meio ambiente, que são demandadas providências urgentes pelos diferentes órgãos e instituições da esfera pública e privada.

As dificuldades observadas neste trabalho para o desencadeamento das ações emergenciais consistem na disputa de poder e as interferências de caráter político, diferentes visões a respeito do mesmo problema e, muitas vezes, distorções entre diferentes setores de uma mesma instituição.

O estudo demonstrou, a partir dos registros de descartes de resíduos químicos (2005 a 2013) no SIEQ, tomando como referência a RMSP, com ênfase para as cidades de São Paulo e Guarulhos, os impactos nos compartimentos solo, ar e água.

O ar $(40,2 \%)$, o solo $(38,1 \%)$ e a água $(6,2 \%)$ estão entre os meios mais afetados nos descartes de resíduos na cidade de São Paulo. Para a cidade de Guarulhos o solo (89,3\%), o ar (39,3\%) e a água (17,9\%) estão entre os meios mais afetados.

O estudo possibilitou a elaboração de 07 mapas temáticos,caracterizando a incidência da prática de descarte de resíduos químicos nas imediações derecursos hídricos e rodovias no Estado de São Paulo, na RMSP e nas cidades de São Paulo e Guarulhos.

Esses mapas revelaram o elevado número de descartes de resíduos químicos na RMSP (189 casos) no período de 2005 a 2013, com destaque para a UGRHI 6. Em 24 casos ficou constatada a contaminação direta de algum corpo d'água, rios (Pinheiros, Tietê e Tamanduateí) e represas (Billings e Guarapiranga). 
O diagnóstico socioambiental realizado quanto à distribuição espacial de ocorrências e abundância dos descartes de resíduos químicos na RMSP revelou ser mais crítica a situação nas cidades de São Paulo e Guarulhos.

Do total de 287 descartes de resíduos no período de estudo desse trabalho, de 2005 a 2013, 189 (66\%) ocorreram na RMSP.

A maior incidência dessas emergências ocorreu na cidade de São Paulo, com 97 registros, seguida por Guarulhos com 28.

Na cidade de São Paulo observou-se como característica marcante ocorrências em distritos mais periféricos, com predominância da maior quantidade de resíduos químicos descartados.

A maior quantidade de resíduos químicos descartados na cidade de Guarulhos foi também observada em zonas geograficamente periféricas.

As ocorrências e quantidades de resíduos químicos descartados nas áreas centrais das cidades de São Paulo e Guarulhos são consideravelmente menores. Nessas regiões reside uma população com melhor infraestrutura urbana e, portanto, melhores condições de se protegerem dos riscos que os resíduos químicos possam oferecer à segurança e à saúde.

Os resultados obtidos a partir da pesquisa dirigida com os principais atores intervenientes nos cenários acidentais mostraram que $78,6 \%$ responderam que o solo foi o meio mais afetado. Esse resultado da pesquisa coincide com os dados da CETESB - Companhia Ambiental do Estado de São Paulo que apontam o solo como o meio físico mais atingido pelos descartes de resíduos químicos.

A pesquisa também evidenciou a opinião dos entrevistados sobre as múltiplas consequências negativas de ordem socioambiental e de saúde pública provocada pelo descarte de resíduos químicos, em especial quando há retardo na resposta emergencial. 
A pesquisa demonstrou que $78,1 \%$ dos entrevistados responderam que sua instituição possui disponibilidade para atendimento 24 horas por dia, incluindo o Corpo de Bombeiros, a CETESB e a Defesa Civil.

Outros $21,9 \%$ responderam que não estão disponíveis 24 horas. Incluem-se nesse caso os técnicos da Secretaria de Meio Ambiente de alguns municípios que prestam o atendimento em horário administrativo, sendo representados aos sábados, domingos, feriados e fora de horário administrativos pela Defesa Civil do município.

Os estudos de caso apresentados nesse trabalho revelaram a complexidade de se enfrentar grandes quantidades de resíduos químicos quando se encontram dispostos diretamente sobre o solo em áreas periféricas da RMSP.

No primeiro caso apresentado, ainda que tenha sido possível identificar o infrator por meio de câmeras de segurança, a remoção dos resíduos ocorreu somente após 13 meses da notificação à CETESB - Companhia Ambiental do Estado de São Paulo.

No segundo caso, não foi possível identificar o infrator e os resíduos permaneceram dispostos irregularmente durante 05 meses. Nesse caso foi estimado em $\mathrm{R} \$ 105.472,38$, o custo para a operação de remoção, transporte, análises químicas e destruição final dos resíduos.

\subsection{Recomendações}

A partir dos dados apresentados neste trabalho, recomenda-se 0 estabelecimento de um conjunto de procedimentos destinado à gestão de situações emergenciais envolvendo o descarte de resíduos químicos, que contemple: (a) critérios para a avaliação ambiental nas emergências envolvendo descarte de resíduos químicos; (b) critérios para avaliação de 
áreas contaminadas; e (c) mecanismos para custear as despesas relativas às intervenções emergenciais e pós-emergenciais.

A seguir é descrito um procedimento ou protocolo relativo a cada um desses itens.

(a) critérios para a avaliação ambiental nas emergências envolvendo descarte de resíduos químicos:

Os critérios aqui mencionados foram apresentados no item 4.3, são eles:

Avaliação da corrosividade, inflamabilidade, emanação de COVs e a reatividade com água dos resíduos químicos.

(b) critérios para avaliação de áreas contaminadas:

Quando no atendimento emergencial se constata a possibilidade dos resíduos químicos comprometerem a qualidade do solo e da água subterrânea, deve-se promover uma investigação confirmatória (amostragem de solo e água subterrânea) de acordo com o estabelecido na:

- Decisão de Diretoria (CETESB) $N^{0}$ 103/207/C/E, que dispõe sobre o procedimento para gerenciamento de áreas contaminadas no estado de São Paulo.

- Manual de Gerenciamento de Áreas Contaminadas, que apresenta de forma lógica e sequencial um conjunto de medidas que assegurem tanto $o$ conhecimento de suas características e dos impactos por elas causados quanto da criação e aplicação de instrumentos necessários à tomada de decisão e as formas e níveis de intervenção mais adequados.

- Normas ABNT, que orientam as primeiras etapas do gerenciamento de áreas contaminadas e de amostragem de solo e de águas subterrâneas, armazenamento, transporte de resíduos perigosos e sua classificação. 
(c) mecanismos para custear as despesas relativas às intervenções emergenciais e pós emergenciais:

Sugere-se a inclusão dos casos de descartes de resíduos químicos dentre as áreas credenciáveis à obtenção de recursos no Fundo Estadual para Prevenção e Remediação de Áreas Contaminadas - FEPRAC.

As sugestões aqui apresentadas se baseiam no Decreto $n^{\circ} 59.263 / 2013$ que regulamenta a Lei Paulista $n^{\circ} 13.577 / 2009$. Esse novo ordenamento jurídico prevê uma série de ações que trata da proteção da qualidade do solo e do gerenciamento de áreas contaminadas.

Um aspecto importante da Lei $n^{0} 13.577 / 2009$ foi a criação do Fundo Estadual para Prevenção e Remediação de Áreas Contaminadas (FEPRAC), vinculado à Secretaria Estadual do Meio Ambiente, destinado à identificação e remediação das áreas contaminadas, em locais cujo responsável legal não possa ser identificado ou não tenham implementado as ações necessárias à sua reabilitação.

O objetivo é apontar procedimentos específicos para a gestão dos descartes de resíduos químicos com base no Decreto $n^{0} 59.263 / 2013$, em especial nos Artigos 18, 19 e 20, que tratam das áreas contaminadas e das responsabilidades.

Esta proposta se aplica aos casos de descartes de resíduos químicos que foram depositados diretamente sobre o solo e observaram-se durante 0 atendimento emergencial evidências de infiltração dos contaminantes no subsolo.

A seguir são apresentadas duas situações envolvendo o descarte de resíduos químicos relacionadas à possibilidade de se identificar ou não os responsáveis.

a) Quando o responsável legal é identificado, o que na maioria das vezes ocorre por meio de câmeras de segurança, por denúncia, pela existência de rótulos nas embalagens ou por outras evidências presentes no local do descarte, os órgãos competentes deverão exigir a imediata remoção dos 
resíduos. Caso sejam constatadas evidências de contaminação do solo, deverá ser exigido o cumprimento da Decisão de Diretoria $\mathrm{n}^{\circ}$ 103/2007/C/E de 22 de junho de 2007 da CETESB - Companhia Ambiental do Estado de São Paulo que trata do "Procedimento para Gerenciamento de Áreas Contaminadas"

b) Quando não for possível a identificação do responsável legal ou houver negligência na remoção dos resíduos, caberá ao Poder Público adotar as providências necessárias para a eliminação dos perigos. Nesses casos caberá à CETESB - Companhia Ambiental do Estado de São Paulo pleitear recursos do FEPRAC, os quais deverão ser ressarcidos pelo responsável legal quando for possível sua identificação.

A FIG. 77 ilustra o resumo de situações envolvendo o descarte de resíduos químicos relacionadas à possibilidade de se identificar ou não os responsáveis e a proposta do trabalho para enfrentamento das situações emergenciais e eventual necessidade de gerenciamento de área contaminada.

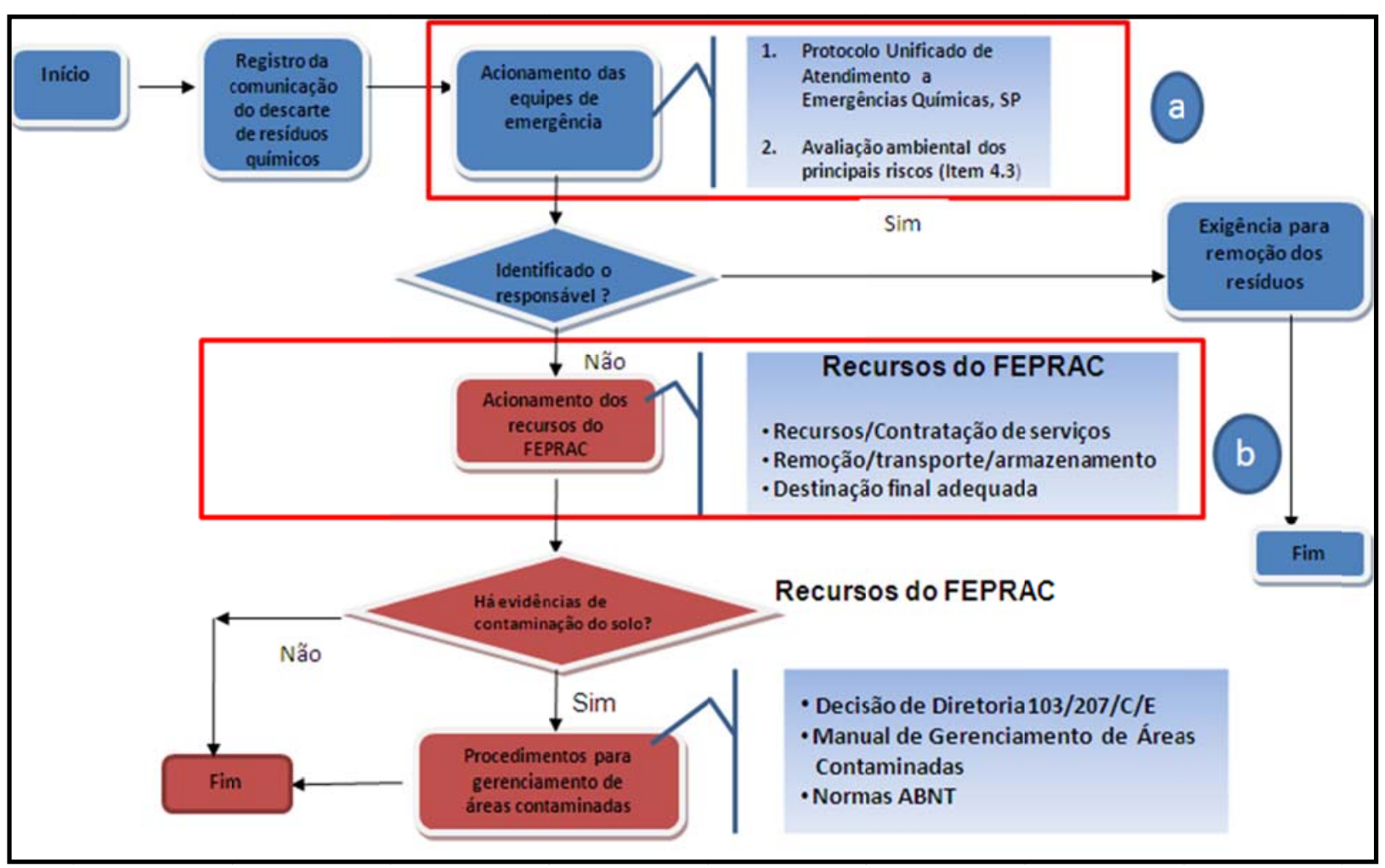

FIGURA 77 - Situações envolvendo o descarte de resíduos químicos 
Para que a CETESB - Companhia Ambiental do Estado de São Paulo possa dispor dos recursos previstos no FEPRAC para casos de descartes de resíduos químicos que ofereçam risco de contaminação do solo e da água subterrânea, faz-se necessário o seu prévio planejamento.

Os recursos necessários para o desencadeamento das ações de remoção, transporte, armazenamento, caracterização, destinação final adequada e remediação da área contaminada poderão ser utilizados mediante a contratação de serviços na modalidade Registro e Preços ${ }^{9}$.

Os serviços aqui citados deverão ser executados de acordo com as disposições das Leis Federais n. ${ }^{\circ}$ 8.666/93 (BRASIL, 1993) e 10.520/02 (BRASIL, 2002).

Em razão das especificações técnicas dos recursos necessários a serem contratados há de se elaborar "Termos de Referências" para cada um dos serviços a serem prestados na fase emergencial e pós-emergencial.

Nos Termos de Referências deverão constar minimamente; (a) a descrição completa do serviço solicitado; (b) escopo dos serviços (incluindo: quantidades envolvidas, local e vigência do contrato); e (c) Exigências Legais, Normativas e Institucionais para a prestação dos serviços.

No termo de referência deve estar estabelecido o quantitativo (resíduos químicos) com sua devida justificativa, o local para prestação dos serviços e o prazo para a execução do contrato.

\footnotetext{
${ }^{9}$ Sistema de compras pelo qual os interessados em fornecer materiais, equipamentos ou gêneros ao Poder Público concordam em manter os valores registrados no órgão competente, corrigidos ou não, por um determinado período e a fornecer as quantidades solicitadas pela Administração no prazo previamente estabelecido.
} 


\title{
9 APÊNDICE
}

\author{
APÊNDICE 1 - QUESTIONÁRIO APLICADO AO GRUPO DE \\ ATENDIMENTOS EMERGENCIAIS ENVOLVENDO DESCARTE DE \\ RESIDUOS QUIMICOS NA REGIÃO METROPOLITANA DE SÃO PAULO \\ CÓPIA DO TERMO DE CONSENTIMENTO LIVRE E ESCLARECIDO \\ DO GRUPO CONTROLE
}

TERMO DE CONSENTIMENTO LIVRE E ESCLARECIDO

Convido-o (a) a participar desta pesquisa de pós-graduação do Instituto de Pesquisas Energéticas e Nucleares - Programa de Pós - graduação, IPEN - USP, que deseja conhecer a atuação da instituição em que você trabalha durante os atendimentos emergenciais com descarte de resíduos químicos em vias públicas onde não é possível identificar os responsáveis por essa ação lesiva ao meio ambiente.

Antecipadamente agradeço sua contribuição ao responder as questões que se seguem com base em sua experiência adquirida na atividade profissional.

As respostas obtidas subsidiarão a tese de doutorado em desenvolvimento pelo pesquisador Jorge Luiz Nobre Gouveia do Programa de Meio Ambiente (CQMA/IPEN) sob orientação da Profa. Dra. Maria Aparecida Faustino Pires.

Título da Tese de Doutorado: "Descarte de resíduos químicos na Região Metropolitana de São Paulo, seus impactos ao meio ambiente - uma proposta de política pública para enfrentamento de situações emergenciais"

A pesquisa será realizada por meio de um questionário contendo 18 perguntas.

Por intermédio deste Termo Ihe são garantidos os seguintes direitos:

1. Solicitar, a qualquer tempo, maiores esclarecimentos sobre esse estudo;

2 . Sigilo absoluto e a privacidade sobre nomes, apelidos, e qualquer informação que possa levar à identificação pessoal;

3. Absoluta possibilidade de negar-se a responder qualquer questão ou informação que julgue prejudicial à sua integridade física, moral e social;

4. Desistir a qualquer tempo de participar da pesquisa;

5. Não ter qualquer custo para participar da pesquisa.

"Declaro estar ciente das informações constantes neste 'Termo de Consentimento Livre e Esclarecido', e entender que serei resguardado (a) pelo sigilo absoluto dos meus dados pessoais, sem qualquer ônus sobre minha participação no estudo 
(pesquisa). Poderei pedir a qualquer momento, esclarecimentos sobre este estudo, recusar a dar informação que julgue prejudicial a minha pessoa, solicitar a não inclusão em documentos de quaisquer informações que já tenha fornecido e desistir, a qualquer momento de participar da pesquisa. Fico ciente de que uma cópia deste termo ficará arquivada com o pesquisador do Instituto de Pesquisas Energéticas e Nucleares, responsável por esta pesquisa."

Nome completo do participante da pesquisa:

Assinatura do participante da pesquisa:

Pesquisador responsável pela pesquisa: Jorge Luiz Nobre Gouveia.

Assinatura da responsável pela pesquisa

Pesquisadores Participantes: Profa. Dra Maria Aparecida Faustino Pires;

Endereço profissional do pesquisador responsável Jorge Luiz Nobre Gouveia: Av Prof Frederico Hermann Jr, 345 Pinheiros CEP: 05459 900, São Paulo, SP.

\section{Questionário}

Título da pesquisa: “Descarte de resíduos químicos na Região Metropolitana de São Paulo, seus impactos ao meio ambiente - uma proposta de política pública para enfrentamento de situações emergenciais

Pesquisador responsável pelo projeto: Jorge Luiz Nobre Gouveia

Entrevistador: Jorge Luiz Nobre Gouveia Data da entrevista:

Número (_

\section{IDENTIFICAÇÃO DO PESQUISADO}

1. Nome:

2. Cidade/bairro onde mora:

3. Idade: ( ) 18 a 30 anos ( ) 31 a 45 anos ( ) 46 a 50 anos ( ) 51 a 65 anos ( ) mais de 65 anos

4. Grau de instrução: ( ) primeiro grau ( ) segundo grau ( ) curso técnico

( ) terceiro grau ( ) mestrado ( ) doutorado

5. Nome da instituição que você trabalha:

6. Quanto tempo atua nesta empresa:

( ) menos de 10 anos ( ) 11 a 20 anos ( ) 21 a 30 anos ( ) mais de 30 anos 


\section{INFORMAÇÕES RELATIVAS AO ATENDIMENTO A SITUAÇÕES DE EMERGÊNCIA ENVOLVENDO DESCARTE DE RESÍDUOS QUÍMICOS}

7. Quantos atendimentos emergenciais envolvendo descarte de resíduos químicos você já participou/atendeu?
( ) 1
( ) 2 a 5
( ) 6 a 10
( ) mais de 10

8. Em sua opinião, qual o principal meio físico afetado envolvendo descarte de resíduos químicos (pode assinalar mais de uma opção)
( ) rio/córrego
( ) rua/rodovia
( ) solo
( ) residências
( ) ar

9. Você já recebeu algum treinamento/capacitação que tenha abordado temas como conhecimentos técnicos e práticos sobre aspectos de segurança com ênfase para atendimento a emergências com produtos químicos?

$\operatorname{Sim}($ ) Não ( )

Em caso afirmativo especificar onde recebeu 0 treinamento:

10. A instituição em que você atua está disponível 24 hs para atendimento a situações emergenciais envolvendo descarte de resíduos químicos?

Sim ( ) Não ( )

11. Há na sua instituição equipamentos de proteção individual (EPIs) para os atendimentos emergenciais?

Sim ( ) Não ( )

Em caso afirmativo você utiliza os equipamentos de proteção individual com que frequência?
Roupa de Proteção
Química/Avental/Jaleco
( ) sempre
( ) às vezes
( ) nunca
Luvas
( ) sempre
( ) às vezes
( ) nunca
Máscara com Filtro
( ) sempre
( ) às vezes
( ) nunca
Óculos de Proteção
( ) sempre
( ) às vezes
( ) nunca
Sapato Fechado
( ) sempre
( ) às vezes
( ) nunca 
12. Em sua opinião quais os órgãos que necessariamente devem participar do atendimento emergencial de descarte de resíduos químicos?

( ) Defesa Civil ( ) Órgão Ambiental ( ) Prefeitura ( ) Secretaria de Saúde

( ) Corpo de Bombeiros ( ) Outro(s):

Especificar:

13. Nos casos em que você atendeu emergências envolvendo descarte de resíduos químicos foi possível identificar os responsáveis?

Sim ( ) Não ( ) ( ) Em alguns casos

Em caso positivo de que forma ocorreu a identificação?

Em caso negativo, assinale qual (quais) tem sido a solução encontrada para a destinação dos resíduos químicos ainda que temporariamente?

( ) pedir apoio a indústria para remoção, transporte e destinação final

( ) armazenar temporariamente em instalações da prefeitura local

( ) outro

Especificar:

14. Em sua opinião quais seriam as principais conseqüências da omissão ou retardo das autoridades públicas em atender prontamente uma emergência envolvendo descarte de resíduos químicos? (pode assinalar mais de uma opção)

( ) exposição da população aos resíduos químicos

( ) reutilização das embalagens (tambores/bombonas) de forma inadequada por parte da população

( ) contaminação do solo, água e do ar

outro: 
15. Do(s) atendimentos(s) em que você participou qual foi o tempo médio para o encerramento da fase emergencial?

( ) 1 dia ( ) 1 a 3 dias ( ) 4 a 7 dias ( ) mais de 7 dias

16. Após ter realizado o atendimento emergencial envolvendo descarte de resíduos químicos você participou de reunião ou grupo de trabalho internamente na sua empresa ou de grupo interinstitucional especificamente para discutir previamente o assunto (descarte de resíduos químicos) como forma de se preparar para um novo episódio?
( ) $\operatorname{Sim}$
( ) Não

17. Os casos de descarte de resíduos químicos que você participou foram notificados a polícia por se tratar de crime ambiental?

( ) Sim ( ) Não ( ) Em alguns casos

18. Na sua instituição há banco de dados centralizados onde são registradas as ocorrências envolvendo emergências químicas?

( )Sim ( )Não

Em caso afirmativo favor indicar a forma de consulta: 


\section{REFERÊNCIAS BIBLIOGRÁFICAS}

AMERICAN PUBLIC HEALTH ASSOCIATION, AMERICAN WATER WORKS ASSOCIATION \& WATER ENVIRONMENTAL FEDERATION. Standard methods for the examination and waste water.22.ed.Washington: American Public Health Association.2012.

ASSOCIAÇÃO BRASILEIRA DO ALUMÍNIO. Guia técnico do alumínio: geração e tratamento de escória. São Paulo. 2007. Técnica Comunicação Industrial Ltda. p. 9-58.

ASSOCIAÇÃO BRASILEIRA DAS EMPRESAS DE LIMPEZA PÚBLICA E RESÍDUOS ESPECIAIS.Panorama dos resíduos sólidos no Brasil. São Paulo. 2014. Disponível em:<http://www.abrelpe.org.br/Panorama/panorama2013.pdf $>$ Acesso em 13 jan. 2015.

ASSOCIAÇÃO BRASILEIRA DE NORMAS TÉCNICAS. Resíduos sólidos classificação (Versão revisada). Rio de Janeiro: ABNT, 2004. (NBR 10.004).

ASSOCIAÇÃO BRASILEIRA DE NORMAS TÉCNICAS. Procedimentos para obtenção de lixiviado de resíduos sólidos. Rio de Janeiro: ABNT, 2004. (NBR 10.005).

BARBIERI, J.C. Desenvolvimento e meio ambiente. As estratégias de mudança da agenda 21. 8. ed. São Paulo. Editora Vozes, 2001.

BRAGA, B.; HESPANHOL, I.;CONEJO, J.G.L.; MIERZWA,J.C.; BARROS, M.T. L.; SPENCER, M.; PORTO, M.; NUCCI, N.;JULIANO, N.;EIGER, S. Introdução à engenharia ambiental: o desenvolvimento sustentável. 2.ed. São Paulo: Pearson, 2009. p. 155 - 156.

BRASIL. Ministério do Trabalho e Emprego. Equipamento de Proteção Individual. Norma Regulamentadora $n^{\circ} 6$ da Portaria $n^{\circ} 3.214$ de 1978.1978. Disponível em:<http://portal.mte.gov.br/data/files/FF8080812DC56F8F012DCDAD35721F5 0/NR-06\%20\%28atualizada\%29\%202010.pdf>Acesso em: 09 jun. 2015.

BRASIL. Lei $n^{\circ} 6.803$, de 02 de julho de 1980 dispõe sobre as diretrizes básicas para o zoneamento industrial nas áreas críticas de poluição, e dá outras providências. Diário Oficial [da] República Federativa do Brasil, Poder Executivo, Brasília, DF, 03 jul.1980.

BRASIL. Lei $n^{\circ} 6.938$, de 31 de agosto de 1981. Dispõe sobre a Política Nacional do Meio Ambiente, seus fins e mecanismos de formulação e aplicação, e dá outras providências. 1981. Disponível em: <http://www.planalto.gov.br/ccivil 03/Leis/L6938.htm>Acesso em: 27 maio 2014. 
BRASIL. Constituição da República Federativa do Brasil de 1988. 1988. Disponível em:<http://www.planalto.gov.br/ccivil 03/constituicao/constitui\%C3\%A7ao.htm> Acesso em: 27 maio 2014.

BRASIL. Lei $n^{\circ} 8.666$, de 21 de junho de 1993. 1993. Estabelece normas gerais sobre licitações e contratos administrativos pertinentes a obras, serviços, inclusive de publicidade, compras, alienações e locações no âmbito dos Poderes da União, dos Estados, do Distrito Federal e dos Municípios. Disponível em:<http://www.planalto.gov.br/ccivil 03/leis//8666cons.htm> Acesso em 24 jun. 2015.

BRASIL. Lei $n^{\circ}$ 9.605, de 12 de fevereiro de 1998.Dispõe sobre as sanções penais e administrativas derivadas de condutas e atividades lesivas ao meio ambiente, e dá outras providências. Disponível em:

<http://www.planalto.gov.br/ccivil 03/Leis/L9605.htm> Acesso em: 27 maio 2014.

BRASIL. Lei 10.520, de 17 de julho de 2002. Institui, no âmbito da União, Estados, Distrito Federal e Municípios, nos termos do art. 37, inciso XXI, da Constituição Federal, modalidade de licitação denominada pregão, para aquisição de bens e serviços comuns, e dá outras providências. Disponível em:<http://www.planalto.gov.br/ccivil 03/leis/2002//10520.htm> Acesso em: 24 jun. 2015.

BRASIL. Lei $n^{\circ} 11.445$, de 05 de janeiro de 2007. 2007. Estabelece diretrizes nacionais para o saneamento básico. Disponível em:

<http://www.planalto.gov.br/ccivil 03/ ato2007-2010/2007/lei/l11445.htm> Acesso em: 27 maio 2014.

BRASIL. Decreto $n^{\circ} 6.514$, de 22 de julho de 2008. 2008. Dispõe sobre as infrações e sanções administrativas ao meio ambiente,estabelece o processo administrativo federal para apuração destas infrações, e dá outras providências. Disponível em: http://www.planalto.gov.br/ccivil 03/ Ato20072010/2008/Decreto/D6514.htm> Acesso em: 27 maio 2014.

BRASIL. Lei $n^{\circ}$ 12.305, de 02 de agosto de 2010.2010a. Institui a Política Nacional de Resíduos Sólidos, altera a Lei no 9.605, de 12 de fevereiro de 1998 e dá outras providências. Disponível em:

<http://www.planalto.gov.br/ccivil 03/ ato2007-2010/2010/lei//12305.htm> Acesso em: 13 maio 2014.

BRASIL. Decreto $n^{\circ} 7.404$, de 23 de dezembro de 2010. 2010b. Regulamenta a Lei no 12.305, de 2 de agosto de 2010, que institui a Política Nacional de Resíduos Sólidos, cria o Comitê Interministerial da Política Nacional de Resíduos Sólidos e o Comitê Orientador para a Implantação dos Sistemas de Logística Reversa, e dá outras providências. Disponível em: <http://www.planalto.gov.br/ccivil 03/ Ato2007-2010/2010/Decreto/D7404.htm> Acesso em: 13 maio 2014. 
BRASIL. Projeto de Lei (PL 2732). Estabelece diretrizes para a prevenção da contaminação do solo, cria a Contribuição de Intervenção no Domínio Econômico sobre Substâncias Perigosas e o Fundo Nacional para a Descontaminação de Áreas Órfãs Contaminadas e altera art. $8^{\circ}$ da Lei ${ }^{\circ}$ 12.305, de 2 de agosto de 2010. 2011. Disponível em:<http://www.camara.gov.br/proposicoesWeb/fichadetramitacao?idProposica o=527624> Acesso em: 29 maio 2014.

BRASIL. Ministério do Meio Ambiente. Planos de gestão de resíduos sólidos: manual de orientação apoiando a implementação da política nacional de resíduos sólidos: do nacional ao local. Brasília, DF. 2012. Disponível em:<http://www.mma.gov.br/estruturas/182/ arquivos/manual de residuos soli dos3003 182.pdf>Acesso em: 22 maio 2014.

BRASIL. Ministério do Meio Ambiente. Agenda 21 global. 2014a. Disponível em:<http://www.mma.gov.br/responsabilidade-socioambiental/agenda21/agenda-21-global>Acesso em: 22 maio 2014.

BRASIL. Ministério do Trabalho e Emprego. Portaria Interministerial n9, de 7 de outubro de 2014.2014b. Publica a Lista Nacional de Agentes Cancerígenos para Humanos (LINACH), como referência para formulação de políticas públicas, na forma do anexo a esta Portaria.Diário Oficial da União:República Federativa do Brasil, Poder Executivo, Brasília, v.151, n 194, 8 de out. 2014.Seção 1, p. 140-142. Disponível em:<http://pesquisa.in.gov.br/imprensa/jsp/visualiza/index.jsp?jornal=1\&pagina =140\&data=2014-10-08 > Acesso em: 14 out. 2014 .

CÂMARA, V.M.;ALONZO, H.G.A. ;BARRIGA, F.D.;ASMUS, C.L.R.F.Lageneración y acumulación de contaminantes y sus amenazas para La salud a corto y largo plazo. In:GALVÃO, L.A.C.; FINKELMAN J.;HENAO, S. (Ed).Determinantes ambientales y sociales de lasalud.Washington, D.C: OPS, 2010. Cap.20, p.458.

CETESB - COMPANHIA AMBIENTAL DO ESTADO DE SÃO

PAULO.Emergências químicas.2013a. Disponível

em:<http://sistemasinter.cetesb.sp.gov.br/emergencia/relatorio.php $>$ Acesso em: 02 jun. 2014.

CETESB - COMPANHIA AMBIENTAL DO ESTADO DE SÃO PAULO. Áreas contaminadas. 2013b. Disponível em:<http://www.cetesb.sp.gov.br/userfiles/file/areas-contaminadas/2013/textoexplicativo.pdf> Acesso em 13 jun. 2014. 
CETESB - COMPANHIA AMBIENTAL DO ESTADO DE SÃO PAULO. Qualidade das Águas Superficiais no Estado de São Paulo 2013. 2013c. Série Relatórios.

Disponível em:<http://www.cetesb.sp.gov.br/userfiles/file/agua/aguas-superficiais/relatorioaguas-superficiais-2013-parte1.pdf>Acesso em: 02 jun. 2014.

CETESB - COMPANHIA AMBIENTAL DO ESTADO DE SÃO PAULO. Valores orientadores para solo e água subterrânea. 2005. Disponível em:<http://www.cetesb.sp.gov.br/solo/legislacao/6-valores-orientadores> Acesso em 01 jun. 2014.

CETESB - COMPANHIA AMBIENTAL DO ESTADO DE SÃO PAULO. o que são áreas contaminadas.2011a. Disponível em:<http://www.cetesb.sp.gov.br/areas-contaminadas/O-que-s\%E3o\%E1\%81reas-Contaminadas/1-oquesao > Acesso em: 26 maio 2014.

CETESB - COMPANHIA AMBIENTAL DO ESTADO DE SÃO PAULO.Guia nacional de coleta e preservação de amostras: água, sedimento, comunidades aquáticas e efluentes líquidos/Companhia Ambiental do Estado de São Paulo: BRANDÃO, C.J.;BOTELHO, M.J.C.;SATO, M.I.Z.;DEUS, A.C.R.;AIBA, C.J.;LOPES,C.F.;FANCHINI, C.R.;ROUBICEK,D.A.;HACHICH, E.M.;FERREIRA, F.J.;QUINAGLIA, G.A.;WATANABE, H.M.;MILANELLI, J.C.C.;BEVILACQUA, J.E.; RODRIGUES, J.C.S.;ALVIM, L.A.C.; SALVADOR, M.E.P.;CARVALHO, C.C.;LAMPARELLI, M.C.;KUHLMANN, M.L.;NIWA, N.A.;RODRIGUES, P.F.;ROCHA,P.S.G.;NIETO, R.;MINÇON, R.F.;SOUZA, R.C.R.;SANTANA, R.V.;ARAÚJO, R.P.A.;PRÓSPERI, V.A.;RIBEIRO, V.P.;BALTAZAR, V.São Paulo: CETESB: Brasília: ANA; 2011b. Disponível em: <http://www2.ana.gov.br/Paginas/catalogopublicacoes.aspx>Acesso em: 13 dez.2013.

CETESB - COMPANHIA AMBIENTAL DO ESTADO DE SÃO PAULO.

Distribuição por UGHRI. Qualidade das águas superficiais no estado de São Paulo. Série Relatórios. 2013c.Disponível em:<http://www.cetesb.sp.gov.br/userfiles/file/agua/aguas-superficiais/relatorioaguas-superficiais-2013-parte1.pdf> Acesso em: 29 maio 2014.

CETESB - COMPANHIA AMBIENTAL DO ESTADO DE SÃO PAULO. Inventário estadual de resíduos sólidos urbanos. 2013d. Disponível em:<http://www.cetesb.sp.gov.br/userfiles/file/residuossolidos/residuosSolidos2013.pdf> Acesso em 13 jan. 2015.

CETESB - COMPANHIA AMBIENTAL DO ESTADO DE SÃO PAULO. Informação técnica n $^{\circ}$ 028/061/ESRD, de 19 de junho de 2006. Plano de recuperação de área degradada. São Paulo, 2006. Interessado: Prefeitura Municipal de São Paulo. Pasta Administrativa PA/29/00332/09 - referente ao bota-fora Sezefredo Fagundes (Arthur Garrido). V. I/II. 
CETESB - COMPANHIA AMBIENTAL DO ESTADO DE SÃO PAULO. Manual de produtos químicos. 2013e. Disponível em: $<$ http://sistemasinter.cetesb.sp.gov.br/produtos/ficha completa1.asp?consulta= AM\%D4NIA\%20ANIDRA\&cod=AM\%D4NIA\%20ANIDRA> Acesso em: 22 mar.

COMISSÃO INTERNA DE PREVENÇÃO DE ACIDENTES.Manual de treinamento. São Paulo. Faculdade de Ciências Farmacêuticas. Universidade de São Paulo: FCF/USP. 1992.

CONSELHO NACIONAL DO MEIO AMBIENTE. Resolução $n^{\circ} 420$, de 28 de dezembro de 2009.2009. Dispõe sobre critérios e valores orientadores de qualidade do solo quanto à presença de substâncias químicas e estabelece diretrizes para o gerenciamento ambiental de áreas contaminadas por essas substâncias em decorrência de atividades antrópicas. Disponível em:<http://www.mma.gov.br/port/conama/legiabre.cfm?codlegi=620> Acesso em: 26 maio 2014.

EMPRESA PAULISTA DE PLANEJAMENTO METROPOLITANO. Região Metropolitana de São Paulo. 2012. Disponível em:<http://www.emplasa.sp.gov.br/emplasa/Indicadores/gsp a.asp > Acesso em: 29 maio2014.

ENVIRONMENTAL PROTECTION AGENCY.Illegal dumping prevention guide book.US EPA .Region 5. Chicago Illinois .1998. Disponível em:<http://www.epa.gov/region5/waste/illegal dumping/downloads/ildmpng.pdf>Acesso em: 25 maio2014.

ENVIRONMENTAL PROTECTION AGENCY.Removal actions at long-term cleanup sites.2011.Disponível em:

$<$ http://www.epa.gov/superfund/programs/er/hazsubs/timecrit.htm> Acesso em: 25 maio 2014.

ENVIRONMENTAL PROTECTION AGENCY.Basic information. What is superfund?2013a. Disponível em:<http://www.epa.gov/superfund/about.htm> Acesso em: 25 maio2014.

ENVIRONMENTAL PROTECTION AGENCY.Characteristic wastes. 2013b. Disponível em:

<http://www.epa.gov/wastes/hazard/wastetypes/characteristic.htm> Acesso em: 06 mar. 2014.

ENVIRONMENT AGENCY.IIlegal waste sites.2010a.Disponível em: $<$ http://www.environmentagency.gov.uk/subjects/waste/1029679/1032559/?lang= e $>$.Acesso em $16 \mathrm{dez}$. 2012. 
ENVIRONMENT AGENCY. Illegal waste sites.2010b. Disponível em:<http://www.environmentagency.gov.uk/news/138898.aspx?month=4\&year=2012\&coverage $=$ National\&p ersona=Prosecution>. Acesso em16 dez. 2012.

FUNDAÇÃO ESTADUAL DO MEIO AMBIENTE. Inventário de áreas contaminadas de Minas Gerais 2014. 2015.Disponível em:

$<$ http://www.feam.br/images/stories/declaracoes ambientais/GESTAO AREAS CONTAMINADAS/inventrio $\% 20$ de $\% 20$ reas $\% 20$ contaminadas $\% 20$ \%202014.pdf> Acesso em 15 jan. 2015.

FUNDAÇÃO SISTEMA ESTADUAL DE ANÁLISES DE DADOS. Disponível em:<http://produtos.seade.gov.br/produtos/divpolitica/> Acesso em 15 set. 2015.

FUNDAÇÃO SISTEMA ESTADUAL DE ANÁLISES DE DADOS. Disponível em:<http://www.seade.gov.br/produtos/perfil regional/index.php $>$ Acesso em 21 abr. 2014.

FREIRIA, R.C. Direito, gestão e políticas públicas ambientais. São Paulo: SENAC, São Paulo. 2011. p. 23.

GIL, A.C. Métodos e técnicas de pesquisa social. 3. ed. São Paulo: Atlas, 1991. 207 p.

GIL, A.C. Como elaborar projetos de pesquisa. 4. ed. São Paulo: Atlas, 2002.

GUARULHOS (Cidade). Prefeitura de Guarulhos. Estatísticas e geografia. Aspectos físicos e territoriais.1997. Disponível

em:<http://www.guarulhos.sp.gov.br/index.php?option=com content\&view=articl e\&id=74\&Itemid=182> Acesso em:30 maio 2014.

GUARULHOS (Cidade). Prefeitura de Guarulhos. Assuntos legislativos. 2008. Disponível

em:<http://leis.guarulhos.sp.gov.br/06 prefeitura/leis/decretos 2008/25303decr. pdf> Acesso em: 30 maio 2014.

GUARULHOS (Cidade). Prefeitura de Guarulhos. Habitação. Etapa II Diagnóstico do setor habitacional - Plano local de habitação de interesse social de Guarulhos. p. 33 - 81. 2011. Disponível

em:<http://www.guarulhos.sp.gov.br/index.php?option=com content\&view=articl e\&id=2955: secretaria-habitacao-faz-primeira-avaliacao-do-

plhis\&catid=106:habitacao\&ltemid=958> Acesso em: 30 maio 2014. 
GUARULHOS (Cidade). Prefeitura de Guarulhos. Estatísticas e geografia. Meio ambiente. 2014a. Disponível em:<http://www.guarulhos.sp.gov.br/index.php?option=com content\&view=articl e\&id=76\&ltemid=184> Acesso em: 30 maio 2014.

GUARULHOS (Cidade). Prefeitura de Guarulhos. Desenvolvimento econômico.Economia de Guarulhos. 2014b. Disponível em: $<$ http://www.guarulhos.sp.gov.br/index.php?option=com content\&view=articl e\&id=7575\&ltemid=1328> Acesso em: 30 maio2014.

GÜNTER, W. M. R. Resíduos Sólidos no Contexto da Saúde Ambiental. Texto de Sistematização Crítica de parte da obra da candidata apresentado ao Departamento de Saúde Ambiental da Faculdade de Saúde Pública da Universidade de São Paulo para obtenção do título de Professor Livre Docente da Universidade de São Paulo Livre Docência.São Paulo, 2008.

GÜNTHER, W.M.R. Áreas contaminadas no contexto da gestão urbana. São Paulo em perspectiva, São Paulo, Fundação Seade, v. 20, n. 2, p. 105117, abr./jun. 2006. Disponível em: <http://www.seade.gov.br>Acesso em: 09 maio 2011.

HIRATA,M.H.; HIRATA, R.D.C.; MANCINI, J.F.Manual de biossegurança. 2. ed. São Saulo. Manole. 2012.p.72-73.

ICHINOSE, D.; YAMAMOTO, M.On the relationship between the provision of waste management service and illegal dumping. Resourceand Energy Economics.v.33.p. 79-93. 2010.

INSTITUTO BRASILEIRO DO MEIO AMBIENTE E DOS RECURSOS NATURAIS RENOVÁVEIS. Padrões de qualidade ambiental.2011.Disponível em:<http://www.ibama.gov.br/rama/padroes-de-qualidade-ambiental > Acesso em: 27 maio 2014.

INSTITUTO BRASILEIRO DE GEOGRAFIA E ESTATÍSTICA. São Paulo Síntese. 2010a. Disponível em:<http://www.ibge.gov.br/estadosat/perfil.php?sigla=sp\#> Acesso em 26 maio 2014.

INSTITUTO BRASILEIRO DE GEOGRAFIA E ESTATÍSTICA. São Paulo Síntese. 2010b. Disponível em:<http://www.ibge.gov.br/estadosat/perfil.php?sigla=rij>Acesso em: 27 maio 2014.

INSTITUTO BRASILEIRO DE GEOGRAFIA E ESTATÍSTICA. Censo 2010c. Disponível em:<http://cidades.ibge.gov.br/xtras/perfil.php?lang $=\&$ codmun $=351880>$ Acesso em: 30 maio 2014. 
INSTITUTO BRASILEIRO DE GEOGRAFIA E ESTATÍSTICA. Produto Interno Bruto dos Municípios. 2011. Disponível em:

<ftp://ftp.ibge.gov.br/Pib Municipios/2011/pdf/tab01.pdf> Acesso em: 07 dez. 2014.

INSTITUTO BRASILEIRO DE GEOGRAFIA E ESTATÍSTICA. Cidades. 2014. Disponível em:<http://cidades.ibge.gov.br/xtras/perfil.php?lang=\&codmun=355030\&search =sao-paulo|sao-paulo> Acesso em: 08 jun. 2015.

INSTITUTO ESTADUAL DO AMBIENTE. Avaliação de áreas contaminadas.2014.Disponível

em:<http://www.inea.ri.gov.br/Portal/MegaDropDown/Licenciamento/GestaodeR iscoAmbientalTec/AvaliacaodeAreasContaminadas/index.htm\&lang=> Acesso em: 02 jun. 2014.

INSTITUTO ESTADUAL DO AMBIENTE. Emergências ambientais tecnológicas ou poluição acidental.2013a. Disponível em:<http://www.inea.ri.gov.br/Portal/MegaDropDown/Monitoramento/Centrodem onitdedesastresamb/Acidentestecnologicos/index.htm\&lang=> Acesso em: 02 jun. 2014.

INSTITUTO ESTADUAL DO AMBIENTE. Gerenciamento de áreas contaminadas do estado do Rio de Janeiro. 2013b. Disponível em:<http://www.inea.rj.gov.br/inea/areas contaminadas.asp.> Acesso em: 19 dez. 2013.

JACOBI, P. R. Desafios e reflexões sobre resíduos sólidos nas cidades brasileiras. In: SANTOS, M.C.L.; DIAS, S.L.V.G (Coord.). Resíduos sólidos urbanos e seus impactos socioambientais.São Paulo, 2012. Cap 4.p. 31.

JENKINS, R.R.; KOPITS, E.; SIMPSON, D. Policy monitor.the evolution of solid and hazardous waste regulation in the United States.Review of Environmental Economics and Policy,v.3,n.1, p.104-120, winter 2009.

KIM, G. S.; CHANG, Y.J.; KELLEHER, D. 2008. Unit pricing of municipal Solid waste and illegal dumping: an empirical analysis of Korean experience.Environmental Economics and Policy Studies 9, 167-176.

LANDRIGAN, P.J.; GROSS, R.L. Chemical wastes - illegal hazards and legal remedies. America Journal of Public Health, Cincinnati, Ohio, v.71, n. 9, p. 985-987, set. 1981.

LUNA, S.V.Planejamento de Pesquisa. Uma Introdução. Elementos para uma análise metodológica.São Paulo, EDUC.1997.

MANAHAN, S.E.Química ambiental. 9.ed. Bookman. 2013 a. p. 669.

Universidade de Missouri, Columbia. 
MANAHAN, S.E.Química ambiental. 9.ed. Bookman. 2013 b. p. 670.

Universidade de Missouri, Columbia.

MICKLIN, M. The ecological transition in Latin America and the Caribbean: theoretical issues and empirical patterns. In:BILLSBORROW, R.E; HOGAN, D.J. (eds). Population and deforestation in the humid tropic.Liège:IUSSP, 1999.

MILLER, T. M. Ciência ambiental.11. ed. São Paulo. Cenage Learning. p. 444. 2007.

MINISTRY OF THE ENVIRONMENT GOVERNMENT OF JAPAN.Survey on illegal dumping of industrial waste in FY 2004.2005. Disponível

em:<http://www.env.go.jp/en/press/2005/1108a.html>Acesso em: 26 maio 2014.

MINISTRY OF THE ENVIRONMENT GOVERNMENT OF JAPAN.Status of improper disposal of sulfate pitch in the first half FY 2005.2006.2006.

Disponivel em: $<$ http://www.env.go.jp/en/press/2006/0215a.html>Acesso em: 24 maio 2014.

MINAYO, M.C.S. O Desafio do Conhecimento. Pesquisa Qualitativa em Saúde.São Paulo. Hucitec/Rio de Janeiro: Abrasco Rio de Janeiro, 1992.

NATIONAL RESEARCH COUNCIL.Committee on Pesticides in the Diets of Infants and children.Washington, DC. National Academy Press, 1993.

ORGANIZAÇÃO PAN-AMERICANA DA SAÚDE.Avaliação regional dos serviços de manejo de resíduos sólidos municipais na América Latinae Caribe, Washington, D.C. p.219, 2005.

POFFO, M.T. Percepção de riscos e comportamento da comunidade diante de acidentes ambientais em áreas portuárias de Santos e São Sebastião.2011.112p.(Pós Doutorado em Psicologia Clínica. Pontifícia Universidade Católica - PUC, São Paulo.

RAE SYSTEMS.Mini RAE 3000. Portable handheld VOC Monitor. 2014. Disponível em:<http://www.raesystems.eu/sites/default/files/downloads/FeedsEnclosureMiniRAE-3000 US DS.pdf> Acesso em: 29 maio 2014.

RIBEIRO, M.A. Ecologizar. Princípios para ação. Brasília, DF. Universa UCB. 2009.

RODRIGUES, G. Avenida Cel. Sezefredo Fagundes apresenta problemas para motoristas e pedestres. A Gazeta da Zona Norte, São Paulo, v.48, n.2488, 26 nov. 2011. Disponível em:

$<$ http://www.gazetazn.com.br/index1.asp?bm=m\&ed $=46 \& s=63 \& m a=193 \& c=0 \&$ m=0>Acesso em: 26 jan. 2015.

SÁNCHEZ, L.E. Desengenharia: o passivo ambiental na desativação de empreendimentos industriais. São Paulo: Edusp.2001.p.166. 
SANTOS, M.C.L. Consumo, descarte, catação e reciclagem: notas sobre design e multicuturalismo. São Paulo, p. 62, 2008.

SÃO PAULO (Cidade). Câmara Municipal. Lei no 11.220 de 20 de maio de 1992. Institui a divisão geográfica da área do município em distritos, revoga a Lei $n^{0} 10.932$, de 15 de janeiro de 1991, e dá outras providências. 1992.

Disponível

em:<http://camaramunicipalsp.qaplaweb.com.br/iah/fulltext/leis/L11220.pdf> Acesso em 21 abr. 2014.

SÃO PAULO (Cidade). Prefeitura Municipal.Olhar São Paulo. Contrastes Urbanos. As dimensões da metrópole.2004a. Disponível em: <http:// http://smdu.prefeitura.sp.gov.br/contrastes urbanos/> Acesso em: 12 fev. $2014 a$.

SÃO PAULO (Cidade). Prefeitura Municipal.OIhar São Paulo. Contrastes Urbanos. Quadro Econômico.2004b.Disponível em: <http:// http://smdu.prefeitura.sp.gov.br/contrastes urbanos/> Acesso em: 12 fev. 2014.

SÃO PAULO (Cidade). Prefeitura Municipal. Subprefeitura Capela do Socorro. 2014. Disponível em:<http://www.prefeitura.sp.gov.br/cidade/secretarias/subprefeituras/capela d o socorro/historico/index.php?p=916> Acesso em: 01 jun. 2014.

SÃO PAULO (Estado). Lei n997, de 31 de maio de 1976. Dispõe sobre o Controle da Poluição do Meio Ambiente.1976a Disponível em:<http://www.cetesb.sp.gov.br/Institucional/documentos/lei 997 1976.pdf> Acesso em: 27 maio 2014.

SÃO PAULO (Estado). Decreto $\mathrm{n}^{\circ}$ 8.468, de 08 de setembro de 1976b. Aprova o Regulamento da Lei $n^{\circ}$ 997, de 31 de maio de 1976, que dispõe sobre a prevenção e o controle da poluição do meio ambiente.1976b. Disponível em: $<$ http://www.cetesb.sp.gov.br/Institucional/documentos/Dec8468.pdf> Acesso em: 27 maio 2014.

SÃO PAULO (Estado). Lei n 12.300, de 16 de março de 2006. Institui a Política Estadual de Resíduos Sólidos e define princípios e diretrizes.2006.Disponível em: http://webspl1.al.sp.gov.br/internet/download?poFilelfs=5469587\&/Projetodelei 566644.docVersãoFinalresíduomaio.05.doc>Acesso em: 05 fev. 2011.

SÃO PAULO (Estado). Decreto n 54.645, de 5 de agosto de 2009.

Regulamenta dispositivos da Lei $\mathrm{n}^{\circ} 12.300$ de 16 de março de 2006, que institui a Política Estadual de Resíduos Sólidos, e altera o inciso I do artigo 74 do Regulamento da Lei $n^{\circ}$ 997, de 31 de maio de 1976, aprovado pelo Decreto $n^{\circ}$ 8.468, de 8 de setembro de 1976.2009a. Disponível em: http://www.al.sp.gov.br/repositorio/legislacao/decreto/2009/decreto\%20n.54.645 \%20de\%2005.08.2009.htm> Acesso em: 06 fev. 2011. 
SÃO PAULO (Estado). Lei $n^{\circ} 13.577$, de 8 de julho de 2009. Dispõe sobre diretrizes e procedimentos para a proteção da qualidade do solo e gerenciamento de áreas contaminadas, e dá outras providências correlatas. 2009b.Disponível em:

http://www.al.sp.gov.br/repositorio/legislacao/lei/2009/lei\%20n.13.577,\%20de\% 2008.07.2009.htm> Acesso em: 05 fev. 2011.

SÃO PAULO (Estado). Coordenadoria Estadual de Defesa Civil São Paulo. Protocolo Unificado de Atendimento a Emergências Químicas no Estado de São Paulo. 2012. Disponível em:

$<$ http://www.defesacivil.sp.gov.br/v2010/portal defesacivil/conteudo/documento s/protocollo p2r2 2012.pdf> Acesso em: 26 maio 2014.

SÃO PAULO (Estado). Secretaria de Estado da Saúde. Vigilância epidemiológica em saúde ambiental e segurança química.In:__ Vigilância epidemiológica em saúde ambiental.São Paulo, 2013a p.28-29. (Caderno de vigilância epidemiológica). Disponível em:<http://www.saude.sp.gov.br/cvecentro-de-vigilancia-epidemiologica-prof.-alexandrevranjac/publicacoes/caderno-de-vigilancia-epidemiologica-em-saudeambiental> Acesso em: 30 maio 2014.

SÃO PAULO (Estado). Deliberação CONSEMA 08/2013. 2013b. Manifesta-se favorável à Minuta de Decreto que regulamenta a Lei 13.577, de 08 de julho de 2009, que dispõe sobre diretrizes e procedimentos para a proteção da qualidade do solo e gerenciamento de áreas contaminadas, e dá outras providências correlatas. Disponível em:

<http://www.ambiente.sp.gov.br/consema/files/2013/01/DEL08.pdf> Acesso em: 29 maio 2014.

SÃO PAULO (Estado). Decreto $n^{\circ}$ 59.263, de 05 de junho de 2013c. Regulamenta a Lei $n^{\circ} 13.577$, de 8 de julho de 2009, que dispõe sobre diretrizes e procedimentos para a proteção da qualidade do solo e gerenciamento de áreas contaminadas, e dá providências correlatas. Disponível em:<http://www.cetesb.sp.gov.br/areascontaminadas/o-que-sao-areas-contaminadas/26-legislacao> Acesso em 08 jun. 2014.

SÃO PAULO (Estado). Secretaria de Meio Ambiente. Parque Estadual da Cantareira.2014a. Disponível em: <http://www.ambiente.sp.gov.br/parque-dacantareira/sobre-o-parque/>Acesso em: 30maio 2014.

SÃO PAULO (Estado). Secretaria de Transportes e Logística. Programa de transporte, logística e meio ambiente. 2014b. Disponível em:<ftp://ftp.sp.gov.br/ftpder/gestao ambiental/AISA PTLMA Parte 1 rev1.pdf >. Acesso em: 29 maio 2014. 
SECRETARIA DE ESTADO DE MEIO AMBIENTE E DESENVOLVIMENTO SUSTENTÁVEL.2013. Disponível em:<http://www.meioambiente.mg.gov.br/emergencia-ambiental/deamb> Acesso em: 02 jun. 2014.

SELLITZ, C.; WRIGHTSMAN, L; COOK, S. Métodos de Pesquisa nas relações sociais2. ed. São Paulo: EPU - Editora Pedagógica e Universitária Ltda, 1987.

SILVA, A.B.; KOVACS, A.; SANTOS, G.A.;CAPELINI, MANSOR, M.T.C.; FILET,M.; CAMARÃO, T.C.R.C.; Introdução. In: Resíduos sólidos. São Paulo:SMA/CPLA, 2010. (Cadernos de Educação Ambiental,6). Disponível em:<http://www.ambiente.sp.gov.br/wp-content/uploads/publicacoes/sma/6ResiduosSolidos.pdf> Acesso em 26 maio 2014.

SIGMAN, H.;1998. Midnight dumping: public policies and illegal disposal of used oil.RANDJournal of Economics 29 (1), 157- 178.

SPÍNOLA, A.L.S. Inserção das áreas contaminadas na gestão municipal: desafios e tendências.2011.289p. Tese (Doutorado em Saúde Ambiental). Faculdade de Saúde Pública da Universidade de São Paulo.

TANAKA, M. Waste management for asustainablesociety. J.Mater Cycles Waste Manag,v.9, p. 2-6, 2007. (Selected Papers in the Symposium on Eco Topia Science (ISETS05): Waste and Emission Management.)

UNITED NATIONS ENVIRONMENT PROGRAMME.Annual report 2013.2014. Disponível em:

http://www.unep.org/annualreport/2013/home chemicalsandwaste.asp>Acesso em: 22 maio 2014.

US NATIONAL LIBRARY OF MEDICINE.Odor threshold.2014a.Disponível em:<http://webwiser.nlm.nih.gov/getSubstanceData.do?substanceld=315\&displ aySubstanceName=Ammonia\&STCCID=\&UNNAID=1005\&selectedDataMenult emID=36> Acesso em: 22 mar. 2014.

US NATIONAL LIBRARY OF MEDICINE.Skin/Eye/Resp. Irritants. 2014b.

Disponível

em:<http://webwiser.nlm.nih.gov/getSubstanceData.do?substanceld=315\&displ aySubstanceName=Ammonia\&STCCID=\&UNNAID=1005\&selectedDataMenult emID=67>Acesso em: 22 mar. 2014

US NATIONAL LIBRARY OF MEDICINE.Agent identification.2014C

Disponível em:

http://webwiser.nlm.nih.gov/getSubstanceData.do?substanceld=315\&displaySu bstanceName=Ammonia\&STCCID=\&UNNAID=1005\&selectedDataMenultemID =124> Acesso em: 22 mar. 
US NATIONAL LIBRARY OF MEDICINE.Threshold limit values.2014d.Disponível em:

$<$ http://webwiser.nlm.nih.gov/getSubstanceData.do?substanceld=315\&displayS ubstanceName=Ammonia\&STCCID=\&UNNAID=1005\&selectedDataMenulteml $\underline{D=64}>$ Acesso em 22 mar. 2014.

VASCONCELLOS, A. R.; PIERI, A.F.;FERRANTE, A.; PIOLI, A.;

BEZERRA,A.C.;SILVA, A.;LOPES, C.F.;PRADO,E.;HADDAD, E.;POFFO, I.R.F.;GOUVEIA,J.L.N.;PARMAGNANI,L.F.;BAPTISTA,L.O.;LAINHA,M.A.J.;TEI XEIRA,M.S.;GREIF,S.Manual de atendimento a emergências químicas. São Paulo: CETESB, 2014. 288 p.

VEIGA, J.E.; ISSBERNER, L.R.Decrescer crescendo. In: Enfrentando os limites do crescimento: sustentabilidade, decrescimento e prosperidade. LENA, P; Nascimento, E.P (Orgs.). São Paulo, 2012.p 107 -134.

VIANNA, M.D.A. A cobertura jornalística sobre poluição do solo por resíduos: Uma análise da Produção por Jornais O Estado de São Paulo e Folha de São Paulo da RIO-92 a 2007. 2012.229p. Tese (Doutorado em Ciência Ambiental), (PROCAM). Universidade de São Paulo.

VIEIRA, P.A. Resíduos: uma oportunidade. Parede, Portugal:Sopa de Letras.2012.p 85.

WILLIAMS, B.A.; MATHENEY, A.R. Democracy, dialogue, and environmental disputes:The constested languages of social regulation. New Haven, CT. Yale University Press.1995.

YIN, R.K.Estudo de caso: Planejamento e métodos.2.ed. Porto Alegre: Bookman.2001. 